\title{
ESTRATIGRAFÍA Y GEOMORFOLOGÍA EN EL ÁMBITO DEL CURSO INFERIOR DEL RÍO LUJÁN, PROVINCIA DE BUENOS AIRES
}

\author{
UNIVERSIDAD NACIONAL DE LA PLATA \\ FACULTAD DE CIENCIAS NATURALES Y MUSEO
}

TESIS PRESENTADA PARA OPTAR AL TITULO DE DOCTOR DE LA UNIVERSIDAD NACIONAL DE LA PLATA.

TESISTA: ENRIQUE FUCKS

DIRECTOR: FERNANDO DE FRANCESCO 


\section{4}

A Diana, Andrés y Simón por un presente lleno de satisfacciones

A mi madre, por su tenacidad en la búsqueda de superación

A mis hermanas, por su gratitud y afecto

A mis sobrinos con cariño

Y a la memoria de mi padre y de Mario 
AGRADECIMIENTOS

Quisiera expresar mi agradecimiento a las siguientes personas:

Al profesor Fernando De Francesco por brindarme su apoyo, consejos y sugerencias desde mi ingreso al ámbito científico académico.

A las Dras. Marina Aguirre y Cecilia Deschamps con quien hemos constituido un equipo de trabajo, y a partir de los trabajos realizados ha surgido valiosa información que enriquecen en gran medida el presente trabajo.

A la Lic. Andrea Cumba por sus sugerencias en lo relacionado a los suelos y la colaboración en los trabajos de campo y gabinete.

A la Dra. Julia Kristensen y Srta. Elena Rastelli por las determinaciones florísticas y las valiosas sugerencias en 10 relativo a la distribución de las poblaciones vegetales.

A mis compañeros O. Gentile y G. Nuccettelli, por las discusiones y momentos compartidos

Al personal del ADA (Ex Obras Sanitarias de la Provincia de Buenos Aires), Vialidad Provincial y Nacional por la información brindada.

A la Dra. Adriana García por las determinaciones micropaleontológicas.

Al Dr. Francisco Fidalgo y Lic. Ubaldo Colado, ya fallecidos, por compartir su experiencia. 
A la SETCIT (Argentina) y DAAD (Alemania), a los Dres. Horst Sterr (Universidad de Kiel) y E. Schnack (CIC-UNLP), por el apoyo y aportes otorgados.

A la Universidad Nacional de La Plata, Facultades de Ciencias Naturales y Museo y Ciencias Agrarias y Forestales por darme la posibilidad de formarme profesional, científica y académicamente.

Y a todos, los que de alguna forma, en el plano familiar y profesional, participaron en la concreción del presente proyecto. 


\section{INDICE}

\section{CAPITULO I}

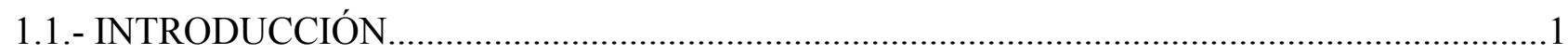

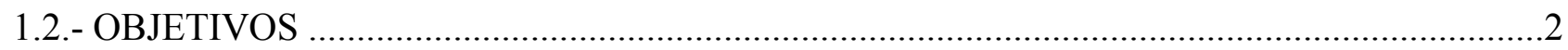

1.3.- METODOLOGÍA DE

TRABAJO. .2

\section{CAPITULO II}

CARACTERÍSTICAS

ÁREA .7

2.1.- UBICACIÓN .7

2.2.-

POBLACIÓN

INFRAESTRUCTURA. .9

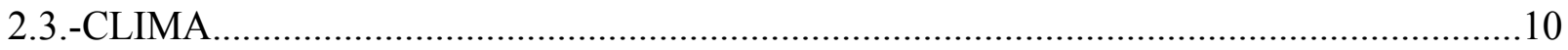

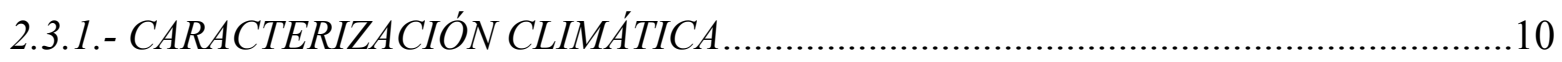

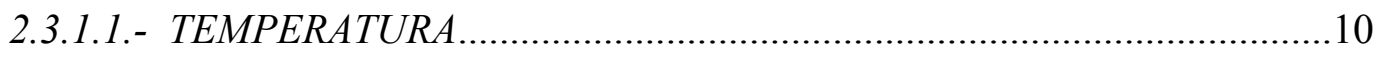

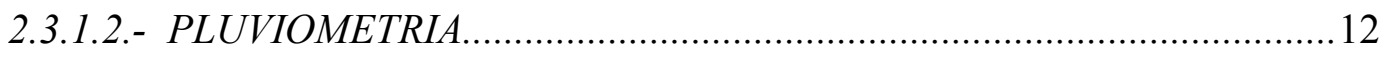

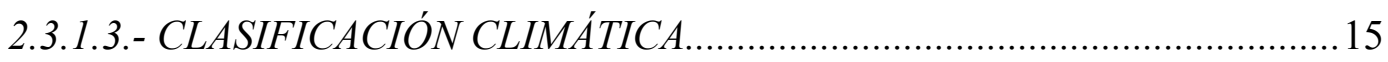

2.3.1.4.- OTRAS CARACTERÍSTICAS............................................................... 18

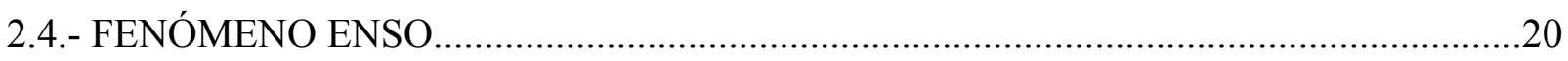

\section{CAPITULO III}

3.1.- EL

CUATERNARIO.

3.2.-ANTECEDENTES

GEOLÓGICOS .26

3.2.- GEOMORFOLÓGICOS 36

3.4.-CARACTERÍSTICAS

PALEOCLIMÁTICAS. 42 


\section{CAPITULO IV}

DESCRIPCIÓN GEOLÓGICA

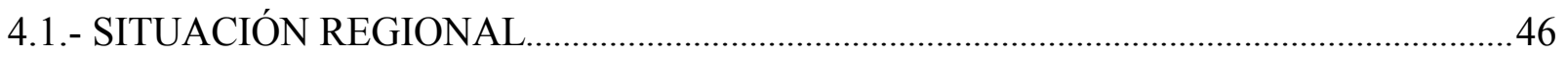

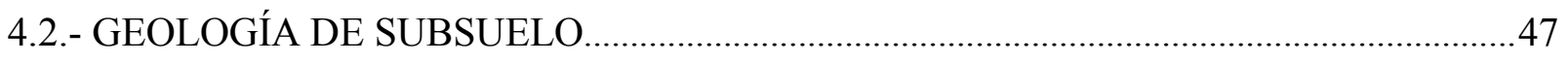

4.2.1.- BASAMENTO CRISTALINO....................................................................

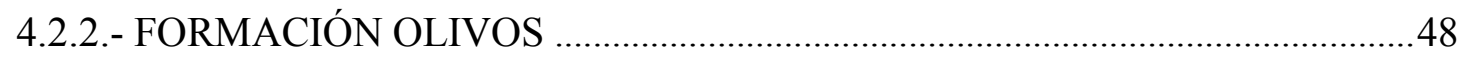

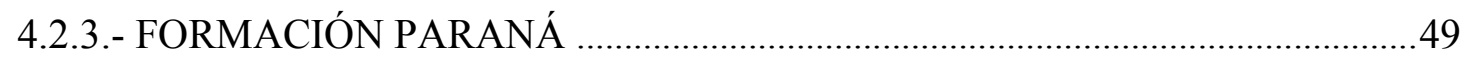

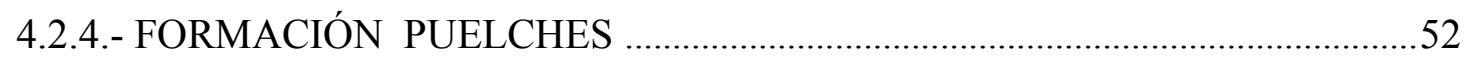

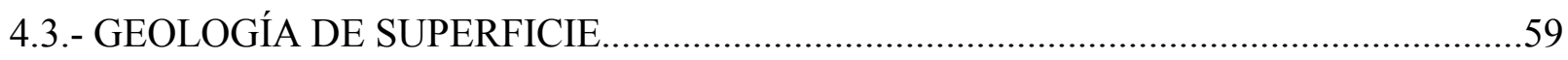

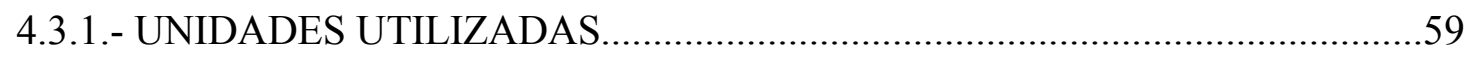

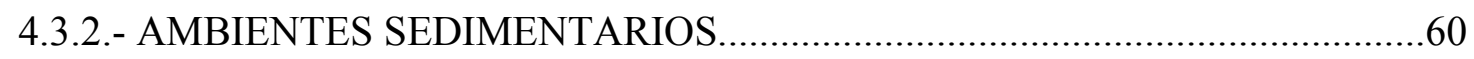

4.3.2.1.- Unidades Continentales...................................................................61

4.3.2.1.1.- SUCESIONES EÓLICAS Y ASOCIADAS ........................62

4.3.2.1.1.1.- UNIDADES LITOESTRATIGRAFICAS ................62

4.3.2.1.1.1.a.-FORMACIÓN PAMPEANO...

. .62

4.3.2.1.1.1.b.-FORMACIÓN LA

POSTRERA ………………....67

4.3.2.1.2.- PERFILES

REPRESENTANTIVOS................................69

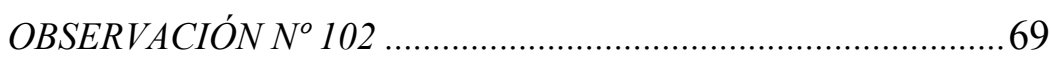

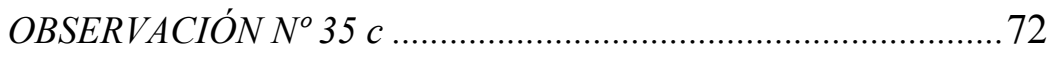

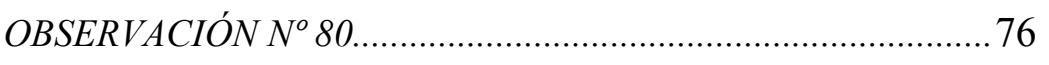

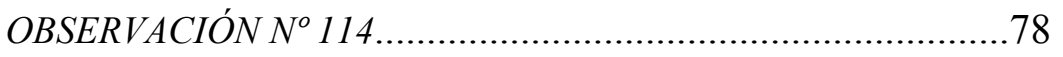

4.3.2.1.2.- SUCESIONES FLUVIALES:...................................................

4.3.2.1.2.1.- UNIDADES LITOESTRATIGRÁFICAS . .80 


\subsection{1.a-FORMACIÓN}

LUJÁN

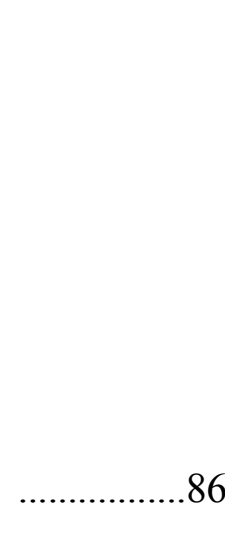

.86

\subsection{2.- UNIDADES PEDOESTRATIGRÁFICAS}

4.3.2.1.2.1.a.a..- MIEMBRO LA CHUMBIADA ......80

4.3.2.1.2.1.a.b- MIEMBRO GUERRERO ................81

4.3.2.1.2.1.a.c.- MIEMBRO RÍO SALADO .............83

4.3.2.1.2.1.b.- ALUVIO ACTUAL .84

4.3.2.1.3.-

PERFILES

REPRESENTANTIVOS. 87

OBSERVACIÓN $N^{\circ} 2$ 87

OBSERVACIÓN $N^{\circ} 1$ 88

OBSERVACIÓN $N^{o}$

20 91

OBSERVACIÓN

52 92

4.3.2.2.- UNIDADES MIXTAS O LITORALES .94

4.3.2.21..- UNIDADES LITOESTRATIGRÁFICAS......... 94 4.3.2.21.a.- FORMACIÓN PILAR . .94 4.3.2.2.1.b.FORMACIÓN

CAMPANA .98 


\subsubsection{1.c.-LIMOS}

DELTAICOS.

107

REPRESENTANTIVOS. 109

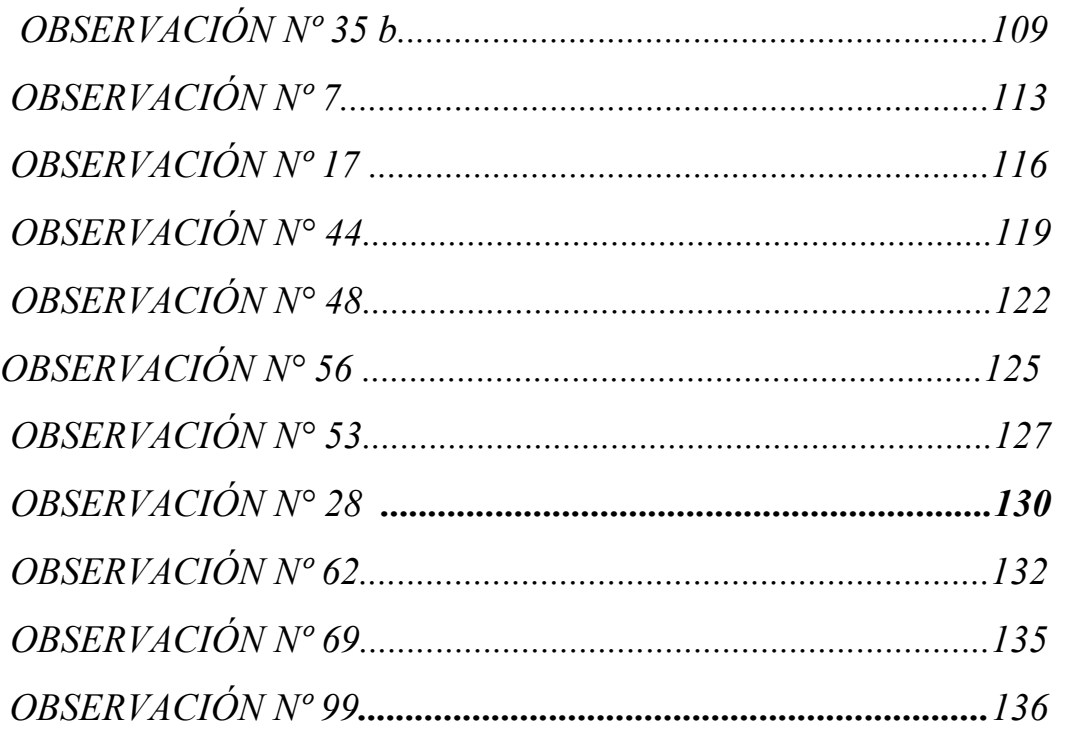

\section{CAPITULO V}

5.1.1.1.- Cuencas de drenaje.

5.1.1.1.a.- Cuenca del Río Luján.

5.1.1.1.b.- Cuenca del Arroyo de la Cruz.....

5.1.1.1.c.- Cuenca del Arroyo El Pescado.

5.1.1.1.d.- Otras Cuencas y Cursos. 


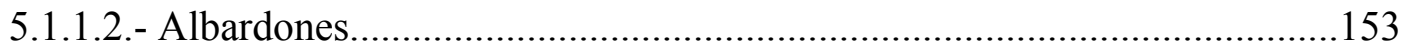

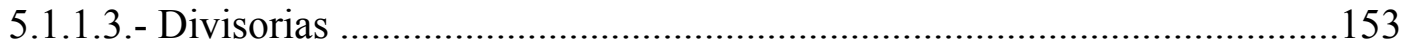

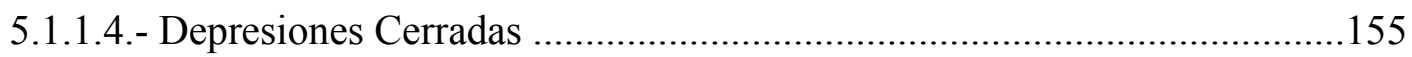

5.1.2.- AMBIENTE LITORAL …..........................................................................157

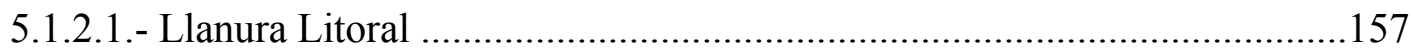

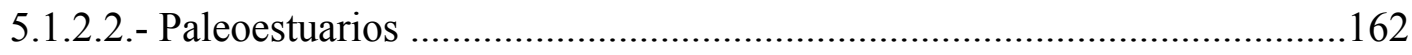

5.1.2.3.- Acantilados relictos.................................................................................164

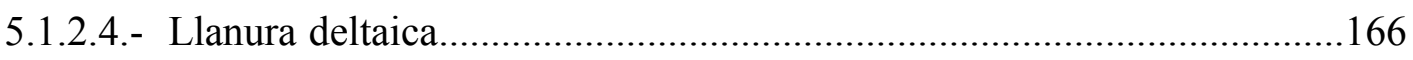

5.1.2.4.1.- Velocidad de Avance del delta................................................168

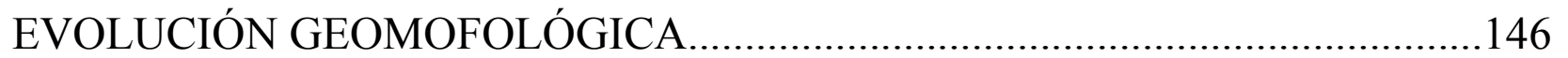

$\begin{array}{llll}\text { CAMBIOS } & \text { PASADOS } & \text { DEL } & \text { NIVEL }\end{array}$

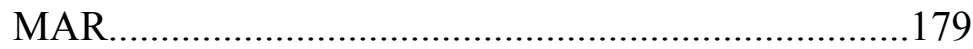

CAMBIOS RECIENTES Y FUTUROS DEL NIEVEL DEL MAR M................................................183

CAPITULO VI

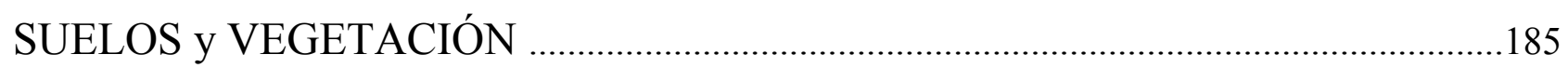

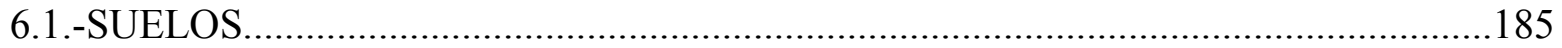

6.1.1.- GEOFORMAS Y SUELOS

ASOCIADOS. 187

6.1.1.1.- Suelos en interfluvios..........................................................................187

6.1.1.2.- Suelos en Pendientes.........................................................................188

6.1.1.3.- Suelos en Depresiones

Cerradas. 189

6.1.1.4.- Suelos en Planicies de Inundaciones, Paleoestuarios y Llanura Litoral (Zonas INUNDABLES) ..................................................................189

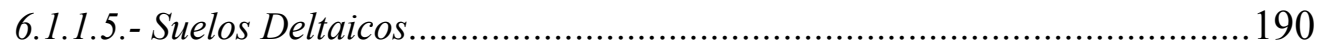

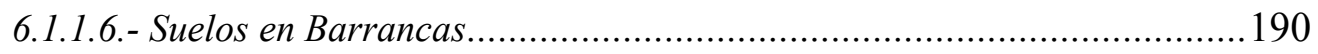




\section{CAPITULO VII}

PELIGROSIDAD

$\mathrm{Y}$

RIESGOS

GEOLÓGICOS .200

7.1.- INTRODUCCIÓN

7.2.- PROBLEMÁTICAS SOBRE SEQUÍAS E INUNDACIONES EN LA REGIÓN PAMPEANA

1

7.3.- POBLEMÁTICAS EN LA ZONA DE ESTUDIO

\section{CAPITULO VIII}

CONCLUSIONES

\section{CAPITULO IX}

BIBLIOGRAFÍA 
El presente estudio tuvo como objetivo central realizar una contribución al conocimiento de la estratigrafía y geomorfología de un sector tan emblemático para la estratigrafía y paleontología del cuaternario en la llanura pampeana. El área de estudio corresponde al sector inferior de la cuenca del Río Luján y del Arroyo de la Cruz, sectores que se vieron afectados durante el cuaternario por los cambios de la línea de costa como producto de oscilaciones del nivel del mar.

Geomorfológica y estratigráficamente se diferenciaron dos ámbitos contrastantes. El sector suroccidental correspondiente a la planicie continental, constituido por un conjunto de unidades estratigráficas relacionadas con la acción eólica y fluvial compuestos por la Formación Pampeano y Fm La Postrera en divisorias y las cuencas de drenaje asociadas a la Fm Luján y al Aluvio actual. En la parte terminal de estas cuencas y correspondiendo a ambientes litorales se reconocieron paleoestuarios, llanuras litorales, paleoacantilados y un sector del delta paranaense. En el subsuelo de estas geoformas se registraron depósitos de la ingresión del pleistoceno tardío a la que se denominó Fm Pilar atribuyéndole una edad correspondiente al subestadio 5e, interpretándose que estas depresiones presentan una génesis anterior a los $120 \mathrm{ka} \mathrm{A.P.}$

Los depósitos originados por la ingresión postglacial han sido designados como Fm Campana, integrada por tres miembros (Molino Viejo, Escobar y Santa Brígida).

El Mb Molino Viejo de carácter transgresivo, compuesto por arcillas a arcillas limosas fluidas de color negro, se desarrolla en prácticamente toda la base de la llanura litoral y sector central de los paleoestuarios. Presenta fauna hologohalina a mixohalina correspondiendo a ambientes estuáricos. El Mb Santa Brígida, esencialmente arcilloso, de color gris, verde y castaño, suprayace al anterior $y$ es atribuido a ambientes de marismas y lagunas 
costeras. El Mb Escobar, desarrollado desde la boca de los paleoestuarios hacia el sector deltaico y compuesto por arenas finas negras en la base y castañas hacia el techo, corresponde a barreras originadas en la parte terminal de los cursos, representando actualmente la llanura litoral con desarrollo de crestas de playa. El estudio de las secuencias estratigráficas y de los rasgos geomorfológicos permitió establecer con precisión el límite de la ingresión holocena, situándose su altura máxima relativa entre los 4 a 4,5 m y dentro de la cuenca del Río Luján en cercanías de la localidad de Pilar.

El abordaje del estudio de las características climáticas y paleoclimáticas permitieron reconocer localmente para los últimos 100 años un incremento en las precipitaciones y temperaturas, observándose regionalmente en los registros estratigráficos, rasgos geológicos y asociaciones faunísticas indicativas de alternancias de estos mismos factores durante el Pleistoceno y Holoceno (geosuelos, depósitos fluviales y lacustres, cambios faunísticos).

El estudio y determinación de las características geológicas y geomorfológicas permitieron realizar una asociación entre estas características y la de los suelos y vegetación. Con respecto a los primeros, utilizando información de campo y del INTA, se cartografiaron siete zonas con características edafológicas distintas, observándose que el ámbito geomorfológico relacionado con la ingresión holocena es la que ha sufrido en menor medida las perturbaciones antrópicas, observándose los suelos con menor desarrollo y capacidad de producción. La vegetación fue abordada con profundidad en los sectores donde se presenta la menor influencia del hombre, discriminándose en la llanura litoral seis comunidades florísticas:Pastizal de "pasto salado", Espartillar, Carpeta flotante, Pajonales de "paja brava", Comunidad de Salicornia y Juncales. 
El abordaje de las problemáticas ambientales de la zona permitió determinar sectores con diferentes rangos de peligrosidad y riesgos, quedando expresado en un mapa específico para esta problemática. Los procesos fluviales fueron identificados como los de mayor importancia y frecuencia, destacándose los sectores de mayor influencia con el objeto de ser considerados en las tareas de planificación. La presencia de canteras constituye una problemática puntual pero muy significativa en áreas urbanas y periurbanas, observándose en muy pocos casos tareas de remediación. 


\section{CAPITULO I}

\subsection{INTRODUCCIÓN}

La investigación que se pone en consideración representa las tareas llevadas a cabo por el autor para optar al título de Doctor en Ciencias Naturales en la Universidad Nacional de La Plata.

Las particularidades y extensión de la región pampeana han permitido a numerosos estudiosos del Cuaternario realizar sus tareas en diferentes especialidades y a escalas muy contrastantes.

El área de estudio abarca el tramo inferior de la cuenca de Río Luján y gran parte de la cuenca del Arroyo de la Cruz, pretendiéndose con esta elección incluir en el ámbito de trabajo diferentes paleoambientes, con el objeto de determinar su interrelación durante la evolución geomorfológica.

El emprendimiento de estudios estratigráficos y geomorfológicos ha permitido reconocer las características y extensión de los agentes y procesos actuantes desde el Pleistoceno tardío al Holoceno, a través de un conjunto de sucesiones sedimentarias aflorantes y del subsuelo y sus diferentes geoformas, permitiendo establecer un esquema estratigráfico y su correlación con áreas vecinas. Otro motivo de elección de la zona se basó en la necesidad de llevar a cabo estas tareas en un área tan comprometida desde el punto de vista urbanístico. Como puede observarse en las cuencas vecinas hacia el sur (Arroyo Escobar y Río de la Reconquista), prácticamente han sido ocupadas por la urbanización, impidiendo y modificando los sectores bajos del paisaje, que son cubiertos inexorablemente por relleno a fin de evitar las inundaciones, enmascarando y disturbando las geoformas de manera definitiva. 


\subsection{OBJETIVOS}

El objetivo central de este estudio es exponer un mapa geológico geomorfológico a escala 1:100.000 con el fin de representar las diferentes unidades estratigráficas y geomorfológicas.

Si bien esta representación cartográfica se realiza a nivel formacional, las descripciones de perfiles y sus representaciones, asociados a las imágenes satelitarias, fotografías y figuras en general, definen de manera precisa situaciones de detalle, permitiendo comprender de manera general y particular, las asociaciones estratigráficas y geomorfológicas presentes.

Establecido el marco geológico - geomorfológico y asociando la información antecedente, relacionada fundamentalmente con la sucesión paleoclimática, se procedió a establecer la evolución paleoambiental del sector.

Con esta información, se desarrollaron tareas de asociación con los suelos, la vegetación y los riesgos de inundación, quedando expuesto claramente la interrelación de estos componentes con las características geológicas y geomorfológicas.

\section{3 METODOLOGÍA DE TRABAJO}

Los trabajos de investigación abarcaron actividades de gabinete, campo y laboratorio. La primera de éstas estuvo centralizada en la recopilación y análisis de antecedentes bibliográficos, material cartográfico, fotográfico y satelital.

Se utilizaron las cartas topográficas del IGM en escala 1:50.000: Campana Sur (3560-6-3), Pilar (3560-12-1), Capilla del Señor (3560-5-4) y Open Door (3560-11-2). También se utilizaron cartas imágenes del IGM con igual 
denominación y escala, que fueron elaboradas a partir de la combinación de imágenes Lansat y spot captadas durante los veranos de 1984 y 1985. Las fotografías aéreas a escala 1:20.000 fueron obtenidas en los vuelos de 1984 y 1995 por el Ministerio de Obras Públicas de la provincia de Buenos Aires, restringiendo la utilización de estas a sectores particulares, donde se hacía necesario realizar estudios detallados. Asimismo, se utilizaron cartas topográficas y cartas imágenes en escala 1:50.000, 1:100.000 y 1:250.000 del área y sectores circundantes a fin de conocer la totalidad de las cuencas de drenaje estudiadas así como las cuencas vecinas, para visualizar regionalmente las particularidades topográficas y geomorfológicas.

Además se utilizaron dos imágenes satelitales. Una LANSAT en las bandas 2, 3 y 4 del año 1999 que permitió obtener una visión integradora regional del ambiente geológico geomorfológico y otra imagen Resource, pancromática, de gran detalle obtenida el año 1989. También se utilizaron foto mosaicos aéreos en escala 1:50.000 obtenidos por el INTA en los años 1967 y 1969 para la caracterización y clasificación de los diferentes ambientes geomórficos.

En base a este material se realizó una primera aproximación sobre los diversos ambientes reconocidos, discriminándoselos a fin de realizar en cada uno de ellos las observaciones de campo.

Las cartas topográficas del IGM y las de suelos del INTA a escalas 1:50.000 Campana Sur (3560-6-3), Pilar (3560-12-1), Capilla del Señor (3560-5-4) y Open Door (3560-11-2), fueron digitalizadas para contar con la base planialtimétrica necesaria para la realización de los distintos mapas .

De cada una de las observaciones de campo se realizaron perfiles geológicos columnares, lo que al ser integrados, permitieron la realización de los diferentes perfiles geológicos complexivos representados. 
Los trabajos de campo consistieron en el reconocimiento de unidades litológicas y geomorfológicas, ya sea a través de sondeos manuales, afloramientos en barrancas y exposiciones en canteras, canales y caminos, procediéndose al muestreo para las determinaciones de texturas, color, contenido fosilífero, etc, como así también, la caracterización de estructuras sedimentarias y demás elementos. La utilización del barreno manual con recuperación de testigo interno y otro helicoidal permitió de acuerdo a las características litológicas de las unidades atravesadas la posibilidad de llegar a profundidades importantes con mayor o menor dificultad, siendo los 6,80 metros la profundidad máxima alcanzada (Fig. 1.1). A medida que se fueron realizando las observaciones, se inferían las asociaciones naturales de las unidades litológicas reconocidas, llegando de esta forma a diagramar el esquema estratigráfico del sector.

Si bien fueron caracterizadas la totalidad de las unidades geológicas observadas, se prestó preferencial atención a aquéllas de génesis litoral, ya que representaban sucesiones no estudiadas en la zona y su ámbito de influencia.

Las unidades continentales, algunas de desarrollo muy restringido (Fm Luján) y otras muy ampliamente extendidas (Fm Pampeano y Fm La Postrera) fueron observadas y caracterizadas en cursos, canteras y cortes de caminos, determinándose que ellas presentan una marcada similitud con las descripciones realizadas en otros sitios de la región pampeana.

En laboratorio, sobre las muestras obtenidas, se procedió a la recuperación de material fosilífero para su identificación y datación absoluta. La caracterización granulométrica se realizó mediante la utilización del hidrómetro basado en la ley de Stokes. Este método mide la densidad de la suspensión a cierta profundidad, considerando que la densidad de una suspensión es proporcional a la concentración de la fase dispersa (Carver, 1971). Las características texturales se determinaron según González Bonorino y Terruggi (1961) . 


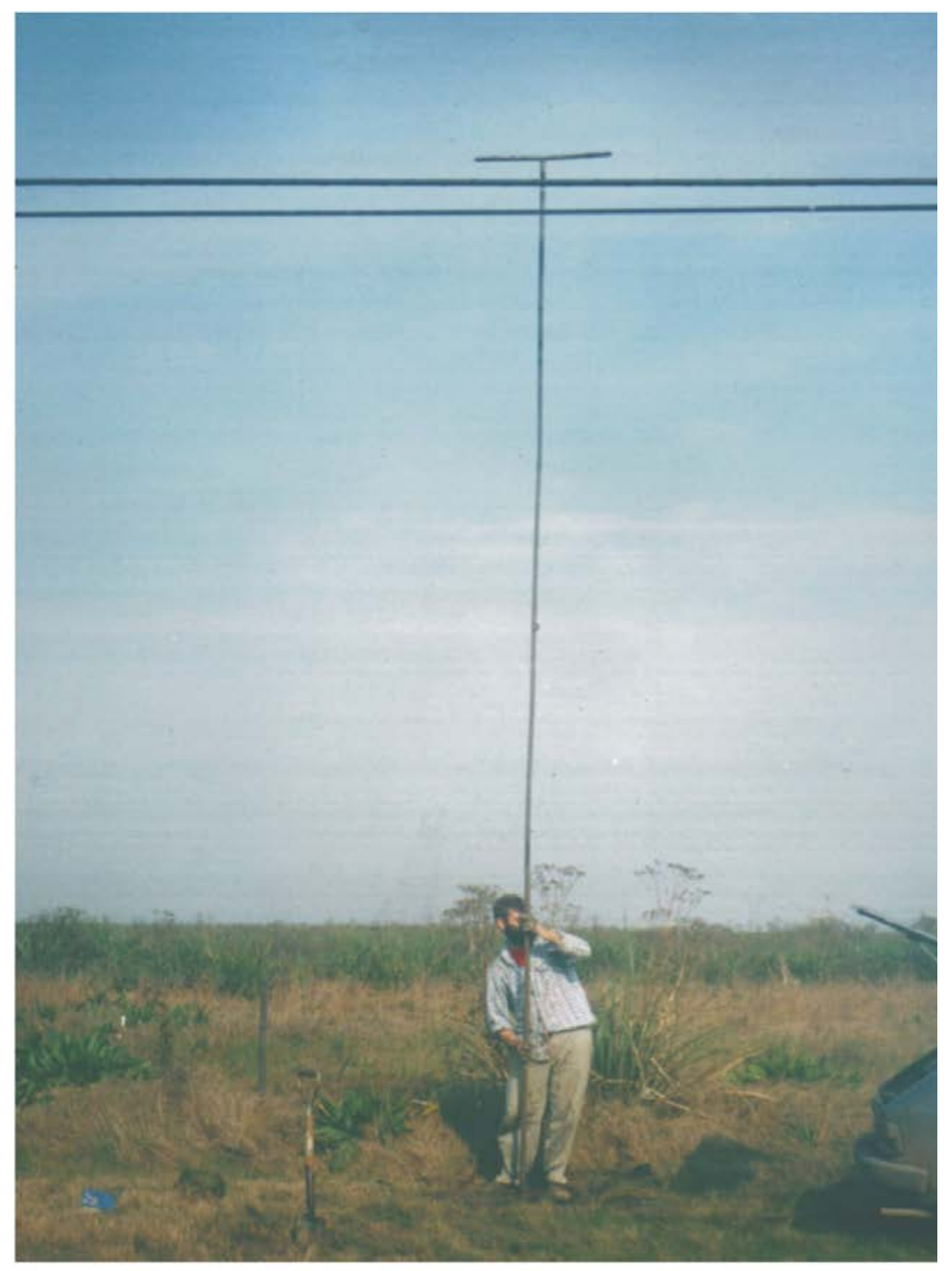

Fig.1.1

Utilización del barreno manual alcanzando profundidades máximas de 6,80 metros.

La utilización del método del hidrómetro, consiste inicialmente en la dispersión del material en una solución de hexa meta fosfato de sodio (calgón) al 5 \%, optándose por separar, una vez disperso, la fracción arena por tamizado. Posteriormente, a través del hidrómetro a intervalos establecidos, se procedió a tomar las mediciones y calcular el porcentaje y diámetro de las partículas en suspensión. 
La etapa final de gabinete, consistió en la búsqueda de datos de perforaciones geotécnicas, dado que la metodología y los objetivos de este tipo de estudios son más adecuados para obtener información de mayor detalle, que los provenientes de las perforaciones para captación de aguas subterráneas y de las perforaciones manuales, permitiendo de esta forma reconocer unidades que con los otros métodos son de difícil concreción.

Con el conjunto de esta información se procedió a la elaboración de los diferentes mapas y perfiles con el objeto de expresar claramente el trabajo realizado. 


\section{CAPITULO II}

\section{CARACTERÍSTICAS GENERALES DEL AREA}

\subsection{UBICACIÓN}

El área de estudio se encuentra ubicada en el noreste de la Provincia de Buenos Aires abarcando una superficie aproximada de $1.275 \mathrm{Km}^{2}$.

La misma esta enmarcada geográficamente por los paralelos $34^{\circ} 1^{\prime}$ y $34^{\circ}$ 30' Latitud Sur y los meridianos $59^{\circ} 1^{\prime}$ y $58^{\circ} 4^{\prime}$ Longitud Oeste. La zona específica de estudio está delimitada hacia el noreste por el Río Paraná de las Palmas, al noroeste por la divisoria que separa el Arroyo Pequería del Arroyo de la Cruz, mientras que el borde sudeste está definido por la divisoria con la cuenca del Arroyo Escobar (Fig.2.1). 


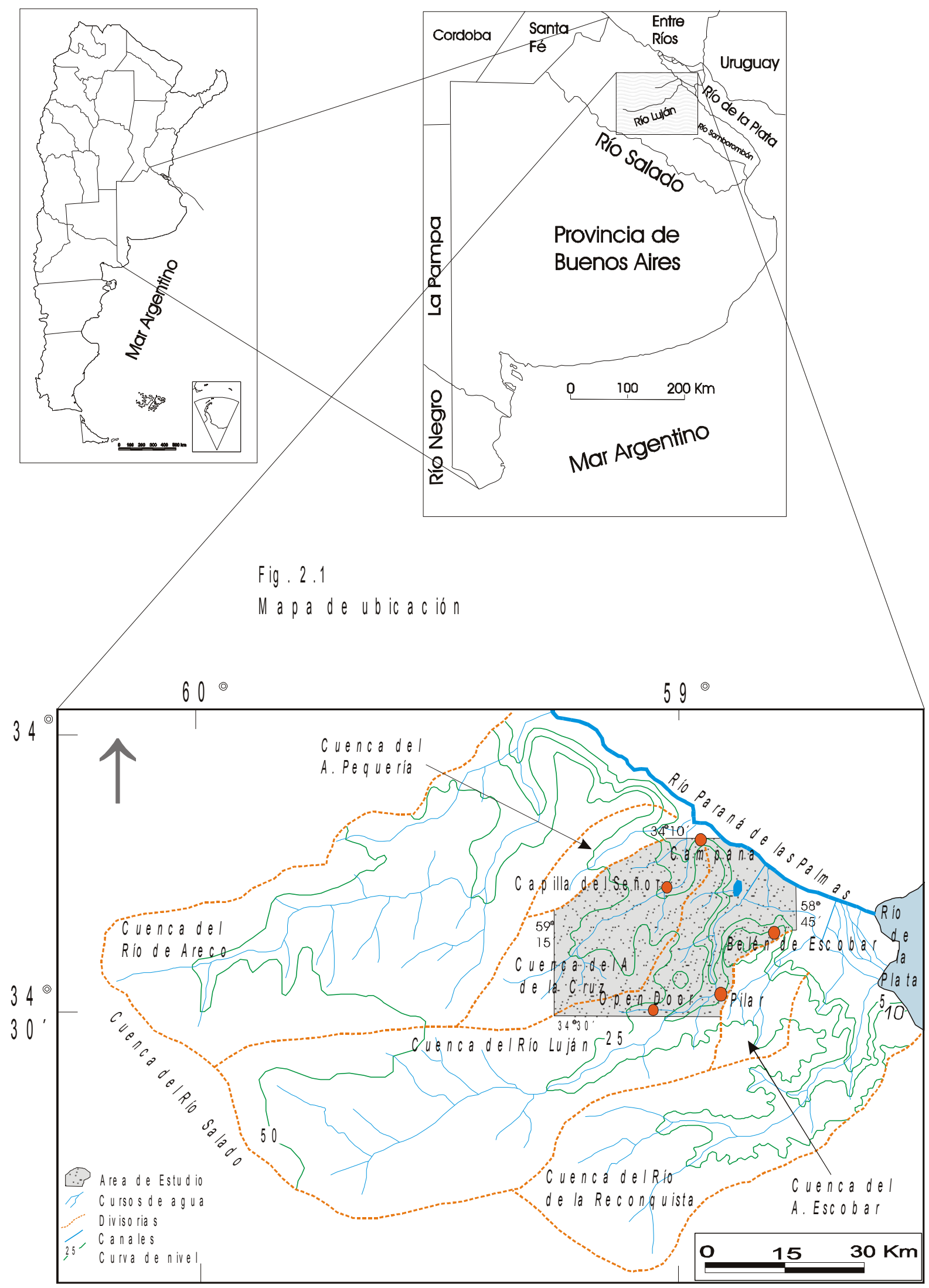




\subsection{POBLACION E INFRAESTRUCTURA}

Las localidades más importantes ubicadas en la zona de estudio por orden de importancia son Pilar, Belén de Escobar, Campana, Capilla del Señor y Open Door. Completan el conjunto localidades mas pequeñas, aisladas o aledañas a las anteriores, formadas a la vera de líneas ferroviarias y caminos y otras más modernas, producto de nuevas formas de urbanización.

La población de los partidos, cuyas ciudades cabeceras responden a las anteriores, están constituidas por:(Estadísticas Bonaerenses-anuario, 1997; Censo Nacional de Población y Vivienda, 2001.) (Tabla 2.1)

\begin{tabular}{|l|l|l|}
\hline PARTIDO & 1991 & 2001 \\
\hline PILAR & 130.187 & 232.463 \\
\hline ESCOBAR & 128.421 & 178.155 \\
\hline LUJAN & 80.645 & 93.992 \\
\hline CAMPANA & 71.464 & 83.698 \\
\hline SAN ANDRES DE GILES & 18.302 & 20.829 \\
\hline EXALTACIÓN DE LA CRUZ & 17.072 & 24.167 \\
\hline
\end{tabular}

Tabla 2.1 Población de los partidos comprendidos parcialmente en el área de estudio

La infraestructura, en relación al transporte es muy importante en esta región. Las principales rutas son las nacionales $\mathrm{N}^{\circ} 8$ y 9 y la provincial $N^{\circ} 6$. Las dos primeras se originan en la Capital Federal, orillando la primera Pilar y la segunda Belén de Escobar y Campana. La ruta 6 
circunvala el Gran Buenos Aires, naciendo en Angel Echeverry, en proximidades a La Plata y terminando en la localidad de Campana.

Completan la red caminera, un conjunto de caminos asfaltados, mejorados y caminos rurales, que permiten vincular el conjunto de localidades principales y de menor importancia y las zonas rurales.

La red ferroviaria está representada por aquellas líneas que partiendo desde la ciudad de Buenos Aires se dirigen hacia el norte, noroeste, noreste y oeste del país, pertenecientes a los ex Ferrocarriles General B. Mitre, General Belgrano, General Urquiza y General San Martín, respectivamente.

\subsection{CLIMA}

\subsubsection{CARACTERIZACION CLIMATICA}

Para la información climática de la región se utilizaron las estadísticas climatológicas del Servicio Meteorológico Nacional, correspondientes a la Estación Buenos Aires (Observatorio Central). La elección de esta estación, se basó en la amplitud temporal de la información (103 años), en la garantía de los mismos (datos publicados) y en la distancia del área de trabajo $(45 \mathrm{Km})$. El período considerado comprende desde 1901 a 2003 .

\subsubsection{TEMPERATURA}

La temperatura media anual del período 1901 - 2003 es de 17,04 ${ }^{\circ} \mathrm{C}$, con valores mínimos medios para el mes de julio con 10,4 ${ }^{\circ} \mathrm{C}$ y máximos medios para el mes de enero con $23,9{ }^{\circ} \mathrm{C}$ (Tabla 2.2 y fig. 2.2).

\begin{tabular}{|l|l|l|l|l|l|l|l|l|l|l|l|l|}
\hline \begin{tabular}{l} 
Ener \\
\hline $\begin{array}{l}\text { Febrer } \\
0\end{array}$
\end{tabular} & $\begin{array}{l}\text { Marz } \\
0\end{array}$ & Abril & $\begin{array}{l}\text { May } \\
0\end{array}$ & Junio & Julio & 0 & Agost & Septiembr & Octubr & Noviembr & Diciembr \\
$e$ & & e & Media \\
\hline 23,9 & 23 & 21 & 17,3 & 14 & 10,8 & 10,4 & 11,7 & 13,7 & 17 & 20 & 22,4 & 17 \\
\hline
\end{tabular}

Tabla 2.2 Temperatura media mensual del período 1901-2003. 


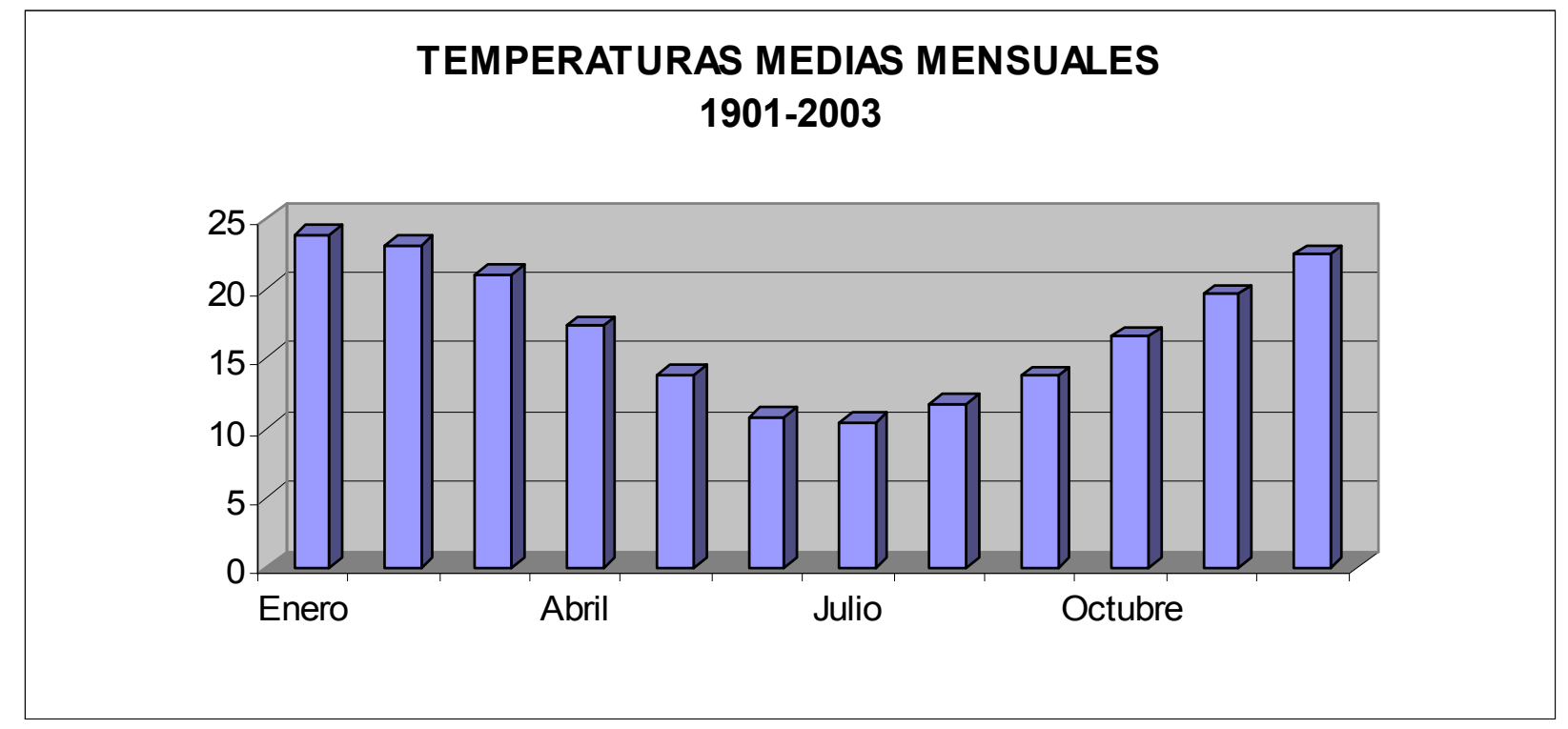

Fig. 2.2 Histograma de la temperatura media mensual para el periodo 1901-2003

Analizando los valores medios anuales de temperatura para cada período, se observa un incremento sostenido desde la primera mitad del siglo XX hasta la actualidad, ya que hasta 1950 el valor medio es de 16,5 ${ }^{\circ} \mathrm{C}$, aumentando progresivamente hasta el período 2001 - 2003 a 18,3 C. Estas variaciones pueden observarse en la tabla 2.3 y fig. 2.3 donde en función de los espacios de tiempo utilizados, las medias varían en mayor o menor grado.

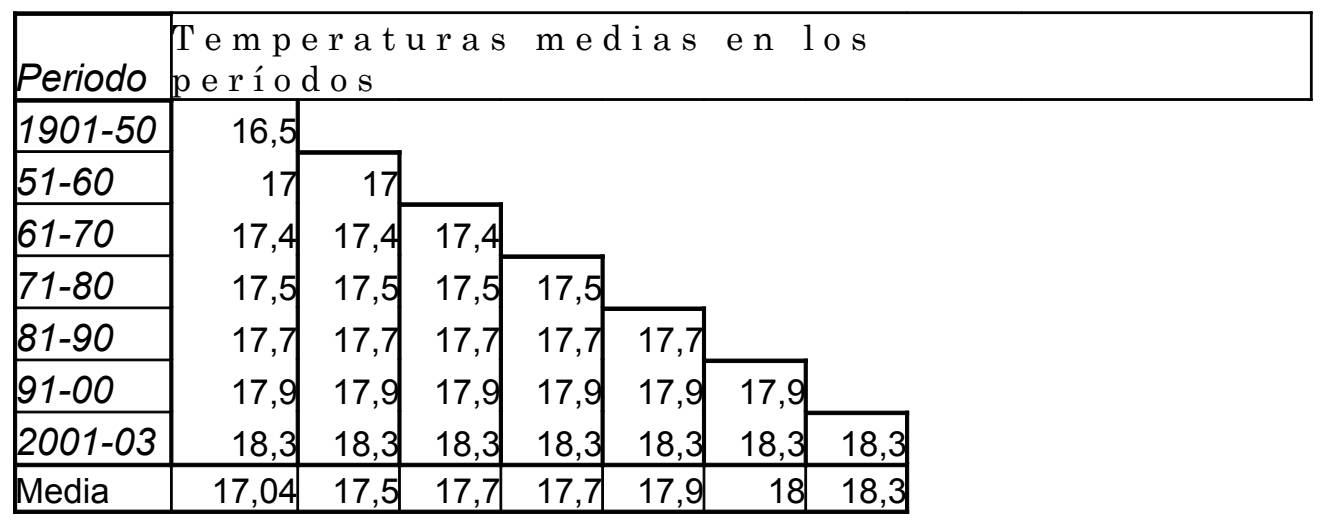

Tabla 2.3 Temperatura media anual de los diferentes períodos. 


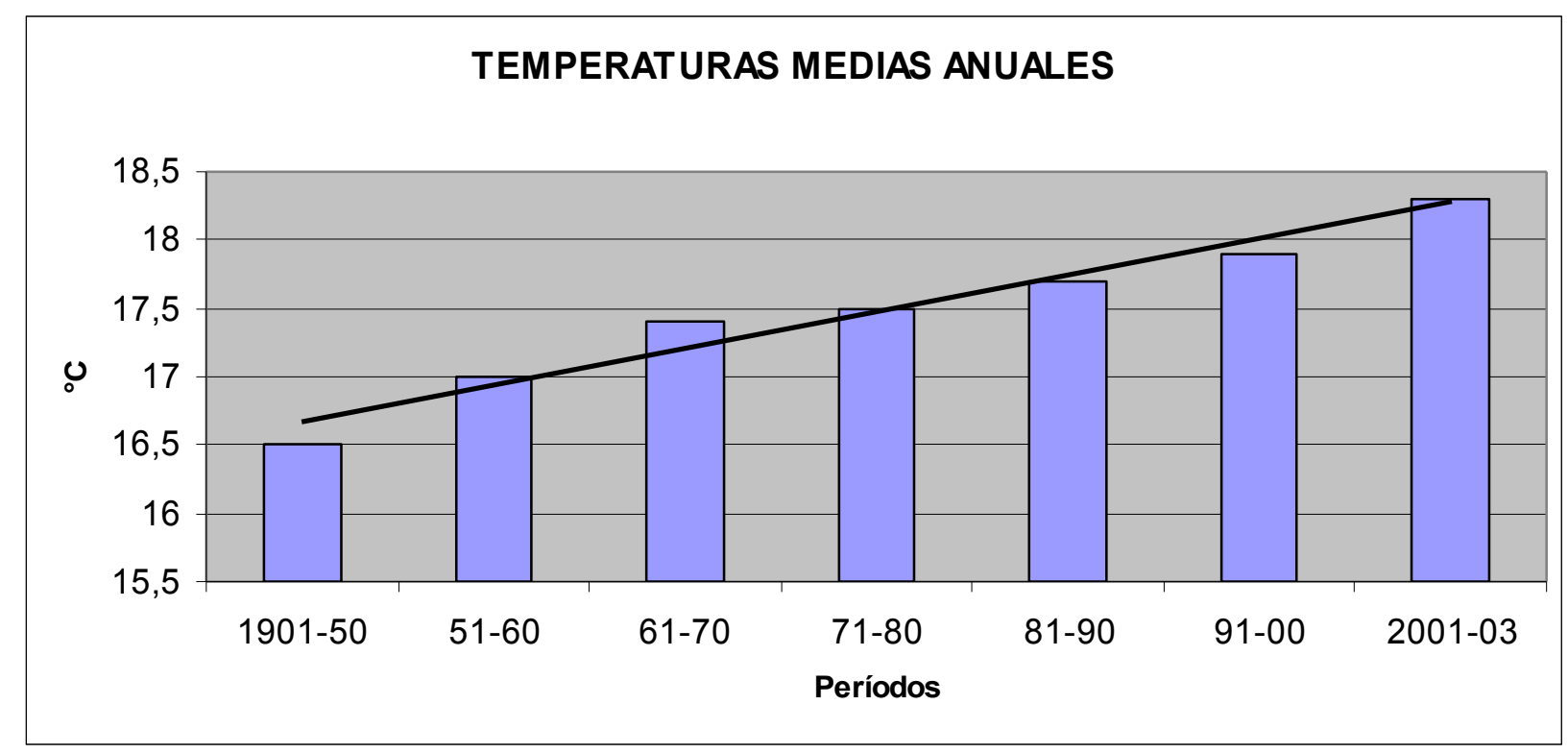

Fig. 2.3 Histograma de temperatura media anual para los diferentes períodos y su tendencia.

\subsubsection{PLUVIOMETRIA}

Los resultados obtenidos en relación a las precipitaciones para el período 1901 -2003 indican que los valores medios anuales son de 1070,3 $\mathrm{mm}$. Las mayores precipitaciones mensuales se producen en marzo con 118,6 mm y las menores en junio con $60,8 \mathrm{~mm}$ (tabla 2.4).

\begin{tabular}{|c|c|c|c|c|c|c|c|c|c|c|c|c|}
\hline Enero & ebrer & Marzo & Abril & Mayo & Junio & Julio & \begin{tabular}{|l|l} 
Agost \\
0
\end{tabular} & $\begin{array}{l}\text { Septiembr } \\
\text { e }\end{array}$ & Octubre & $\begin{array}{l}\text { Noviembr } \\
e\end{array}$ & $\begin{array}{l}\text { Diciembr } \\
e\end{array}$ & Total \\
\hline 107,8 & 89,9 & \begin{tabular}{|l|l|}
118,6 \\
\end{tabular} & 101 & \begin{tabular}{l|l|}
1,86 \\
\end{tabular} & 60,83 & $\begin{array}{ll}360,96 \\
\end{array}$ & 67,62 & 76,43 & \begin{tabular}{|l|l|}
3 & 102,509 \\
\end{tabular} & 100,9 & 102 & 21070,36 \\
\hline
\end{tabular}

Tabla 2.4 Precipitaciones medias mensuales para el período 1901 - 2003.

La estación mas lluviosa es el verano con $315 \mathrm{~mm}$ y la de menor valor corresponde al invierno con $205 \mathrm{~mm}$. El histograma de las precipitaciones mensuales es bimodal, con la moda principal en el otoño y secundaria en la primavera (fig. 2.4). 


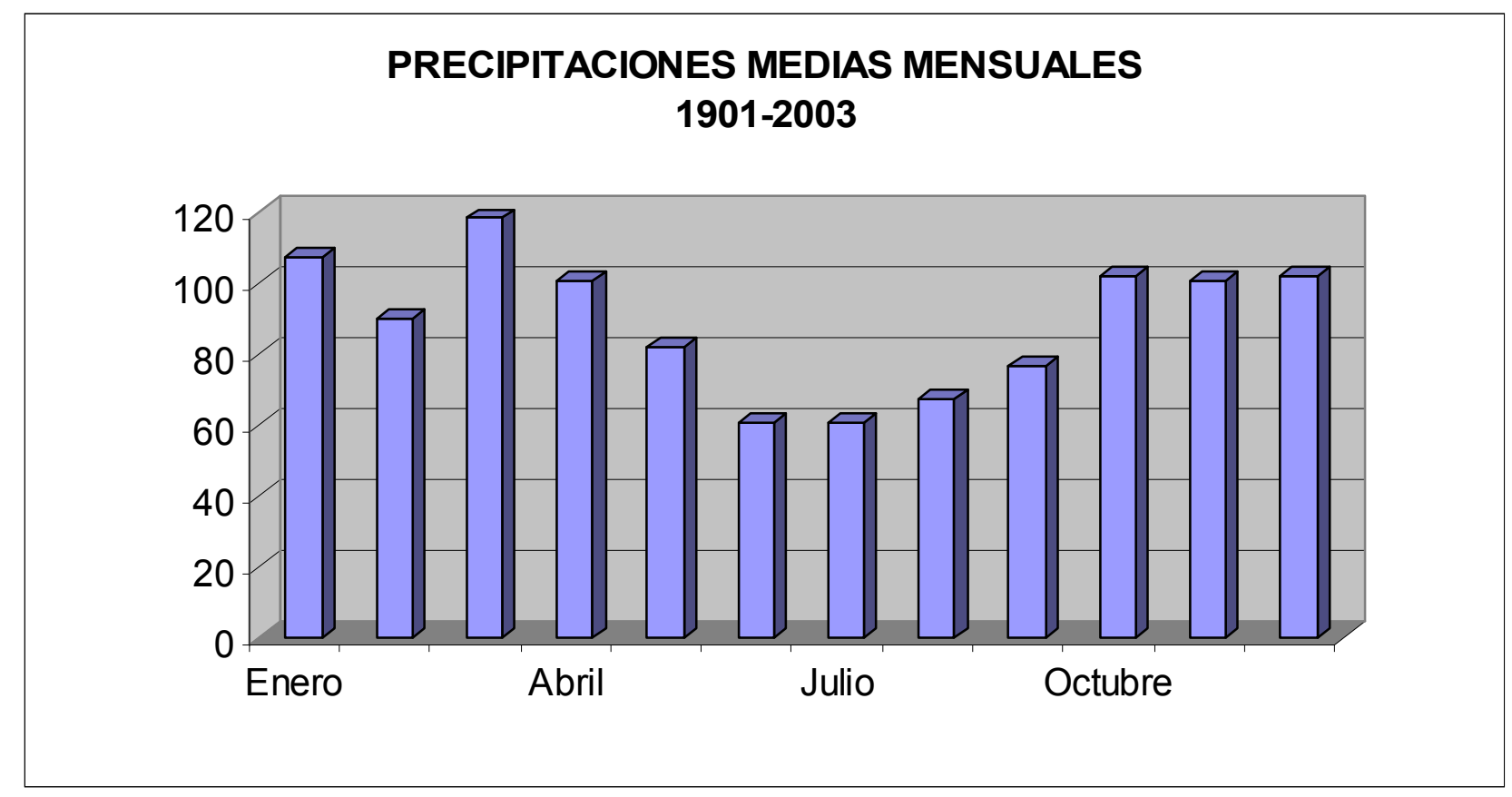

Fig. 2.4 Histograma de precipitaciones.

Si analizamos las precipitaciones medias en los diferentes períodos y las precipitaciones anuales podemos observar una tendencia hacia el incremento desde 1950 hasta la actualidad (Tabla 2.5 y figs. 2.5 y 2.6). En este sentido se observa que en el período 51/70 las precipitaciones se incrementaron con respecto a los primeros 50 años del siglo XX en $100 \mathrm{~mm}$ aproximadamente y durante el periodo $71 / 03$ en $250 \mathrm{~mm}$ en relación al mismo período.

VALORES MEDIOS DE PRECIPITACION

\begin{tabular}{|c|c|c|c|c|c|c|c|c|c|c|c|c|c|}
\hline Periodo & Enero & Febrero & Marzo & Abril & Mayo & Junio & \begin{tabular}{|l|} 
Julio \\
\end{tabular} & $\begin{array}{l}\text { Agost } \\
\end{array}$ & \begin{tabular}{|l} 
Septiembr \\
$e$
\end{tabular} & Octubre & $\begin{array}{l}\text { Noviembr } \\
e\end{array}$ & \begin{tabular}{|l|} 
Dicie \\
mbre
\end{tabular} & Total \\
\hline $1901-50$ & 83,8 & 77,5 & 110,6 & 103,1 & 75,4 & 54,4 & 54,7 & 63,8 & 82,1 & 86,6 & 90,4 & 98 & 980,7 \\
\hline $51-60$ & 144 & 39 & 105 & 92 & 95 & 78 & 71 & 84 & 67 & 104 & 103 & 52 & 1089 \\
\hline $61-70$ & 92 & 88 & 135 & 108 & 69 & 61 & 59 & 64 & 62 & 118 & 101 & 119 & 1076 \\
\hline $71-80$ & 144 & 142 & 113 & 77 & 59 & 77 & 87 & 76 & 81 & 100 & 94 & 93 & 1143 \\
\hline $81-90$ & 121,6 & 122,6 & 153,9 & 106,3 & 92,1 & 50 & 52,9 & 63,2 & 77,7 & 139,3 & 131,2 & 103 & 1214 \\
\hline $91-00$ & 127 & 87,9 & 94,1 & 139,7 & 112,4 & 71,1 & 58,8 & 58,2 & 63,8 & 117,8 & 107 & 151 & 1188 \\
\hline 2001-03 & 207,9 & 196,7 & 226 & 101,1 & 128,9 & 58 & 85,5 & 106,8 & 84,2 & 145,8 & 171,7 & 140 & 165 \\
\hline
\end{tabular}

Tabla 2.5 Precipitaciones medias mensuales para los diferentes períodos. 


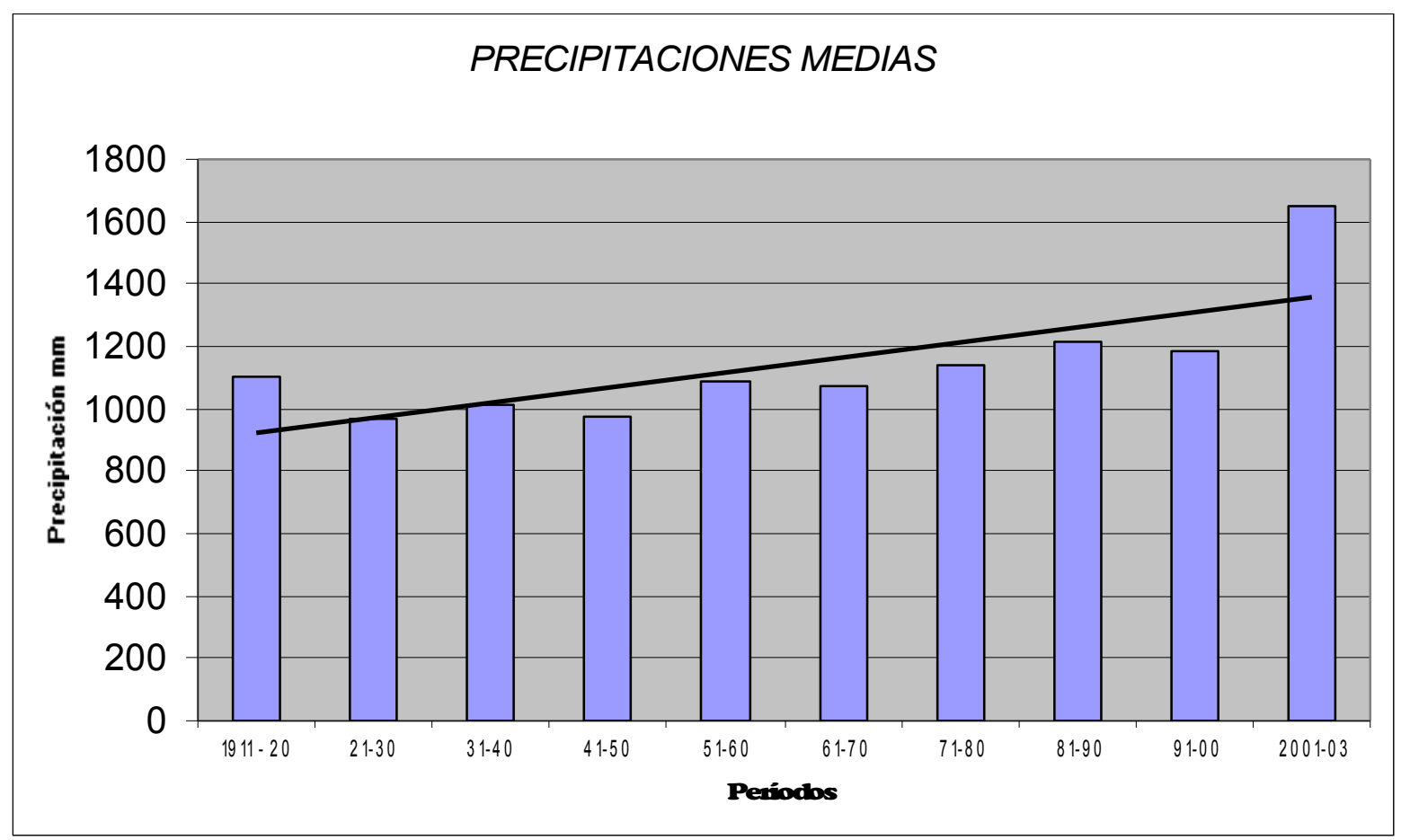

Fig. 2.5 Histograma de precipitaciones medias de los periodos.

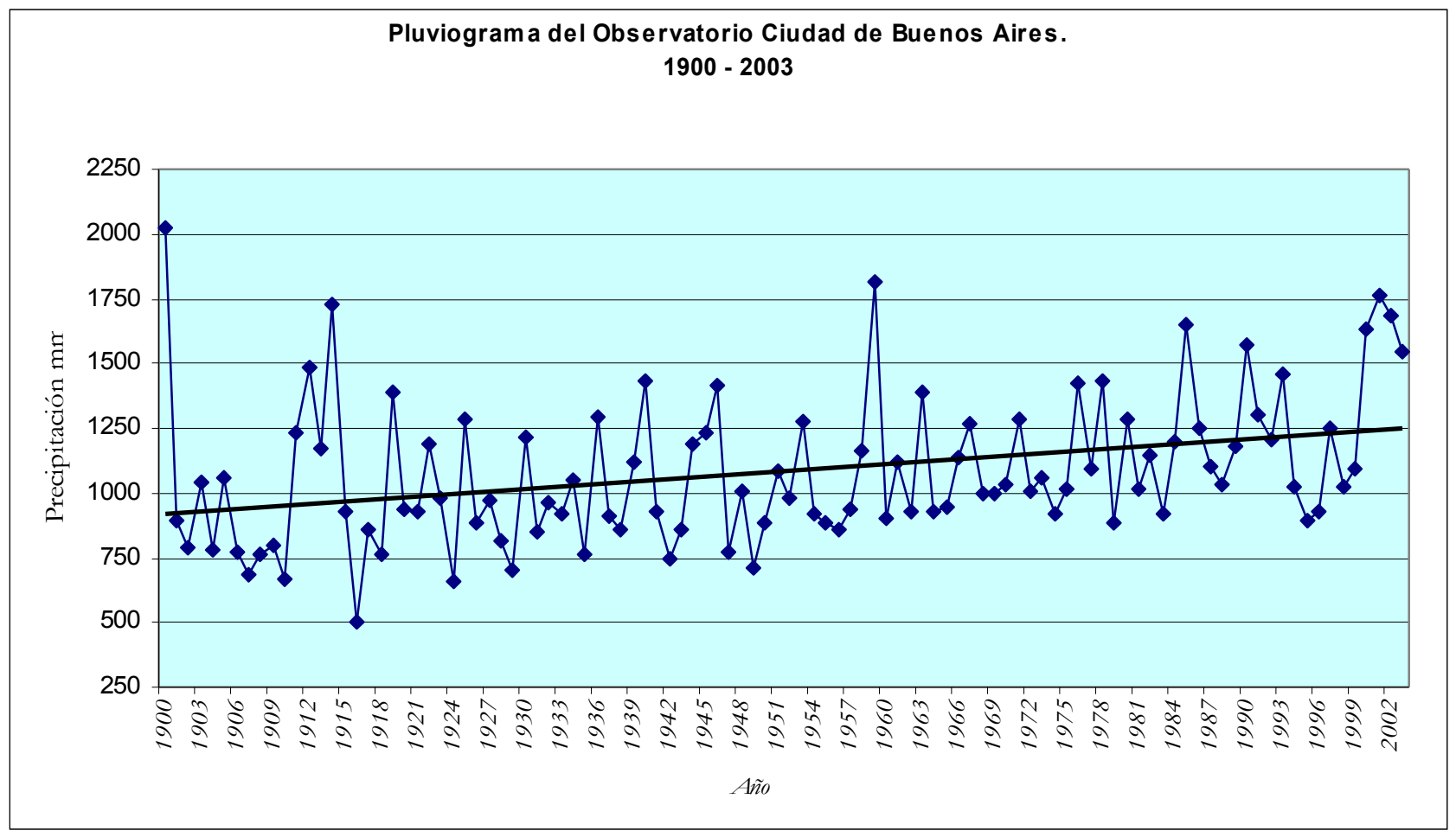

Fig. 2.6 Pluviograma de la Est. Observatorio de la Ciudad de Buenos Aires. 


\subsubsection{CLASIFICACIÓN CLIMÁTICA}

Analizando las temperaturas y precipitaciones, los valores de evapotraspiración (potencial y real) son esenciales para realizar el balance hídrico (Thornthwaite-Mather, 1957) y consecuentemente la clasificación climática, según Burgos y Vidal (1951).

\begin{tabular}{|c|c|c|c|c|c|c|c|c|c|c|c|c|c|}
\hline \multicolumn{11}{|c|}{$\begin{array}{l}\text { BALANCE HIDRICO ESTACION BUENOS AIRES } \\
\text { PERIODO 1901-2003 }\end{array}$} & \multicolumn{3}{|c|}{$\begin{array}{l}\text { Latitud } 34^{\circ} 35^{\prime} \\
\text { Longitud } 58^{\circ} 29^{\prime} \\
\text { Elevación } 25 \text { Mts. }\end{array}$} \\
\hline & ENE & FEB & MAR & $\mathrm{ABR}$ & MAY & IUN & IUL & $\mathrm{AGO}$ & SEP & OCT & NOV & DIC & ANUAL \\
\hline $\mathrm{T}^{\circ} \mathrm{C}$ & 24 & 23 & 21 & 17 & 14 & 11 & 10 & 12 & 14 & 17 & 20 & 22 & \\
\hline & 10,7 & 10 & 9 & 6,6 & 4,7 & 3,2 & 3,1 & 3,6 & 4,6 & 6,2 & 8 & 9,7 & 79,4 \\
\hline EP s/a & 3,8 & 3,6 & 3 & 2,1 & 1,5 & 0,9 & 0,9 & 1,1 & 1,4 & 1,9 & 2,7 & 3,4 & \\
\hline $\mathrm{FC}$ & 36,9 & 31 & 32 & 28 & 27 & 25 & 26 & 28 & 30 & 34 & 35 & 38 & \\
\hline EP mm & 140 & 112 & 95 & 59 & 40 & 22 & 23 & 31 & 42 & 64 & 95 & 128 & 853 \\
\hline$P(\mathrm{~mm})$ & 108 & 90 & 119 & 101 & 82 & 61 & 61 & 68 & 76 & 103 & 101 & 102 & 1070 \\
\hline P-EP mm & -32 & -22 & 23 & 42 & 42 & 39 & 37 & 37 & 34 & 38 & 6,1 & -26 & \\
\hline PPaa (mm) & -58 & -81 & & & & & & & & & & -26 & \\
\hline A mm & 101 & 86 & 109 & 150 & 150 & 150 & 150 & 150 & 150 & 150 & 150 & 126 & \\
\hline VA mm & -25 & -15 & 23 & 41 & o & 0 & 0 & o & o & 0 & 0 & -24 & \\
\hline ER mm & 133 & 105 & 95 & 59 & 40 & 22 & 23 & 31 & 42 & 64 & 95 & 126 & 836 \\
\hline $\mathrm{D} \mathrm{mm}$ & 7,42 & 7,2 & & & & & & & & & & 2 & 16,6 \\
\hline EX mm & & & & 1,5 & 42 & 39 & 37 & 37 & 34 & 38 & 6,1 & & 235 \\
\hline
\end{tabular}

Tabla 2.6 Balance hídrico según el método de Thornthwaite-Mather (1957).

Considerando los excesos y déficit de agua se procedió a realizar el cálculo de los índices siguientes para llevar a cabo la caracterización climática (tablas 2.6 y 2.7).

\begin{tabular}{|l||l||l||}
\hline Indice de Aridez: & 1,95 \\
Indice de Humedad: & 27,5 \\
Indice Hídrico: & 26,3 & $\mathrm{~B}_{1}$ \\
Indice de Eficiencia Térmica: & 852,5 & $\mathrm{~B}_{2}^{\prime}$ \\
Concentración Estival de la Eficiencia Térmica: & 44,6 & $\mathrm{a}^{\prime}$ \\
\hline
\end{tabular}


Tabla 2.7 Índices para la clasificación climática según Burgos y Vidal (1951). En base a estos valores puede definirse el tipo climático resultante como Húmedo, Mesotermal, con Nulo o Pequeño Déficit de Agua y Concentración Estival de la Eficiencia Térmica inferior al 48\%, 0 sea: $\mathbf{B}_{\mathbf{1}} \mathbf{B}_{\mathbf{2}}{ }^{\prime} \mathbf{r} \mathbf{a}^{\prime}$.

Con un valor anual de $1070 \mathrm{~mm}$, la precipitación supera a la evapotranspiración potencial de $852,5 \mathrm{~mm}$ y a la real de $836,3 \mathrm{~mm}$, produciéndose un exceso anual de $235 \mathrm{~mm}$ susceptibles de infiltrar y escurrir superficialmente.

A partir del análisis de estas condiciones definidas precedentemente, puede considerarse que existen excesos hídricos del orden de $10 \mathrm{~s} 235 \mathrm{~mm}$ durante siete meses del año, estimándose que dadas las características geológicas - geomorfológicas del sector estudiado, existen condiciones adecuadas para que un porcentaje importante de dichos excesos, se infiltre.

Como complemento de lo expuesto, es importante incorporar la gráfica del Balance Hídrico que se establece para el período 1901 - 2003, donde son observables los períodos de déficit, recarga y excesos en la región. Se ha utilizado una capacidad de campo de $150 \mathrm{~mm}$ acorde con las características edáficas (suelos francos, arenosos finos) y de vegetación (cultivos con raíces profundas) (Fig. 2.7). 


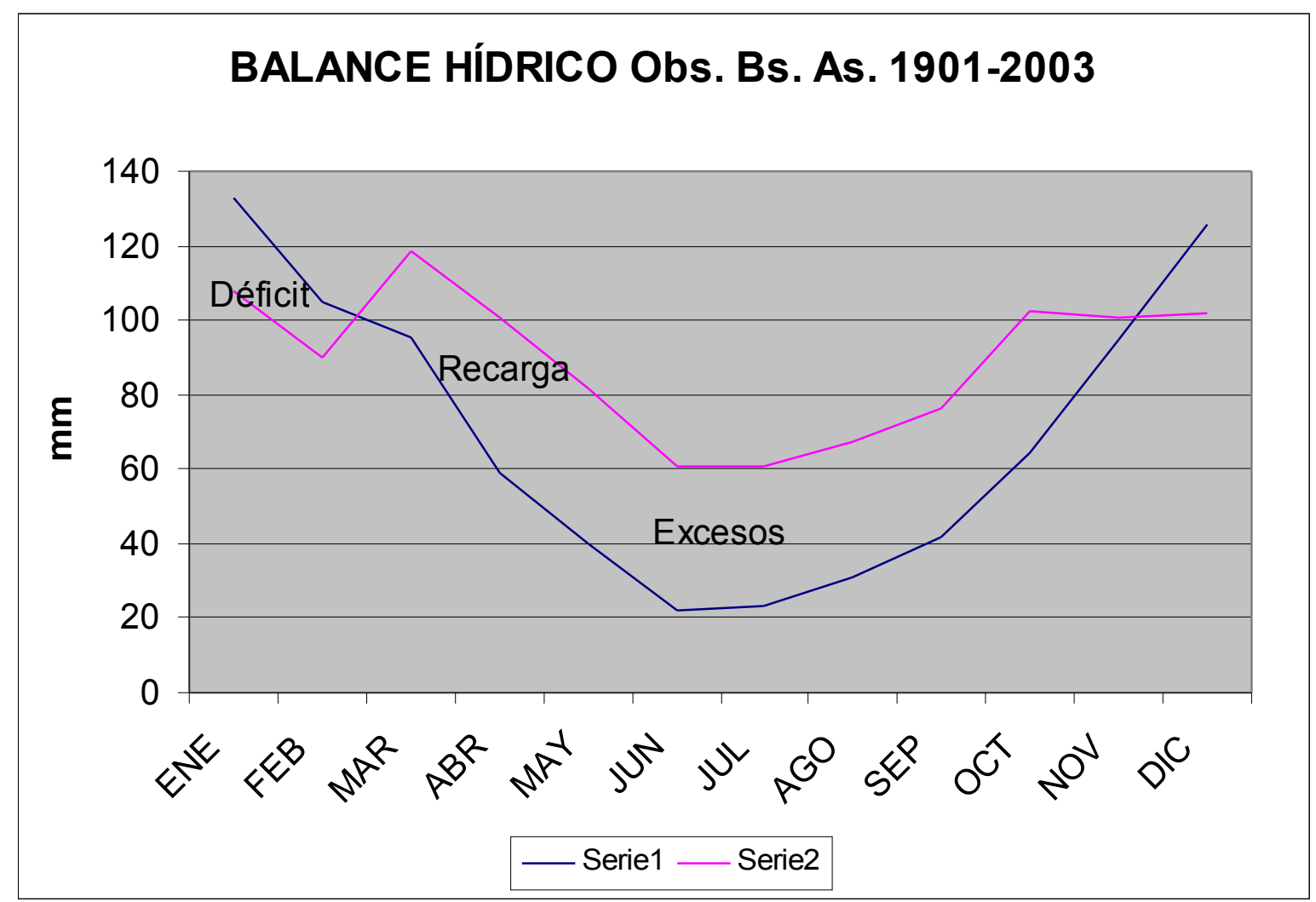

Fig. 2.7 Balance Hídrico. Serie 1:Evapotranspiración

Serie 2: Precipitación

Köppen, W. (1923), realizó una clasificación climática considerando simultáneamente la precipitación, la temperatura y la distribución de la vegetación. De acuerdo a estos elementos le corresponde a la región un clima templado cálido, húmedo, con precipitaciones regulares todos los meses y veranos calurosos, o sea Cfa (fig. 2.8). 


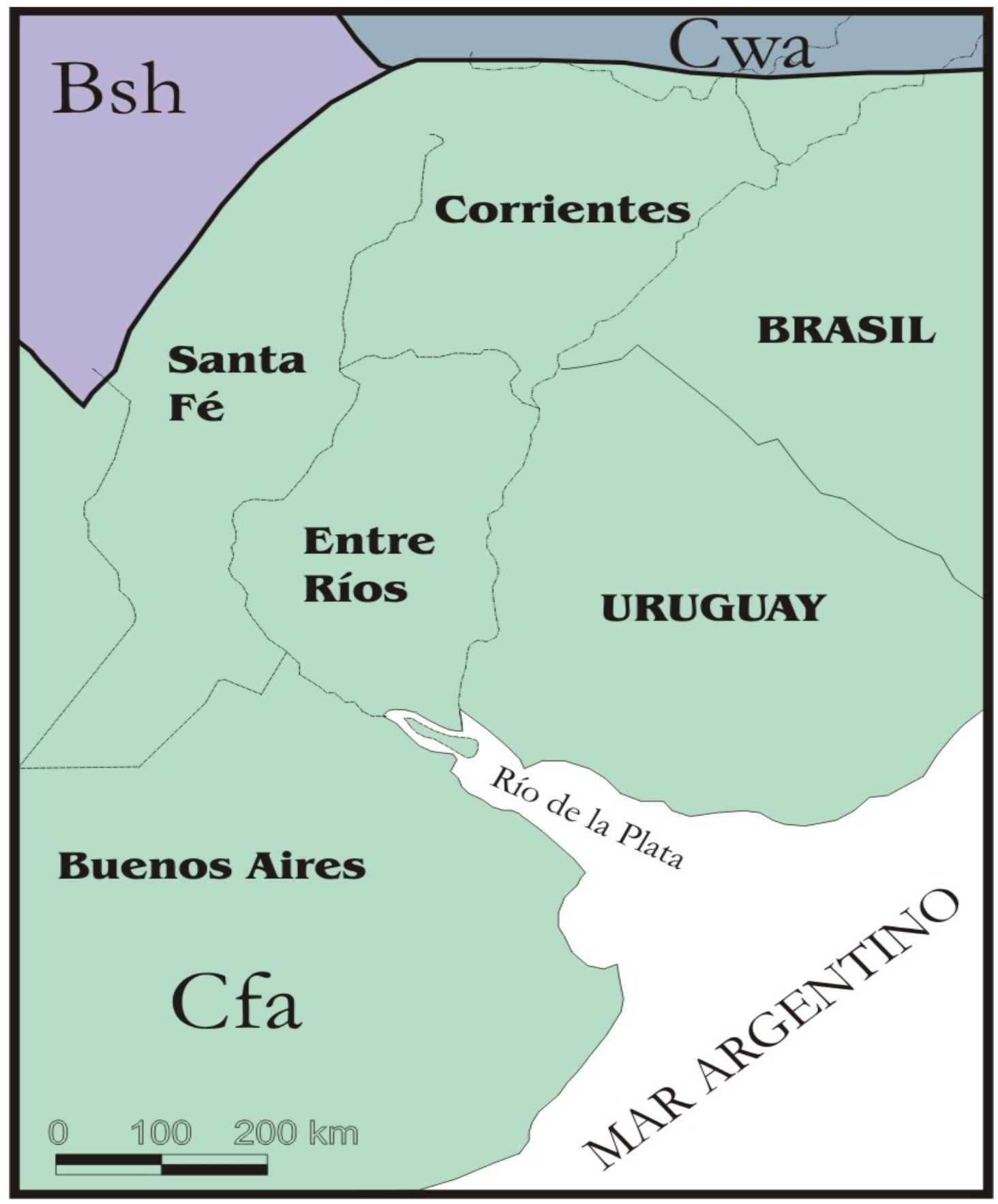

Fig. 2.8 Regiones climáticas de acuerdo al criterio establecido por Köppen, 1923.

\subsubsection{OTRAS CARACTERÍSTICAS}


Un fenómeno meteorológico de características muy especiales que se produce en todo el litoral noreste de la Provincia de Buenos Aires es la denominada "sudestada". Constituye un estado de mal tiempo, caracterizado por vientos regulares a fuertes, con velocidades mayores a $35 \mathrm{~km} / \mathrm{h}$ del sector sudeste, precipitaciones persistentes, débiles a moderadas y temperaturas relativamente bajas (Servicio Meteorológico Nacional, 1989). Este aumento del nivel de las aguas es producido por la combinación de un anticiclón que se ubica en el sector litoral marítimo patagónico y el ciclón en el centro de la Mesopotamia y el limite fronterizo occidental de Brasil con Uruguay. Este choque entre las masas de aire frío y húmedo provenientes del sureste y cálida y húmeda del norte de propiedades físicas distintas, hace que disminuya la presión atmosférica, produciéndose una depresión, la que al acentuarse, hace que aumente la circulación del viento.

La mayor frecuencia de estos vientos es en primavera, produciéndose a fines de otoño e invierno el mayor número de sudestadas intensas (Fig. 2.9) (García, 1992).

Los mayores efectos de la acción directa de este fenómeno se observan en la parte terminal del delta del paraná y los sectores ribereños del Río de la Plata. El aumento de nivel de las aguas del Estuario Platense produce no solo la inundación directa de las zonas aledañas, sino que debido al efecto barrera, produce sobre los cursos y canales que drenan sus aguas a él, la inundación de sus planicies de inundación y zonas aledañas. La sudestada del año 1940 es la más alta registrada, con un valor que superó escasamente los 4,50 metros. Sin embargo, en abril de 1959, la combinación de las precipitaciones, la creciente del Río Paraná y la sudestada, hicieron que gran parte del delta y sectores aledaños, resultaran anegados (Bonfils, 1962). 


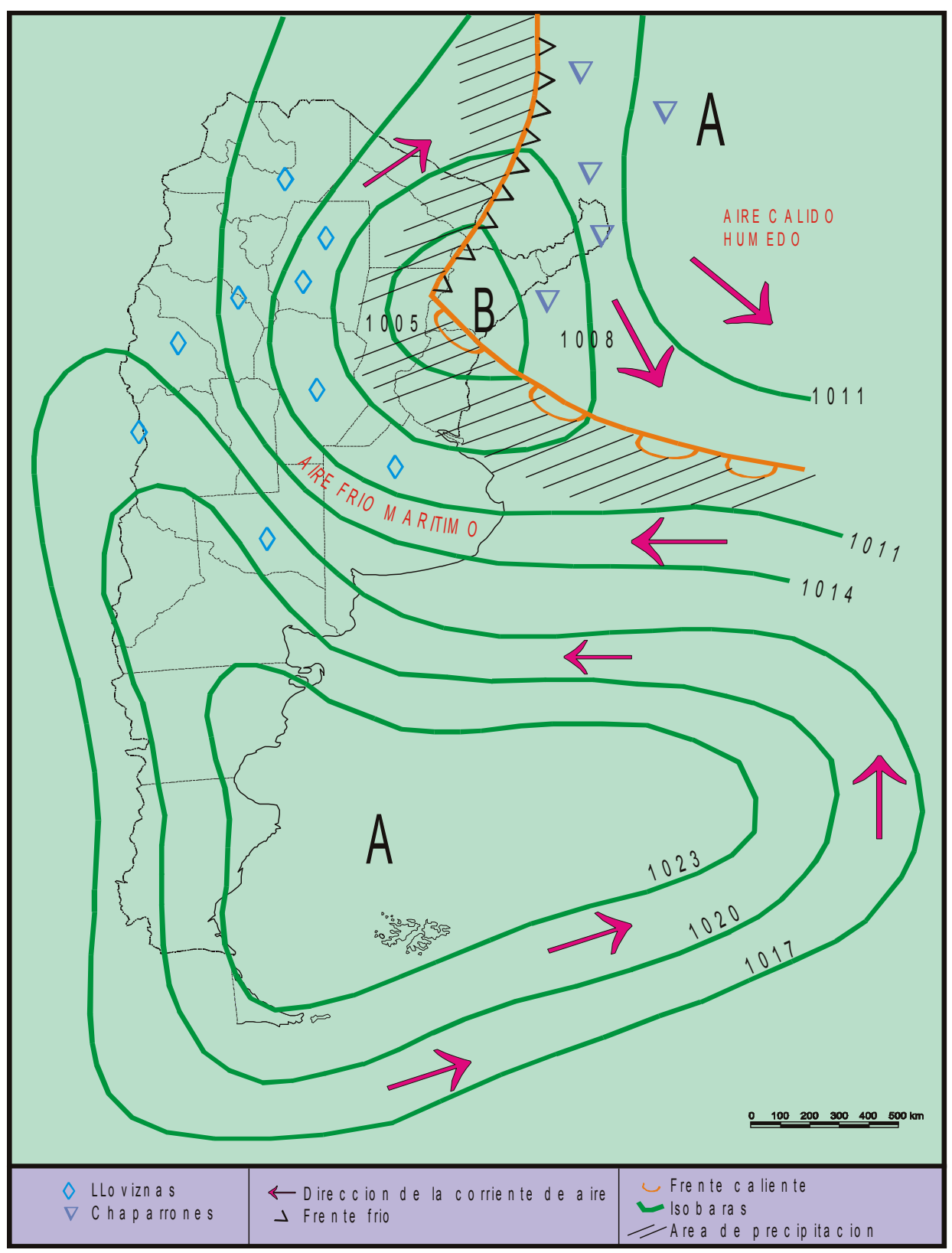

Fig. 2.9 Situación sinóptica correspondiente a una sudestada en el Río de la Plata (Tomado de García, 1992).

\subsection{FENOMENO ENSO}

El fenómeno ENSO es el conjunto de anomalías climáticas donde el episodio cálido El Niño y frío de La Niña constituyen los extremos. El ciclo ENSO tiene un promedio de cuatro años, aunque se observan variaciones que van 
de dos a siete años (Nuñez, 2002). El efecto EL NIÑO se refiere a un calentamiento de las aguas costeras frente a Perú y Ecuador, lo que es acompañado por lluvias torrenciales con consecuencias catastróficas.

A partir de la década del 60, la región pampeana se vio afectada por un período húmedo donde los efectos ocasionados por el evento EL NIÑO produjeron un conjunto de inundaciones de consecuencias variadas. En este período se sucedieron inundaciones del Río Paraná en los años 1966, 1977, 1982/83, 1992 y 1997/98, presentando las tres ultimas sus efectos negativos más importantes, superando los $30.000 \mathrm{~m}^{3} / \mathrm{s}$ por varios meses y un derrame anual superior a $1.000 .000 \mathrm{hm}^{3}$, considerándoselos de moderada a intensa magnitud (Borus y Goniadzki, 2002; Goniadzki y Borus, 2002).

Si bien existen indicios de eventos El Niño en las costas Peruanas y Chilenas desde 1525 (Ortlieb y Hocquenghem, 2001 y bibliografía allí citada) y en 1545 para la cuenca del Río Paraná (Angulo, 2001), solo algunas de estas han tenido una vinculación directa con las crecientes del Río Paraná (Andersen et al., 1993; Ramage, 1986; Schnack et al., 2001, entre otros). A través de datos históricos puede establecerse la asociación de los años de ocurrencia del episodio El Niño con aquellos en que se produjeron las inundaciones en las cuencas de los ríos Paraná Paraguay (Tabla 2.8) (Andersen et al., 1993; Schnack et al., 2001).

\begin{tabular}{|c|c|}
\hline Año de episodio & $\begin{array}{c}\text { Año de registro de inundaciones } \\
\text { extraordinarias }\end{array}$ \\
\hline 1877 & 1878 \\
\hline 1904 & 1905 \\
\hline 1911 & 1912 \\
\hline 1913 & 1913 \\
\hline 1918 & 1919 \\
\hline 1923 & 1923 \\
\hline 1925 & 1926 \\
\hline 1930 & 1931 \\
\hline 1932 & 1932 \\
\hline 1939 & 1939 \\
\hline 1951 & 1951 \\
\hline 1953 & 1954 \\
\hline 1957 & 1957 \\
\hline 1963 & 1963 \\
\hline
\end{tabular}




\begin{tabular}{|c|c|}
\hline 1965 & $1965 / 1966$ \\
\hline 1972 & 1974 \\
\hline 1976 & 1977 \\
\hline 1982 & $1982 / 1983$ \\
\hline 1986 & 1987 \\
\hline 1991 & 1992 \\
\hline 1997 & $1997 / 1998$ \\
\hline
\end{tabular}

Tabla 2.8 Episodios El Niño e inundaciones en la cuenca de los ríos

Paraná-Paraguay (Según Andersen et al., 1993; Schnack et al., 2001)

Del análisis de los datos de la tabla 2.8 surge que la recurrencia entre episodios de El Niño es entre de 2 y 7 años, observándose entre los años 1877 y 1904 y entre 1939 y 1951 una amplitud mayor, lo que no implica necesariamente que no hayan ocurrido, sino que pudieron ser de baja magnitud y por lo tanto no producir aumentos significativos de caudal en la cuenca del Paraná. A podido establecerse que durante el primer período (1877/1904) han existido un conjunto de sucesos con precipitaciones importantes en la región pampeana (Moncaut, 2003) aunque no queda establecido una relación directa con los episodios de El Niño. 


\section{CAPITULO III}

\subsection{EL CUATERNARIO}

El Cuaternario constituye el período más corto y más moderno del sistema estratigráfico. Se encuentra dividido en dos Épocas, Pleistoceno y Holoceno situándose el límite inferior a los 1.8 Ma (Gradstein y Ogg, 1996) y por convención el límite entre ambos a los $10.000{ }^{14} \mathrm{C}$ años.

Las características más destacables del Cuaternario son las grandes extensiones glaciales y la evolución del hombre. Los grandes cambios climáticos han tenido una participación muy activa en prácticamente todos los continentes, ya sea englazando grandes porciones de sus territorios o influyendo con períodos de precipitaciones muy contrastantes en las áreas extraglaciales. En sectores litorales, las glaciaciones y deglaciaciones produjeron descensos y elevaciones del nivel del mar, producto del juego glacioeustático.

El estudio isotópico del oxígeno en sedimentos marinos profundos ha aportado información significativa sobre los cambios climáticos producidos en el Cuaternario, definidos como estadios isotópicos, definiéndose aproximadamente unos 50 ciclos glaciales e interglaciales para este período (Shackleton et al., 1990).

En la figura 3.1 puede observarse la reconstrucción de la temperatura oceánica superficial de verano en el océano Atlántico Norte basadas en asociaciones de foraminiferos como estimaciones de paleotemperatura (Ricciardi, 1995). 


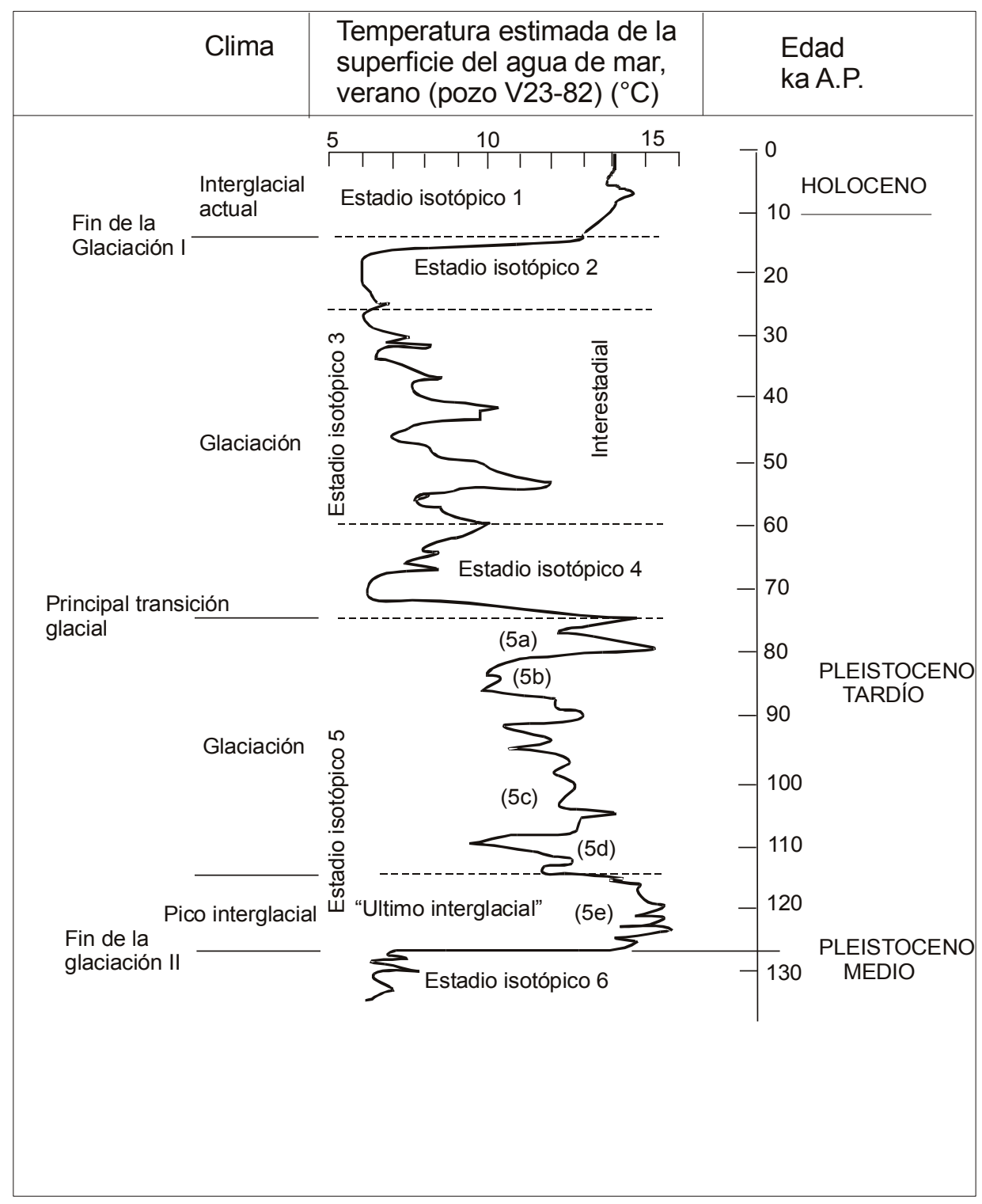

Fig. 3.1.- Los estadios isotópicos según Shacketon y Opdyhe (1973). A la izquierda se muestran las condiciones climáticas generalizadas y cambios climáticos mayores (Ruddiman, 1977).

En la actualidad los conocimientos sobre el Cuaternario superan ampliamente a aquéllos que fueron utilizados para su jerarquización y caracterización inicial. Se conoce que no solamente el número de las glaciaciones fue mayor a las cuatro clásicas, sino que el inicio de éstas comenzaron mucho antes del límite propuesto al Cuaternario, incluso antes del último período del Terciario (Mioceno superior) (Rabassa, 1999). 
Si bien el hombre alcanza su máximo grado evolutivo en este período, el Cuaternario no puede ser caracterizado tampoco por este proceso. Al igual que las glaciaciones, los primeros homínidos son conocidos mucho antes de los $1.8 \mathrm{Ma}$, (Australopithecus afarensis, aproximadamente 4 Ma) y las industrias más antiguas son datadas en 2,7 Ma (Calmels y Carballo, 1993).

La Comisión de estratigrafía del International Union of Geological Science (IUGS) y el International Geological Correlation Program (IGCP) han propuesto utilizar, para situar el límite Terciario-Cuaternario como estratotipo en un perfil situado en Vrica, sur de Italia. Esta localidad presenta una unidad de origen marino en la que se sitúa la primer aparición de un ostrácodo (Cytheropteron testudo) de aguas frías. El límite superior de esta unidad se ubica al final de la inversión paleomagnética Olduvai situada en 1.8 Ma (Gradstein y Ogg, 1996).

Es preciso destacar la dificultad de establecer un estratotipo de carácter universal, ya que el descripto en Italia se encuentra actualmente en revisión, debido a que la fauna existente representaría condiciones locales en el Mar Mediterráneo, no comparables a los diferentes procesos dominantes en los distintos continentes, como así también, a los diferentes momentos en que estos han comenzado.

El Holoceno comienza por convención a los $10.000{ }^{14} \mathrm{C}$ años A.P. Y está caracterizado, al igual que el periodo anterior, por los cambios climáticos. Este período ha sido bien estudiado a través de la paleontología y la palinología, a las que se suman los estudios de isótopos del oxígeno, los que permiten precisar los cambios climáticos individualmente y/o en conjunto con las dataciones absolutas.

De manera convencional el Holoceno se ha dividido en temprano, medio y tardío. El Holoceno temprano finaliza alrededor de los 7.000 años ${ }^{14} \mathrm{C}$ A.P., con la fusión final de los remanentes de la última gran calota glacial en el Hemisferio Norte y el retorno del agua de fusión glacial a los océanos. 
Asimismo, coincide con el comienzo del incremento de la acción antrópica sobre los recursos naturales (Dawson, 1992). El Holoceno medio se extiende hasta aproximadamente los 3.000 años ${ }^{14} \mathrm{C}$ A.P. con el final del Máximo Térmico del Holoceno ("Hypsithermal").

\subsection{ANTECEDENTES GEOLOGICOS}

El descubrimiento de un esqueleto de Megatherium en las barrancas del Río Luján en las cercanías de la ciudad homónima puede considerarse una de las primeras referencias históricas acerca de las particularidades existentes de esta temática en la región pampeana. Este hallazgo se produjo durante el virreinato del Marqués de Loreto en el año 1789, y si bien no se realizó ninguna caracterización de las unidades geológicas involucradas, el hallazgo de estos fósiles produjo el asombro y los cuestionamientos propios que tiempo después, permitirían en la misma área, realizar los esquemas estratigráficos para gran parte de esta región.

Las primeras investigaciones geológicas, fueron realizadas por d' Orbigny (1842), Darwin (1846), Bravard (1857), entre otros. Si bien estos trabajos tenían como objetivo central el estudio fosilífero, ya sea marino o continental, fueron muchas las observaciones puramente geológicas que complementaron sus contribuciones e incluso, realizaron los primeros ensayos de clasificación de las sucesiones sedimentarias.

Doering (1882, 1884) en su esquema estratigráfico parcialmente aplicable a la región caracterizó en forma detallada a las unidades cenozoicas y en forma superficial a las más modernas. Dentro de sus formaciones neógenas y aflorantes, introduce la Formación Pampeana, con el Piso Pampeano Inferior, del Plioceno, representado por las toscas en el fondo de los ríos Paraná y de la Plata y el Piso Pampeano Lacustre, de edad Pleistoceno, constituidos por "arcillas gris-verdosas de Luján; con 
Paludestrina ameghini, Ampullaria australis" asignada al Cuaternario o Dilivual.

Dentro de su Diluvial, se encuentran los pisos Querandino y Platense, Pleistocenos, correspondiendo a "depósitos marinos y semimarinos..." los primeros y a "depósitos lacustres..." los segundos, constituidos por una "marga calcárea gris-blanquecina...". Culmina la secuencia con los pisos Aimariano y Ariano, de génesis fluvial y de edad Reciente.

Ameghino (1881, 1884) realiza un conjunto de caracterizaciones de las sucesiones sedimentarias en diferentes ámbitos de la región pampeana y específicamente en el trabajo de 1884 describe un perfil del Río Luján. Ameghino (1889) sobre la base del esquema anterior, realiza una división de la formaciones cenozoicas en función de las especies de moluscos existentes en tres épocas: eógena, neógena y plioneógena.

En relación a las unidades aflorantes en la región, Ameghino (1889) divide a la Formación Pampeano, definida prácticamente por d'orbigny (1842) y Darwin (1846), en cuatro pisos: Pampeano Inferior o Ensenadense, representando las toscas del fondo del río de la Plata, con una intercalación de sedimentos marinos (Interensenadense) de 1 a 3 metros de espesor, Pampeano Medio o Belgranense, constituida por "espesos mantos de conchillas marinas", Pampeano Superior o Bonaerense "menos compacto y menos coherente que el Pampeano Inferior, y constituido por una masa de elementos mas pulverulentos...." y en general "menor proporción de cal y una cantidad mayor de arena...." y Pampeano Lacustre o Lujanense, caracterizada por su poca extensión y limitada al fondo de las depresiones actuales. A todas estas unidades el autor les atribuye una edad pliocena.

Posteriormente a la depositación del Lujanense, con fauna constituida totalmente por moluscos vivientes, encontramos a los terrenos postpampeanos e integrados por los pisos Querandino, representado por una cadena de bancos marinos costaneros, el Platense, compuesto por estratos 
de arena y arcilla, con una mezcla de carbonatos de calcio, de color gris ceniza, a veces bastante oscuro, de origen fluvial y lacustre, el Piso Aimará, de origen fluvial, depositado sobre las barrancas de los arroyos al que corresponde el delta del Paraná y el Ariano, "depósitos cuya formación data de una época posterior a la ocupación del país por los españoles". La edad de estas unidades corresponden al Cuaternario las dos primeras y las restantes al Reciente, previo y posterior a la ocupación española.

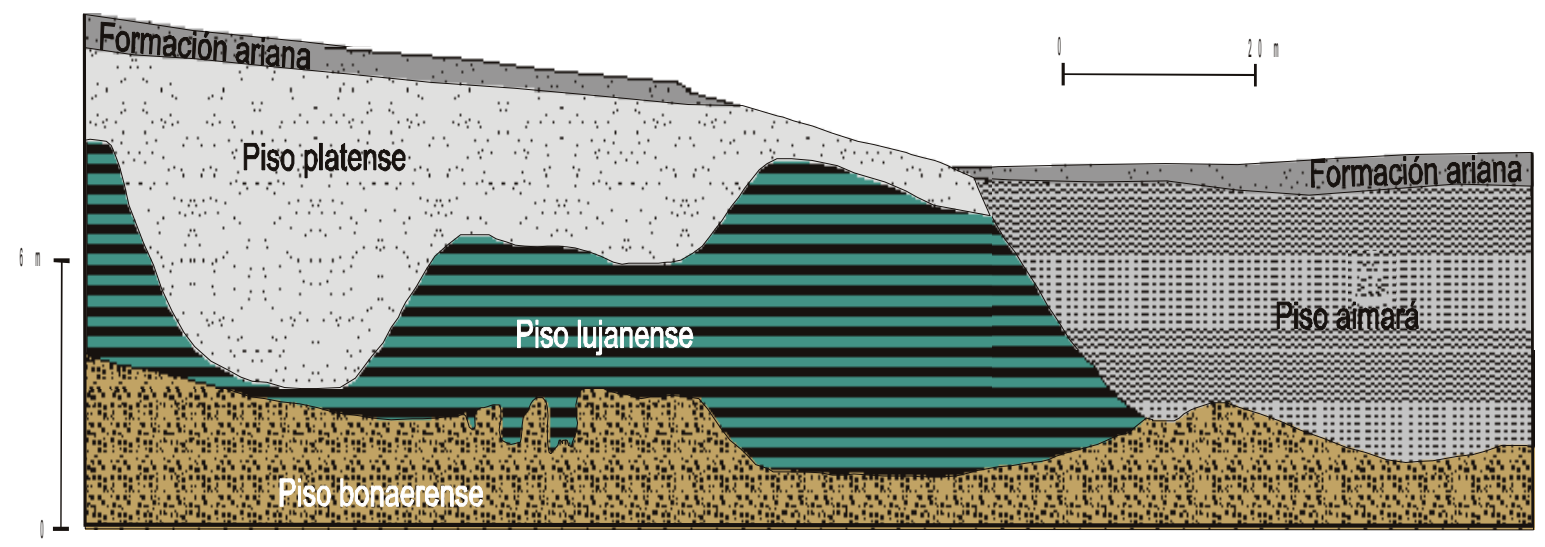

Fig. 3.2.- Perfil simplificado de Ameghino (1889) de las barrancas del Río Luján en la localidad homónima.

Joaquín Frenguelii, por más de cuatro décadas, basado en el esquema ya constituido por Ameghino, realizó aportes de gran importancia, no sólo geológicos y paleontológicos, sino también de tipo climático. En 1957, en una de sus últimas contribuciones, considera a los "terrenos superficiales. de la Pampasia en dos Series: Pampiano y Pospampiano.

Considerando la región, la sucesión geológica se halla integrada por el Ensenadense, el Belgranense y el Bonaerense. El primero está representado por "limos loessoides de color pardo, con tintes amarillentos, grisáceos, rojizos y a veces verdosos". En el sector medio se intercala una unidad marina, a la que Ameghino (1881) denominó ".Transgresión Interensenadense." Por encima se observa al Bonaerense, "eminentemente loessico", de color pardo claro, de grano fino y homogéneo, sin 
estratificación. Como sustitución lateral de este piso tenemos al Belgranense, considerada no un verdadero horizonte estratigráfico, sino de una facies costanera del bonaerense.

El Postpampiano comienza con sedimentos fluviales correspondientes al Lujanense, "que ocupan el fondo de cauces y cuencas" compuestas por "limos loessoides de color verde grisáceo...". En la zona costera, producida por un incremento del estuario platense se deposita el Querandinense, debiéndolo considerarlo como un subpiso. Estos depósitos producidos por la transgresión, no deben ser confundidos, según el autor con los del Platense, de carácter regresivos, constituidos por acumulaciones conchiles. Simultáneamente a esta depositación, en los cauces se depositaban "capas muy delgadas, de color blanco grisáceo o amarillento..." y " un manto de loess en todo el resto de la región ." asignados al Platense. La sucesión culmina con el Cordobense, loéssico, el Aimarense "antiguo humus negro" y Arianense, "capa humífera de formación actual".

En esta contribución, el autor no hace mención a la edad de las series, aunque expone claramente que con la depositación del Lujanense termina el Pleistoceno Argentino. 


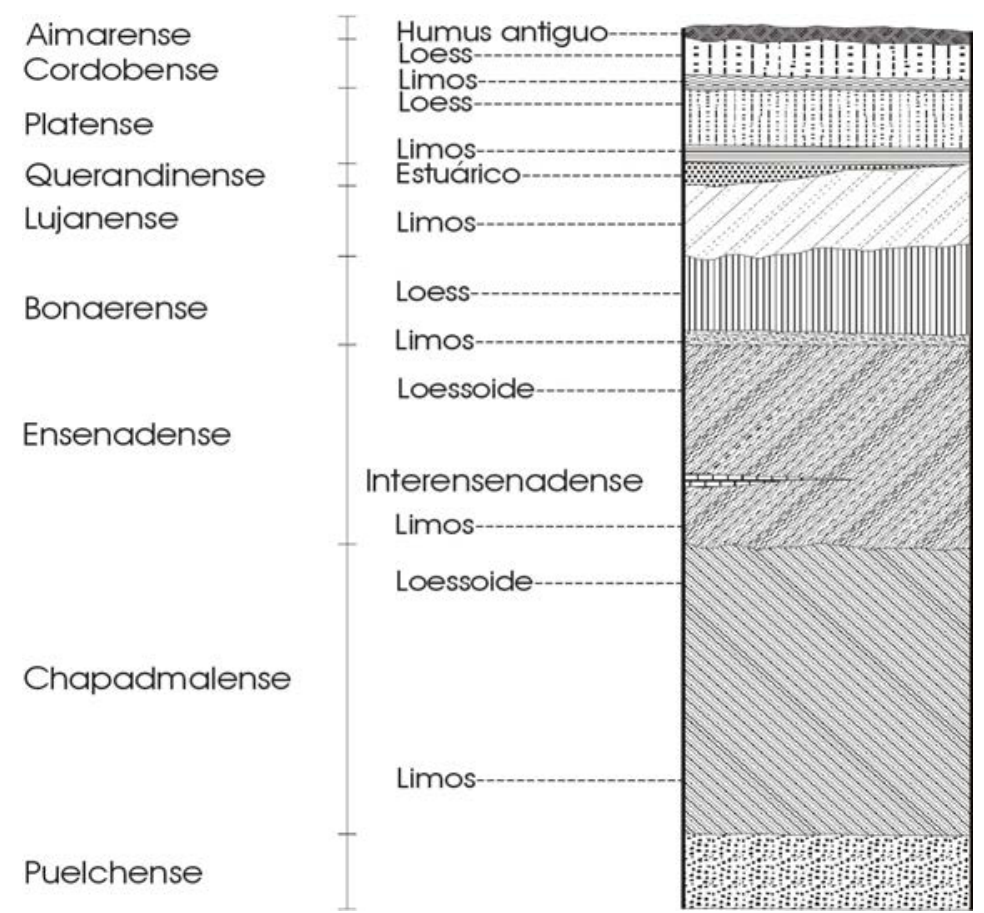

Fig. 3.3. Perfil estratigráfico combinado de la Región Pampeana (Frenguelli, 1957).

Tricart (1973) reconoció en el sector continental, adyacente a la Bahía Samborombón un Pampiano y un Postpampiano. El primero, Cuaternario antiguo, lo considera "solamente un depósito", de origen eólico, que no conserva ninguna forma del relieve original, mientras que el Postpampiano presenta formas identificables.

Observa tres ingresiones marinas, el Querandinense y Platense del Pleistoceno medio y superior respectivamente $y$ el Dunkerkiano, representando por un resalto de 1 a 1,5 metros del Holoceno. El Lujanense y Platense de origen fluvial y a E3 y El como depósitos producto de dos acciones eólicas fuertes, a la vez generadoras de cubetas, todas estas Pleistocenas.

Fidalgo et al. (1973 a y b), desarrollaron para el sector continental de la Bahía Samborombón un esquema estratigráfico, utilizando el concepto de unidades litoestratigráficas. En estas contribuciones se distinguen y cartean cuatro unidades de origen continental que en orden de edad 
decreciente son: Formación Pampiano, constituido por "limos arcillosos a limos arenosos, de color castaño a castaño rojizo ...". En los valles y de origen fluvial se desarrolla la Formación Luján, separada en los Miembros Guerrero y Río Salado, compuesto por "limo arenoso color castaño claro... "y un "limo arcillo-arenoso, verde..." el primero y por "arenas limosas de color gris blanquecino, con abundante cantidad de Littoridina y Tropicorbis..." el segundo. La edad de esta unidad es Pleistoceno superior - Holoceno.

Distribuida por toda el área a modo de manto o localizada en sectores puntuales con espesores mas importantes se observa la Formación La Postrera, compuesta por "sedimentos areno limosos a limos arenosos, de color castaño amarillento, de origen eólico..." y de edad Pleistoceno superior - Holoceno. Por último, dentro de las unidades continentales, se encuentra el Aluvio Reciente, constituido por "limos arcillosos a limos arenosos, de color gris blanquecinos..." ocupando las depresiones en diferentes ambientes geomorfológicos.

Las unidades de origen marino identificadas corresponden a la generadas por las ingresiones del Pleistoceno superior y Holoceno, agrupadas en las Formaciones Pascua, Destacamento Río Salado y Las Escobas. La primera, intercalada a modo de cuña en la Formación Pampiano, compuesta por sedimento arenosos, con alta concentración de valvas de moluscos fuertemente cementadas y de edad Pleistoceno tardío. La segunda compuesta por arenas a arenas limosas, de color negro a gris oscuro, también de edad Pleistoceno superior. Esta ingresión es reinterpretrada en Fidalgo (1979) como originada en lagunas costeras relacionadas con la última ingresión. 
$D$ iv iso ria $s$

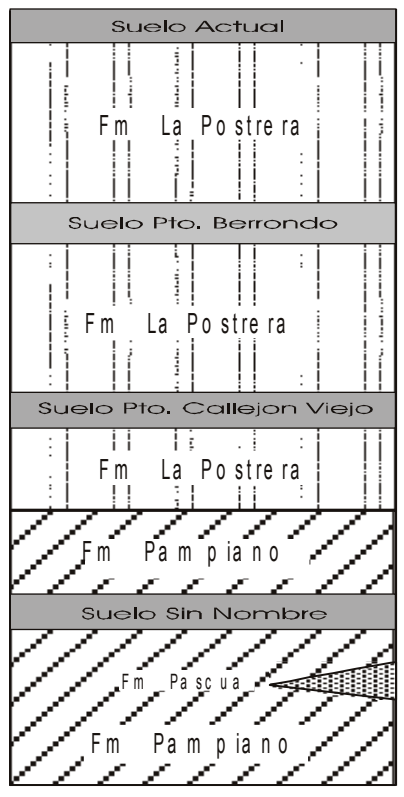

Va lle s

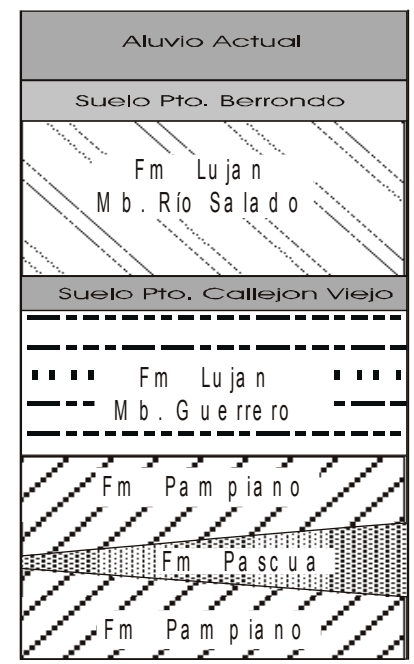

Costa

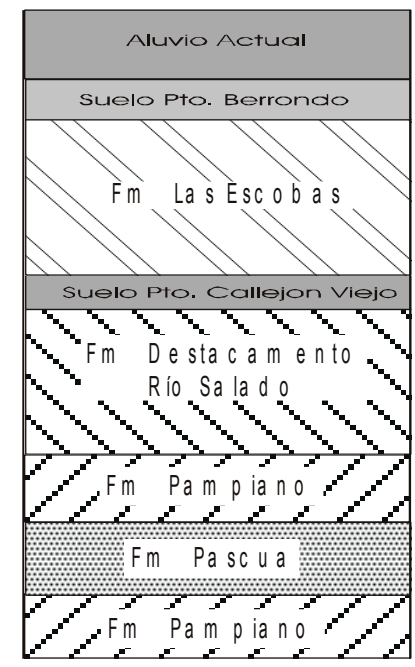

Fig. 3.4.- Perfiles esquemáticos de las Unidades Litoestratigráficas en los ambientes más característicos de la región (Tonni, y Fidalgo, 1978).

La última ingresión estaría representada por la Formación Las Escobas, compuesta por los Miembros Canal 18 y Cerro de la Gloria, integrada por "sedimentos arenosos que alternan con lentes y estratos limosos y arcillosos..." y "sedimentos conchiles con matriz arenosa que forman los conocidos cordones..." atribuyéndoles edad holocena.

Por último, identifican las Unidades Edafoestratigráficas Suelo La Pelada, Suelo Puesto Callejón Viejo y Suelo Puesto Berrondo desarrolladas en la parte superior de la Fm Pampiano, en el Mb Guerrero y en el Mb Río Salado respectivamente.

Fidalgo et al. (1975) agrupan informalmente con el nombre de "Sedimentos Pampeanos" a los depósitos de limos con fracciones subordinadas de arena y arcilla indistintamente, castaños amarillentas a castaños rojizos distribuidos en las provincias de Buenos Aires, Santa Fe y parte de La Pampa, Entre Ríos, Córdoba, Corrientes, Chaco y San Luis. 
Dillon y Rabassa (1985) basados en las características litológicas y espesor establecen una nueva unidad litoestratigráfica en el valle del Río Salado a la que denominan Mb La Chumbiada. De génesis fluvial, está compuesta por arenas finas con limo, de color castaño, marcada estratificación e intercalación de niveles conglomerádicos, asignándole edad Pleistoceno superior. Los depósitos de esta nueva unidad corresponden a la base del Mb Guerrero de la Fm Luján (Fidalgo et al. 1973 b). Con la creación de esta nueva unidad litoestratigráfica la Fm Luján queda integrada de base a techo por los Miembros La Chumbiada, Guerrero y Río Salado.

Riggi, et al. (1986) definen en la Ciudad de la Plata las Formaciones Ensenada y Buenos Aires, de edad mamífero Ensenadense y Lujanense respectivamente y correlacionables con el Ensenadense y Bonaerense de Frengüuelli (1957). Las dataciones radiocarbónicas sobre "tosca" proporcionan edades mayores a 30.000 años A.P. para la Fm Ensenada y menores a 16.000 años A.P. para la Fm Buenos Aires.

Dangavs y Blassi (1992) definen la Fm Lobos para la cuenca del Río Salado a sedimentitas friables y compactas de grano fino de color gris claro, gris amarillento a amarillento oliváceo, asignándole una génesis estuárica y edad holocena. Dangavs y Blassi (1995 a y b) describen en la localidad de Luján sobre el río homónimo una sucesión integrada por las Formaciones Ensenada, Buenos Aires, Luján (Miembros La Chumbiada, Guerrero y Río Salado) y La Postrera III. Dangavs y Blassi (2003) proponen el cambio de rango de la Fm Lobos, asignándole la denominación de Mb Lobos, de génesis fluvio-lacustre y edad Pleistoceno tardío tardío. En base a esto se sugiere que la Fm Luján quede integrada por los Miembros La Chumbiada, Lobos y Río Salado.

Cavallotto (1995) realizó un esquema de las sucesiones sedimentarias fundamentalmente holocenas al sur de la capital federal, utilizando los conceptos de formación, y subordinando a ésta a la facies. Reconoce un 
paquete sedimentario que "comprende el ciclo transgresivo - regresivo originado con posterioridad a la última glaciación".

Estas contribuciones, más las desarrolladas por otros autores y la presente, constituyen un conjunto de trabajos que exponen las características de las secuencias estratigráficas de prácticamente toda la región costera y continental del noreste de la provincia de Buenos Aires.

En el cuadro 3.1 se exponen los diferentes esquemas estratigráficos para la región, destacándose que éstos fueron realizados en diferentes épocas y con diferentes objetivos, por lo que se encuentran asociados esquemas estratigráficos donde la ubicación temporal de las unidades, creadas en base al contenido fosilífero resultaba el elemento principal, a diferencia de lo trabajos actuales, donde lo constituyen las características litológicas. 


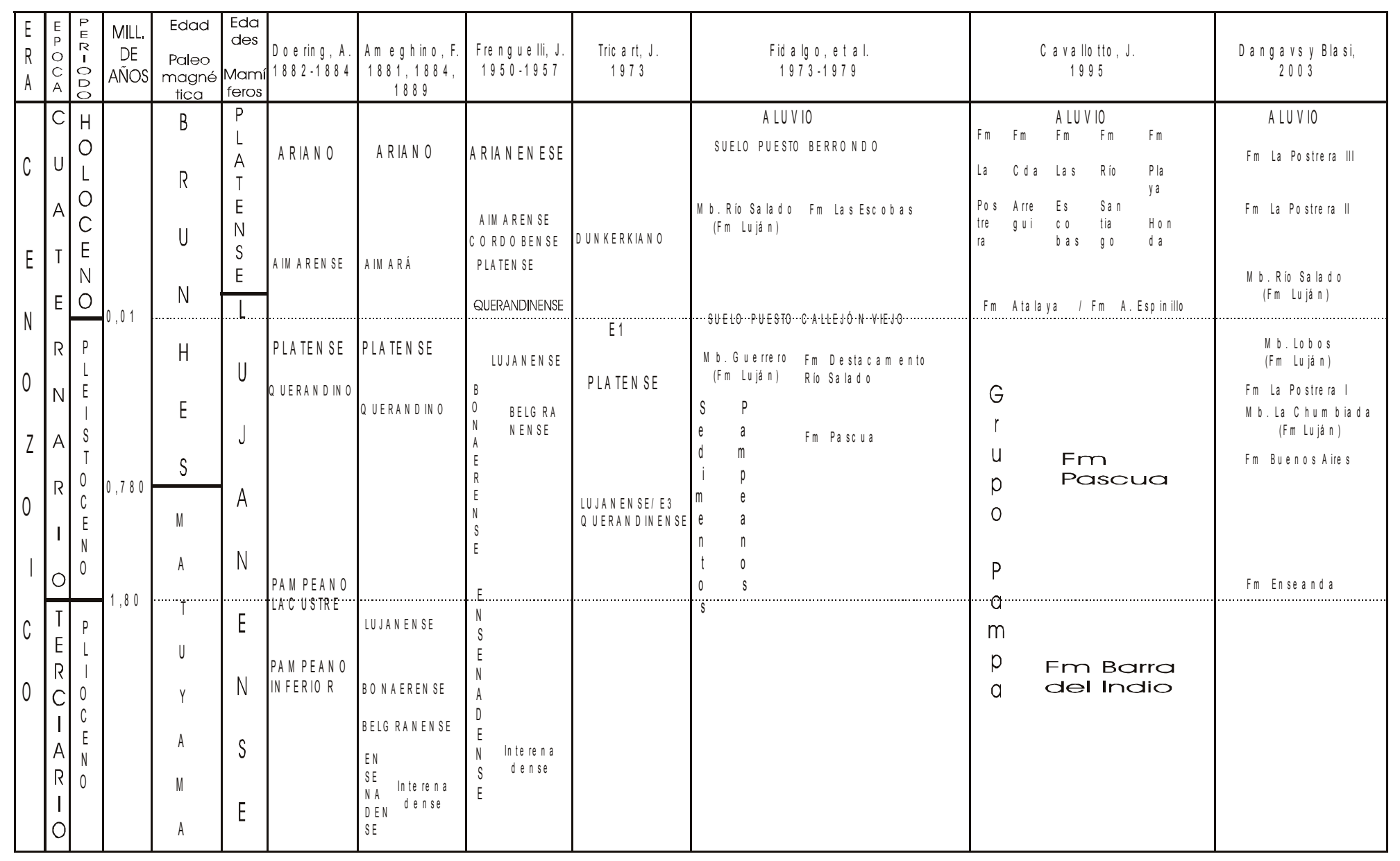

Cuadro 3.1 Cuadro Estratigráfico donde se exponen los diferentes esquemas 


\subsection{ANTECEDENTES GEOMORFOLÓGICOS}

Desde mediados del siglo XIX, muchos fueron los naturalistas que han realizado subdivisiones del territorio argentino en general y de la región pampeana en particular de acuerdo a sus rasgos morfológicos. Entre los primeros se destacan de Moussy (1864), Burmeister (1876), Delachaux (1908), entre otros.

En el ámbito provincial, Tapia (1937) dividió la Provincia de Buenos Aires según aspectos topográficos, geológicos y morfológicos, en cinco regiones: serrana, marginal de las planicies patagónicas, de la llanura bonaerense, costera y aluvial del delta. El ámbito de trabajo se ubica en la región de llanuras bonaerenses, caracterizada por afloramientos dominantes pleistocenos y aluviales del delta.

Frenguelli (1946) realizó una división del territorio argentino basado en criterios genéticos y morfológicos en grandes regiones (Planicies, Montañas e Islas) y subregiones con criterios accesorios. Dentro de las primeras nos ubicamos en lo que de Moussy (1864) denominó Pampasia, y dentro de ésta a la Pampasia central baja. En la obra de 1950 referida a la Provincia de Buenos Aires, la divide en tres zonas morfológicas mayores: Sierras, pampa y región de San Blas, con subdivisiones, situándose la zona de trabajo en lo que denominó pampa baja y delta (Fig. $3.5)$. 


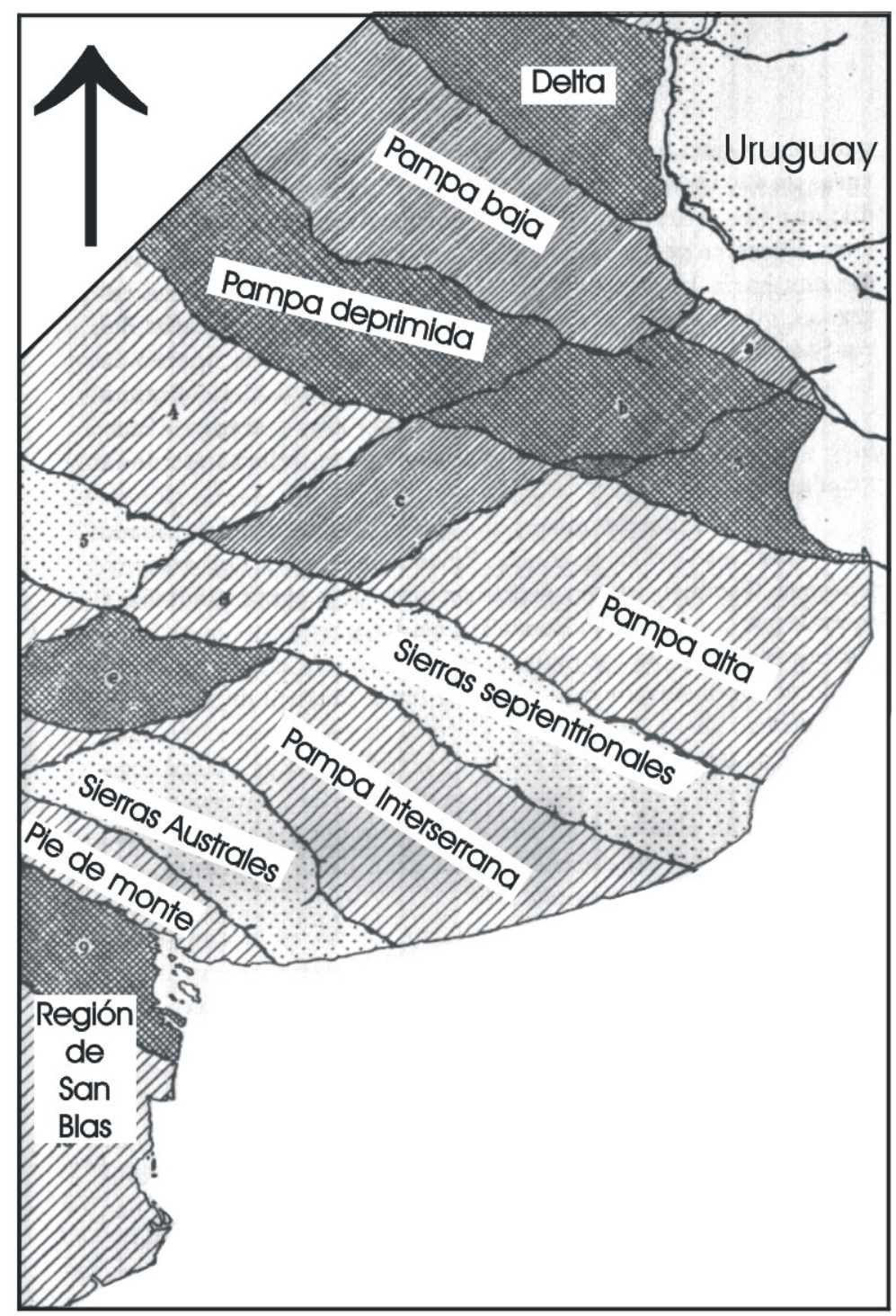

Fig. 3.5 Regiones en la provincia de Buenos Aires de acuerdo a Frenguelli (1950).

Daus (1946) expuso en forma pormenorizada las características de las "Llanuras Argentinas". Atento a criterios morfográficos se refiere a la llanura chaco - pampeana como la parte del territorio que va desde el Río Pilcomayo al norte hasta el Río Colorado al sur, que al este limita con los ríos Paraguay, Paraná, de la Plata y el Océano Atlántico. El límite oeste de menor precisión, con las sierras y cordilleras. Dentro de ésta se refiere a la Pampa Oriental o húmeda como la llanura argentina por 
excelencia, subdividiéndola por rasgos secundarios. El autor acuna el concepto de "Pampa Ondulada", refiriéndola a "la franja ribereña a los ríos Paraná y de la Plata, entre las ciudades de Rosario y Buenos Aires". La misma se caracteriza por un relieve suavemente ondulado y una barranca en el borde ribereño que va entre las ciudades anteriormente mencionadas.

Utilizando el concepto de provincia geológica Rolleri (1975) basado en criterios estratigráficos, estructurales, geomorfológicos y evolutivos, realizó la subdivisión de la provincia de Buenos Aires en seis Provincias Geológicas (Fig.3.6).

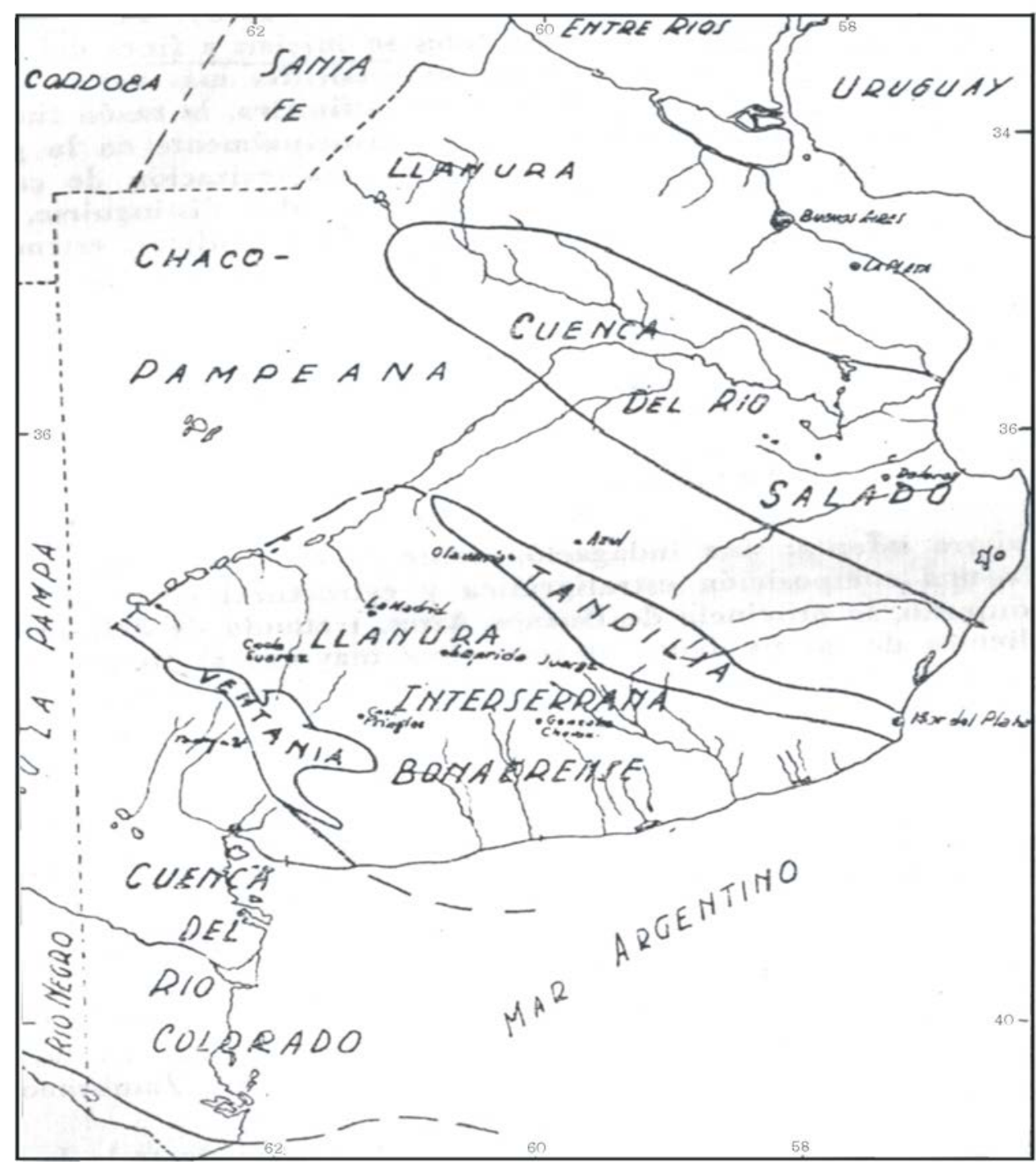

Fig. 3.6

Provincias geológicas en la provincia de Buenos Aires (Rolleri, 1975). 
A la Llanura Chaco-Pampeana correspondería la zona de estudio, caracterizada por ser una zona llana, con cubierta cenozoica continental y marina, apoyadas directamente en secuencias precámbricas, paleozoicas y aun más jóvenes, sin que aparezcan sedimentos cretácicos en la columna, salvo los aulacógenos a los que se encuentran restringidos.

Para el ámbito de la provincia de Buenos Aires, Fidalgo (1992) diferencia dos ambientes mayores, Sierras (Australes y Septentrionales) y llanuras. Esta última es subdividida de acuerdo a las características del drenaje en regiones exorreicas (pampa ondulada, deprimida e interserrana), regiones arreicas (del noroeste y norpatagónica) y endorreicas (lagunas encadenadas del oeste y depresión de Chasicó) (fig. 3.7).

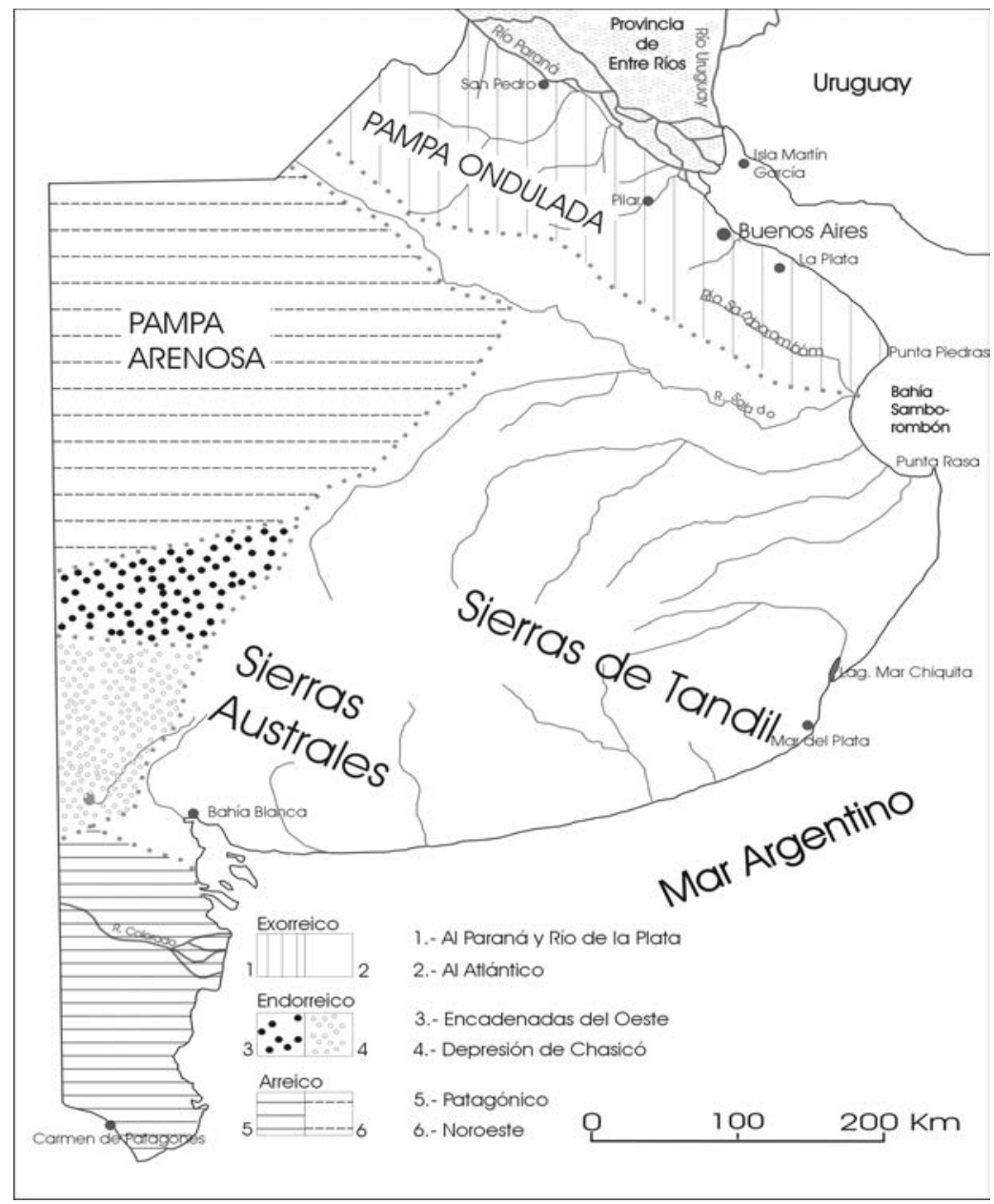

Fig. 3.7 Mapa que representa las diferentes regiones de la provincia de Buenos Aires (Fidalgo, 1992). 
Específicamente el área de estudio se encuentra ubicado en la "pampa ondulada". Esta región comprende a las cuencas con drenaje hacia los ríos Paraná y de la Plata y a la cuenca del Río Samborombón. Se caracteriza por presentar cauces de ríos y arroyos bien definidos y cuencas claramente desarrolladas, dándole al paisaje su aspecto ondulado.

Codignotto y Aguirre (1993) realizan la evolución geomorfológica del sector continental de la Bahía Samborombón vinculados con los cambios del nivel del mar en el Holoceno. Reconocen tres sectores morfológicos dominantes: Islas de Barrera, Espigas de Barrera, Lagunas Costeras y Planicies de marea.

Este conjunto de trabajos sintetizan de manera general y particular las diferentes particularidades geomorfológicas del área de estudio y zona de influencia, a los que se le suman un conjunto trabajos específicos. 
(Cuadro 3.2) DIVISIONES DENTRO DE LA PROVINCIA DE BUENOS AIRES

\begin{tabular}{|c|c|c|c|c|c|}
\hline Autores & $\begin{array}{l}\text { Tapia } \\
\text { (1937) }\end{array}$ & $\begin{array}{c}\text { Frenguelli } \\
(1950)\end{array}$ & $\begin{array}{c}\text { Rolleri } \\
\text { (1975) }\end{array}$ & $\begin{array}{c}\text { Fidalgo } \\
\text { (1992) }\end{array}$ & $\begin{array}{c}\text { Daus } \\
(1946)\end{array}$ \\
\hline Regiones & $\begin{array}{l}\text { Serranas, lomadas y } \\
\text { Serranías } \\
\text { Marginal de Planicies } \\
\text { patagónicas } \\
\text { Llanuras Bonaerenses } \\
\text { Costera } \\
\text { Delta }\end{array}$ & 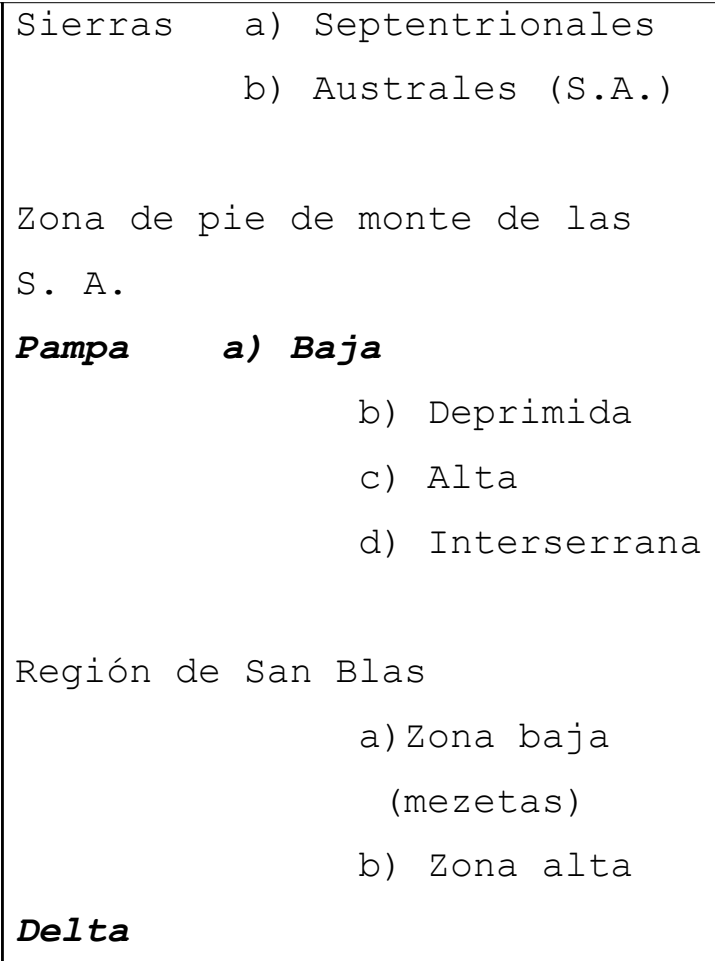 & $\begin{array}{l}\text { Tandilia } \\
\text { Ventana } \\
\text { Cuenca del río } \\
\text { colorado } \\
\text { Llanura Interserrana } \\
\text { Bonaerense } \\
\text { Cuenca del río Salado } \\
\text { Llanura Chaco pampeana }\end{array}$ & $\begin{array}{l}\text { Exorreico } \\
\text { Pampa Ondulada } \\
\text { Pampa deprimida } \\
\text { Pampa Interserrana } \\
\text { Edorreico } \\
\text { Lag. Encadenadas del } \\
\text { Oeste } \\
\text { Depresión de Chasicó } \\
\text { Arreicas } \\
\text { Del Noroeste } \\
\text { Norpatagónica }\end{array}$ & \begin{tabular}{|l|l|} 
Llanura \\
Chaco Pampeana \\
a) Chaco \\
b) Pampa Oriental \\
1) Pampa Ondulada \\
2) Pampa Deprimida \\
3) Llanura interpuesta \\
4) Pampa Alta \\
c) Pampa Occidental
\end{tabular} \\
\hline
\end{tabular}




\subsection{CARACTERÍSTICAS PALEOCLIMÁTICAS}

Las características paleoclimáticas de la región pampeana pueden inferirse a través de las particularidades litológicas, conjuntamente con la fauna y flora involucradas.

Las Unidades Litoestratigráficas del Pleistoceno tardío están constituidas por sedimentos de origen continental (predominantemente eólicos y fluviales) y litoral. Los términos superiores de la Formación Pampeano (Gonzáles Bonorino, 1965) y la sección inferior de la Formación La Postrera (Fidalgo et al., 1973 a y b) se desarrollan en las divisorias; en los cursos de agua se observan los Miembros La Chumbiada (Dillon y Rabassa, 1985) y Guerrero (Fidalgo et al., 1973 b) de la Formación Luján (Fidalgo et al., 1973 b) y como unidad de génesis litoral vinculada a paleolineas de drenaje la Formación Pilar (Fucks y De Francesco, 2003).

Las fluctuaciones glaciales dentro del último ciclo glacial desarrollado durante el Pleistoceno tardío produjeron procesos de aridización que han sido datados entre los 15.000 y 14.500 años ${ }^{14} \mathrm{C}$ AP y/o 11.500-10.500 años ${ }^{14} \mathrm{C}$ AP (Quattrocchio y Borromei, 1998 y bibliografía allí citada). Si bien estos depósitos loéssicos representarían estas condiciones, diferentes niveles con desarrollos variables de paleosuelos revelan condiciones temporariamente y/o localmente más benignas de condiciones cálidas y húmedas (Iriondo y Krohling, 1999; Tonni y Fidalgo, 1978; Imbellone y Cumba, 2003).

Tonni (1992), basado fundamentalmente en la fauna, define para el Pleistoceno tardío un clima semiárido a árido. La fauna observada en este período en la Formación Luján es de estirpe patagónica y/o central con algunos elementos subtropicales (Tonni y Fidalgo, 1978). 
Las condiciones climáticas áridas a semiáridas y frías del Pleistoceno tardío dominaron en la base del Holoceno temprano con el registro de los últimos representantes de la megafauna pleistocénica.

Para el Holoceno medio se registra un pulso cálido y húmedo sugeridos por el ingreso de mamíferos de estirpe brasílica como Monodelphis dimidiata y Holochilus sp. registrados en Fortín Necochea (partido de General Lamadrid) con una datación de $6.010 \pm 400$ años ${ }^{14} \mathrm{C}$ A.P. (Crivelli et al., 1987; Tonni, 1990) coincidente con el Máximo Térmico del Holoceno. Con el mejoramiento climático producido por la deglaciación comienza a desarrollarse el Suelo Puesto Callejón Viejo (Fidalgo et al., 1973 b) con fechados a partir de los $10 \mathrm{Ka}{ }^{14} \mathrm{C}$ (Figini et al., 1999).

Para la mayor parte del Holoceno tardío se observan condiciones semiáridas a áridas encontrando a Microcavia australis como especie típica, apareciendo nuevamente especies brasílicas hacia los 1960 y 1000 años ${ }^{14} \mathrm{C}$ A.P. (Deschamps y Tonni, 1992 y Rabassa et al., 1989 respectivamente) indicando pulsos más templados y húmedos. Asimismo, se observan variaciones zoogeográficas, señalando que algunas fluctuaciones húmedas pueden no ser detectadas por cambios faunísticos o la existencia de asociaciones ecológicamente incompatibles se deban a rápidos cambios climático ambientales (Tonni, 1992).

Para la parte alta de la cuenca del Río Paraná análisis palinológicos y sedimentológicos determinaron que para el Pleistoceno tardío y base del Holoceno (hasta los 8.000 años ${ }^{14} \mathrm{C}$ A.P.) dominaban condiciones áridas. Entre los 8.000 a los 3.500 años ${ }^{14} \mathrm{C}$ A.P. se registra un evento húmedo y desde los 3.500 años ${ }^{14} \mathrm{C}$ A.P. hasta los 1.500 años ${ }^{14} \mathrm{C}$ A.P. se establece otro evento árido, pero a partir de aquí se instalan las condiciones húmedas actuales (Stevaux, 1997).

Para la llanura Argentina (centro y norte del país), Iriondo y García (1993) sobre la base de características geológicas y faunísticas, reconocen para el Pleistoceno tardío y base del Holoceno un clima árido y 
frío, con depósitos eólicos y fauna patagónica. Entre los 8.500 y 3.500 años ${ }^{14} \mathrm{C}$ A.P. el clima es de tipo húmedo subtropical, con fauna brasílica. A partir de los 3.500 y hasta los 1.000 años ${ }^{14} \mathrm{C}$ A.P. las condiciones son de tipo seco subtropical. Desde los 1000 años ${ }^{14} \mathrm{C}$ A.P. hasta la Pequeña Edad de Hielo las condiciones son similares a las actuales, produciéndose durante este período avances de los glaciales en la cordillera, condiciones frías y secas en la llanura pampeana, para a partir de su finalización instalarse las condiciones cálido- templadas actuales (Tonni et al., 1999).

En la cuenca del Río Luján, de acuerdo a elementos sedimentológicos y de análisis polínicos se observa para la transición Pleistoceno - Holoceno un aumento de las precipitaciones con condiciones húmedas con la alternancia de fluctuaciones de corto tiempo entre inundaciones y falta de agua. Entre los 9.000 y 3.000 años ${ }^{14} \mathrm{C}$ A.P. se observa un aumento de la temperatura y tendencia a la sequía a partir de los 7.000 años (Prieto et al., 1998). Las diferencias observadas con respecto a otras localidades podrían deberse a condiciones locales.

El desarrollo del paleosuelo Puesto Callejón Viejo estaría indicando condiciones templado húmedas hacia los 9.000 años ${ }^{14} \mathrm{C}$ A.P (Zárate, et al., 1995). Entre los 3500 y 2900 años ${ }^{14} \mathrm{C}$ A.P. el desarrollo de un suelo correlacionable con el Suelo Puesto Berrondo indicaría condiciones similares a las actuales. Para el Holoceno tardío se evidencian condiciones de clima subhúmedo seco (Prieto et al., 2000). Los fósiles invertebrados incluidos en los depósitos de la ingresión holocena sugieren temperaturas del agua superiores a las actuales (Aguirre, 1990).

Por último una asociación de mamíferos hallados en la Formación La Postrera del sitio Lobería I, indican ambientes áridos a semiáridos hacia $440 \pm 60$ años A.P. (Tonni et al., 1999) correlacionable con la Pequeña Edad de Hielo (Rabassa et al., 1989) para la Pampa Húmeda. Estos autores infieren un significativo proceso de aridización entre los siglos XVII Y XIX, traducido en sequías, desecación y salinización de lagunas y 
formación de campos de dunas, propiciado por la expansión de los glaciares en el sector cordillerano

En la figura 3.8 se asocia la curva de paleotemperatura, (Ricciardi, 1995) los eventos paleoclimáticos y las unidades litoestratigráficas identificadas para este período de tiempo.

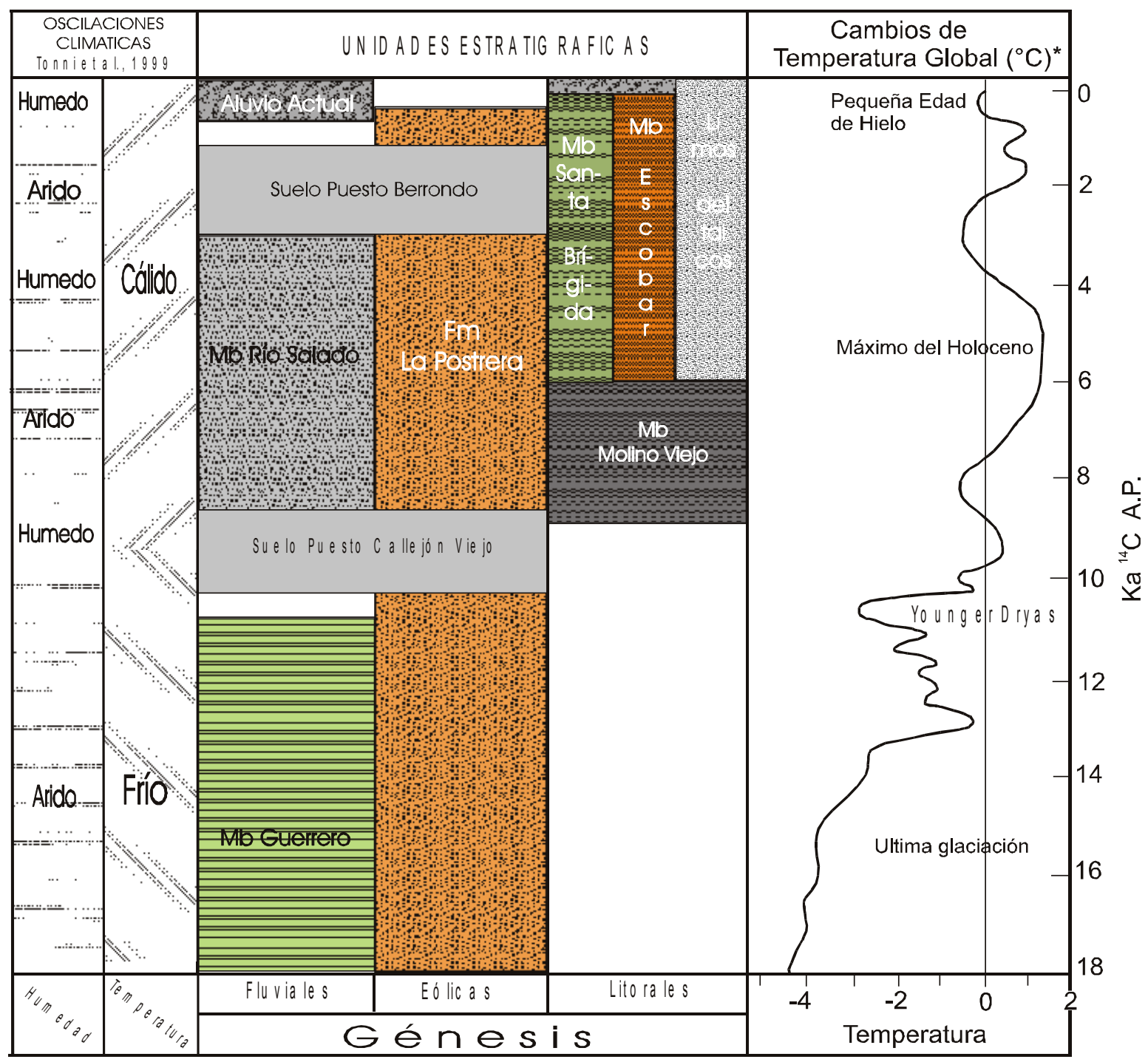

Fig. 3.8 Curva de paleotemperatura y unidades estratigráficas asociadas 


\section{CAPITULO IV \\ DESCRIPCIÓN GEOLÓGICA}

\section{1 SITUACION REGIONAL}

La amplia región del borde sudamericano, especialmente desde el alto de Cabo Polonio (Uruguay) hasta la boca del Río Negro (sur de la provincia de Buenos Aires) se caracteriza por una serie de altos que delimitan un conjunto de cuencas sedimentarias con depósitos Cretácicos - Terciarios. El origen de estos depocentros esta vinculado a procesos de fracturación extensional sobre primitivas zonas de debilidad durante la apertura del Atlántico Sur en el Mesozoico tardío (Yrigoyen, 1999 b).

Desde el punto de vista estructural y regional, el área de estudio se encuentra emplazado en el Cratón del Río de La Plata, y específicamente en el umbral del Plata-Martín García (Yrigoyen, 1999 a) que separa las cuencas de Punta del Este al norte y Salado al sur (Fig. 4.1). 


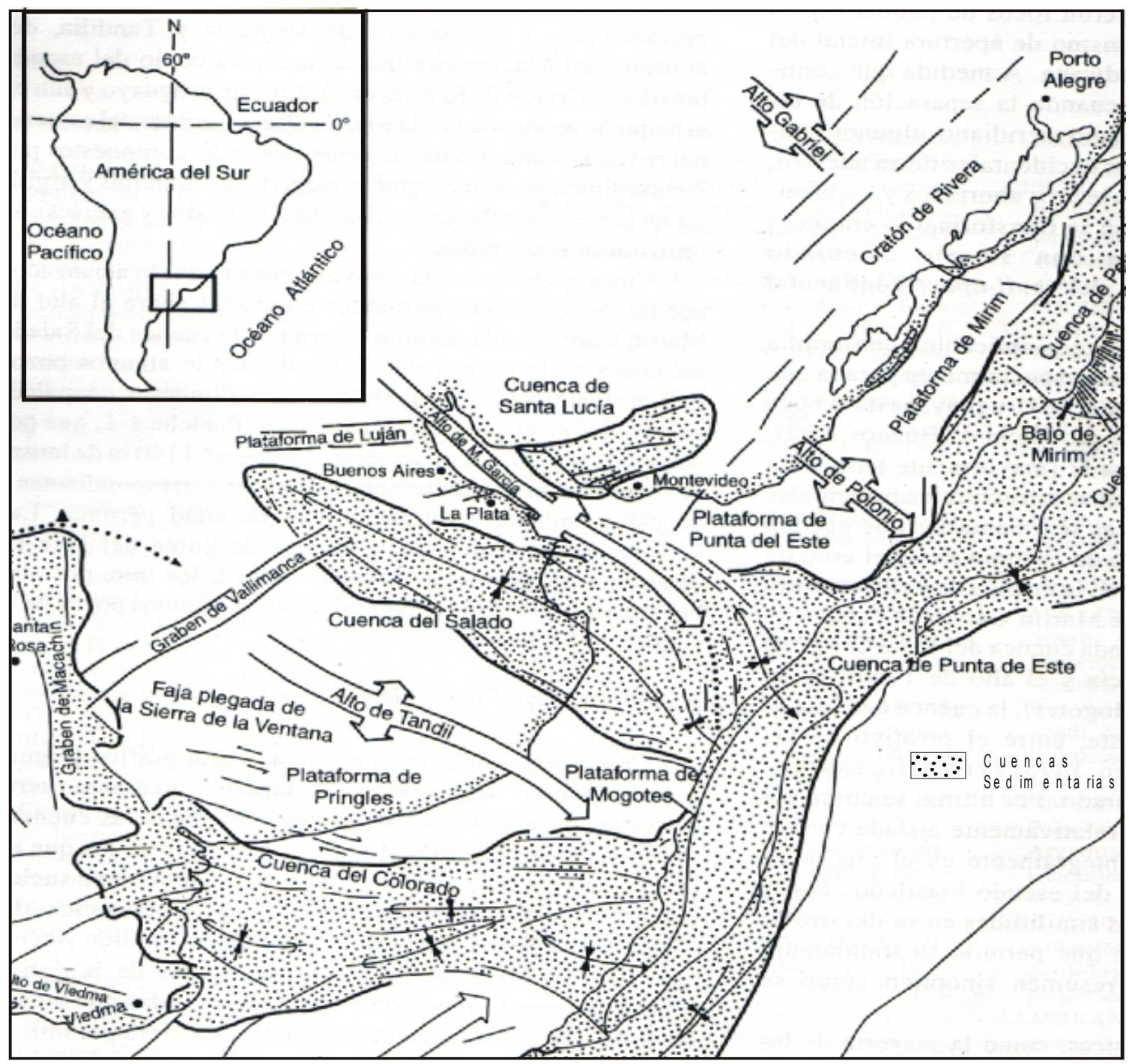

Figura 4.1 Elementos estructurales de la región (Tomado de Yrigoyen, 1999 b).

Debido a esta situación estructural, la profundidad a la que se encuentra el basamento cristalino difiere notablemente a medida que nos alejamos del centro de este alto.

\subsection{GEOLOGÍA DE SUBSUELO}

\subsubsection{BASAMENTO CRISTALINO}

Los afloramientos del basamento cristalino ubicados en la Isla Martín García a unos $70 \mathrm{~km}$ de la región estudiada permiten realizar una 
caracterización sobre las particularidades litológicas de estas rocas. De edad precámbrica media a superior, fueron agrupadas en el Complejo Martín García, estando integradas por anfibolitas, esquistos, gneises, migmatitas, rocas filonianas y movilizados granitoides y rocas ultrabásicas (Dalla Salda, 1981), que por edad y evolución geológica se las agrupa en el Cratón del Río de la Plata (Dalla Salda et al., 1988).

Inicialmente, sucesiones sedimentarias compuestas por grauvacas y pelitas, intruidas por cuerpos básicos y ultrabásicos fueron sometidos a metamorfismo regional a facies de anfibolitas almandínicas. Estas rocas fueron afectadas posteriormente por un evento deformacional dúctil aproximadamente a los 2.085 a 2.500 Ma. Posteriormente (1870 y 1600 Ma) siguió una segunda deformación de similares características a la anterior, acompañada por metamorfismo regional dinamotérmico que provoca la recristalización profunda del complejo (Dalla Salda, 1999).

Con posterioridad, se produce la elevación a niveles corticales superiores, provocando la diaftóresis parcial de las rocas, con la intrusión de cuerpos graníticos y tonalíticos (Dalla Salda, 1999).

Diversas perforaciones han permitido detectar rocas del basamento cristalino, observándose como en la Ciudad de Buenos Aires (Olivos) se encuentra a $-245 \mathrm{~m}$, en el Río Paraná Miní (taller de varadero) a -146 m y aflorando en la Isla Martín García a 25 m (Sala, 1969; Yrigoyen, 1975).

\subsubsection{FORMACIÓN OLIVOS (Yrigoyen, 1975)}

Esta unidad se dispone en discordancia sobre el Basamento Cristalino, localizándose su techo en el área de estudio (Otamendi) a -85 m aproximadamente (Yrigoyen, 1992).

Está compuesta por arenas gruesas a conglomerádicas, de color pardo rojizo, amarillentas o grisáceas a verde claro, cuarzosas, con nódulos de yeso y anhidrita. Alternan fangolitas y arcillas arenosas pardo rojizas. Presenta un espesor en el subsuelo de la ciudad de Buenos Aires de $210 \mathrm{~m}$ aproximadamente, incrementándose hacia la cuenca del salado. 
Se le atribuye una génesis continental y edad Oligoceno - Mioceno inferior. Presenta claros indicios de fracturación, similares a las del Basamento Cristalino, sin llegar a afectar a la suprayacente Fm Paraná (Yrigoyen, 1975, 1992, 1999 b).

\subsubsection{FORMACIÓN PARANÁ (Yrigoyen, 1975)}

Esta unidad ha sido someramente descripta en el área de estudio, en base a perforaciones efectuadas, en la mayoría de los casos con fines aplicados. Muchas de las características asignadas a esta formación, provienen de las observaciones efectuadas en las barrancas del Río Paraná en la provincia de Entre Ríos, fundamentalmente al norte de la capital provincial. Por ello, los datos de las características texturales y particularmente el espesor, resultan muy variables.

Estos sedimentos han sido denominados inicialmente como Piso Paranense (Doering, 1882), El Verde (Groeber, 1945), Formación Arcillas Verdes (Santa Cruz, 1972). Esta sucesión sedimentaria es de características granodecreciente y compuesta por dos secciones muy contrastantes. La sección inferior, arenosa, que hacia la base se torna regularmente gravosa y la superior, representada por arcillas fundamentalmente verdosas a gris verdosas, oscuras, compactas y con abundantes contenidos fosilíferos.

Según González Bonorino y Cetrángolo (1962), en el subsuelo de Capital Federal, está constituida por arcillas limosas, verde grisáceas, plásticas, sin estratificación y a veces con nódulos de carbonato de calcio de hasta 0,03 m de diámetro, así como restos de bivalvos marinos. Manifiestan, además, que puede ocurrir que las perforaciones no recuperen los niveles arenosos intercalados, que se observarían según otros autores, en las barrancas del Río Paraná. Le continúan en profundidad intercalaciones arenosas a conglomerádicas finas, notándose un incremento de las psamitas.

Los autores citados "utsupra" consideran tanto a la Formación Paraná como a la suprayacente Formación Puelches como constituyentes de una secuencia 
vertical arena-arcilla-arena, interpretándolo como un ciclo marino representado de abajo hacia arriba por: 1) arenas inferiores correspondientes a un ciclo litoral transgresivo, 2) arcillitas verdosas de plataforma y 3) arenas de la Formación Puelches de carácter litoral y regresivo.

Estos depósitos se habrían originado en un ambiente litoral de aguas con salinidad cambiante, generalmente salobre (Herbst y Zabet, 1987), de poca profundidad y con influencia deltaica (Iriondo, 1973), bajo condiciones de clima subtropical a tropical húmedo (Brea et al., 2001).

Por debajo de la Formación Paraná y hasta unos $290 \mathrm{~m}$ se ubican las denominadas "arcillas pardas", constituidas preferentemente por limos arcillosos de color castaño claro, que algunos equiparan a posibles depósitos de loess (González Bonorino y Cetrángolo, 1962).

La edad de la Formación Paraná se asigna al Mioceno Medio-Tardío, desarrollándose en el sector litoral y centro del país, uniéndose por el norte a la manga del Tethys (Fig. 4.2). En esta transgresión, solamente quedarían emergidas la cordillera de los Andes, un conjunto de sierras y los escudos de Guyana y de Brasilia fundamentalmente (Ramos, 1999).

Estos depósitos traslapan a los de la Fm Olivos, aumentando su espesor hacia la cuenca del salado. La cota del techo se mantiene prácticamente constante, aunque no se puede descartar que hacia el eje de la cuenca del salado, la suave combatura de toda la pila sedimentaria se deba a reactivaciones de las fracturas existentes ligadas a la iniciación de la epirogenia miocena (Yrigoyen, 1975).

El techo de esta unidad en el sector de estudio se sitúa a unos $-40 \mathrm{~m}$ (Santa Cruz, 1972; Hernández et al., 1995).

Estos depósitos se habrían formado como consecuencia de aumento del nivel del mar acontecido en el Atlántico sur como resultado del ascenso de temperatura (Clímax cálido del Neógeno) con posterioridad a la apertura del Pasaje de Drake, limitado este avance sobre el continente a una 
paleogeografía no muy diferente de la actual (Aceñolaza, 2000). En sectores de la Patagonia durante el Mioceno medio la fauna indica la presencia de aguas cálidas similares a las existentes actualmente en Brasil (Malumnián y Náñez, 1996) cuyas condiciones ambientales subtropicales se extendieron por el norte de Argentina hasta el norte de la Patagonia (Alberdi at al., 1997).

El retiro de esta transgresión en el Mioceno tardío permitió la formación de extensas planicies reconocidas como "edad de las planicies australes" (Pascual y Bondesio, 1982) con el desarrollo de sabanas abiertas, observándose la formación de los pastizales modernos hacia el Pleistoceno (Janis, 1993). 


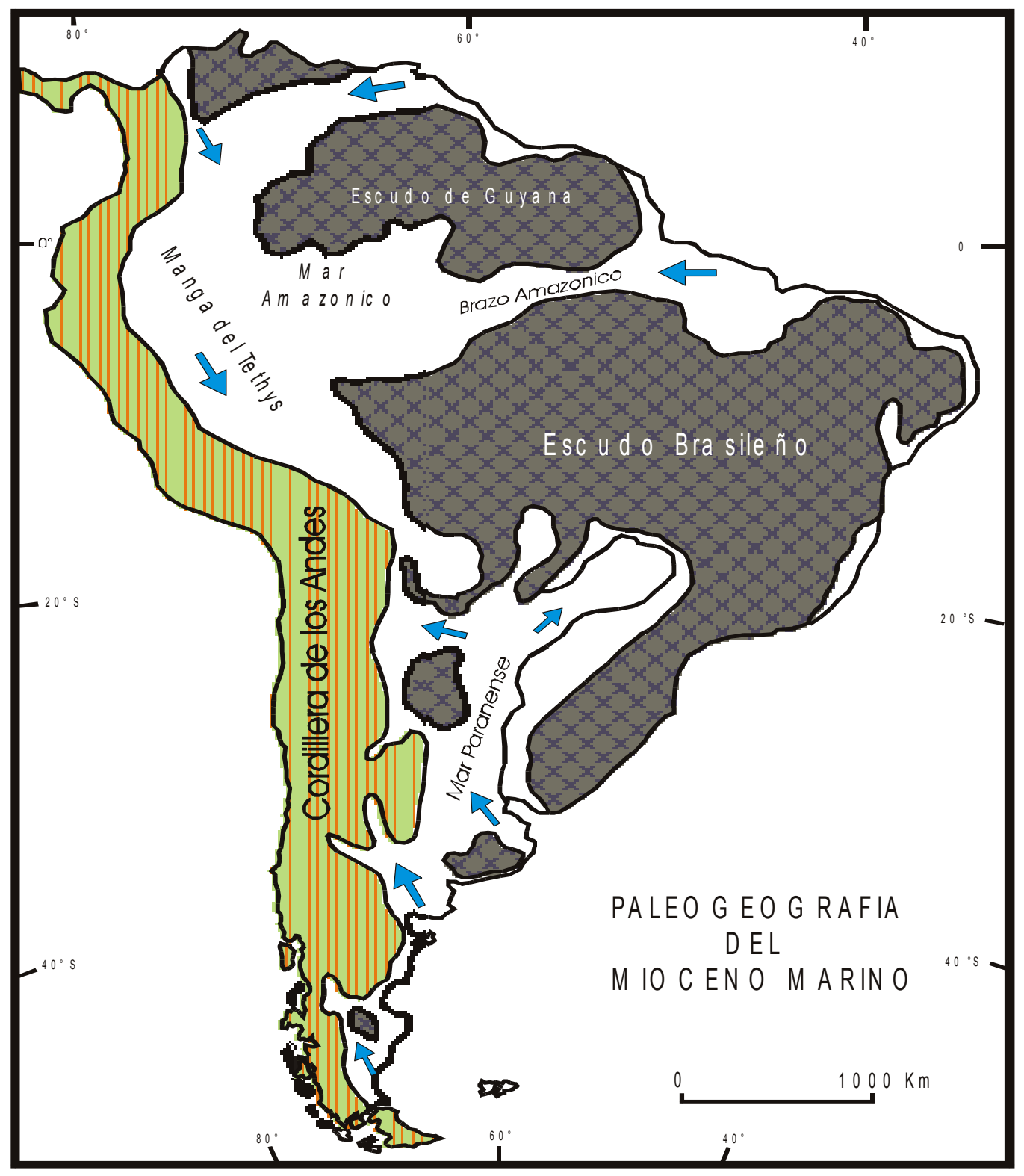

Figura 4.2. Distribución de la transgresión Paranense

(Tomada de Ramos, 1999)

\subsubsection{FORMACIÓN PUELCHES (Santa Cruz, 1972)}

Denominada Piso Puelches por (Doering, 1882), ya era conocido con anterioridad por otros investigadores como Burmeister, (1863 en Santa Cruz, 1972) y Ameghino (1881).

En general, está compuesta por psamitas limpias, de grano mediano a fino, de color anaranjado grisáceo a anaranjado amarillento pálido, de 
composición cuarzosa (Santa Cruz, 1972). Hacia la cuenca del Salado y Bahía Samborombón, su composición se torna arcillosa.

El cuarzo es el mineral más abundante, ya que integra del 85 al 93 o de los minerales livianos, predominando los individuos subredondeados en las fracciones de 88 micrones.

En cuanto a las arcillas las más abundantes son las del tipo montmorillonítico, alcanzando valores de 60 a 65 \% notándose la presencia de illita y caolinita en proporciones variables.

La fauna esta compuesta fundamentalmente por vertebrados (peces y mamíferos) y restos de árboles (Rusconi, 1933).

Se observa distribuida el noreste de la provincia de Buenos Aires, subsuelo deltaico (Groeber, 1961) y parcialmente en las provincias de Entre Ríos, Corrientes y Santa Fe.

En el área de estudio y zona de influencia la base se encuentra a unos -40 m de profundidad, observándose una suave inclinación hacia los ríos Paraná y de la plata y con mayor pendiente hacia la cuenca del salado (Auge y Hernández, 1983) (Fig. 4.3). 


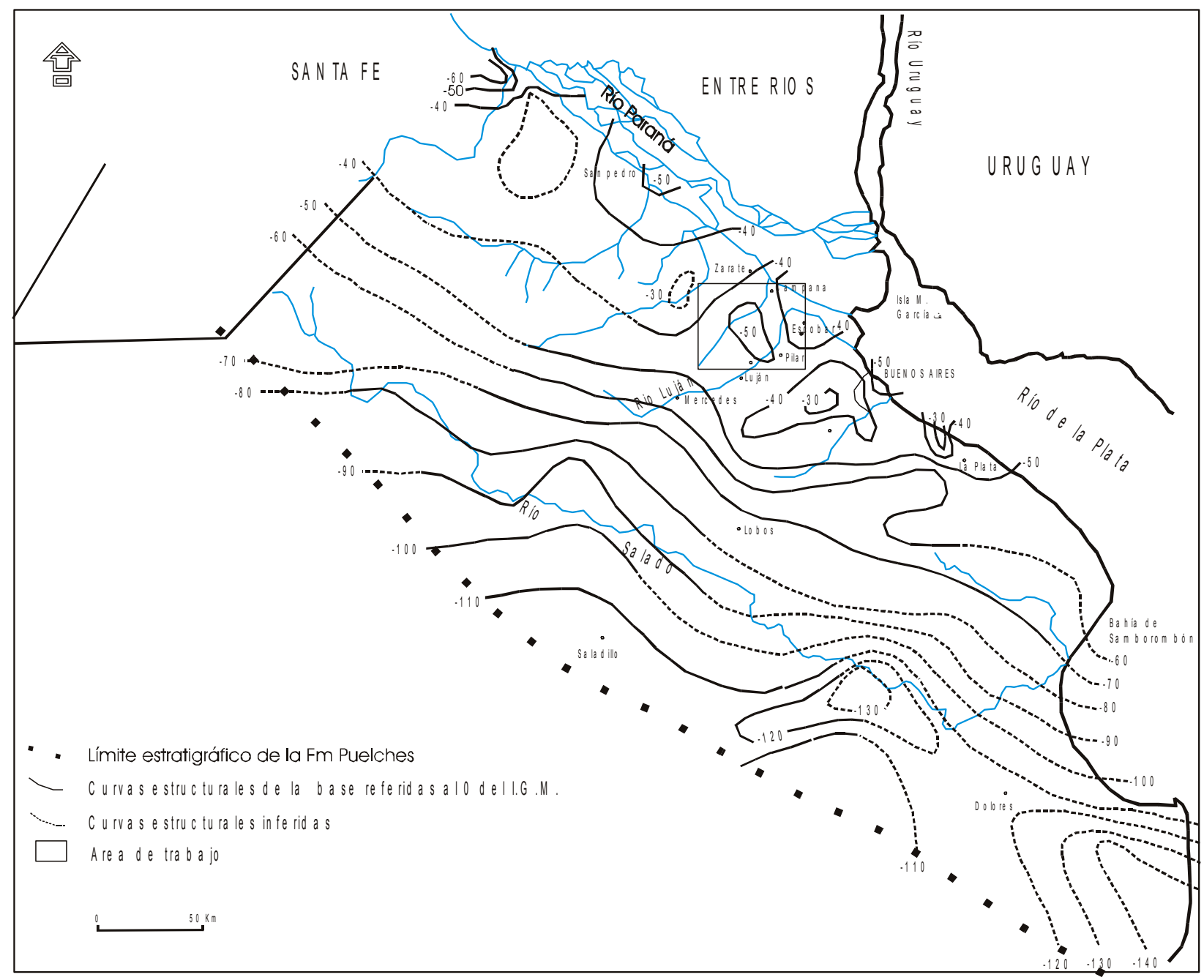

Fig. 4.3 Mapa estructural del piso de la Fm Puelches (Tomado de Auge y Hernández, 1983)

El techo presenta regionalmente una inclinación similar a la base, con un alto morfológico elongado en sentido NO-SE sobre el límite noreste de la provincia. En San Nicolás se registra a una cota de $-10 \mathrm{~m}$, extendiéndose por todo el sector noreste hasta la Ciudad de La Plata para observar un alto a cota -20 m (Auge y Hernández, 1983; Auge, 1995) (Fig. 4.4). 


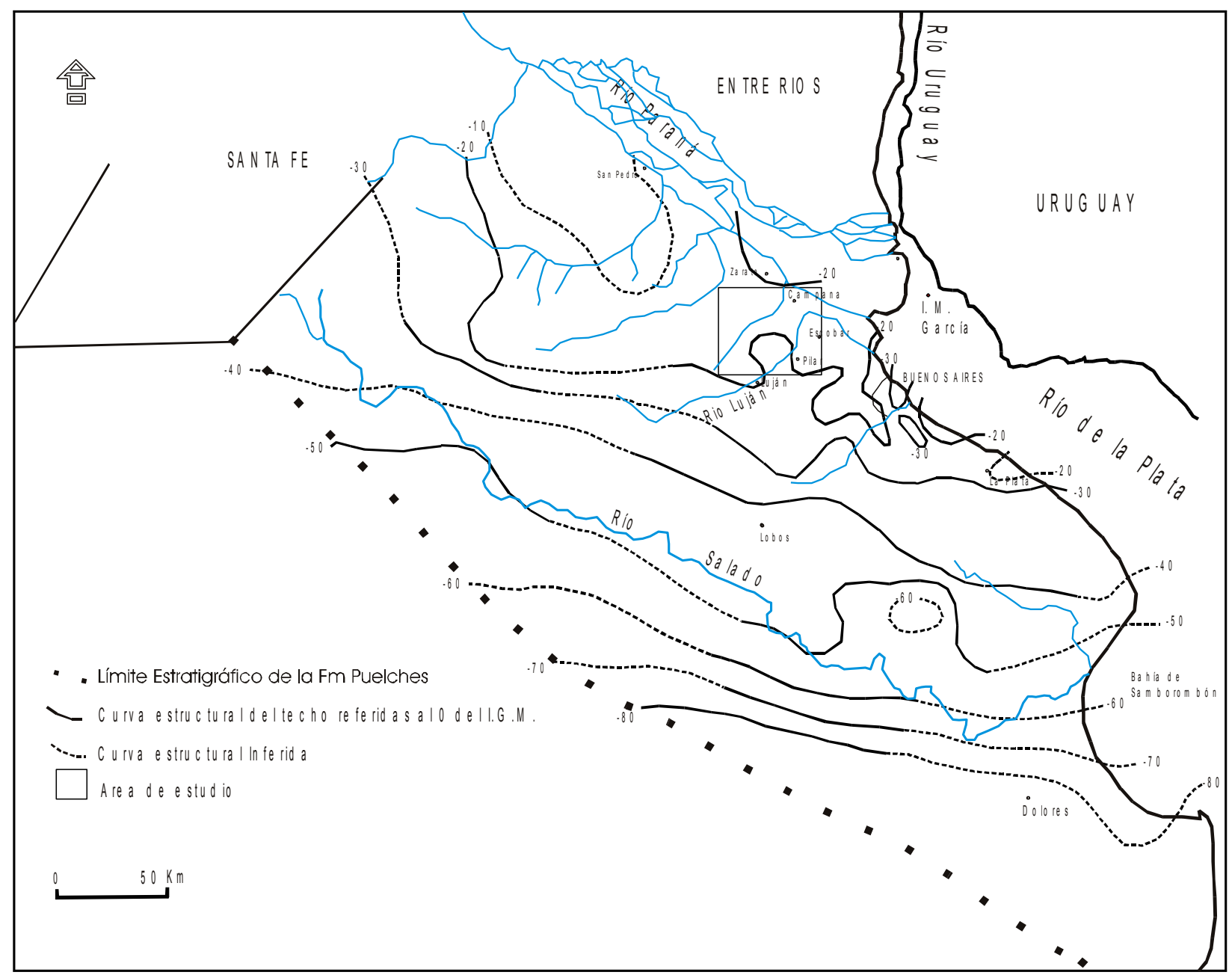

Figura 4.4 Mapa estructural del techo de la Fm Puelches (Tomado de Auge y Hernández, 1983)

El espesor comprobado para esta unidad oscila entre 20 y 40 m, aunque en regiones vecinas (Zárate) puede disminuir hasta 9 metros y en otras aumentar hasta 86 m (Auge y Hernández, 1983) (Fig. 4.5), concluyendo que las variaciones marcadas, no sólo en su espesor sino también en su granometría, son permanentes, aunque en general las texturas arenosas son las mas representativas. Éstas se encuentran acompañadas por niveles de limos y arcillas, en ocasiones más abundantes que las arenas. Las gravas se encuentran distribuidas en lentes de extensiones aparentemente limitadas, pero prácticamente en cualquier profundidad, aumentando su presencia hacia la base. 
Estas variaciones hacen que, cuando aumenta el contenido pelítico en el techo de la unidad, el paso hacia la Formación Pampeano suprayacente, a veces no resulte claramente discernible.

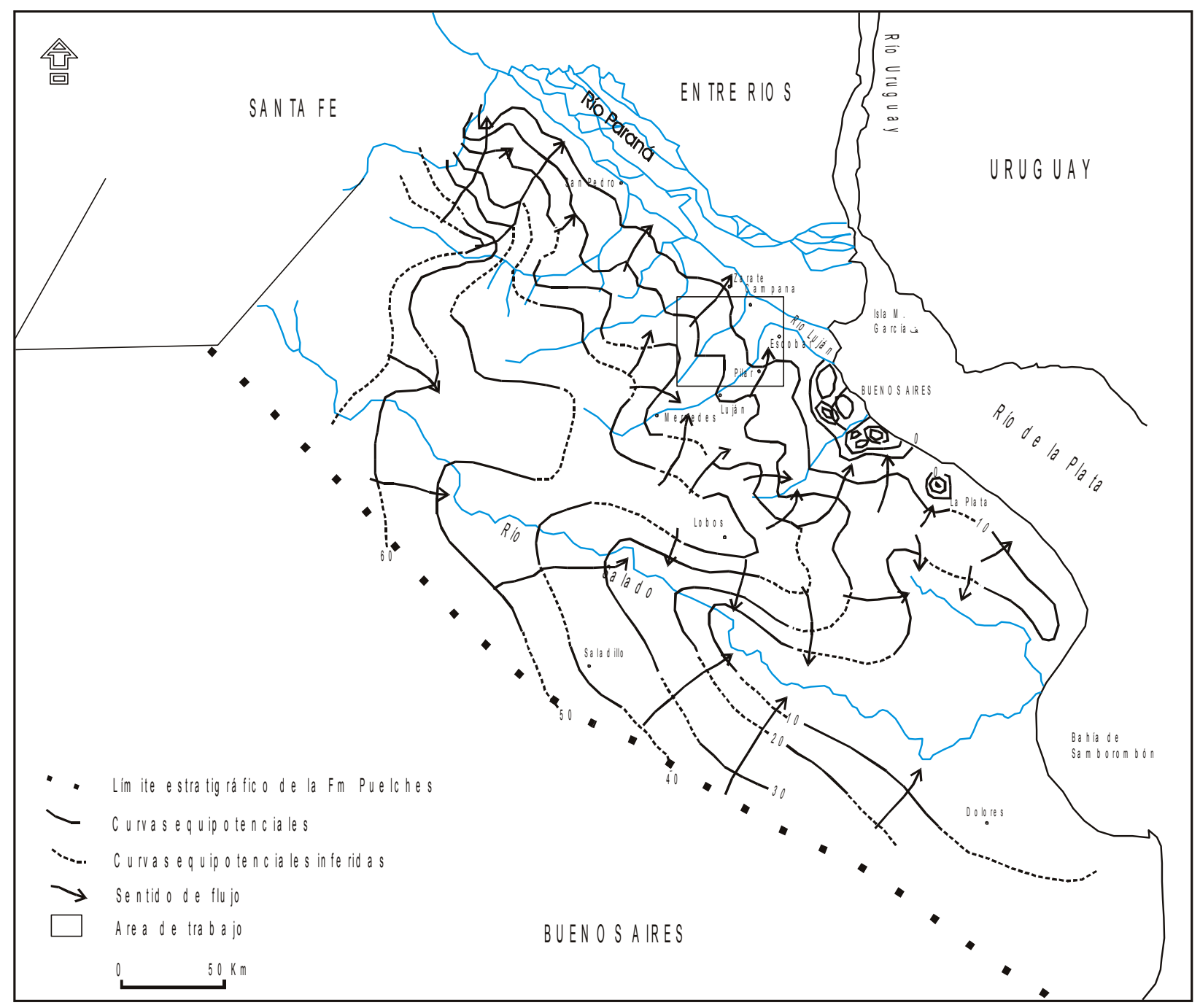

Fig. 4.5 Mapa isopáquico de la Fm Puelches (Tomado de Auge y Hernández, 1983)

El origen, según Santa Cruz (1972), basado en estudios detallados con parámetros estadísticos, es fluvial y de planicie de inundación con diseño individual anastomosado.

Iriondo (1999) correlacionó esta unidad con la Fm Ituzaingó, la que posee espesores de 160 metros en la Provincia de Corrientes y 15 m en la Ciudad de Paraná. Regionalmente se observa que el espesor va disminuyendo hacia 
el sur, interpretando que las variaciones locales tiene que ver con el proceso sedimentario (Herbst, 2000). Santa Cruz (1994) reconoció en la localidad de Campana, un espesor de $110 \mathrm{~m}$ disponiéndose directamente en discordancia sobre la Fm Olivos. Este contacto indicaría la erosión de la Fm Paraná, con un nivel de base bajo con posterioridad a la transgresión paranense. Otra hipótesis de esta situación sería que parte de la Fm Puelches considerada corresponda a la Fm Paraná, y que por ausencia del manto arcilloso suprayacente (no depositado o erosionado) haya experimentando una transformación de sus aguas hacia calidades aptas. Esta situación debe ser acompañada por una presión hidrostática menor para que la Fm Paraná no salinice el agua de este paleocanal.

Por su contenido paleontológico (vertebrados y troncos de árboles) se le asignó una edad Plioceno superior - Pleistoceno inferior (Rusconi, 1933; Pascual et al., 1965; Brea et al., 2001).

En general, podría establecerse que sobre "las planicies australes" generadas por el retiro del mar paranense (Pascual y Bondesio, 1982) se desarrolló el río "proto Paraná" (paloerío Ituzaingó) de tipo entrelazado con barras arenosas transversales (Herbst, 2000), con pendiente similar al actual Río Paraná, en una cuenca de escasa subsidencia y solo afectada por movimientos epirogénicos poco relevantes (Chebli et al., 1989).

En la Fig. 4.6 pueden observarse la distribución, espesores y relaciones de las diferentes unidades litoestratigráficas de la región. 

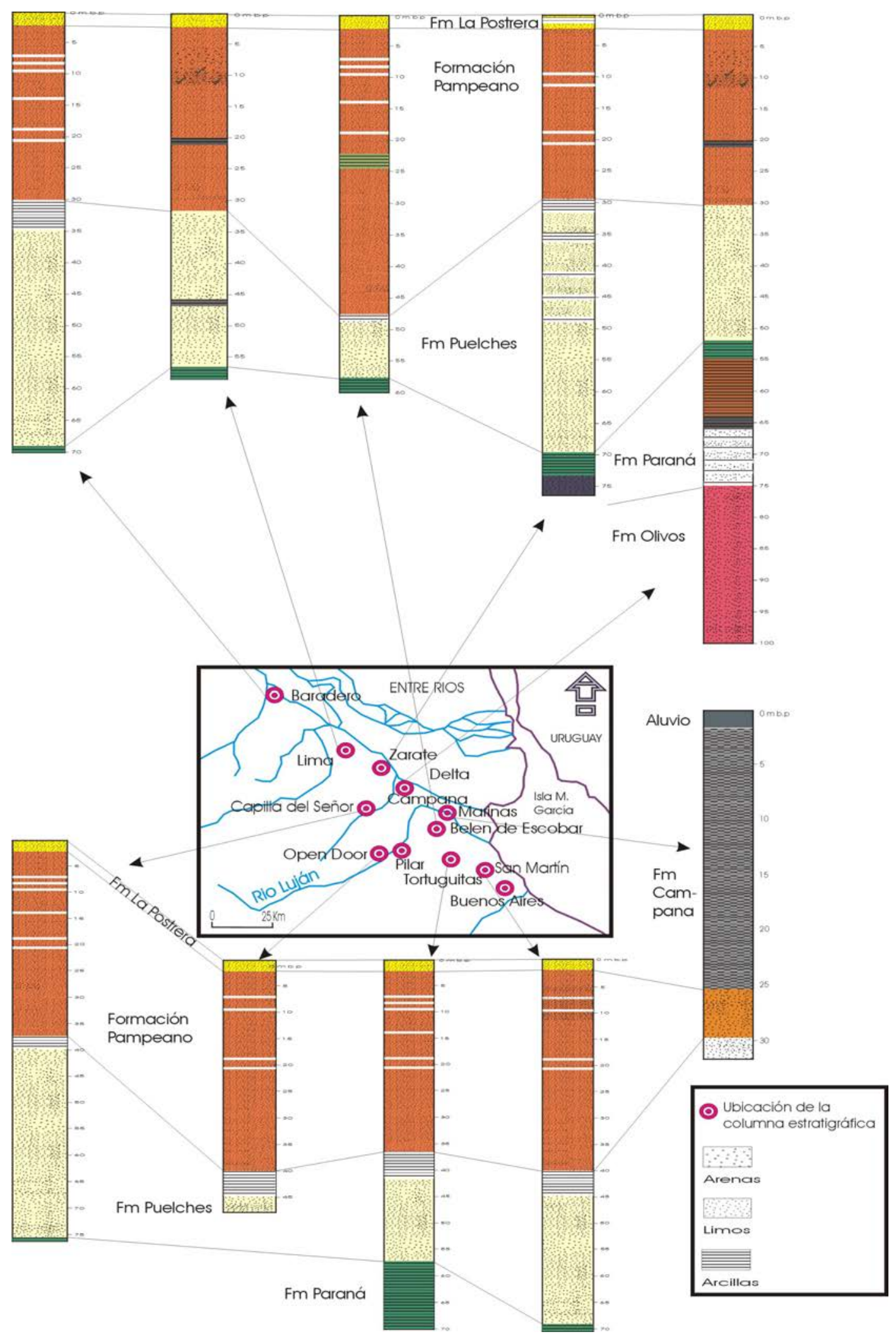

Fig. 4.6 Perfiles estratigráficos de la región 


\subsection{GEOLOGIA DE SUPERFICIE}

\subsubsection{UNIDADES UTILIZADAS}

De acuerdo a las características del trabajo, se creyó conveniente la utilización de Unidades Litoestratigráficas y Pedoestratigráficas de acuerdo al Código Argentino de Estratigrafía (1992). Si bien en trabajos geológicos del Cuaternario han sido utilizadas otras unidades (Aloestratigráficas y Separadas por Discontinuidades) la observación y precisión de discontinuidades es muy difícil de determinar en trabajos donde el reconocimiento se realiza prácticamente en su totalidad por medio de sondeos. Asimismo, el escaso espesor de algunas de las unidades identificadas constituye otro elemento en contra de la utilización de estas (separadas por discontinuidades) ya que estas parecen adaptarse mejor a depósitos donde los espesores son mas importantes.

Las Unidades Litoestratigráficas comprenden "cuerpos definidos de rocas distinguibles y delimitables sobre la base de características litológicas observables y de sus relaciones estratigráficas (Art. 24, Código Argentino de Estratigrafía, 1992).

La unidad fundamental es la Formación, mapeable en superficie o subsuelo, completándose la clasificación con Miembro y Estrato de rango menor y Grupo de rango superior (Art. 27 y 28).

La denominación de algunas unidades litoestratigráficas se han mantenido, dado que presentan características litológicas similares a las definidas fuera del área y ser ampliamente reconocidas en todo el ámbito bonaerense. En el caso de las unidades litorales, ha resultado conveniente denominarlas con topónimos locales, ya que sus características litológicas presentan particularidades propias y no claramente extrapolables. 
De acuerdo al Código Argentino de Estratigrafía, (1992), las Unidades Pedoestratigráficas "son cuerpos de rocas constituidos por uno o más horizontes pedológicos desarrollados en una 0 más unidades estratigráficas, y que están o han estado cubiertos por ellas" (Art. 49). La unidad fundamental es el geosuelo, el que no debe considerarse como un suelo o paleosuelo, sino un conjunto de éstos reconocible como un horizonte estratigráfico arealmente extenso (Art. 54). Si bien la identificación de estos perfiles de meteorización ha sido exigua, su existencia, características y ubicación estratigráfica permiten correlacionarlas con los geosuelos definidos en otros sectores del ámbito pampeano.

\subsubsection{AMBIENTES SEDIMENTARIOS}

Las sucesiones estratigráficas se hallan representadas por unidades generadas en medios sedimentarios continentales, marinos y mixtos o de transición (Dunbar y Rodgers, (1957), Selley, (1970), Crosby (1972), Blatt, et al. (1972) en Zarauza et al. 1977).

Las unidades reconocidas (Fig. 4.7) se han correlacionado con sucesiones identificadas en el área o zona de influencia, integrándose dentro del esquema estratigráfico propuesto (Cuadro 4.1). 


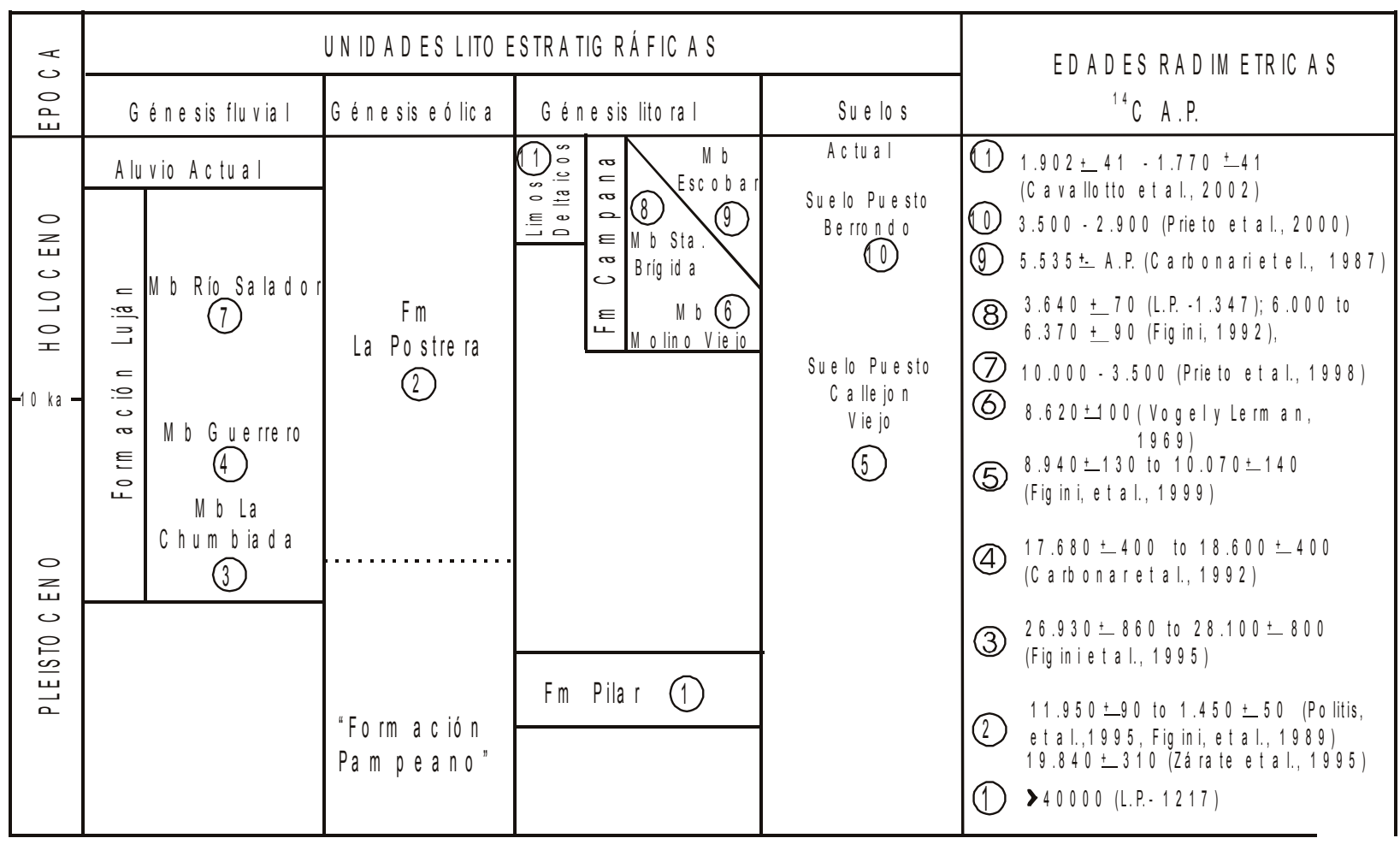

Cuadro 4.1 Representación de las unidades estratigráficas del área de estudio.

En la figura 4.8 se representa la ubicación de todos las observaciones realizadas, como así también las canteras que permiten una visualización muy clara de las unidades involucradas. A esos puntos se le suman las observaciones realizadas a lo largo de la mayoría de los caminos y canales que por su presencia continua no han sido individualizadas.

\subsubsection{UNIDADES CONTINENTALES}

La génesis de las unidades continentales está asociada a procesos eólicos y en menor proporción gravitacionales y fluviales. Dentro de los generados por los dos primeros procesos se incluyen a las Formaciones Pampeano y La Postrera y en los de génesis fluvial a los depósitos de la Formación Luján y al Aluvio actual. Cabe señalar, que en el caso de la Formación Pampeano, es común observar facies generadas por procesos eólicos, fluviales, lacustres y gravitacionales, como asimismo la presencia de niveles de paleosuelos. 


\subsection{SUCESIONES EOLICAS Y ASOCIADAS}

Estas unidades superficiales se han reconocido coronando la columna estratigráfica en todo el ámbito no influenciado por la ingresión holocena y por los cursos de agua, como asimismo, por debajo de estas unidades, a través de observaciones directas o indirectas.

Las observaciones de mayor relevancia, si bien se han obtenido en forma discontinua, en canteras, cortes de caminos y paleoacantilados, y dado el grado de semejanza que presentan, permiten establecer una aproximación muy consistente sobre sus particularidades y relaciones.

4.3.2.1.1.1 UNIDADES LITOESTRATIGRÁFICAS RECONOCIDAS

\subsection{1.a FORMACIÓN PAMPEANO (González Bonorino, 1965)}

Como se manifestara precedentemente, los depósitos pertenecientes a esta unidad se definieron en González Bonorino (1965). Asimismo han sido agrupados en los "Sedimentos Pampeanos" (Fidalgo et al., 1975); Formaciones Buenos Aires y Ensenada (Riggi et al., 1986) entre otros.

Debido a que esta unidad ha sido observada, ya sea a través de afloramientos naturales y/o artificiales o por intermedio de perforaciones en prácticamente todo el área de estudio, se la ha considerado como el sustrato sobre el que se han desarrollado los procesos y agentes que han motivado la generación de las unidades geomorfológicas y litoestratigráficas más modernas.

Características litológicas: Está integrada por un limo arcilloso a arcillo arenoso de color castaño a castaño fuerte (7,5YR 5/3 a 7,5YR 4/6) . Los sectores inferiores presentan en términos generales, tonalidades más claros que los depósitos suprayacentes, al igual que los sectores edafizados y lacustres que rompen la homogeneidad del depósito de aspecto masivo. Cuando la granulometría aumenta, al menos en los porcentajes de arenas muy finas, parece disminuir rápidamente la proporción de arcillas. En general los valores de limos son los menos variables, ya que 
generalmente alcanzan del 40 al 50 \% aproximadamente, variando en cambio la proporción de arcillas y arenas, (Riggi et al., 1986). En oportunidades son abundantes los agregados arcillosos cuyo origen, clástico, pedogenético o diagenético, por ahora, resulta poco claro.

La sección superior está compuestas preferentemente por limos que constituyen comúnmente el 50 al 60 \% del depósito, con fracciones subordinadas de arena y arcilla, presentando a veces concentraciones de limo arcilloso en forma de capas continuas más compactadas, de 0,20 a 0,30 m o algo más de potencia, así como la presencia de cutanes arcillosos, de color castaño claro a gris y negro, formando manchas milimétricas, que constituyen remanentes de paleosuelos y que han sido descriptos en Fidalgo (1983); Nabel et al. (1995); Iriondo y Krohling (1999); Imbelloni y Cumba (2003); entre otros. Muchos de estos paleosuelos, pueden corresponder genéticamente a más de un ciclo de formación.

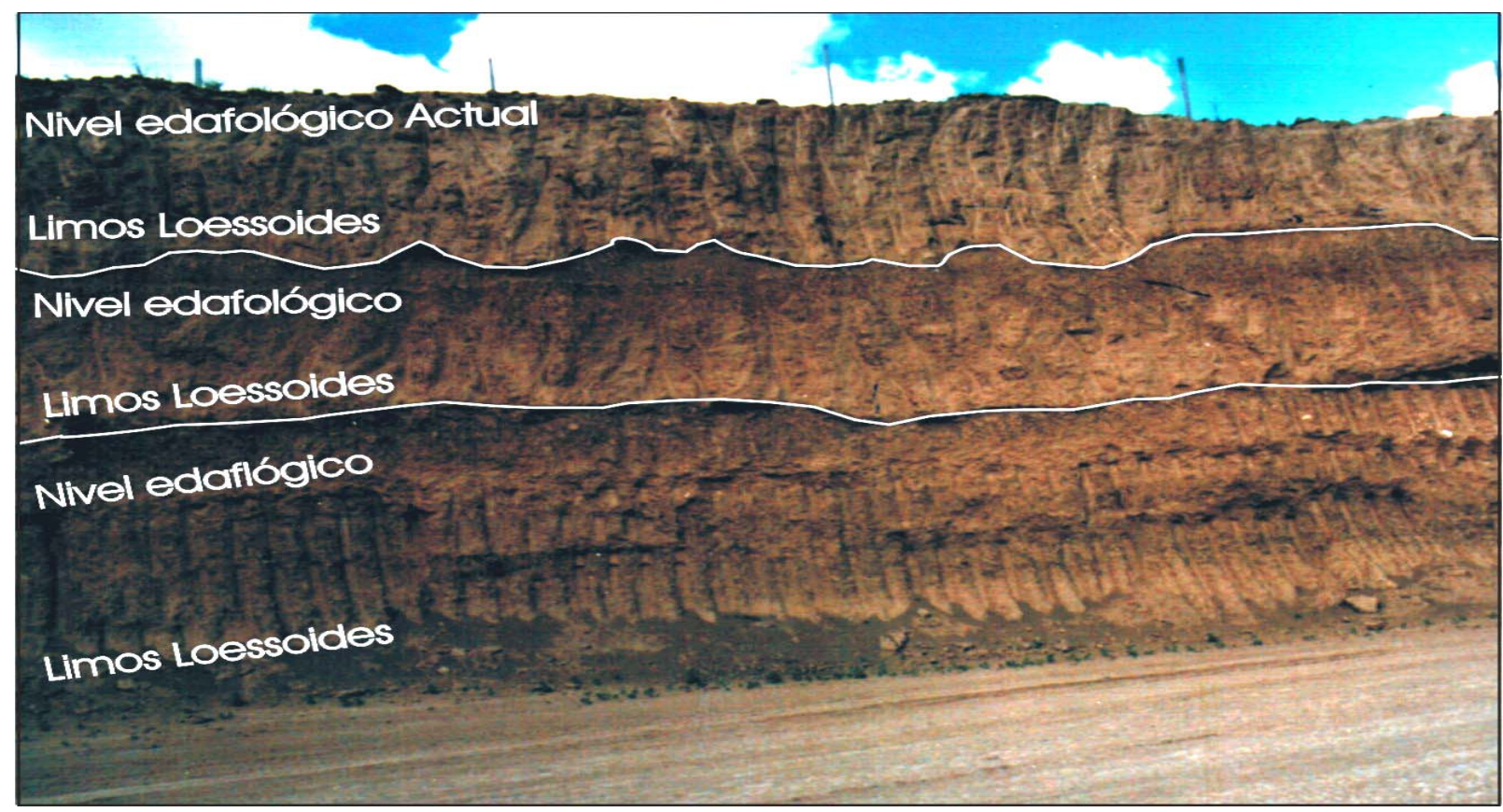

Figura 4.9 Formación Pampeano y Fm La Postrera con niveles pedológicos.

La tosca se presenta en forma de venas, en variadas direcciones, tanto verticales, subverticales como horizontales y generalmente se presentan en conjunto. Ocupan franjas de 0,40 a $0,60 \mathrm{~m}$ de espesor y en extensión 
horizontal puede alcanzar decenas de metros. En oportunidades esta disposición de las venas al entrecruzarse nos ha llevado a la denominación de formas en enrejado, que integran poliedros con núcleos de sedimentos limo arcillosos castaños típicos de la roca hospedante. Las venas horizontales suelen presentarse juntas o muy próximas en la parte superior de la acumulación de carbonato y se separan hacia abajo a lo largo de los 0,40 a 0,60 m de potencia o altura en que se desarrollan. Posiblemente esta disposición del carbonato copie la estructuración previa de estos sedimentos, generados por procesos pedogenéticos.

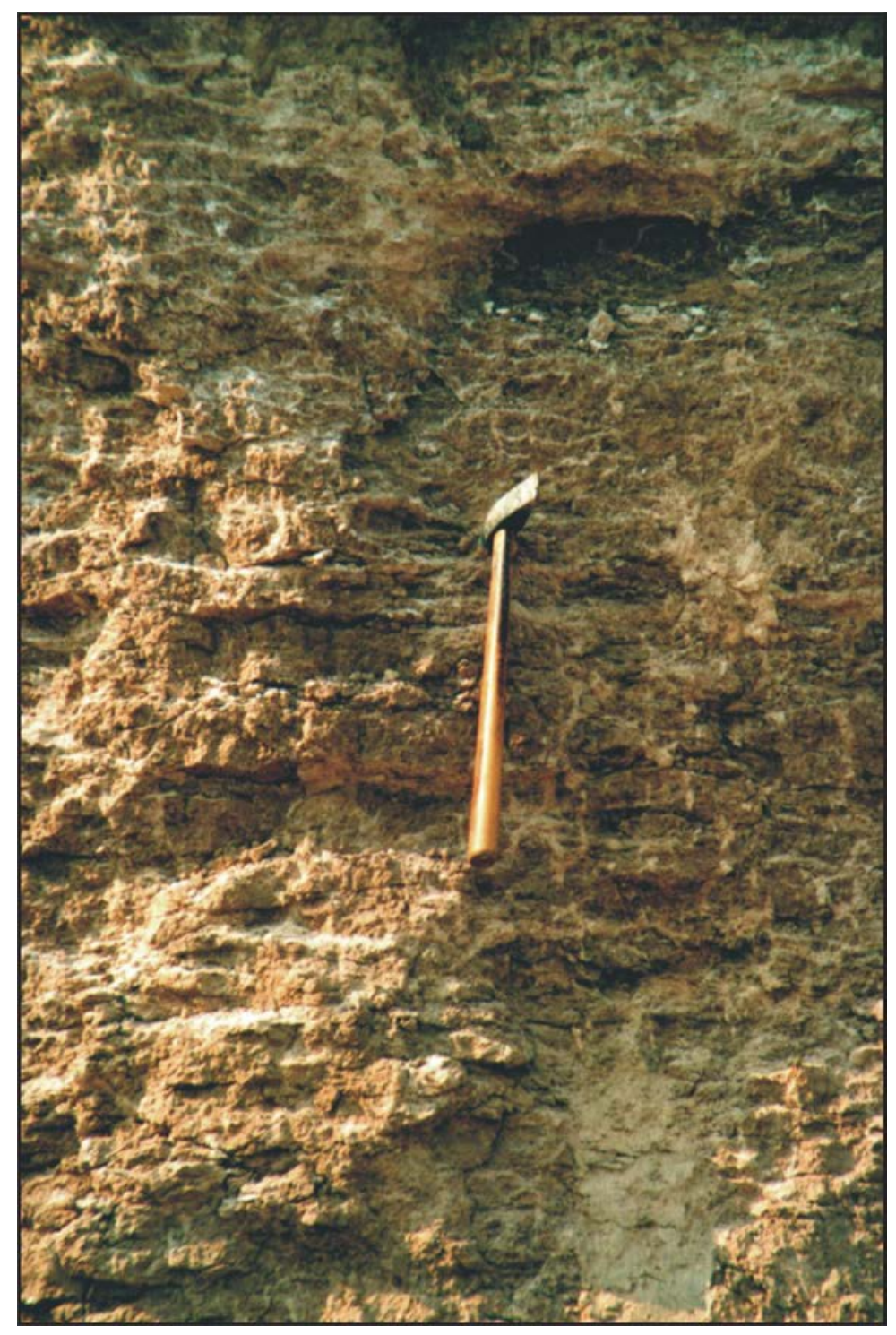

Fig. 4.10 Fotografía de tosca en enrejado. 
La base de esta unidad se encuentra en contacto con la Fm Puelches. Este contacto es comúnmente discernible en las perforaciones, aunque en ocasiones en que la unidad infrayacente se presenta con proporciones de pelitas importantes, suele ser transicional.

Hacia arriba suelen observarse en discordancia, las unidades fluviales de la Fm Luján, litorales de la ingresión holocena y eólica de la Fm La Postrera.

Es común observar dentro de esta unidad lentes lacustres de algunos centímetros de espesor (50 a $100 \mathrm{~cm}$ término medio) en general de tonalidades verdosas con laminaciones horizontales. En forma puntual ha sido observada una secuencia fluvial descripta en el perfil 35.

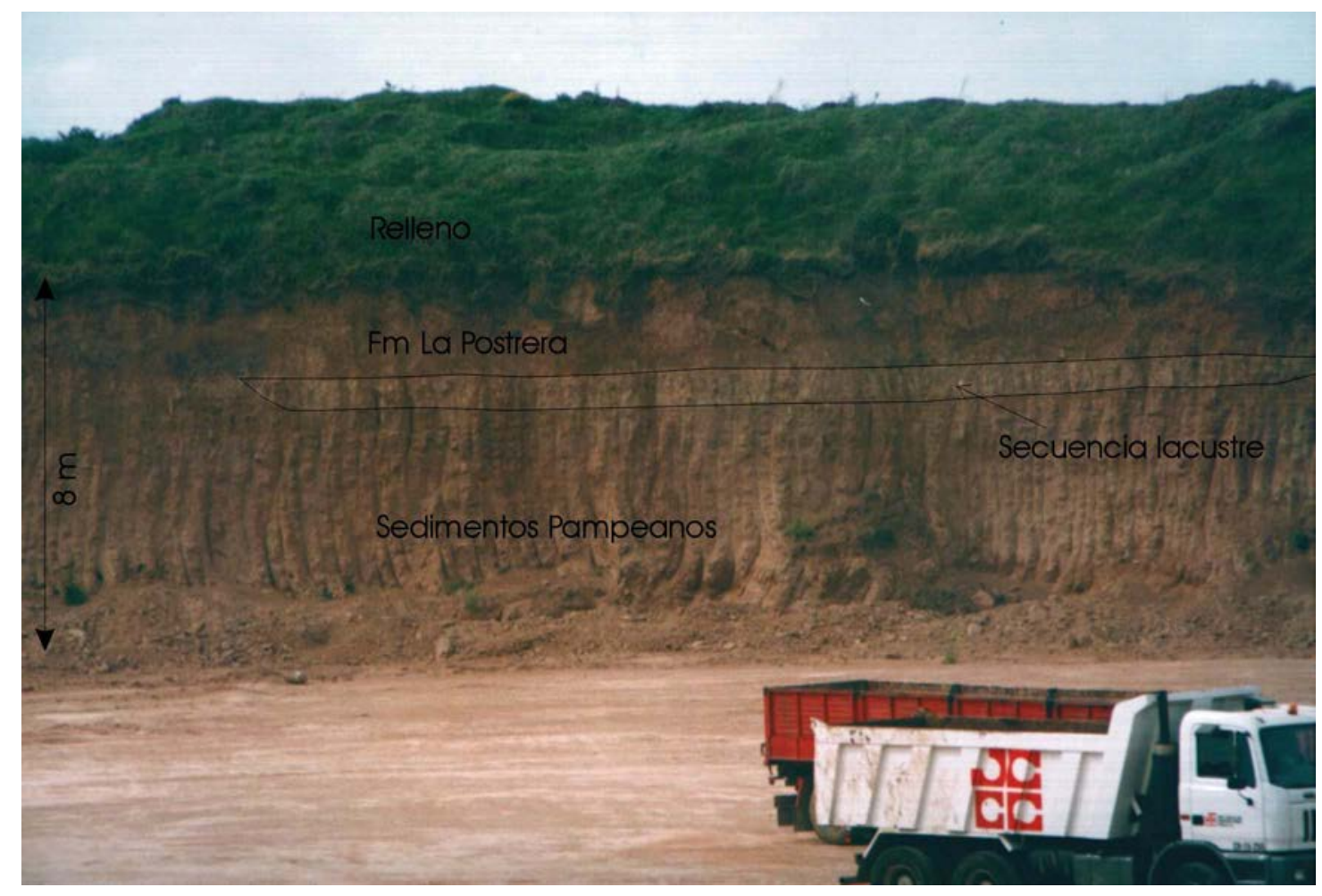

Figura 4.11 Facies lacustres desarrollada sobre la Fm Pampeano.

En la localidad de Pilar, se la ha observado supra e infrayaciendo a estos depósitos sedimentos de una ingresión marina del Pleistoceno tardío correlacionada con el Interglacial sangamon o estadío 5 e. 
La Fm Pampeano a sido reconocida en la zona de estudio en muchas de las canteras activas o abandonadas y en el área de influencia que abarca gran parte de la provincia de Buenos Aires (Nabel et al., 1995; Imbelloni y Cumba, 2003) y Santa Fe (Iriondo, 1987).

La sección inferior se correlaciona con el Ensenadense de Frenguelli (1957), Formación Ensenada (Riggi et al., 1986), Fm Rosario (Iriondo, 1987) y Unidades I-V (Nabel et al.,1995). La sección superior se correlaciona con el Bonaerense de Frenguelli (1957), Formación Buenos Aires (Riggi et al., 1986), Fm Tezanos Pinto (Iriondo, 1980) y Unidades VI-VIII (Nabel et al., 1995).

Edad: En el ámbito bonaerense el conjunto de estos depósitos abarcan desde el Mioceno medio al Pleistoceno superior (Fidalgo et al., 1999). En la Ciudad de La Plata, en sus 28 metros superiores se observan fósiles que permitirían asignarles una edad que va desde el Pleistoceno medio al Pleistoceno tardío (Riggi et al., 1986). Estudios paleomagnéticos llevados a cabo en estos depósitos en las localidades de La Plata, Buenos Aires y Baradero (Re y Orgueira, 1991; Nabel, 1999; Nabel et al., 1995 entre otros) permitieron determinar edades magnéticas Brunhes y Matuyama, observándose este pasaje en el techo de la Fm Ensenada o en la base de la Fm Buenos Aires.

Espesor: El espesor de la Formación Pampeano alcanza comúnmente los $40 \mathrm{~m}$, disminuyendo hacia las barrancas del Río Paraná o hacia los ejes de las cuencas de drenaje.

Distribución: Los sedimentos de esta unidad están distribuidos en gran parte de la región, y en una porción importante del área de estudio. Constituye la mayor parte de los primeros metros de la superficie topográfica, estando cubierta puntualmente por escasos metros de espesor de la Formación La Postrera en divisorias y por espesores más importantes atribuidos a la ingresión holocena y depósitos fluviales. En general constituye las divisorias de aguas y las paredes de valle. 
Contenidos Fosilifero: Cérvidos, megamamíferos, Équidos, Camélidos, roedores y moluscos de agua dulce (veáse Pardiñas et al., 1995).

4.3.2.1.1.1.b FORMACIÓN LA POSTRERA (Fidalgo et al., 1973 b)

Características litológicas: Los sedimentos de esta unidad constituyen los depósitos que caracterizan los divisorias de agua.

La existencia de esta Formación en la Pampa Ondulada fue mencionada y representada por Fidalgo (1983) y Fidalgo y Martínez (1995), y resulta claro que los rasgos de esta unidad, cuando se los puede observar en exposiciones, presentan un aspecto masivo y su condición de estar poco compactados y casi sueltos, salvo en los sectores edafizados.

Presenta un color castaño claro a amarillo rojizo (7,5YR 6/3 a 7,5YR 6/8) en ocasiones con tonos similares a los sedimentos infrayacentes de la $\mathrm{Fm}$ Pampeano (7,5YR 5/3 a 7,5 YR4/6).

Espesor: El espesor en la región puede alcanzar a 1,0 ó 2,0 m en términos generales.

Relaciones. Se la encuentra rematando, en gran parte de la región el perfil geológico dado por la Fm Pampeano. Su continuidad lateral es muy difícil de precisar, debido a la influencia que ejerce el gran desarrollo de los perfiles de suelos y su marcada complejidad, de acuerdo a las detalladas descripciones publicadas por INTA (1996-1997). 


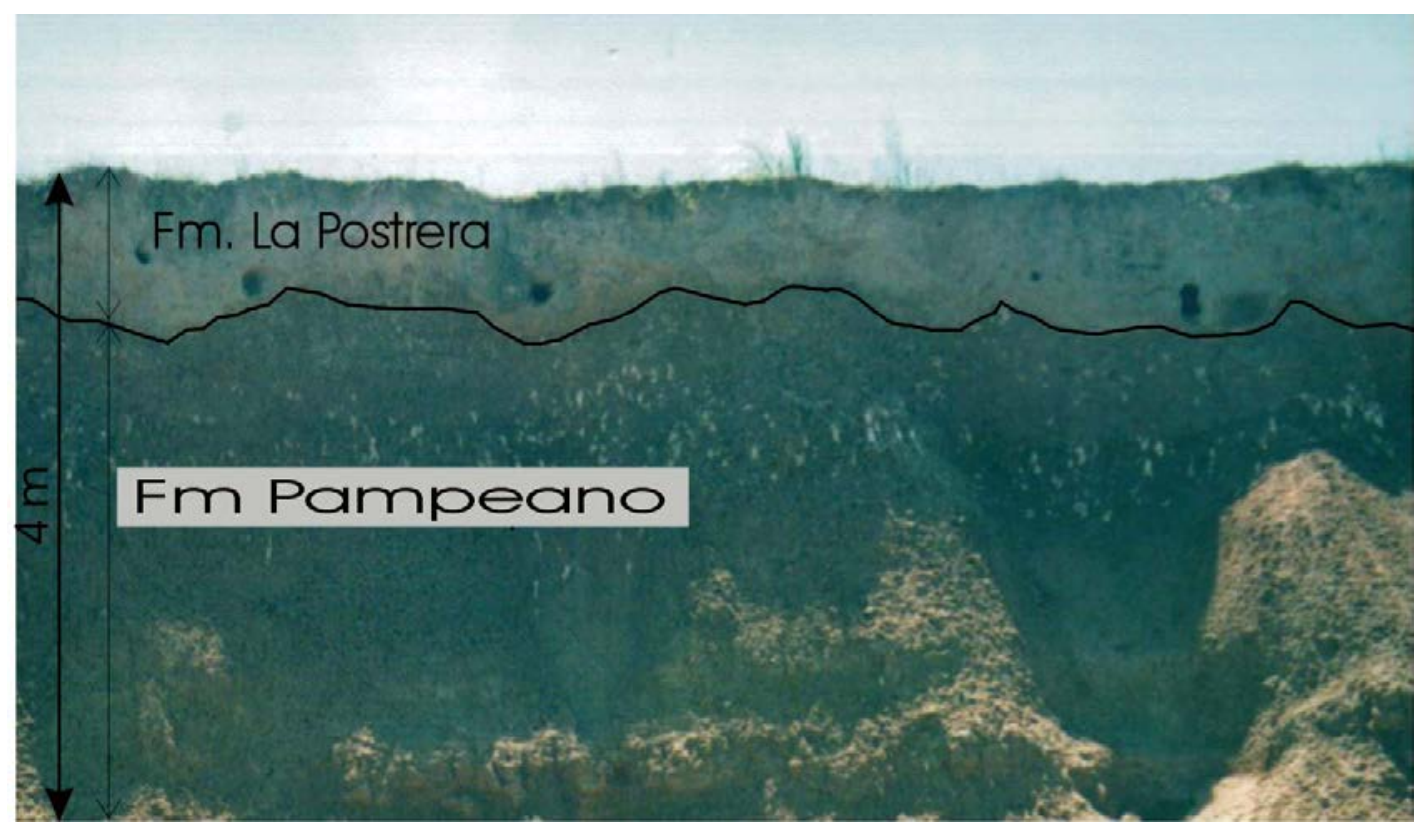

Fig. 4.12 Exposición de la Fm La Postrera suprayaciendo a la Fm Pampeano.

Distribución: Se observa en forma discontinua, fundamentalmente en divisorias. Su observación puede precisarse en cortes de canteras y caminos.

Ambiente Sedimentario: Corresponden a depósitos eólicos, generados aparentemente por diferentes pulsos depositacionales, evidenciados al igual que la Fm Pampeano, por niveles de paleosuelos interpuestos en su depósito (Fidalgo y Martínez, 1995).

Edad: Pleistoceno tardío - Holoceno. Dataciones radiocarbónicas obtenidas en fósiles de este depósito indican un rango de 10.710 t90 (Figini et al., 1989) a 440 „60 (Tonni, 1985). Zárate, et al. (1995) determina una edad de $19.840 \pm 310$ años AP al sur de la provincia de Buenos Aires. Corresponde parcialmente a los estadíos isotópicos ${ }^{18} 01$ y 2 (Shackleton y Opdyhe, 1973).

Correlaciones: Médano Invasor (Tapia, 1937), Platense y Cordobense (Frenguelli, 1957), Fm Junín (De Salvo, 1969), E1 y E3 (Tricart, 1973). 


\subsection{PERFILES REPRESENTANTIVOS}

Estas representaciones han sido obtenidas considerando diferentes situaciones, como espesores importantes, distribución, relaciones y particularidades litológicas entre las más importantes.

\section{OBSERVACION N 102}

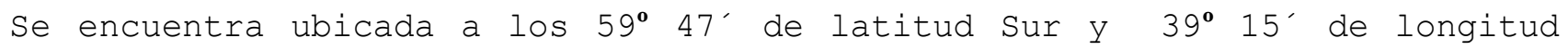
Oeste, en la cantera "Santa Susana" ubicada sobre un camino vecinal a $7 \mathrm{~km}$ al este sudoeste de la localidad de Otamendi, en cota de $15 \mathrm{msnm}$, sobre la margen derecha del Arroyo de la Cruz (fig. 4.8).

La sección presenta una potencia de $7,30 \mathrm{~m}$ representada por dos unidades litoestratigráficas y paleosuelos asociados. En la parte media se localiza una lente hidromórfica mejor expresada en el frente noroeste, con unos 150 $\mathrm{m}$ de extensión lateral y con aproximadamente 0,50 m de espesor con rasgos hidromórficos muy acentuados (fig. 4.11).

UNIDAD A: Correspondiente a horizontes eluviales e iluviales de 0,45 y 0,35 m respectivamente. Color castaño en húmedo (7,5YR 3/2) y textura arcillo limosa. Plástico y adhesivo. Con abundante materia orgánica humificada, localizada en los espacios radiculares en los primeros $\mathrm{cm}$ superficiales. Estructura en bloques subangulares medios que rompen a bloques medios pequeños. Recubrimiento arcillo-húmico y moteados de Fe y Mn. Raíces escasas y finas. Limite gradual y plano.

Entre los 0,80 y 1,20 m se observa un sedimento castaño (7,5YR 3/3), arcillo limoso. Plástico y adhesivo. Bloques subangulares, pequeños, débiles que rompen a bloques subangulares muy pequeños débiles, moteados de Fe y Mn muy escasos, finos y precisos. Recubrimiento de arcilla escaso, discontinuo y fino. Límite neto y plano. (Fm La Postrera) 
UNIDAD B: Entre los 1,20-2,05 m. Se observa un limo arcilloso, castaño en húmedo (10YR 4/3), plástico y adhesivo. Bloques subangulares, pequeños, que rompen a bloques subangulares muy pequeños con escasos moteados de Fe y Mn. Recubrimiento de arcilla continuos, gruesos. Se observan macroscópicamente abundantes clastos gruesos de suelo y/o sedimentos. (Paleosuelo en diamicton de la Formación Pampeano)

Entre los 2,05-2,40 m se observa un sedimento castaño oscuro en húmedo (10YR 3/3), franco limoso, masivo, friable. Concreciones escasas y finas de Fe-Mn. Carbonato de calcio diseminado en la masa y en concreciones. (Formación Pampeano)

UNIDAD C: 2,40-4,00 m. Castaño claro amarillento (10YR 5/4), muy duro. Con calcretas continuas y fuertemente cementadas que podrían denominarse horizontes "K master" (Gile at al., 1966) que hacia la base de este horizonte se presenta mejor expresada.

Por debajo de esta unidad, en el frente sur se observa una lente hidromórfica de aproximadamente $50 \mathrm{~cm}$ de espesor. Gris verdoso claro (hoja 1 para gley 5/5GY) con estructura en bloques angulares pequeños.

4,00-6,00 m. Castaño amarillento oscuro en húmedo (10YR 4/4). Limo arenoso. Masivo. Duro. Áspero al tacto. Muy compactado. Con abundante porosidad. (Formación Pampeano)

6,00-7,30 m. Castaño oscuro (10YR 3/3), arcillo limoso. Plástico y adhesivo. Prismas medios a pequeños fuertes que rompen a bloques angulares pequeños fuertes. Revestimientos de arcilla y sesquióxidos continuos y gruesos. Moteados de hierro y manganeso pequeños. (Paleosuelo en la Formación Pampeano) 


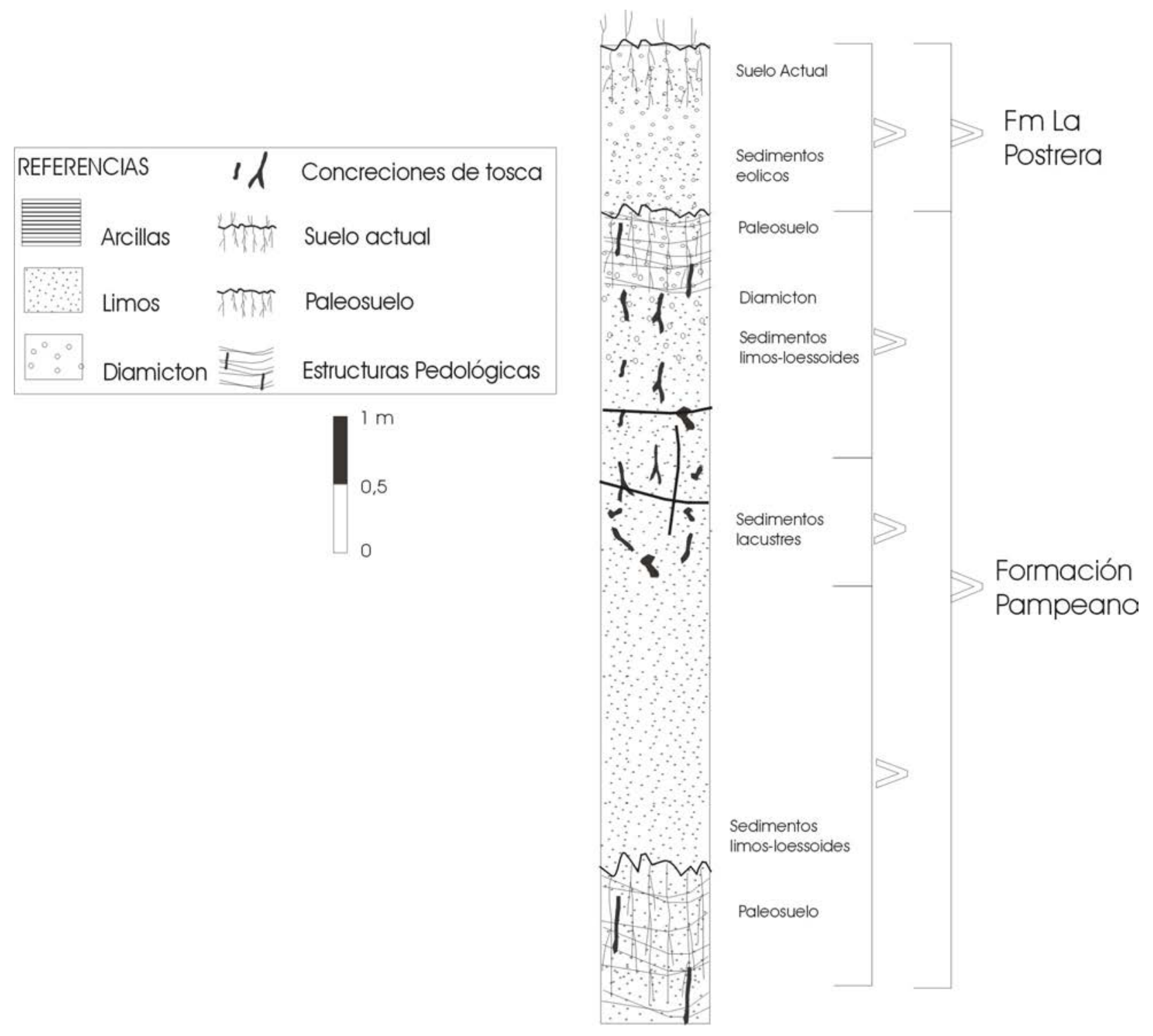

Figura 4.13 Perfil estratigráfico de la cantera "Santa Susana". 


\section{OBSERVACIÓN N 35 c}

Se encuentra en la cantera "Los Sauces" en cercanías de la Ciudad de

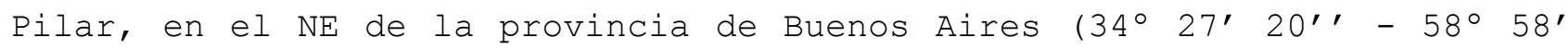
00'l), entre las líneas de los ex ferrocarriles General Urquiza y San Martín, al norte y sur respectivamente, en la finalización de la divisoria que separa el Río Luján del Arroyo Carabasa. Topográficamente se ubica a $9 \mathrm{~m}$ snm. (Fig. 4.8)

Está compuesto por un depósito granodecreciente producto del relleno de un canal de aproximadamente $200 \mathrm{~m}$ de ancho y un espesor máximo de 6,5 m (Fig. 4.14 y 4.15). Este paleocanal se desarrolla dentro de sedimentos lossoides de la Formación Pampeano. De base a techo se observan las siguientes unidades:

UNIDAD A: Desde el piso de la cantera se observan 1,50 m de un sedimento limoso de color castaño oscuro (7,5YR 3/2), muy resistente, con pátinas de color negro, al igual que el tapiz interno de los numerosos canalículos milimétricos. Se observan muñecos de tosca de hasta 0,50 m de largo, equidimensionales y de color negro. (Formación Pampeano). En discordancia de erosión le continúan

UNIDAD B: una secuencia estratificada de 1,5 a $2 \mathrm{~m}$ de espesor, compuesta por estratos de $0,30 \mathrm{~m}$ de espesor medio (fig. 4.15, foto A), fundamentalmente psefíticos en la base a arenosos gruesos en el resto del perfil, con láminas de fango de escasos $\mathrm{cm}$ de espesor e internamente con laminación paralela. Los estratos de rodados ubicados en la base, matriz sostén, presentan clastos bien redondeados, compuestos por $\mathrm{CO}_{3} \mathrm{Ca}$ (tosca), arena parcialmente endurecida de color castaño muy pálido (10YR 7/3) con abundantes pesados y limos (Formación Pampeano), de 0,05 a 0,06 m de diámetro. De esta secuencia se extrajo una fauna significativa, compuesta por peces de agua dulce (Pimelodidae indet, Leporinus sp, Serrasalminae indet) tortugas de agua dulce y mamíferos terrestres, peces de agua salobre (Pogonias cromis) y marinos (Carcharias taurus y Myliobatis sp.). Si bien los clastos presentan un buen redondeamiento, la escasa 
resistencia mecánica de gran parte de ellos indicaría un escaso transporte.

Lateralmente, a unos $100 \mathrm{~m}$ hacia el este, esta sucesión estratificada en discordancia sobre la Formación Pampeano, comienza con un estrato de 0,50 m de espesor, fundamentalmente arenoso, caótico, con una alta concentración de conchillas, muy fragmentadas. Continúa en contacto neto con un estrato de $0,35 \mathrm{~m}$ de espesor netamente orgánico, compuesto por conchillas de Diplodum, en su gran mayoría enteras y articuladas (fig. 4.15, foto 1 B). También se observan restos de Ostrea sp. La edad ${ }^{14} \mathrm{C}$ obtenida en Diplodum es mayor a 40.000 AP (LP-1345).

Esta secuencia con estratificación entrecruzada presenta variaciones en sentido lateral, observándose principalmente estratificación tabular y en artesa subordinada (fig. 4.15, foto 1 C).

UNIDAD C: Por encima se observan $5 \mathrm{~m}$ de una arena limosa a limosa, amarillenta castaño (10YR 6/6), groseramente masiva, aunque se observan superficies de canal y escasas laminaciones de 2 a $3 \mathrm{~cm}$ distribuidas en su masa (fig. 4.15, foto 1 D). (Depósitos de canal)

UNIDAD D: Culmina el perfil con un depósito castaño a castaño grisáceo (10YR 5/2), resistente, con escasas concreciones de tosca equidimensionales y alargadas de 1 a 2 m de eje mayor, como así $\mathrm{CO}_{3} \mathrm{Ca}$ en forma diseminado. (Formación Pampeano)

El tipo y estructura de la secuencia fluvial indicaría divagación lateral progresiva del cauce, asociadas a la migración de ondas de arena bajo condiciones de muy bajo régimen de flujo y la existencia de superficies de canal sin estratificación interna, indicaría la colmatación súbita del paleocauce (Spalletti, 1980). 


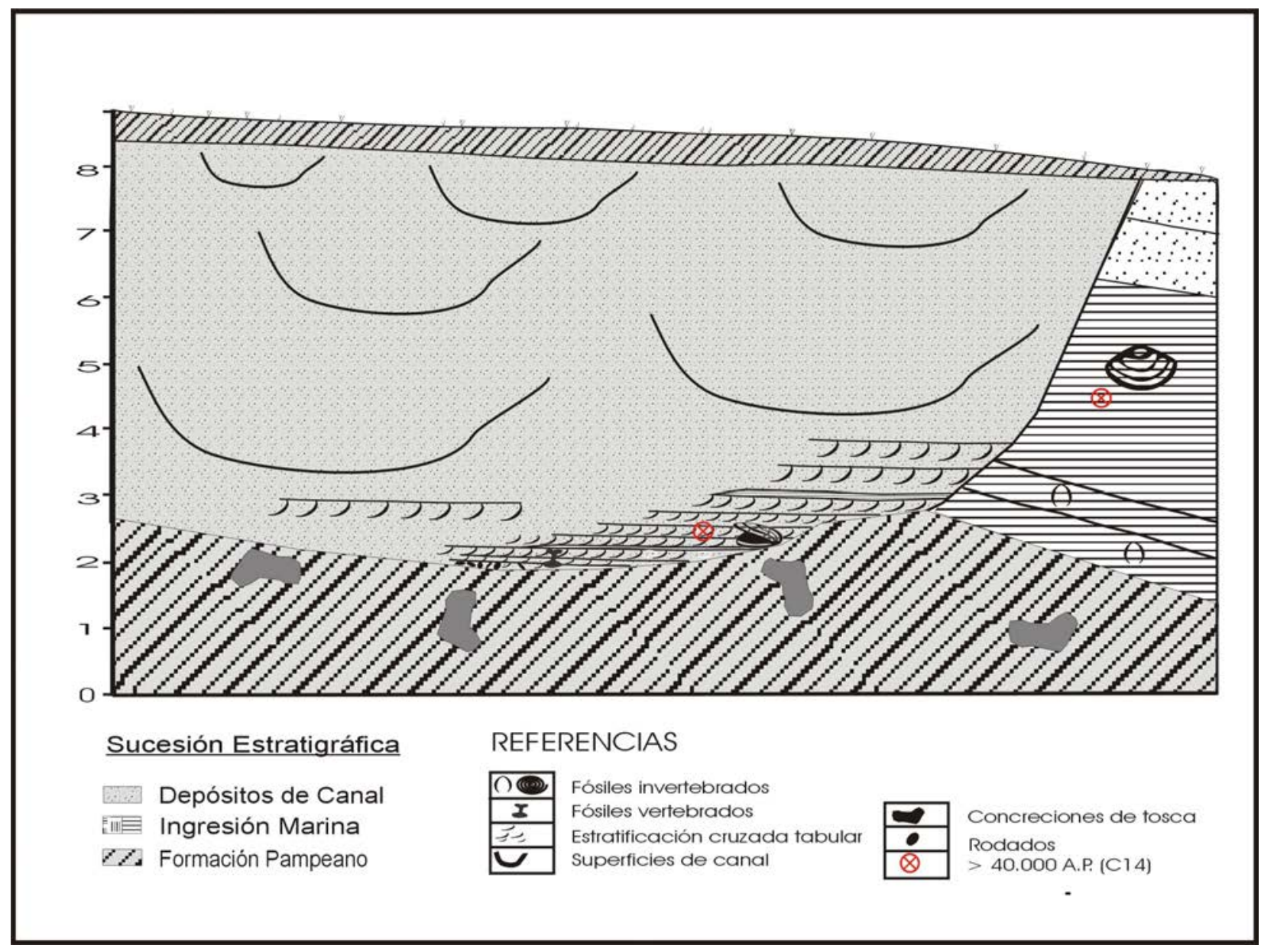

Figura 4.14 Perfil so de la cantera Los Sauces 
Fig. 4.15 Fotografías de la observación 35c indicando las diferentes facies 


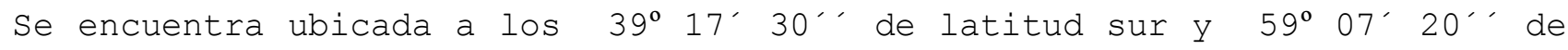
longitud oeste, en una cantera $2 \mathrm{~km}$ al este sudeste de la localidad de Capilla del Señor, a cota de $17,5 \mathrm{~m}$ snm sobre la pared de valle de la margen izquierda del Arroyo de la Cruz (Fig. 4.8).

UNIDAD A: De base a techo se observan 1,9 metros de un sedimento castaño oscuro (10YR 3/3), muy resistente, con concreciones de tosca equidimensionales en la base y hacia el techo en forma transicional se observan láminas horizontales e inclinadas compuestas por tosca de color gris claro y superficies de igual sentido de un sedimento limoso de color gris oscuro. (Formación Pampeano y paleosuelo)

UNIDAD B: Hacia arriba y lateralmente, en forma discordante se observa un sedimento gris verdoso oscuro (hoja 1 gley 4/10y) de 1,4 m de espesor, muy estructurado hacia el techo con concreciones de tosca en forma de enrejado. Se separan en pequeños bloques y gránulos, con la presencia de pátinas de color negro (hoja 1 gley 2,5/N) en sus superficies. (Facies lagunares $y$ paleosuelo)

UNIDAD C: En contacto neto le continúan $0,80 \mathrm{~m}$ de un sedimento castaño oscuro (7,5YR 3/2 a 7,5YR 3/4), homogéneo con concreciones de tosca en posición vertical, rematando con 0,70 m del mismo sedimento pero con tosca con forma de enrejado fino. (Formación Pampeano y paleosuelo)

UNIDAD D: En transición se observa un sedimento castaño (10YR 6/4) limoso, de 2,0 m de espesor, homogéneo y friable, que rápidamente se estructura en bloques subangulares medios. (Fm La Postrera) 

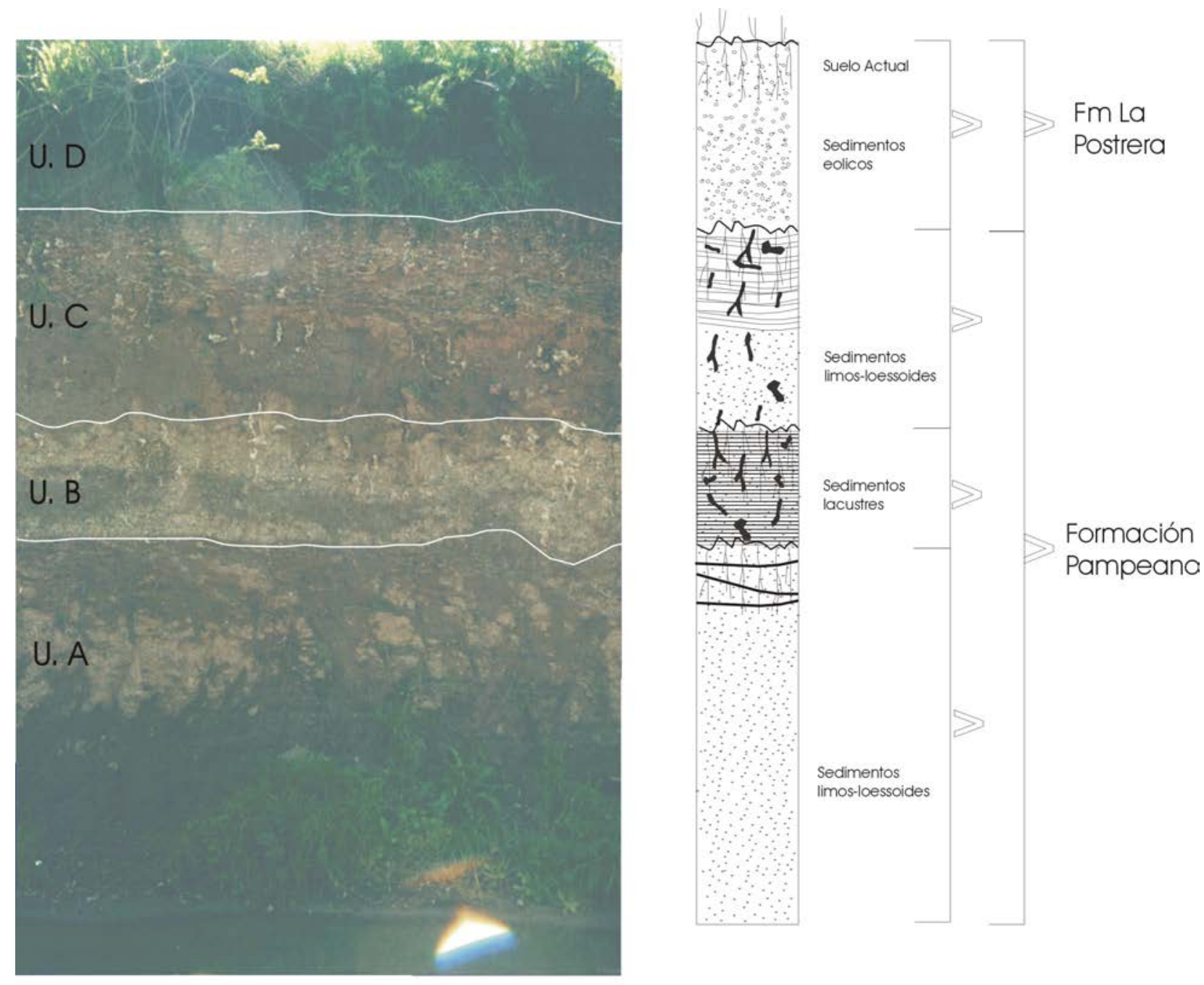

\begin{tabular}{|lll|}
\hline REFERENCIAS I Concreciones de tosca \\
Limos Arcillas thith Suelo actual \\
Arenas
\end{tabular}

Figura 4.16 Fotografía y perfil estratigráfico de sucesiones continentales compuesta por la Fm Pampeano y Fm La Postrera con niveles edafológicos y lacustres. 


\section{OBSERVACION No 114}

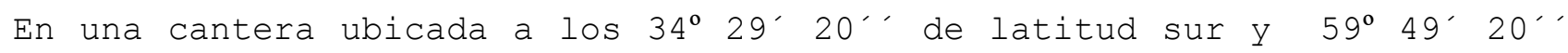
de longitud oeste, en la ex Ea. San Miguel, al suroeste de la ciudad de Pilar, en la divisoria entre el Río Luján y el arroyo Carabassa. La cota aproximada es del orden de los 20 metros (Fig. 4.8).

UNIDAD A: De base a techo se observa $0,50 \mathrm{~m}$ de un sedimento castaño rojizo (5YR 4/3), homogéneo y compacto. (Formación Pampeano)

UNIDAD B: Le continúan en contacto neto $2,70 \mathrm{~m}$ de un sedimento castaño grisáceo oscuro (1OYR 4/2), con gran entoscamiento en forma de venas en la parte inferior y media y en enrejado fino hacia el techo. Es muy compacto y de textura limosa. (Formación Pampeano con paleosuelo)

UNIDAD C: En discordancia se observan 1,80 metros de un sedimento limoso, de color castaño amarillento (10YR 5/6), friable, escasamente estructurado en la base con bloques grandes de 0,06 m de largo, que hacia el techo aumenta notablemente la estructuración con un diseño de tamaño menor, pasando a tonos más oscuros. (Fm La Postrera) 

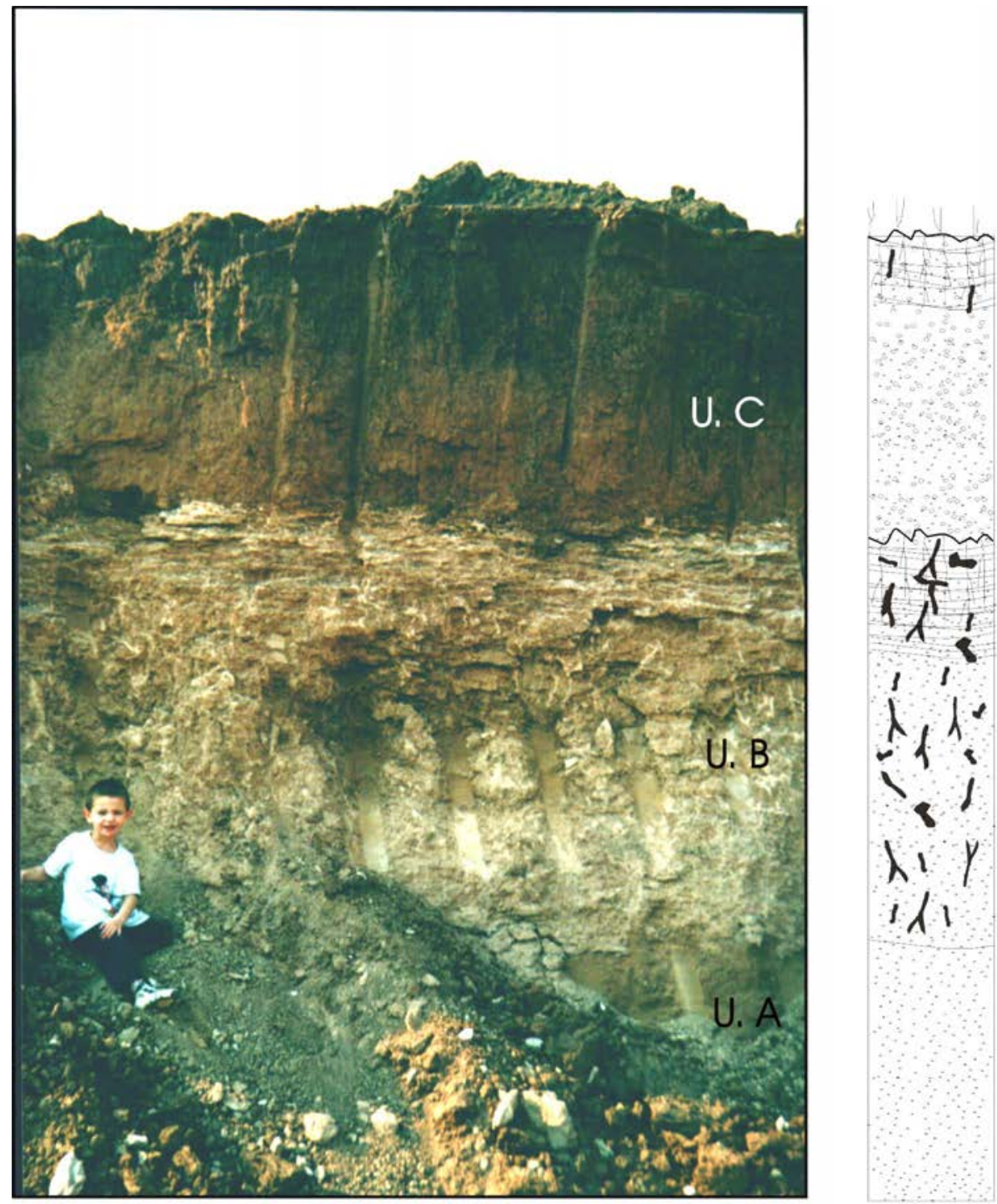

Fm La

Postrera

Formación

Pampeano

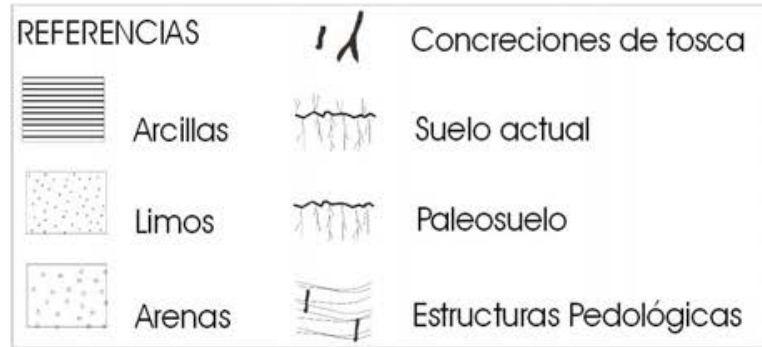

Figura 4.17 Fotografía y perfil estratigráfico de la observación 114 
4.3.2.1.2 SUCESIONES FLUVIALES: La observación de secuencias completas generados por procesos fluviales (fundamentalmente Fm Luján) no pudo ser identificada en el área, ya que la escasa antigüedad de la mayoría de los cursos del área, el nivel de las aguas en estos, la accesibilidad y el estado de los afloramientos, han limitado su observación, a diferencia con lo que ocurre en la misma cuenca, en la localidad de Luján, donde el desarrollo de estos depósitos es más importante. (cf. Ameghino, 1889; Dangaus y Blasi, 1995)

\subsection{UNIDADES LITOESTRATIGRÁFICAS RECONOCIDAS}

\subsection{1.a FORMACION LUJÁN (Fidalgo et al., 1973 b)}

Asociada genéticamente con los valles más importantes del sector, se presenta una secuencia sedimentaria apoyada discordantemente sobre el sustrato de la Formación Pampeano.

De acuerdo a las diferencias litológicas se han podido identificar tres miembros:

\subsection{1.a.a MIEMBRO LA CHUMBIADA (Dillon y Rabassa, 1985)}

Características litológicas: Está constituida por arenas a arenas limosas, color castaño amarillento (10YR 5/4) a castaño amarillento claro (10YR 6/4), homogéneas, en sectores con estratificación entrecruzada y laminación paralela.

Relaciones: En discordancia sobre la Formación Pampeano e infrayaciendo al Mb Guerrero. Se la observa en los cursos principales en la base de las barrancas con los niveles bajos de agua.

Espesor: Del orden de los 0,30 a $0,40 \mathrm{~m}$. 
Distribución: Esta unidad se observa limitada a los cursos principales como el Arroyo de la Cruz y el Río Luján. En el Río Luján se la puede observar en la localidad de Manzanares, aguas arriba y en el Arroyo de la cruz en un sector muy restringido aguas arriba de la ruta 8.

Contenido Fosilifero: Fósiles de agua dulce y terrestres. (Ver Ameghino, 1889)

Ambiente Sedimentario: Origen fluvial con facies de canal. (Dangaus y Blasi, 1995)

Edad: Dataciones radiocarbónicas realizadas en el A. Tapalqué arrojaron edades entre $26.930 \pm 860$ y 28.100 \pm 800 (Figini, 1995) y $28.900 \pm 800$ (Carbonari, et al., 1992), correspondiendo al Pleistoceno tardío. Estas edades permiten asignarles una correspondencia con la primera etapa del estadío isotópico ${ }^{18} \mathrm{O} 3$ ((Shackleton y Opdyhe, 1973).

Correlaciones: Con la parte basal del piso Lujanense (Ameghino, 1889); (Frenguelli, 1957) y sección inferior del Miembro Guerrero de la Fm Luján (Fidalgo et al., 1973 b)

\subsection{1.a.b MIEMBRO GUERRERO (Fidalgo et al., 1973 b)}

Esta unidad fue definida en el sector inferior de la cuenca del Río Salado. Esta constituida por un paquete sedimentario de origen fluvial, compuesto esencialmente por arenas limosas castañas en la base y limos areno arcillosos de color verde en su parte superior. Posteriormente Dillon y Rabassa, (1985) separan de este miembro el tramo inferior dándole identidad propia y a lo que denominan Mb La Chumbiada quedando integrada la Fm Luján por este miembro, el Mb Guerrero y el Mb Río Salado. Dangavs y Blasi, (2003; nom subs. Dangavs y Blasi, 1992) atribuyen a sedimentos esencialmente fangosos y colores "amarillo pálido, gris claro y oliva pálido a gris oliva" al Mb Lobos homologándolos con la parte cuspidal del Mb Guerrero. 
Si bien esta unidad actualmente no corresponde con su definición original, el uso tan extendido de su denominación nos lleva a conservarlo.

Características litológicas: Limos arenosos a arcillosos de color castaño grisáceo (2,5YR 5/2), homogéneos, en sectores con estratificación entrecruzada o laminación.

Relaciones laterales y vertical: Se desarrolla sobre el Mb La Chumbiada o sobre la Fm Pampeano, infrayaciendo al Mb Río Salado y acotada prácticamente a los cursos de agua. En la cuenca del Río Salado se la observa como depósito de cubetas a lo largo del curso principal (Dangavs et al., 2003)

Espesor: Del orden de 1 metro.

Distribución: Se la ha observado en el Río Luján en las inmediaciones de Pilar aguas arriba y ha sido ampliamente descripto en la Ciudad de Luján (Ameghino, 1889; Dangavs y Blasi, 1995).

Ambiente Sedimentario: Fluvial con facies de desborde (Dangavs y Blasi, $1995)$

Edad: Se han obtenido edades radiocarbónicas de esta unidad dentro del rango de 19.320 a 21.760 14C A.P. (Figini et al., 1995). Cerca de la ciudad de Olavarría se determinaron edades entre los 17.680 y 18.600, ambos con \pm 400 (Carbonari, et al., 1992). Tonni et al. (1999) y bibliografía citada informan de edades hasta los $13.070 \pm 120$ realizada sobre colágeno. Correspondería a gran parte del estadío isotópico ${ }^{18} 02$ (Shackleton y Opdyhe, 1973).

Correlaciones: Con el Lujanense (Ameghino, 1889; Frenguelli, 1957), parte superior del Mb. Guerrero (Fidalgo et al., 1973) y Mb Lobos (Dangavs y Blasi, 2003) 


\subsection{1.a.c MIEMBRO RIO SALADO (Fidalgo et al., 1973 b)}

Características litológicas: Sedimentos fangosos a fango arenosos, macizos, de color gris claro (10,5YR 7/2) a gris (10,5YR 5/1), con espesores medios de $1 \mathrm{~m}$.

Relaciones laterales y verticales: Se la observa ya sea en discordancia o transicionalmente sobre el Miembro Guerrero o sobre el suelo desarrollado en este, sobre la Formación Pampeano, y sobre el Mb Santa Brígida de la Fm campana.

Distribución: Se la observa desarrollada sobre los cursos de agua principales, que en nuestro caso corresponde al río Luján en las inmediaciones de la localidad de Pilar y en el arroyo de la Cruz en las cercanías de Capilla del Señor. En sentido transversal a los cursos, ocupa prácticamente las barrancas de éstos ya que desaparece a escasos metros de ésta.

Contenidos fosilífero: Gasterópodos (Littoridina parchappii y Biomphalaria peregrina) Ostracodos, Diatomeas, espículas y carófitas (Prieto et al., 1998)

Ambiente Sedimentario: La sedimentación de esta unidad y su contenido paleontológico sugiere un ambiente de escasa energía, probablemente lagunar. Utilizando edades ${ }^{14} \mathrm{C}$ puede observarse como a partir de los 10.000 A.P. evoluciona a un ambiente palustre, con exposición subaérea y desarrollo de suelo hacia los 3.560 A.P. aproximadamente (Prieto et al., 1998)

Edad: De acuerdo a determinaciones efectuadas aguas arriba de la zona de estudio en el Río Luján entre las ciudades de Luján y Mercedes (Prieto et al., 1998) se observan edades de $10.870 \pm 90,10.780 \pm 60,10.120 \pm 50$, $10.330 \pm 50$ y $3.560 \pm 60$ de base a techo 
En el A. Tapalqué se han obtenido edades para la parte inferior de esta unidad dentro del rango 7.830 a 10.280 A.P. (Figini et al., 1995). Tonni, et al., (1999) y bibliografía citada precisan un rango de $10.270 \pm 70$ a $3.395 \pm 107$ años A.P. para esta unidad. Estas edades permiten asignarles una correspondencia con el estadío isotópico ${ }^{18} \mathrm{O} 1$ (Shackleton y Opdyhe, 1973) .

Correlaciones: Con el Platense fluvial de Doering, (1882); Ameghino (1889) y Frenguelli (1957).

\subsection{1.b ALUVIO ACTUAL (Fidalgo et al., 1973 a y b)}

Características litológicas: Estos sedimentos presentan diferentes características de acuerdo a la geoforma que ocupan. En los albardones, están constituidos por limos a limos arcillo arenosos, de color gris (10YR5/1) a castaño grisáceo (10YR 5/2) a gris muy oscuro (10YR 3/1), de consistencia dura en seco y homogénea. En las planicies de inundación y sectores inundables, están constituidos por arcillas plásticas y adhesivas, de color gris verdoso (hoja 1 gley 6/1), a gris verdoso oscuro (hoja 1 gley 4/1), presentándose parcial o totalmente edafizados con rasgos hidromórficos.

Relaciones: Se halla desarrollada en sectores de escurrimiento fluvial, sobre cualquier unidad de cualquier origen (eólica, fluvial, litoral y suelos) ya sea en discordancia o transicionalmente.

Espesor: Presentan sus mayores espesores en las inmediaciones de los cursos principales, constituyendo los albardones. Un espesor excepcional se observa en el Río Luján aguas arriba de la ruta $\mathrm{N}^{\circ}$ 9, donde alcanza los 3,5 metros debido a situaciones locales expuestas en el capítulo VII. (Fig. 5.20).

En las planicies de inundación suelen presentar espesores generales de $0,40-0,60 \mathrm{~m}$. 
En otras localidades se lo observa suprayaciendo a La Postrera III con espesores mayores a 1,30 m y depositados en el presente (Dangavs y Blasi, 2003). En la región de Tandil se observan espesores de 1,2 m con elementos postconquista española (Gentile, 1995). En la Bahía de Samborombón se observan espesores máximos de 1,50 m (Fidalgo et al., 1973 a) .

Distribución: En prácticamente todas las líneas de drenaje y sectores deprimidos del paisaje se observan sedimentos fluviales y palustres asignados al Aluvio actual. Cuando no existe el Geosuelo Puesto Berrondo desarrollado en el Mb Río Salado se hace muy difícil separar ambos depósitos fluviales.

Contenidos Fosilifero: Como fósil mas importante se encuentra Littoridina sp., Planorbis y fauna posconquista española (Ovis Aries y Bos taurus) y elementos antrópicos (restos de ladrillos, alambres y plásticos entre los más comunes).

Ambiente Sedimentario: Secuencias de desbordes (Albardones), de planicies de inundación y lacustres en cuencas cerradas.

Edad: De acuerdo a los elementos encontrados en la zona se le asigna una edad posterior a la conquista española, lo que no implica que existan depósitos de mayor antigüedad. Al sur de Sierras Australes los sedimentos fluviales mas modernos han sido agrupados en la Fm Chacra La Blanqueada atribuidos al Pleistoceno - Reciente (Rabassa, 1985). Asimismo Zavala y Quattrocchio (2001) observaron en depósitos atribuidos a esta unidad formas de fauna introducida y material arqueológico post-contacto. Borromei (1995) obtuvo edades ${ }^{14} \mathrm{C}$ con valores anteriores a este contacto cultural.

Correlaciones: Piso Aimarano, Doering, (1884), piso Aimará, (Ameghino, 1889); Aimarense, (Frenguelli, 1957), Fm Chacra La Blanqueada (Rabassa, 1985); Fm Aluvio (Dangavs y Blasi, 2003). 
Si bien las observaciones de estas unidades han sido escasas, la ubicación en las diferentes sucesiones estratigráficas permiten correlacionarlas con precisión con el conjunto de descripciones del ámbito pampeano.

\subsection{2.a GEOSUELO PUESTO CALLEJÓN VIEJO}

Este geosuelo se encuentra desarrollado en el área de estudio en sedimentos del Mb Guerrero de la Fm Luján. Esta representado por un sedimento arcillo limoso, muy estructurado en bloques de $2 \mathrm{~cm}$ de alto por $0,5 \mathrm{~cm}$ de diámetro con tonalidades mas oscuras ( 7,5YR 3/1) que la unidad en que se desarrolla y mas plástico, con abundante presencia de cútanes.

Fidalgo (1992) propone utilizar este geosueolo como límite Pleistoceno -Holoceno. En el Río Quequén Grande ha sido datado un suelo correlacionado con el Geosuelo Puesto Callejón Viejo en $9.000 \pm 70$ años radiocarbónicos A.P. (Zárate et al., 1995).

\subsection{2.b GEOSUELO PUESTO BERRONDO}

Este geosuelo se lo ha observado en el área de estudio en sedimentos del Mb Río Salado de la Fm Luján. Esta constituido por sedimentos arcillo limosos, gris oscuro $(7,5 \mathrm{YR} 4 / 1)$ muy estructurados en bloques pequeños de gran consistencia.

En la localidad de Luján sobre las barrancas del mismo río se ha datado un paleosuelo en esta posición estratigráfica asignándole edades ${ }^{14} \mathrm{C}$ en un rango de $3500-2900$ A.P. (Prieto et al., 2000).

En la zona terminal de la cuenca del Río Salado se desarrolla a partir de los sedimentos litorales de la Fm Las Escobas, siendo sepultado por el Aluvio reciente o la Fm La Postrera (Fidalgo et al., 1973 a y b).

\subsection{PERFILES REPRESENTANTIVOS}




\section{OBSERVACION N 2}

Este perfil se observa en un afloramiento de $10 \mathrm{~m}$ de largo sobre la margen izquierda del Arroyo de la Cruz a unos 100 metros aguas arriba de la ruta 8. Se ubica en la hoja Open Door a una cota aproximada a los 19 metros. El ambiente geomórfico corresponde a la Pampa Ondulada y particularmente en la barranca del mencionado curso (Fig. 4.8).

Se observa una secuencia esencialmente fluvial, con un espesor de 1,20 m compuesta por dos unidades litoestratigráficas, que de base a techo son las siguientes.

UNIDAD A: Desde el pelo de agua se observan $20 \mathrm{~cm}$ de un sedimento arcillo limoso, de color castaño (7,5YR 4/4) a castaño oscuro (7,5YR 3/2), finamente laminado. (Mb La Chumbiada, Fm Luján)

UNIDAD B: Por encima, en discordancia de erosión le continúan $70 \mathrm{~cm}$ de un sedimento arcilloso a arcillo limoso de color castaño grisáceo (10YR 5/2), con abundantes concreciones de tosca, fundamentalmente en la base de 0,1 a 0,5 cm. También se observan rodados de la $\mathrm{Fm}$ Pampeano. En esta unidad fueron observados restos Ovis arie. (Aluvio)

Por encima en forma transicional se pasa a un sedimento de $30 \mathrm{~cm}$ de espesor con una tenue estructuración en bloques y es cubierto por un sedimento limoso, grisáceo (10YR 6/1) y homogéneo. (Suelo enterrado y Aluvio parcialmente edafizado) 

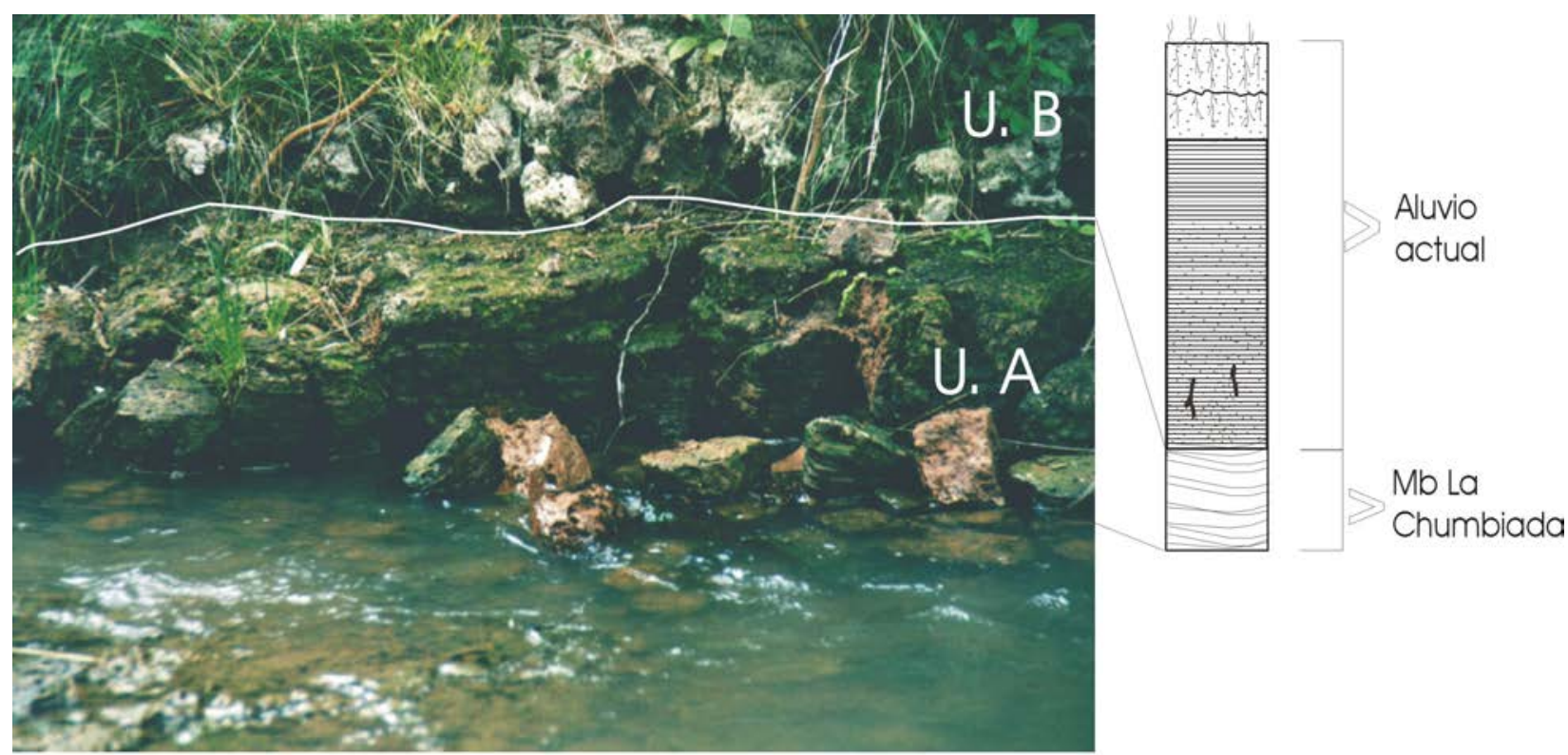

Figura 4.18 Fotografía y perfil estratigráfico de la observación 2

\section{OBSERVACION $N^{o} 1$}

Se desarrolla en la barranca de la margen izquierda del Arroyo de la Cruz 400 m agua arriba de la localidad de Capilla del señor. Se sitúa a una cota de 12,5 m. Sobre un sustrato conformado por la Fm Pampeano se desarrolla una secuencia eminentemente fluvial con un espesor total de 2,4 metros (Fig. 4.8).

UNIDAD A: En la base con un espesor de $1,3 \mathrm{~m}$ se observa un sedimento castaño (10YR 4/3) que en su parte expuesta se presenta relativamente friable, pero que a medida que se limpia la superficie se torna resistente. Presenta gran cantidad de concreciones de $\mathrm{CO}_{3} \mathrm{Ca}$ de formas alargadas en el sentido vertical y equidimensionales de hasta 0,03 $\mathrm{m}$ de diámetro. 
En sus 0,30 m superiores se presenta estructurado en bloques de $2 \mathrm{~cm}$ de alto por $0,05 \mathrm{~m}$ de diámetro de color gris muy oscuro (7,5YR 3/1) y plástico, con abundante presencia de cutanes. (Formación Pampeano $\boldsymbol{y}$ Geosuelo Puesto Callejón Viejo)

UNIDAD B: En contacto neto se observa un sedimento gris claro (10YR 7/1) de $0,37 \mathrm{~m}$ de espesor, homogéneo, con presencia de concreciones de tosca fácilmente delezneable de 0,05 m de diámetro, equidimensional, con una gran cantidad de orificios milimétricos.

Hacia arriba se va paulatinamente oscureciendo y estructurando en bloques, pero de una consistencia muy dura de unos 0,17 m de espesor. (Mb Río Salado y Geosuelo Puesto Berrondo)

UNIDAD C: Transicionalmente se pasa a un sedimento castaño grisáceo de 0,70 m de espesor, homogéneo, muy duro, limo arenoso, donde actualmente se desarrolla el suelo actual. (Aluvio parcialmente edafizado) 

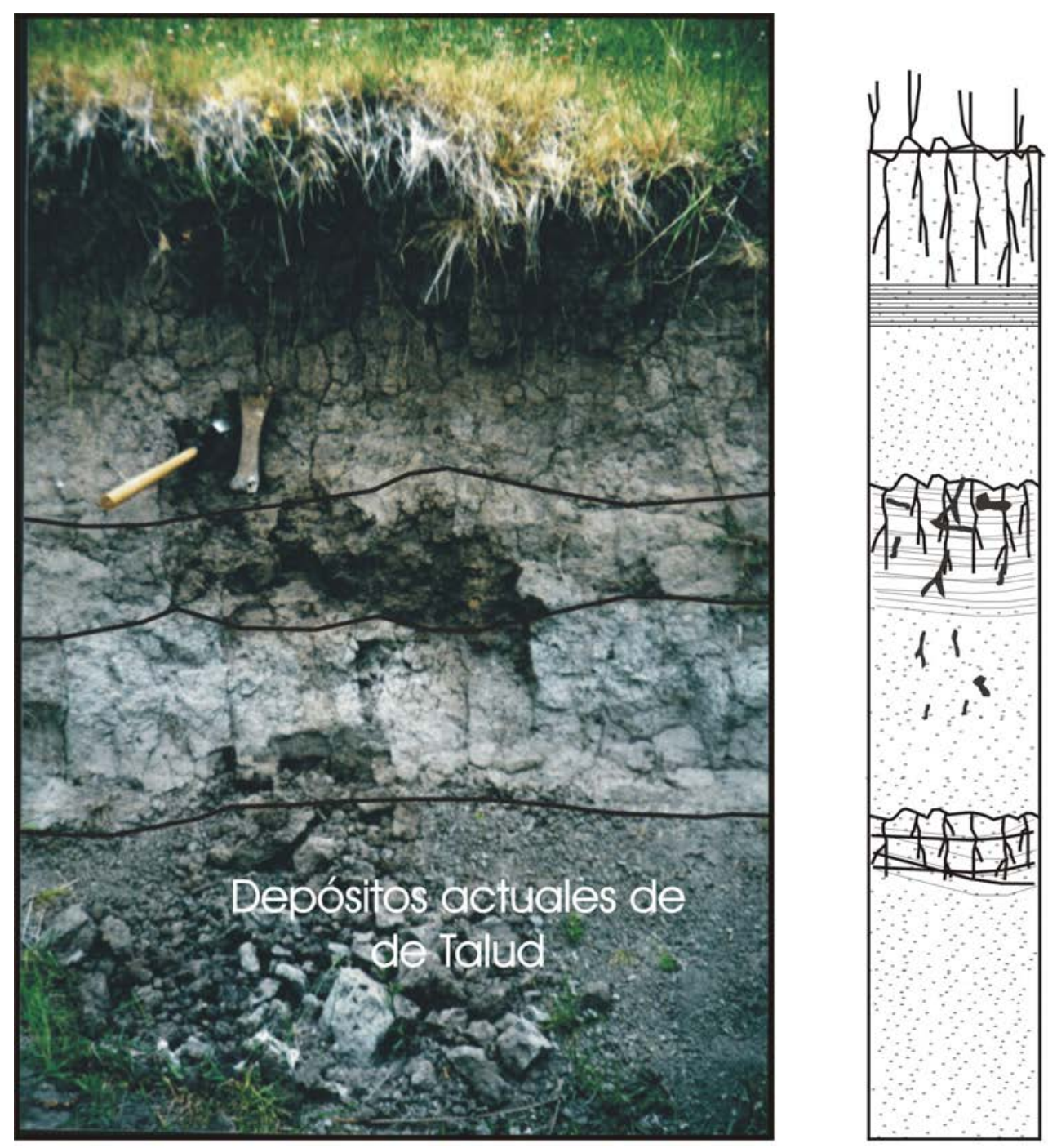

Suelo actual

Aluvio Actual

Geosuelo Puesto Berrondo

Mb Río

Salado

Geosuelo Puesto Callejón Viejo

Formación Pampeano

\begin{tabular}{|c|c|c|c|}
\hline \multicolumn{4}{|c|}{ REFERENCIAS } \\
\hline 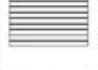 & Arcillas & $1 \lambda$ & Concreciones de tosca \\
\hline & Limos & 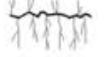 & Suelo actual \\
\hline & Arenas & तMTतX & Paleosuelo \\
\hline
\end{tabular}

Figura 4.19 Fotografía y perfil de la observación 1. 


\section{OBSERVACION $N^{\circ} 20$}

Sobre la margen izquierda de la barranca del Río Luján, cerca del límite sur de la hoja y el curso. Se observa en los bordes del cauce la existencia de dos barrancas de $1,5 \mathrm{~m}$ cada una separadas por unos $4 \mathrm{~m}$ en sentido horizontal, observándose en la barranca inferior desde el pelo de agua (Fig. 4.8).

UNIDAD A: Con un espesor aproximado de unos 0,20 $\mathrm{m}$ se observa un sedimento castaño oscuro (7,5YR 3/3), saturado de agua, resistente y homogéneo. (Formación Pampeano)
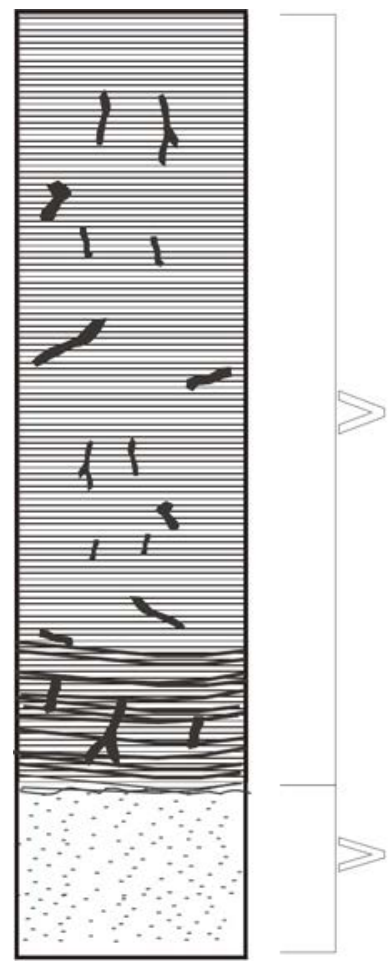

$\mathrm{Mb}$ Guerrero

$1,5 \mathrm{~m}$

Formación

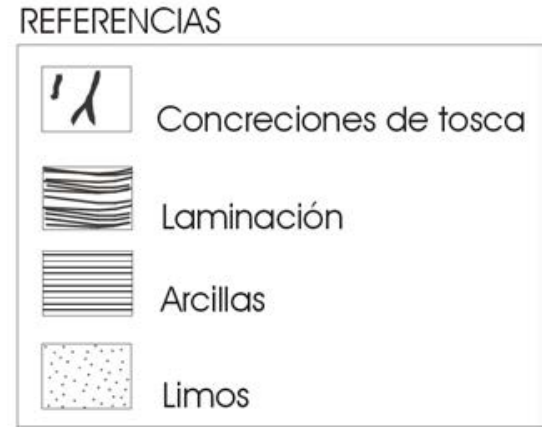

Figura 4.20 Perfil de la observación 20

UNIDAD B: En contacto neto le continúan $1,50 \mathrm{~m}$ de un sedimento de color verde amarillento, arcilloso, plástico y adhesivo. El sector basal se encuentra finamente laminado. Presentan manchas rojo amarillentas y 
concreciones de carbanato de calcio, alargadas, verticales y de aspecto radiciforme. (Mb Guerrero, Fm Luján)

\section{OBSERVACION N $N^{o} 52$}

Sobre la margen derecha del Río Luján, antes de la confluencia del Arroyo Carabasa, en el borde externo de un meandro se observa un perfil de unos 4 $\mathrm{m}$ de altura a una cota de 7,5 m aproximadamente (Fig. 4.8).

UNIDAD A: Desde el pelo de agua y con un espesor de 0,50 $\mathrm{m}$ se observa un sedimento limo arcilloso, homogéneo, castaño oscuro (7,5YR 3/2) la parte inferior húmeda a castaño grisáceo (7,5YR 5/2) de tonos claros en la parte superior más seca, con concreciones de tosca de forma irregular de hasta 0,05 m. (Mb Guerrero, Fm Luján)

UNIDAD B: Se Observan 3,50 m de un sedimento castaño grisáceo (7,5YR 5/2) a grisáceo (7,5YR 6/1), en sectores verdosos (hoja 1 gley 6/5GY), limoso a arenoso fino, con elementos antrópicos en su interior. (Aluvio Actual) 


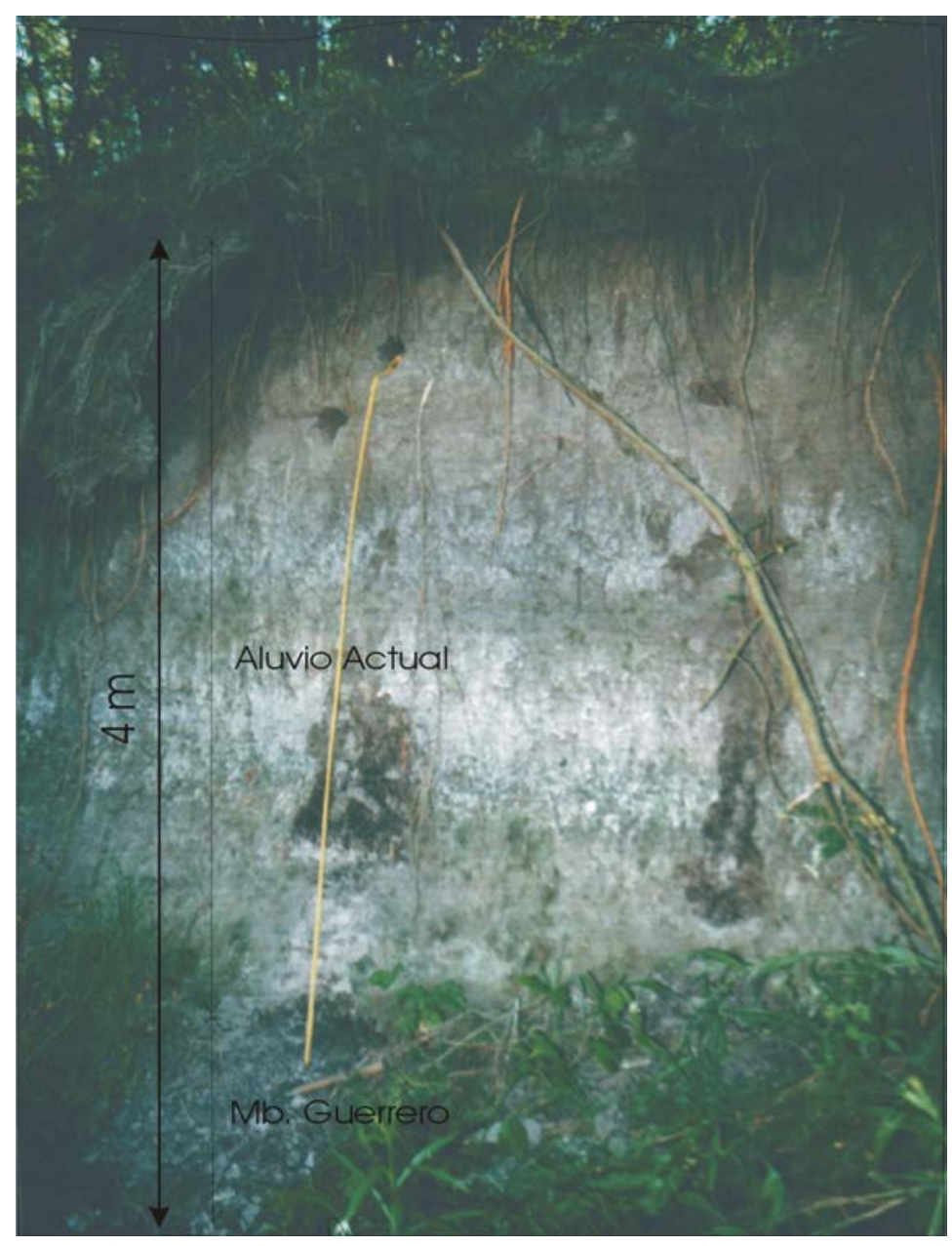

Fig. 4.21 Fotografía de las unidades estratigráficas de la observación 52 . 


\subsubsection{UNIDADES MIXTAS O LITORALES}

Dentro de estas unidades se reconocieron los depósitos correspondientes a las ingresiones marinas del Pleistoceno tardío y Holoceno y a los depósitos deltaicos.

\subsection{UNIDADES LITOESTRATIGRÁFICAS}

4.3.2.2.1.a FORMACIÓN PILAR (Fucks y De Francesco, 2003)

Esta unidad ha sido caracterizada en una cantera en explotación en la zona periurbana de la localidad homónima.

Está representada por una secuencia sedimentaria de naturaleza granocreciente, que varía de un sedimento arcilloso a uno areno limoso, discriminándose dos secciones:

\section{Sección inferior}

Está constituido fundamentalmente por secuencias arcillosas masivas, de color gris verdoso oscuro (hoja 1 gley 4/10y) que cambian lateralmente a secuencias arenosas estratificadas de tonos amarillentos $(2,5 Y$ 7/3) a castaños amarillentos claros $(2,5 Y$ 6/4). El análisis textural de una muestra permitió determinar un contenido de $87 \%$ de arcilla, 10,6\% de limo y 2,3 o de arena.

De acuerdo a lo observado, en la zona de Pilar esta unidad alcanzaría un espesor aproximado de 12 metros.

\section{Sección superior}


Está compuesta por un sedimento limoso fino de color amarillo claro, masivo que pasa transicionalmente hacia arriba a un sedimento arenoso de $1 \mathrm{~m}$ de espesor, constituida por arenas de grano medio, de color amarillo claro a grisáceo $(2,5 Y$ 7/4 a 2,5Y 7/1), con intercalaciones de arenas gruesas de color rojo a amarillento fuerte (2,5YR 5/6).

Contenido Fosilífero de la formación: Se han podido identificar ostrea sp., Mactra isabelleana y Tagelus plebeius, esta última en posición de vida. En la isla Martín García fueron observados además Erodona mactroides y fragmentos de Thais haemastoma (González y Ravizza, 1987). Entre los foraminíferos encontramos Ammonia beccarii y Elphidium sp. y ostrácodos (Cyprideis sp., Cytheraceae) con baja diversidad y bajo número de especies.

Distribución de la formación: Se encuentra acuñada dentro de la Formación Pampeano. En la cuenca del Río Luján se la ha detectado sobre la margen derecha unos quinientos metros hacia el noroeste de la cantera descripta en la observación 35 c, a una cota aproximada de 6,00 m s.n.m. dispuestos en discordancia sobre los sedimentos Pampeanos y con alta concentración de Ostrea sp.

También ha sido identificada en la cantera Los Seibos en la Ex Ea. San Miguel (obs. 92), por debajo del piso de explotación a una profundidad de 10 metros aproximadamente (Zanja de desagüe) .

Para la ejecución del puente sobre el curso del Río Luján sobre la ruta 9 (obs. 7), las perforaciones geotécnicas muestran una arcilla verde, plástica, con conchillas, que asociamos a esta unidad.

Fuera del área de estudio, fue encontrada en el Arroyo de la Cruz y la ruta 6 y en la zona de San Fernando y Tigre se la ha detectado y caracterizado, mapeándose los paleocauces por donde ésta ingresó al continente (López, 2000). 
Las cotas en las cuales se observa, varían mucho dentro y fuera del área de estudio ya que están vinculadas al paleorelieve y momento de la transgresión. Es por esto que es muy importante determinar la línea de máximo avance ya que en estos casos queda reflejado la edad y cota de la ingresión.

Edad: De acuerdo a la posición estratigráfica, cota y a la edad absoluta establecida sobre Tagelus sp (> 40 ka LP-1217, obs. 35 b) correspondería al Pleistoceno tardío, probablemente al Interglacial sangamon 0 al subestadio isotópico 5e acontecido hace 120.000 años aproximadamente. Al sur de la provincia de Buenos Aires una datación por U/Th arrojó una edad de $93,5 \pm 3,5 \mathrm{ka}$ (Isla et al, 2000).

La edad radiocarbónica obtenida constituye el límite inferior o edad mínima de la muestra, ya que la actividad residual de esta no es significativamente diferente del background, no pudiéndose transformarla en una edad C -14 precisa, siendo el límite superior el infinito (Figini, 1993).

Correlación: Se correlaciona con el Belgranense (Ameghino, 1889), Fm Pascua (Fidalgo et al., 1973 a), Trangresión Interglacial (González y Ravizza, 1987) . 


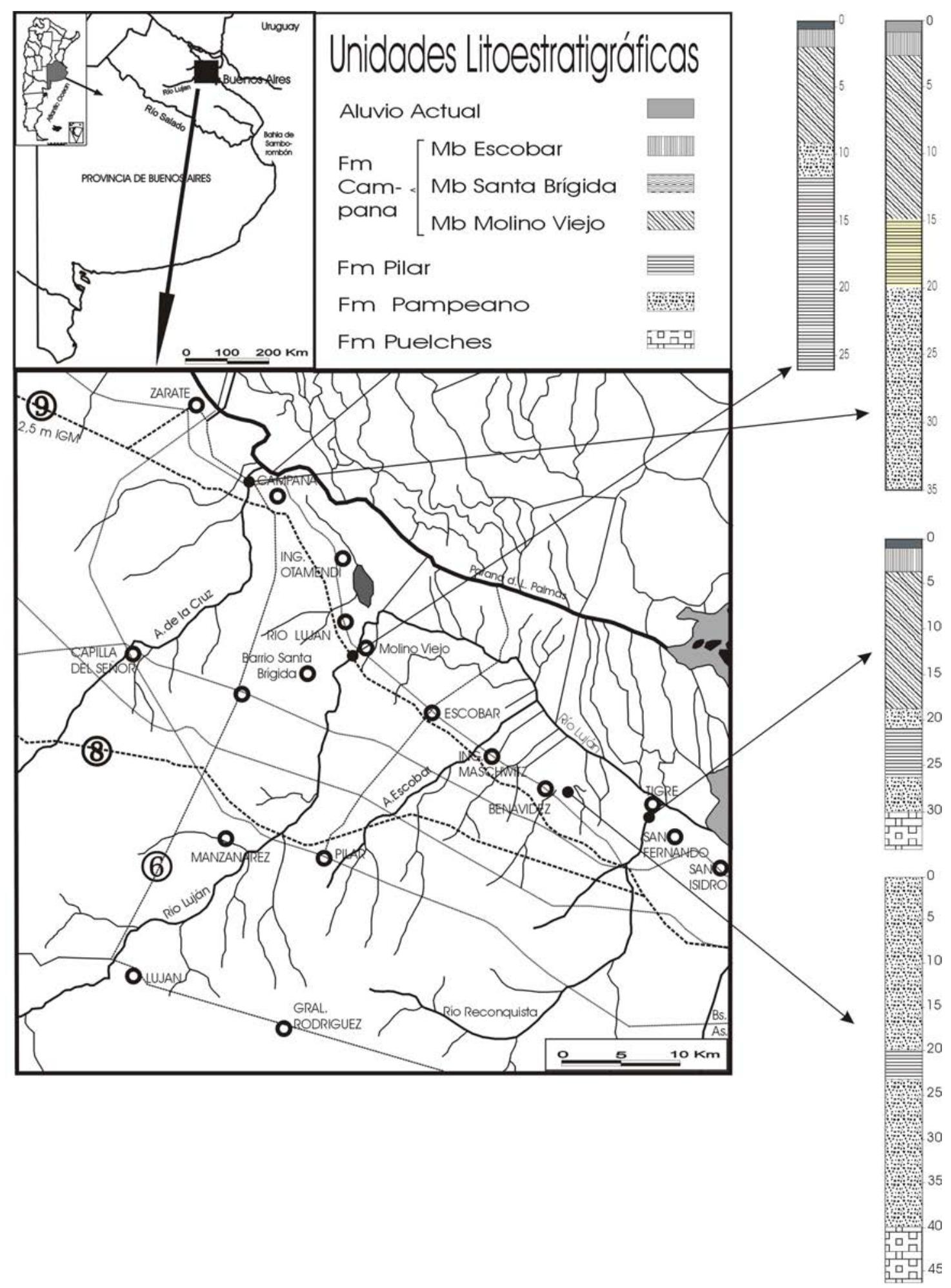

Fig. 4.22. Perfiles columnares y puntos de observación de la Fm Pilar. 
4.3.2.2.1.b FORMACION CAMPANA (Fucks y De Francesco, 2003)

Esta unidad está representada por la ingresión producida por el último ascenso del nivel con posterioridad a la última glaciación. Ocupa desde la base de los paleoacantilados hacia los niveles inferiores, prácticamente siempre por debajo de la cota de 5 metros, conformando los paleoestuarios y llanura costera, encontrándose en gran parte del subsuelo deltaico (Groeber, P., 1961; Vogel y Lerman, 1969).

Las particularidades de la variación del nivel del mar (curva de ascenso) son discutidas en el capitulo 5.

De acuerdo a sus características litológicas se la ha podido dividir en tres miembros:

\subsubsection{1.b.1 MIEMBRo MOLINo VIEJo (Fucks y De Francesco, 2003)}

Está caracterizada por sedimentos fundamentalmente arcillosos, a arcillo limosos, de escasa consistencia, de color negro a negro azulado saturados de agua $(2,5 \mathrm{~N})$ a gris verdosos en seco (5 GY 2/5). Suele presentarse con características muy fluidas, lo que permite, por un lado, perforarlos muy fácilmente y por otro, una recuperación de muestra muy escasa.

Se han observado a lo largo de su espesor, concreciones de carbonato de calcio, alargadas de no más de $3 \mathrm{~cm}$ y concéntricas de 0,4 a 0,5 cm de diámetro.

También se observan niveles de escasos cm de espesor de granulometrías más gruesas distribuidas a lo largo del perfil. Se ha manifestado en la base del perfil de algunas perforaciones, un sedimento arenoso grueso de no más de $10 \mathrm{~cm}$ de espesor.

Resultado de los análisis texturales:

\begin{tabular}{|l|l|l|l|l|}
\hline Muestra & $\circ$ arena & $\frac{\circ}{\circ}$ limo & $\%$ arcilla & Clasificación \\
\hline 34 & 19,8 & 42 & 40 & Limo arcillo- \\
\hline
\end{tabular}




\begin{tabular}{|l|l|l|l|l|}
\hline & & & & arenoso \\
\hline $17 \mathrm{~b}$ & 9,5 & 32,5 & 58,3 & Arcilla limosa \\
\hline $63 \mathrm{c}$ & 14 & 21,4 & 75,2 & $\begin{array}{l}\text { Arcilla areno- } \\
\text { limosa }\end{array}$ \\
\hline $69 \mathrm{~b}$ & 1,3 & 11,2 & 87,5 & Arcilla \\
\hline 68 & 26,5 & 41,8 & 31,7 & $\begin{array}{l}\text { Limo arcillo- } \\
\text { arenoso }\end{array}$ \\
\hline
\end{tabular}

Distribución: Se encuentra presente en gran parte del ámbito de la ingresión holocena, fundamentalmente en el sector central de los paleoestuarios y en toda la zona exterior (planicie litoral y delta).

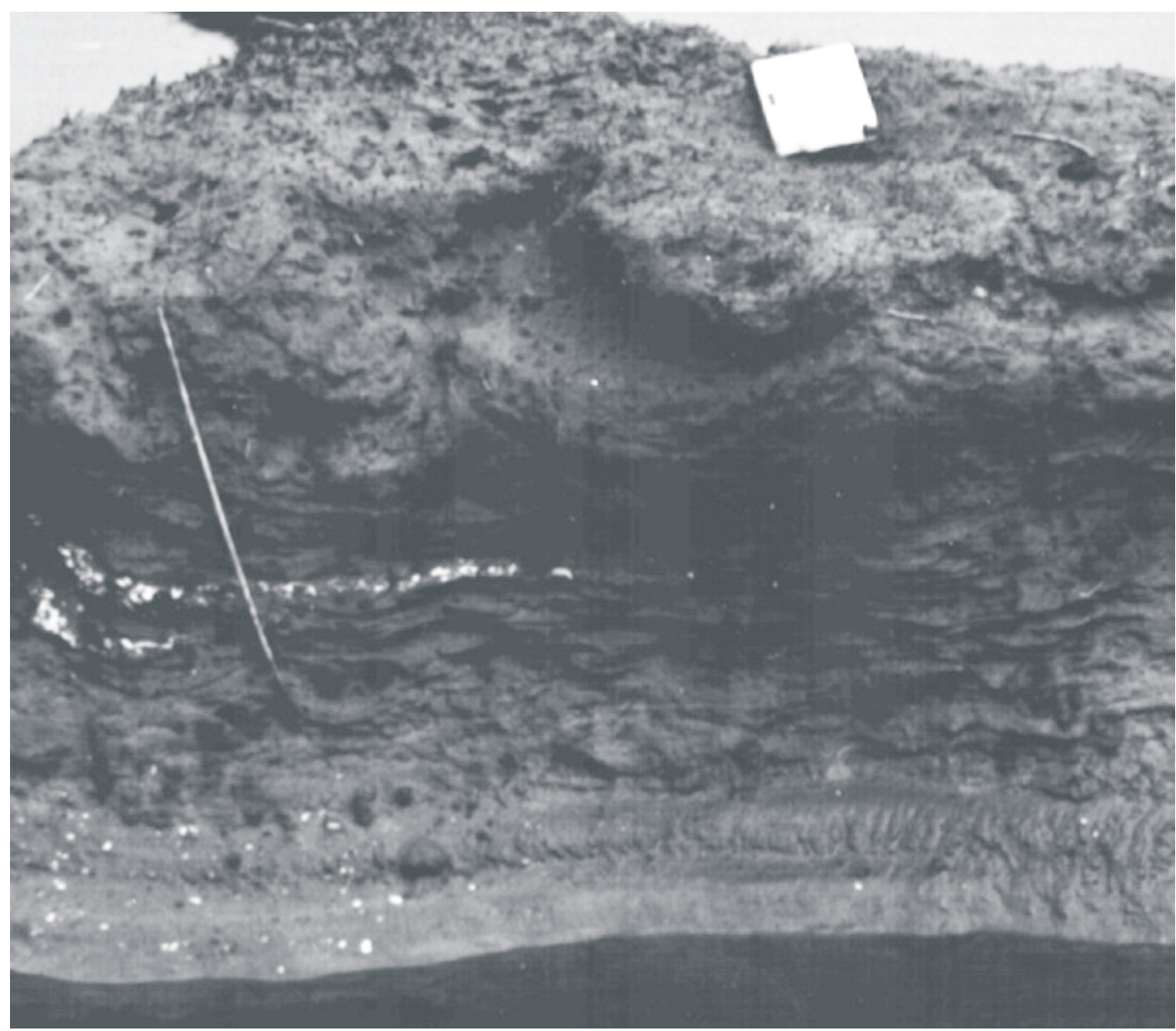

Fig. 4.23. Fotografía del fango negro del Mb Molino Viejo donde se observa estratificación flaser y láminas con conchillas.

De acuerdo a su ubicación, se la observa con diferentes características de contacto y espesor. En el punto extremo de penetración en el 
continente, se halla intercalada en secuencias sedimentarias fluviales (Fm Luján) o suprayaciendo a la Formación Pampeano. En relación a la primera, se la encuentra en discordancia de erosión sobre el Mb La Chumbiada, observándose moluscos en posición de vida dentro de éste. También, se lo observa apoyada directamente sobre la Formación Pampeano, con el desarrollo de orificios de $3 \circ 4 \mathrm{~cm}$ de diámetro y en otros, con organismos en posición de vida dentro de éstos.

En el resto del área, se la ha detectado por perforaciones, descansando en discordancia sobre la Formación Pampeano y la Formación Pilar, apoyando directamente la arcilla fluida o a través de un estrato muy delgado de arena gruesa con los tonos descriptos.

En relación con la forma de sus superficies, se observa en los paleoestuarios en sección transversal, una base cóncava y un techo horizontal, con pequeñas inflexiones.

Presenta espesores variables, fluctuando entre 0,35 m (punto extremo de penetración en el continente) en cercanías de Manzanares, a 4,00 m término medio en cercanías de los cursos de la Cruz y Luján sobre la Ruta 9 .

De la información obtenida de las perforaciones efectuadas por la Dirección Provincial de Vialidad para la realización de los puentes sobre el Río Luján y Arroyo de la cruz en las rutas 9 y 6, esta unidad se extendería hasta una profundidad de $9 \mathrm{~m}$ en la primera localización, dando un espesor total de 4,5 $\mathrm{m}$ y hasta una profundidad de $-13 \mathrm{~m}$, en la segunda, determinando un espesor de 12 metros. Una perforación en el Delta estaría indicando un espesor de 15 a 20 m atribuidos al Querandino cubiertos por un espesor similar de sedimentos deltaicos (Bonfils, 1962).

Los diferentes espesores encontrados y las variadas morfologías del piso de la unidad estarían indicando los diferentes rasgos geomorfológicos donde estas secuencias trasngresivas se depositaron. Cuanto mas negativa era la geoforma previa a la ingresión, mayor es la columna depositada y 
mas antigua su edad. Esto queda expresado claramente en el subsuelo deltaico, donde la edad obtenida presenta una clara similitud con las obtenidas en la plataforma continental atlántica a cotas similares (Guilderson, 2000)

Contenido Fosilífero: Es común la presencia de restos de invertebrados como Tagelus plebeius, Erodona mactroides, Mactra isabelleana, Littoridina sp., la mayoría de los cuales se encuentran enteros y en buena proporción articulados.

De acuerdo al contenido fosilífero, son especies de ambiente estuárico con salinidad variable de alogohalino a mixohalino. Otra característica de esta especie es su ubicación submareal a intermareal, de fondos blandos, béntonicos y de baja energía (Aguirre, 1990).

Asimismo, la morfología de las concreciones carbonáticas podrían estar indicando distintos niveles pedogenéticos, asociadas a ambientes de intermarea.

Sección tipo: Si bien esta unidad se mantiene con características similares a excepción del espesor, la sección tipo se ha establecido en la inmediaciones de la ruta 9 y el Río Lujan $\left(34^{\circ} 18^{\prime}\right.$ de latitud sur y $58^{\circ} 50^{\prime} 30^{\prime \prime}$ de longitud oeste) (Fig. 4.8).

Edad: En las inmediaciones de Campana, en el subsuelo deltaico a -18 m.b.b.p., se dató materia orgánica resultando $8.620+-100$ A.P. (Vogel y Lerman, 1969).

Correlaciones: Esta unidad se correlaciona con el Querandino de Doering, (1882), la base del Querandinense de Frenguelli, (1957); Samborombonense, (Groeber, 1961); Fm Destacamento Río Salado, (Fidalgo et al., 1973 a); Fm Atalaya, (Parker, 1990). 
4.3.2.2.1.b.2 MIEMBRO SANTA BRIGIDA (Fucks y De Francesco, 2003)

Representada principalmente por sedimentos arcillo limosos, plásticos y adhesivos, de color verde, castaños y en ciertos casos grisáceos (hoja 1 gley 5/10Y; 10 YR 5/3 y 10YR 4/2; hoja 1 glay 7/10Y y hoja 1 glay 4/10Y)

En buena parte de su distribución se han observado concreciones de tosca de forma elongada y bifurcadas, con orificio central, de hasta $8 \mathrm{~cm}$ de longitud.

En el sector más interno (cercano a la localidad de Manzanares) se presenta con un color verde a verde grisáceo, plástico y masivo con un espesor de 0,40 metros.

Hacia el exterior del paleoestuario, se presenta de un color castaño con sectores castaños grisáceos, arcillo limoso y finamente laminado. Entre estos dos sectores, sólo es detectado a través de perforaciones manuales.

Resultado de los análisis texturales:

\begin{tabular}{|l|l|l|l|l|}
\hline Muestra & $\circ$ arena & $\circ$ limo & $\circ$ arcilla & Clasificación \\
\hline 42 & 1,4 & 21,3 & 77,3 & Arcilla limosa \\
\hline 43 b & 1,1 & 19,1 & 79,8 & Arcilla limosa \\
\hline 43 a & 7,4 & 23,2 & 69,4 & Arcilla limosa \\
\hline 63 & 4,7 & 26,4 & 68,9 & Arcilla limosa \\
\hline 69 a & 3,2 & 22,7 & 74,1 & Arcilla limosa \\
\hline 65 & 2,9 & 19,4 & 77,5 & Arcilla limosa \\
\hline
\end{tabular}

Distribución: Se encuentra en el interior de los paleoestuarios del Río Luján y Arroyo de la cruz, en discordancia sobre las arcillas fluidas del Mb Molino Viejo y por debajo de sedimentos aluviales actuales. Hacia el continente se encuentra acuñado entre los sedimentos de la Formación Luján y hacia fuera del paleoestuario pasa gradualmente hacia el Miembro Escobar. 
Debido a que el miembro infrayacente se ubica en el centro de los estuarios relictos, esta unidad sobrepasa estos depósitos, apoyándose en estos sectores, directamente sobre los Formación Pampeano.

Presenta un espesor máximo del orden de los $3 \mathrm{~m}$ en cercanías del eje de los paleoestuarios, disminuyendo hacia los bordes y ápice de estos.

Contenidos Fosilífero: Erodona mactroides y Tagelus plebeius.

Ambiente sedimentario: Corresponden a un depósito generado a partir de la estabilización del nivel del mar en el momento de máximo ascenso y a las primeras etapas regresivas, con fauna de ambiente estuárico. Debido a las barreras generadas en las bocas de los paleoestuarios, esta unidad representaría secuencias correspondientes a lagunas costeras y marismas.

Sección tipo: La sección tipo ha sido definida en el sector aledaño al barrio Santa Brígida en el centro del paleoestuario del Río Luján.

Edad: De acuerdo a su posición estratigráfica y las edades absolutas (LP1347- $3640 \pm 70$ años C-14 AP ), 6.000 a 6370 C-14 A.P. (Figini, A., 1992) y 5.770 C-14 A.P. (González y Ravizza, 1987) correspondiendo al Holoceno medio.

Correlaciones: Con la sección superior del Querandinense (Frenguelli, 1957), Mb Canal 18 de la Fm Las Escobas (Fidalgo et al., 1973 a) entre los esquemas más tradicionales.

\subsubsection{1.b.3 MIEMBRO ESCOBAR (Fucks y De Francesco, 2003)}

Esta unidad está compuesta por dos secciones que si bien texturalmente no presenta prácticamente variaciones, difieren marcadamente en cuanto a su color. Es esencialmente una arena fina limosa, a limo arenoso, de color gris negruzco en la parte inferior y castaño a castaño verdoso con sectores rojizos amarillentos en la sección superior. En seco 10YR 7/3 a 6/4 y en húmedo 10YR 5/6. El contacto entre ambas es neto aunque en 
algunos casos se han observado intercalaciones entre estos depósitos (Fig. 4.30)

Se han observado en la sección superior concreciones de hierro y manganeso de $2-3 \mathrm{~cm}$ de diámetro. Es frecuente la existencia de concreciones de yeso en forma de rosetas de $0,5 \mathrm{~mm}$ a $2 \mathrm{~cm}$ de diámetro y de carbonato de calcio (tosca) milimétricas. Estas últimas presentan formas circulares y bifurcadas, con orificio central, que tienen $10 \mathrm{~cm}$ de longitud y $1 \mathrm{~cm}$ de diámetro.

La fracción arena, desde el punto de vista mineralógíco, está constituida en un 80 a 90 \% por granos de cuarzo y plagioclasa (andesina básica), con proporciones subordinadas de trizas vítreas, hornblendas y clastos líticos, presentando además espículas de esponja. Dentro de esta litología y color, se observan niveles, muchas veces importantes, de arenas limosas y arcillas de color negro a negro grisáceas, con restos fósiles similares a los descriptos.

En los afloramientos naturales y artificiales, se observa estratificación laminar, compuestas fundamentalmente por arenas finas limosas de color castaño claro y arcillas de color oscuro, estratificación flaser y en menor proporción ondulosa. 


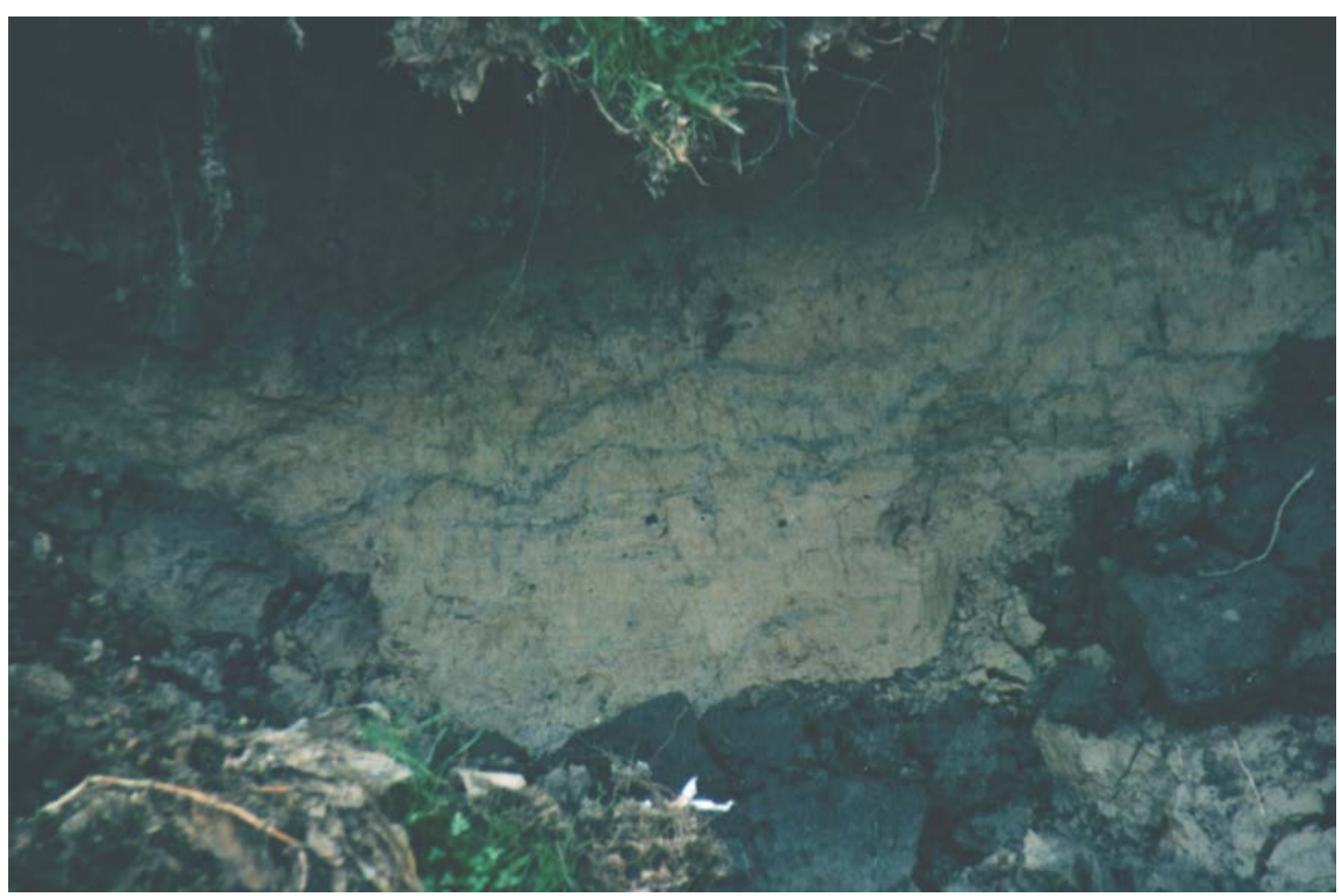

Fig.4.24 Fotografía de los sedimentos arenosos del Mb Escobar donde se puede observar la estratificación flaser.

Resultado de los análisis texturales:

\begin{tabular}{|l|l|l|l|l|}
\hline Muestra & $\frac{\circ}{\circ}$ arena & $\frac{\circ}{\circ}$ limo & $\frac{\circ}{\circ}$ arcilla & Clasificación \\
\hline 12 & 48 & 33,9 & 18,1 & $\begin{array}{l}\text { Areno } \\
\text { limoarcillosa }\end{array}$ \\
\hline 11 & 31,4 & 29,2 & 39,4 & $\begin{array}{l}\text { Arenoarcilla } \\
\text { limosa }\end{array}$ \\
\hline 15 & 37,2 & 43,5 & 19,3 & $\begin{array}{l}\text { Limo arcillo- } \\
\text { arenoso }\end{array}$ \\
\hline 28 & 43,4 & 38,2 & 18,4 & $\begin{array}{l}\text { Arena limo } \\
\text { arcillosa }\end{array}$ \\
\hline
\end{tabular}

Distribución: Se la encuentra ocupando prácticamente toda la boca de los paleoestuarios y llanura litoral, en una franja que en el Río Luján abarca unos $5 \mathrm{~km}$ de ancho y de unos $4 \mathrm{~km}$ en el Arroyo de La Cruz. 
Espesor: El Miembro Escobar presenta un espesor de aproximadamente $2 \mathrm{~m}$, descansando en discordancia sobre el Mb Molino Viejo y la Fm Pampeano. Está cubierto por el Aluvio actual en discordancia en los bordes de los cursos principales y transicionalmente en el resto del área, observándose en su techo el desarrollo de procesos pedogenéticos.

Lateralmente se observa un pasaje gradual hacia el continente con el Miembro Santa Brígida y neto con los sedimentos deltaicos hacia el este.

Contenidos Fosilífero: Se observan escasos fragmentos de Erodona mactroides, en general bastante fracturadas. Foraminíferos como Elphidium sp. y Ammonia becarii y especies de Cytheraceae indet. dentro de los ostrácodos.

Ambiente Sedimentario. Esta unidad respondería a la redistribución de sedimentos deltaicos en un ambiente dominado por procesos litorales en un estuario platense más amplio que el actual, dando como resultado la formación de barreras y llanuras litorales con crestas de playas en su superficie.

Sección tipo: La sección tipo puede considerarse en las inmediaciones de la ruta 9 y Río Luján.

Edad: De acuerdo a su posición estratigráfica corresponde al Holoceno medio - superior. Un ejemplar de Balaenoptera cf. physalus en Baradero arrojó una edad ${ }^{14} \mathrm{C}$ media de $5.535 \pm 75$ A. P. (Carbonari et al., 1987).

Correlaciones: Este miembro se correlaciona con la parte superior del Querandinense y el Platense (Frenguelli, 1957); Fm Las Escobas, (Fidalgo et al., 1973 b); Facies Cerro de la Gloria (Cavallotto, 1995).

\subsection{LIMOS DELTAICOS}


En el sector deltaico se han realizado un conjunto de perforaciones (121, 122 y 32) donde se ha podido determinar las características de estos depósitos en sus 5 o 6 metros superficiales.

Características litológicas: Esta compuesto por una limo arenoso, de color gris oscuro (hoja 1 gley 3/N), plomizo, que hacia la base se hace progresivamente arcilloso y con alternancia de colores que varían desde el gris (hoja 1 gley 4/N), verde (hoja 1 gley 4/10GY), y castaño (7,5 YR 4/2). Presentan concreciones de Fe y Mn de 0,4 a 0,5 cm de diámetro y manchas de oxidación, observándose a largo de todo el perfil gran cantidad de materia orgánica parcialmente descompuesta con restos de maderas.

Frente a la ciudad de Campana a cota de $2 \mathrm{~m}$, la sucesión sedimentaria comienza con 12 metros integrado por limos y areniscas limosas gris verdosos, finamente laminada (Bonorino, 1965).

Espesor: Una perforación en el taller del varadero indica un espesor de 10 a 20 metros de estos sedimentos "arenas aluviales y depósitos palustres" compuestos por arcillas y arenas dispuestos sobre la arcilla Querandina (Bonfils, 1962). Parker y Marcolini (1992) describen profundidades de 10 a 15 metros de sedimentos deltaicos dispuestos sobre la Fm Atalaya de génesis estuárica.

Distribución: Se encuentra depositada sobre los sedimentos de la ingresión marina holocena, limitada en ambas márgenes por las llanuras litorales, cordones barreras y demás geoformas relacionadas a esta ingresión o directamente limitada por los depósitos loessoides de la Fm Pampeano.

Ambiente Sedimentario: Es de carácter progradante donde es posible determinar un conjuntos de facies sedimentarias. La llanura subaérea deltaica presenta actualmente procesos vinculados con la evolución de los albardones en ríos y arroyos relacionados con sedimentos limo arenosos a 
areno limosos y hacia adentro de éstos (sectores centrales de islas) la depositación de sedimentos arcillosos (Parker y Marcolini, 1992).

Edad: Estos sedimentos se depositan como consecuencia de la estabilización y descenso del nivel del mar producido aproximadamente a partir de los $6.000{ }^{14} \mathrm{C}$ A.P. Estos procesos continúan hasta la actualidad no solo en los sectores subaéreos, sino y fundamentalmente en forma subacueo, en la mayor parte del río de la Plata (Cavalloto, 1988).

Correlaciones: Aimará (Ameghino, 1889); Fm Playa Honda (Parker, 1990).

Limos Deltaicos

Mb Molino Viejo (Fm Campana)

Frm Puelches
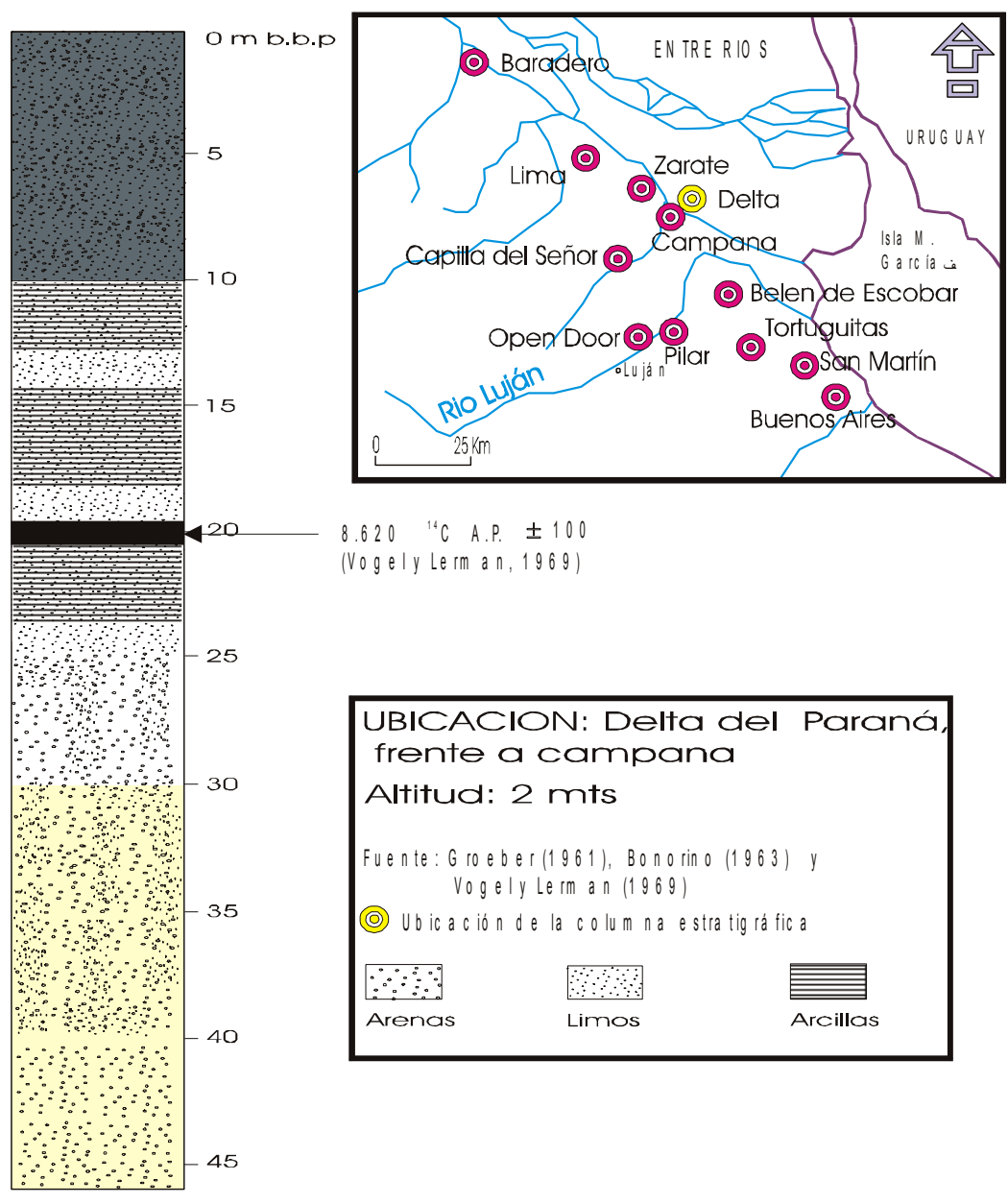

$8.620{ }^{14} \mathrm{C}$ A.P. \pm 100

(Vogely le rm a n, 1969 )

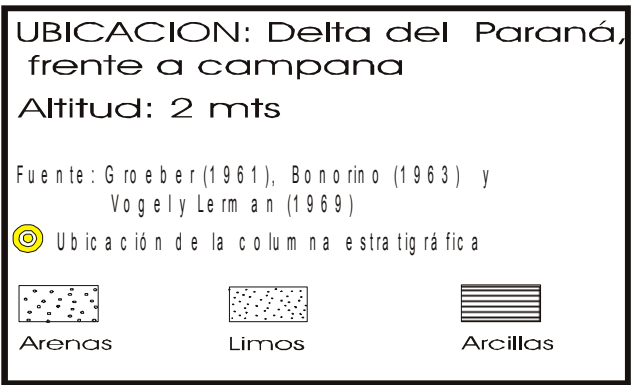

UBICACION: Delta del Paraná Altitud: 2 mts

$$
\begin{aligned}
& \text { Fuente: Groeber(1961), Bonorino (1963) y } \\
& \text { (a) Ubic a ción de la colum na e stra tig rá fic a }
\end{aligned}
$$

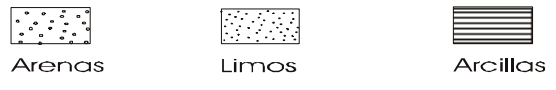

Fig.4.25. Perfil del sector deltaico frente a la ciudad de Campana. 


\subsubsection{PERFILES REPRESENTANTIVOS}

Las descripciones de estas unidades se han realizado, principalmente, en muestras provenientes de perforaciones manuales, seleccionándose para su presentación un conjunto representativo en cuanto a distribución areal y secuencias integrantes, se refiere.

Las descripciones de las unidades litológicas se realizaron in situ, obteniéndose de acuerdo al tipo de observación diferente grado de información. En las escasas exposiciones naturales y/o artificiales, la determinación de estructuras sedimentarias, texturas, contenido fosilífero y concreciones, permitió contar con información complementaria para la caracterización de las unidades reconocidas. No obstante, la mayoría de las observaciones de estas unidades (Fig. 4.8) se efectuaron con barreno manual, realizándose con esto las correspondientes descripciones.

\section{OBSERVACION N 35 b}

Este perfil se ha levantado en una cantera "Los Sauces" en la zona periurbana de la localidad de Pilar, en la pared de valle a unos $300 \mathrm{~m}$ del Río Luján, con una cota aproximada del techo de unos 6 metros $\left(34^{\circ}\right.$ $\left.27^{\prime} 20^{\prime}, 58^{\circ} 58^{\prime} 00^{\prime \prime}\right)$ (Fig. 4.8).

Unidad A: Ubicada en el extremo oeste del frente, en la base del perfil, se observa una secuencia arcillosa, que en su sector aflorante presenta una estructura masiva, es plástica y de color verde oscuro en húmedo (hoja 1 gley 4/10Y) a castaño verdoso en seco (hoja 1 gley 5/10y), observándose un espesor de $4 \mathrm{~m}$. En sus 1,30 $\mathrm{m}$ superiores, se observan concreciones verticales alargadas y bifurcadas de carbonatos de calcio (tosca) de hasta $12 \mathrm{~cm}$ de largo y 1 - $2 \mathrm{~cm}$ de diámetro, como así también concreciones menores de formas y dimensiones variadas, siendo las planares las más comunes. También es frecuente la presencia de diques 
verticales e inclinados de 20 a $100 \mathrm{~cm}$ de largo y de 0,2 a $3 \mathrm{~cm}$ de espesor, rellenos de un sedimento limoso, friable, con manchas de oxidación, presentando Ostrea sp., Mactra isabelleana y Tagelus plebeius, esta última en posición de vida (Fig. 4.27).

A unos $70 \mathrm{~m}$ del extremo oeste se observa una marcada estratificación y un mayor contenido de arena y de tonos castaños claros a amarillentos (2,5Y 6/4) que llega a ser predominante en los términos superiores; el espesor observado en este sector es de $1,5 \mathrm{~m}$ con una inclinación de unos $25-30^{\circ}$ hacia el noroeste.

Unidad B: Rematando el perfil, en el extremo nordeste de la cantera, en discordancia sobre la unidad $A$, se observa un sedimento limoso fino de color amarillo claro $(2,5 \mathrm{Y} 7 / 4$ a 2,5Y 7/1), masivo, de 0,30-0,50 m de espesor con algunas intercalaciones laminares de arcillas, con abundantes orificios de 1 a $2 \mathrm{~mm}$ de diámetro y 2-3 cm de largo, tapizados internamente por material fino de color rojo oscuro a negro o, en algunos casos, ocupados por carbonatos de calcio deleznable. También se observa en menor proporción, concreciones de tosca, de color oscuro, rodados de 2 a $3 \mathrm{~cm}$ de diámetro del sedimento arcilloso subyacente y moldes de raíces.

Dentro de esta secuencia, que en general presenta una estructura homogénea, se observan escasos fragmentos de Ostrea de hasta 0,5 cm de diámetro y orificios milimétricos tapizados por material de color negro, siendo común, además, la presencia de concreciones alargadas de tosca de $1,5 \mathrm{~cm}$ de largo y escasos milímetros de diámetro. 


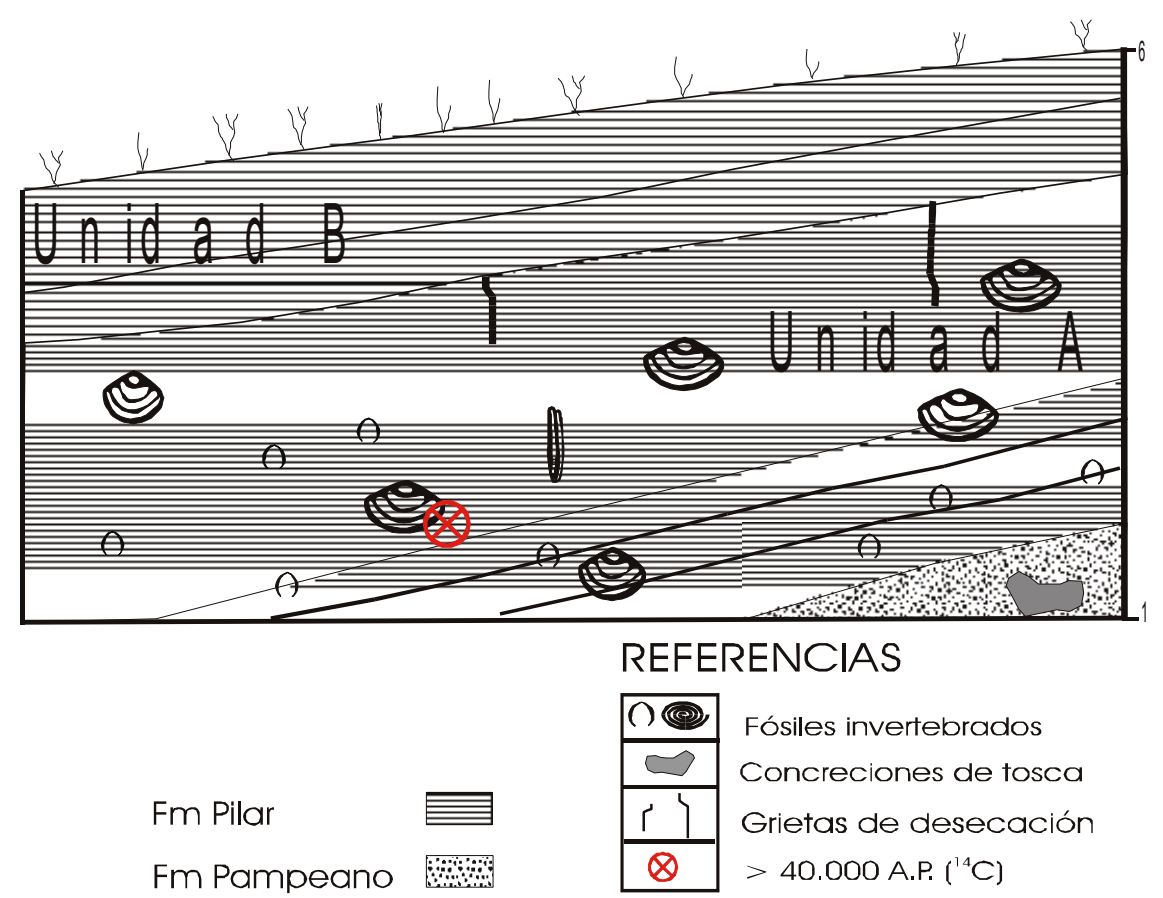

Fig. 4.26.- Perfil estratigráfico de la observación 35 b 
Fiq. 4.27. - Fotografías de la diferentes secuencias litorales de la observación $35 \quad 6$ 


\section{OBSERVACION $N^{\circ} 7$}

Esta observación se llevó a cabo sobre la margen izquierda del Río Luján, aguas arriba con respecto a la ruta 9. Se encuentra ubicada en la Hoja Campana, a una cota aproximada de $3 \mathrm{~m}$. La geoforma corresponde a la barrera generada en la boca del paleoestuario de este curso, donde se desarrolla actualmente el albardón. (Fig. 4.8)

El perfil completo ha sido realizado integrando la observación directa del tramo de barranca, la descripción de muestras obtenidas mediante barreno y la información analizada de una perforación geotécnica, aledaña, realizada para la ejecución del puente sobre el Río Luján, por parte de Vialidad Nacional en 1955.

\section{OBSERVACIÓN DIRECTA}

UNIDAD A: Se observan $40 \mathrm{~cm}$ de un sedimento duro, grisáceo (10YR 6/1), limoso, homogéneo, con gran cantidad de raíces. (Aluvio parcialmente edafizado)

UNIDAD B: Le continúan $47 \mathrm{~cm}$ de un sedimento gris oscuro (10YR 4/1), estructurado en bloques, arcilloso, con cutanes, raíces actuales escasas y concreciones de tosca equidimensionales. En el contacto con la unidad superior se observan restos de ladrillos. (Suelo enterrado)

UNIDAD C: Hacia abajo hasta el pelo de agua se observan $87 \mathrm{~cm}$ de un sedimento arenoso fino, con laminación paralela y en sectores laminación flaser.

Se observan concreciones alargadas de forma elongada de hasta $11 \mathrm{~cm}$ de largo y $1 \mathrm{~cm}$ de diámetro y otras con bifurcaciones, prácticamente todas con orificio central. Es común la presencia de manchas amarillentas de 2 - $3 \mathrm{~cm}$ y otras concreciones equidimensionales de color negro que se rompen al presionarlas. 
Esta unidad al igual que una parte del horizonte suprayacente suele presentar gran cantidad de eflorescencias salina. (Mb Escobar, Fm Campana)

\section{CON BARRENO}

continúan hasta los $4,50 \mathrm{~m}$ el mismo sedimento variando a tonos castaños grisáceos a gris oscuro (10YR 5/2 a 10YR 4/1) y contenidos de conchillas enteras y fracturadas de Erodona mactroides. (Mb Escobar, Fm Campana)

UNIDAD D: A partir de los $4,50 \mathrm{~m}$, en forma transicional se hace arcilloso a arcillo limoso, negro a gris oscuro (10YR 2/1 a 10YR 4/1), con bivalvos articulados. A los $6,75 \mathrm{~m}$ se observa un sedimento netamente arcilloso, tixotrópico (fluido), de color negro, con abundantes restos de bivalvos. El barreno penetra muy fácilmente y se termina a los 7,80 m. ( Mb Molino Viejo, Fm Campana)

PERFORACIÓN GEOTECNICA (Vialidad Nacional, 1955)

UNIDAD D: hasta los 8 m continua el "fluido" arcilloso blando con conchillas. ( Mb Molino Viejo, Fm Campana)

UNIDAD E: Le continúan $4 \mathrm{~m}$ de un sedimento limo arcillo arenoso con vetas amarilentas. (Fm Pampeano)

UNIDAD F: De la unidad anterior se pasa a los $12 \mathrm{~m}$ a una arcilla verdosa, muy plástica, que en perforaciones cercanas presentan restos de conchillas, con un espesor de 12 metros hasta la profundidad máxima de 26 m b.b.p., sin encontrar la base. (Fm Pilar) 
UBICACION: Rio Luján y Ruta 9

Altitud: $3 \mathrm{mts}$

Fuente: Generada y Vialidad Nacional

(C) Ubicación de la columna estratigráfica

\section{REFERENCIAS}

\section{Arcillas}

Limos

Arenas

l I Concreciones de tosca Restos vegetales

(1) Restos fósiles

ED Yeso en rosetas

त्राTh suelo actual

ग17T Suelo Enterrado

U(แ) Estratificación flaser

Estratificación paralela

- Elementos antrópicos
Aluvio Actud..

.

Fm Campana....

\section{Mb Escoba}

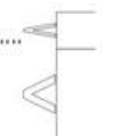

Viejo

Formación
Pampeano.

Formación Pila.

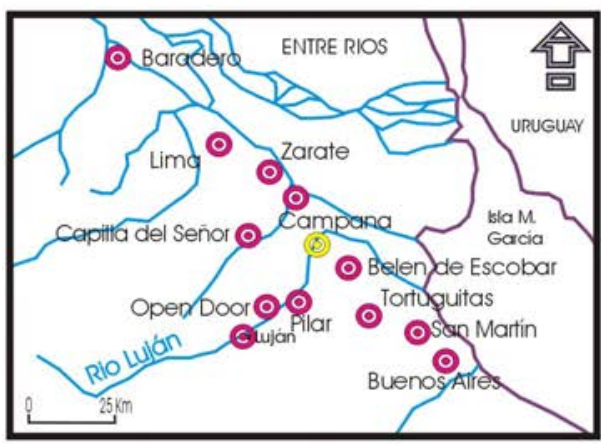

के

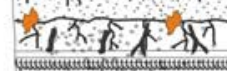

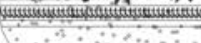

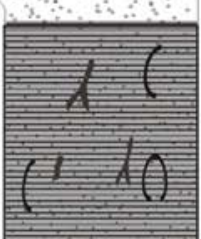

5

10

15

20

25

Fig. 4.28 Perfil estratigráfico de la observación n 7 


\section{OBSERVACIÓN N 17}

Se encuentra sobre la margen derecha del Arroyo El Pescado y la Ruta 9 a una cota aproximada de $3 \mathrm{~m}$. La geoforma corresponde a la barrera generada en la boca del paleoestuario de este curso. (Fig. 4.8)

UNIDAD A: En los $0,40 \mathrm{~m}$ superiores se observa un sedimento arcilloso a arcillo limoso de color negro(hoja 1 gley 3/5GY), plástico y adhesivo, con cutanes y raíces. (Aluvio actual parcialmente edafizado)

UNIDAD B: A partir de esta profundidad aparece en forma transicional un sedimento arenoso fino, arcilloso, de color castaño amarillento (10YR 6/4), con gran cantidad de tosca de forma elongada de hasta $5 \mathrm{~cm}$ de largo. Por debajo de los primeros $0,30 \mathrm{~m}$ el sedimento se hace arenoso castaño claro, con algunos niveles con mayor proporción de tosca hasta los 2,0 m. Se observan en su interior pequeños agregados de yeso en roseta de 3 a $5 \mathrm{~mm}$ de diámetro.

UNIDAD C: A los $2 \mathrm{~m}$ aparece en forma abrupta un sedimento negro (10YR 2/1), que presentan en su techo láminas de 2 a $3 \mathrm{~mm}$ de sedimentos arcillosos de color negro (como turba) y láminas de arena fina de color castaño rojizas. Hacia abajo el sedimento se hace arenoso fino, gris oscuro, en donde puede observarse láminas de 1 a $2 \mathrm{~mm}$ de arcillas negras y de arenas castañas.

A los 2,85 m se hace algo más arcilloso, con presencia de concreciones de tosca. ( Mb Escobar, Fm Campana)

UNIDAD D: De los 3 a los $3,40 \mathrm{~m}$ se perfora fácilmente obteniéndose una arcilla negra (2,5Y 3/1), fluida, observándose en la base conchillas enteras, algunas articuladas y otras fracturadas. (Mb Molino Viejo, Fm Campana)

UNIDAD E: El barreno termina a 3,40 m en un sedimento muy duro de difícil perforación. (Fm Pampeano) 


\begin{tabular}{|c|c|}
\hline \multicolumn{2}{|c|}{ REFERENCIAS } \\
\hline & A rc illa s \\
\hline & $\operatorname{Lim} 0 \mathrm{~s}$ \\
\hline & A re nas \\
\hline I & concrecionesde tosca \\
\hline & Restos vegetales \\
\hline & Re sto s fó sile $s$ \\
\hline 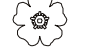 & Yeso en ro setas \\
\hline उराtind & Sue lo a c tual \\
\hline तरात्रत & Suelo Enterrado \\
\hline
\end{tabular}

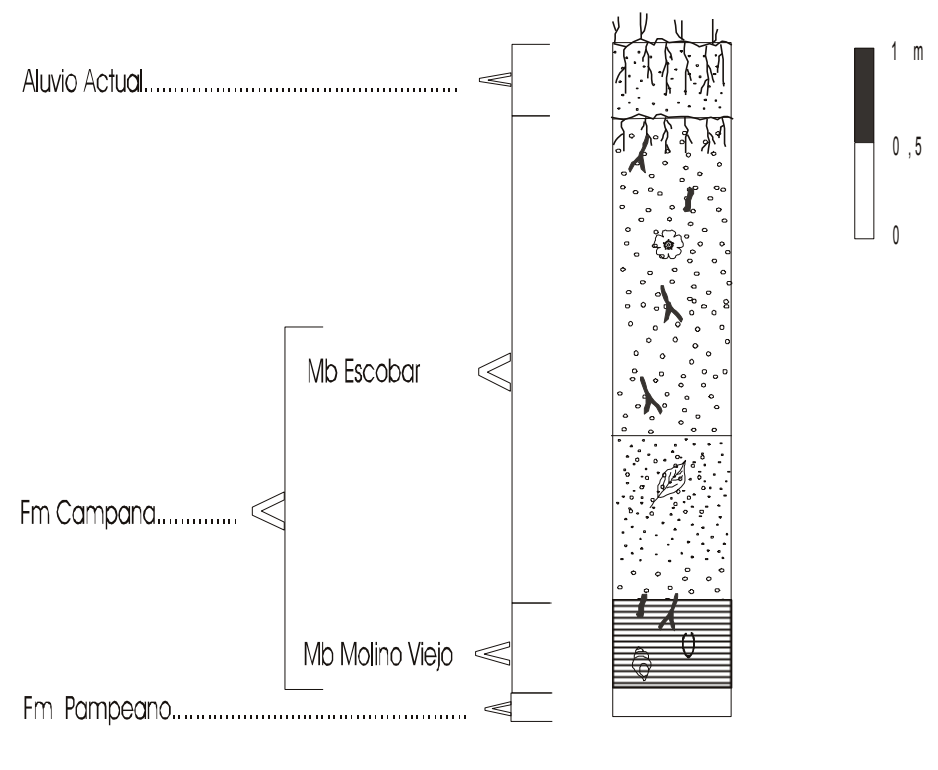

Fig.4.29 Perfil estratigráfico de la observación n 17 


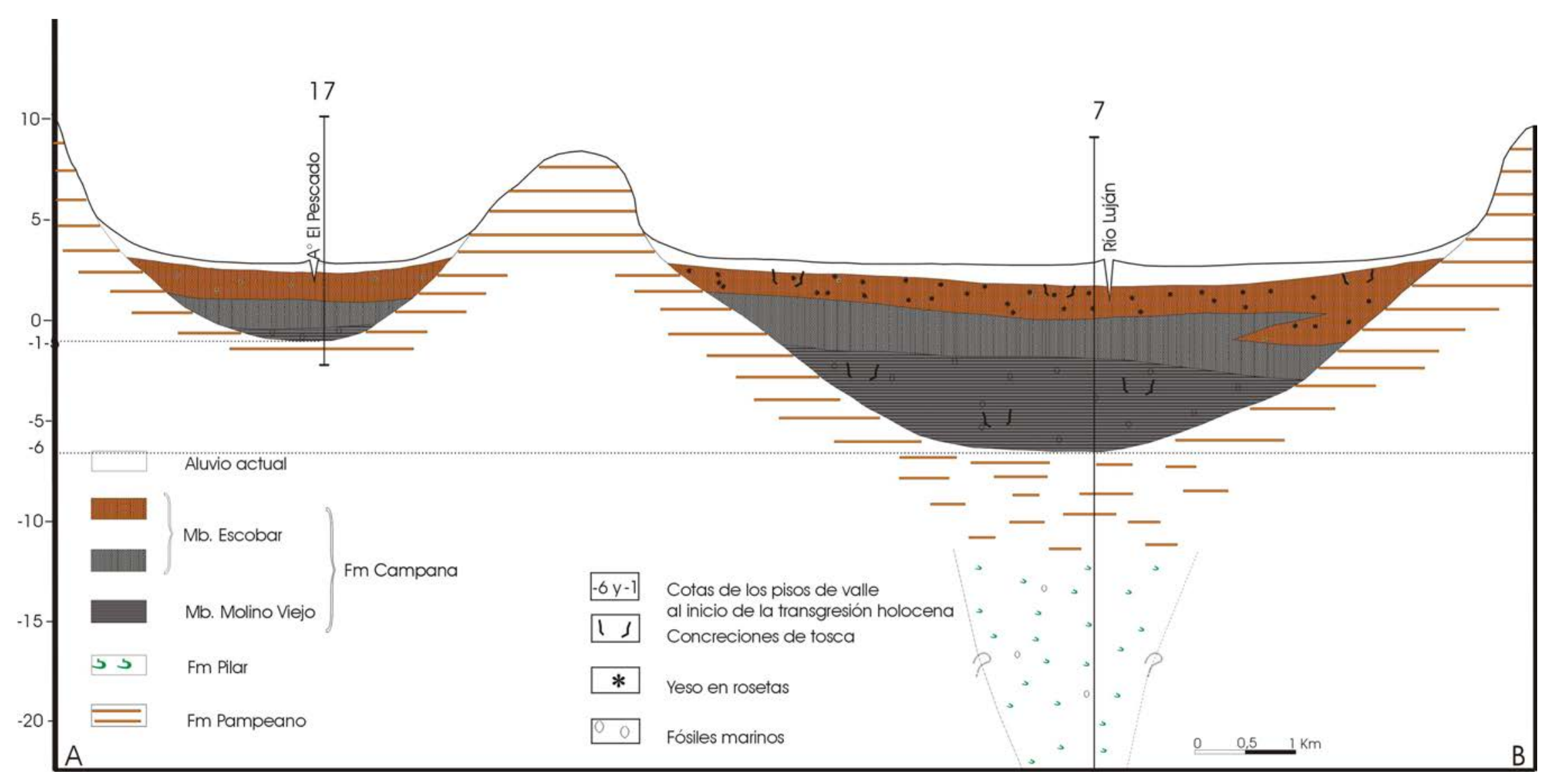

Fig. 4.30 Perfil estratigráfico trasversal al Río Luján y Arroyo del Pescado sobre la ruta 9 


\section{OBSERVACIÓN N $N^{\circ} 44$}

Se desarrolla en la margen izquierda del Río Luján, dentro del paleoestuario generado por la ingresión holocena. La geoforma es plano a plano cóncava con una cota aproximada de 3 a 3,5 m. (Fig. 4.8)

UNIDAD A: Desde la superficie hasta los $0,90 \mathrm{~m}$ se observa un sedimento arcillo limoso, gris oscuro (2,5Y 4/1), con gran cantidad de raíces fundamentalmente hacia la parte superior. (Aluvio parcialmente edafisado)

UNIDAD B: A partir de esta profundidad y hasta los $1,80 \mathrm{~m}$ se observa un limo fino a arcilloso castaño rojizo (5YR 4/3).

De 1,80 a 2,30 m se presenta un sedimento arcilloso, a arcillo limoso de color castaño (7,5YR 5/6), con gran cantidad de valvas enteras y articuladas de Erodona mactroides. (Mb Santa Brígida, Fm Campana)

UNIDAD C: A partir de los 2,30 y hasta los $8,50 \mathrm{~m}$ la secuencia comienza con una arena gris $(7,5 \mathrm{YR} 6 / 1)$ de poco espesor pasando transicionalmente a una arcilla fluida, de color gris oscura a negra (7,5YR 3/1). Se observan escasas concreciones de tosca alargadas de hasta 0,004 m de largo. Esta secuencia se presenta muy fácil de perforar. (Mb Molino Viejo, Fm Campana)

El material en todo su espesor se comporta muy similar (fluida), apareciendo en su parte final una arena gruesa, gris clara y $10 \mathrm{~cm}$ de un material arcilloso muy duro de color castaño. (Fm Pampeano) 


\begin{tabular}{|c|c|}
\hline \multicolumn{2}{|c|}{ REFEREN CIAS } \\
\hline & A rc illa s \\
\hline & $\operatorname{Lim}$ os \\
\hline$\lambda 1$ & Concrecionesde tosca \\
\hline & Re sto s fó siles \\
\hline रोगी & Su e lo a c tual \\
\hline
\end{tabular}

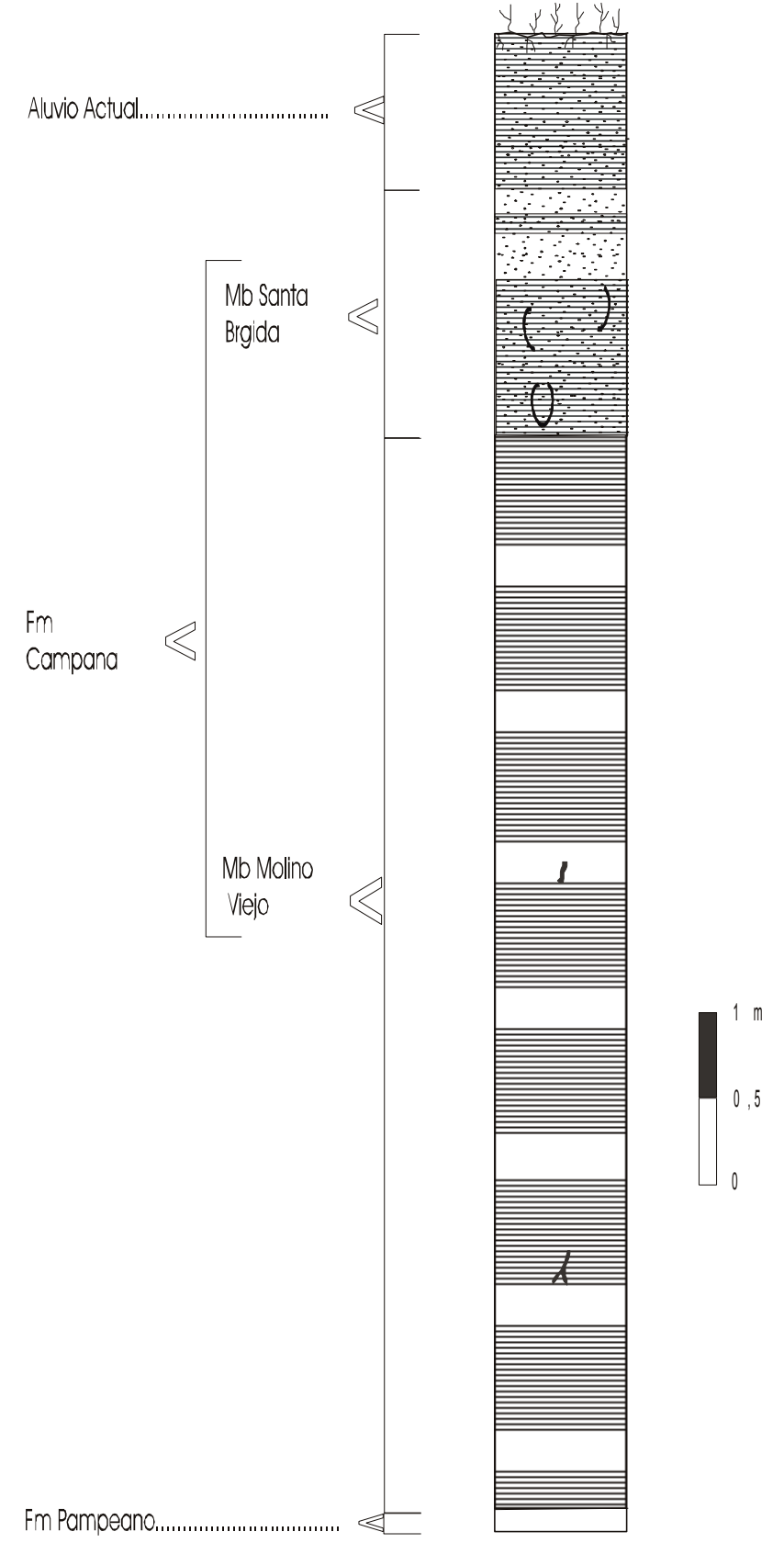

Fig. 4.31 Perfil estratigráfico de la observación n 44 

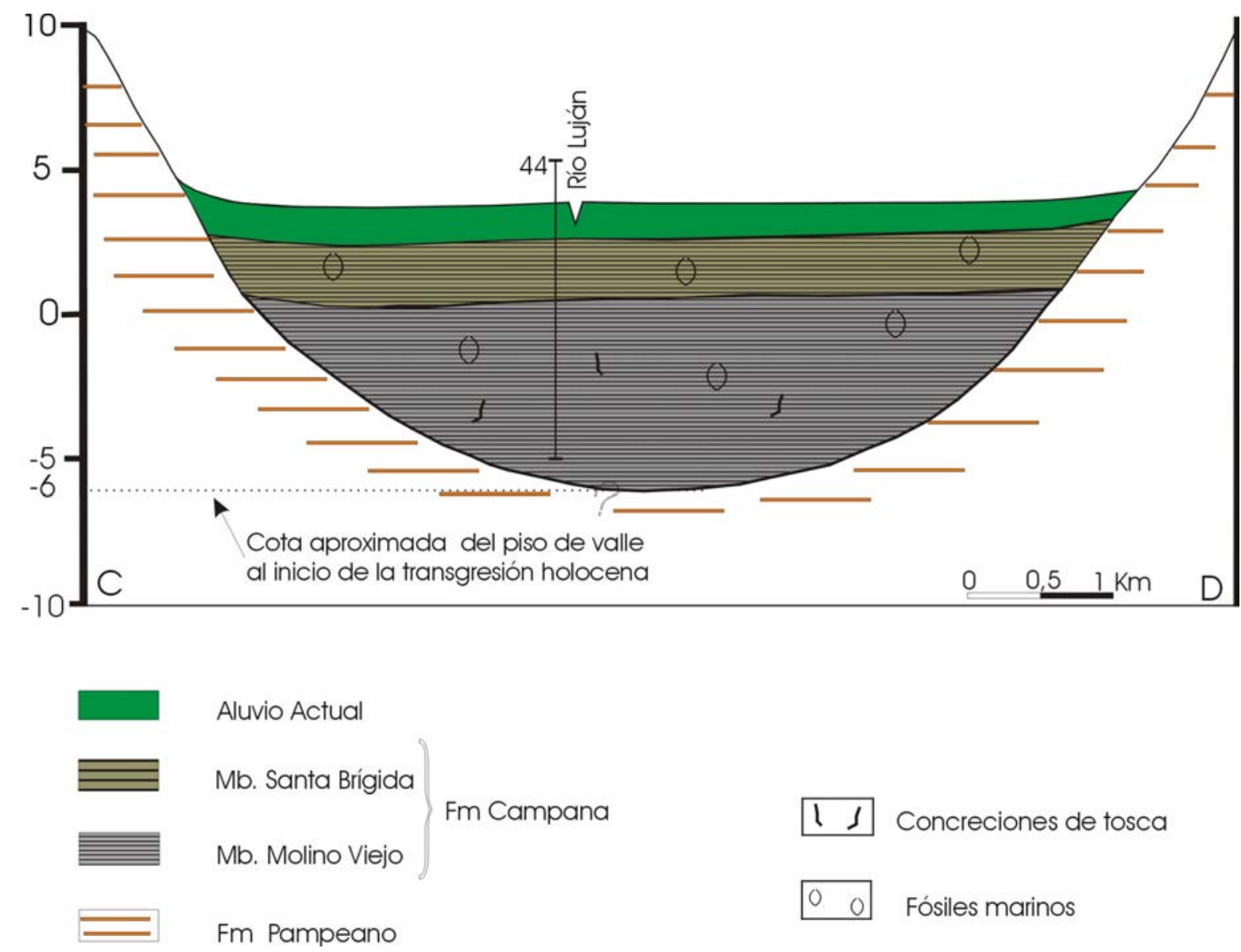

Fig. 4.32. Perfil estratigráfico trasversal C-D al Río Luján frente al Barrio Santa Brígida. 


\section{OBSERVACION $N^{\circ} 48$}

La perforación se desarrolla en el centro del paleoestuario del Río Luján, aledaña a las vías del ex ferrocarril Gral. San Martín. Cota aproximada de 4 m en una pendiente local plana. (Fig. 4.8)

UNIDAD A: Desde la superficie hasta $0,60 \mathrm{~m}$ la secuencia está compuesta por un sedimento arcilloso a arcillo limoso, castaño verdoso (2,5Y 4/2), plástico y adhesivo con raíces de la vegetación actual.

Desde los 0,60 a los $0,90 \mathrm{~m}$ se observa en forma neta un sedimento de color negro oscuro (2,5Y 3/1), con presencia de gran cantidad de gasterópodos fluviales (Planorbis sp) es plástico y adhesivo.

Entre los 0,90 a los 1,10 m se hace grisáceo verdoso oscuro (hoja 1 gley 4/5GY), limo arcilloso, con rodados de arcilla castaña de dimensiones milimétricas y láminas de micas. (Sedimentos fluviales actuales, parcialmente edafizados)

UNIDAD B: En forma neta se observa entre los 1,10 a los 1,50 m una arcilla verde a verde grisácea (hoja 1 gley 3/10GY), con concreciones de tosca alargadas de hasta $1 \mathrm{~cm}$ de tamaño máximo y láminas de arcilla castaña amarillenta.

A los 1,50 y hasta $2,20 \mathrm{~m}$ se observa un sedimento arcilloso verde grisáceo (hoja 1 gley 4/5G), con sectores rojo amarillento (5YR 5/6) y gran cantidad de tosca de hasta $1,50 \mathrm{~cm}$ de largo y 0,4 cm de diámetro, unidireccionales y con orificio central.

En su parte inferior el sedimento varía a una arcilla limosa plástica y adhesiva, de color castaño claro (10YR 6/4), con concreciones de tosca y manchas ocres. (Mb. Santa Brígida, Fm Campana) 
UNIDAD C: En contacto neto se continúan entre los 2,20 a 7,75 m una arcilla negra grisácea a azulada (hoja 2 gley de 3/5B a 5/PB), fluida, con pequeños agregados de color ocre fácilmente delezneable. Se observan pequeñas valvas de Erodona mactroides enteras y articuladas. La perforación finaliza sin encontrar la base de la unidad.

\section{REFERENCIAS}

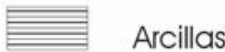

Limos

I Concreciones de tosca

Q 0 Restos fósiles

thith suelo actual

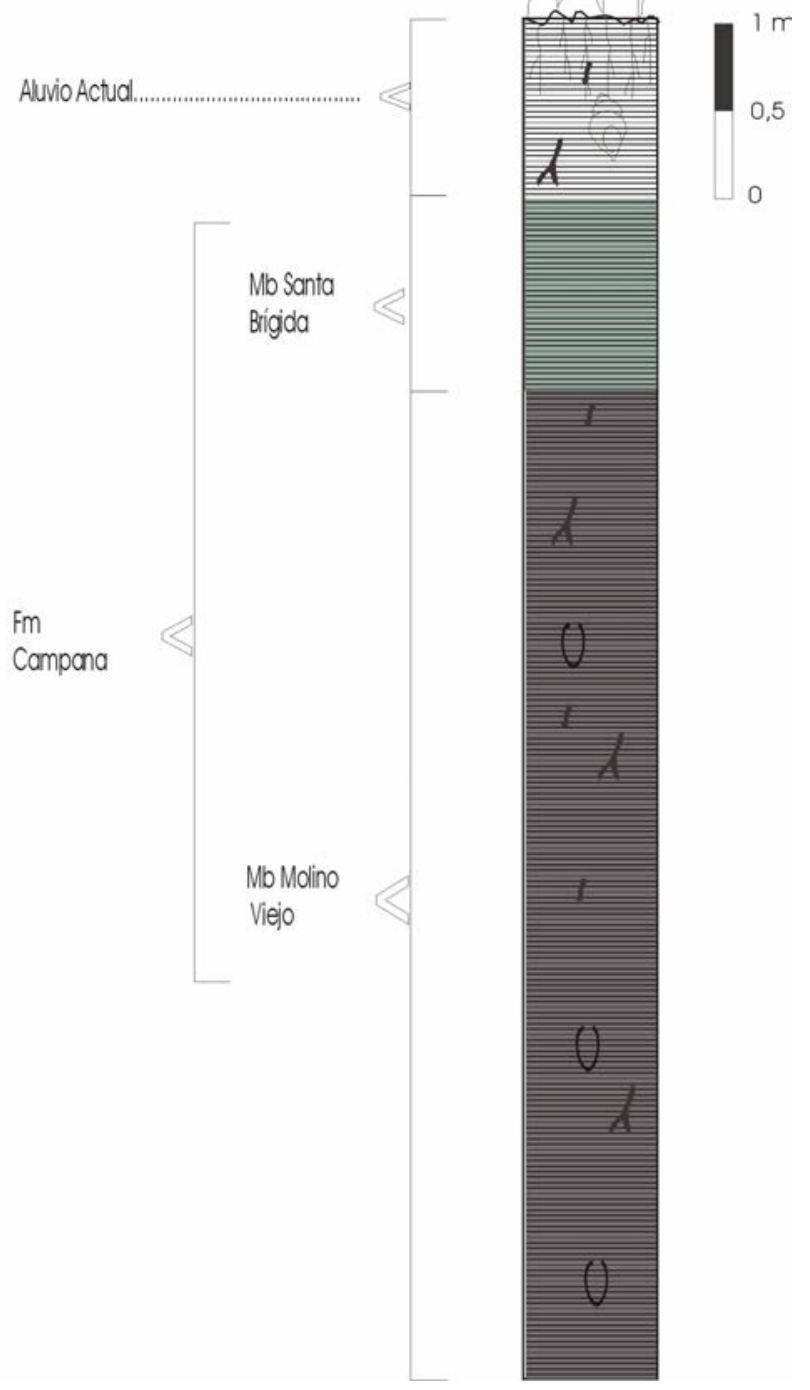

Fig. 4.33 Perfil estratigráfico de la observación $n^{\circ} 48$ 

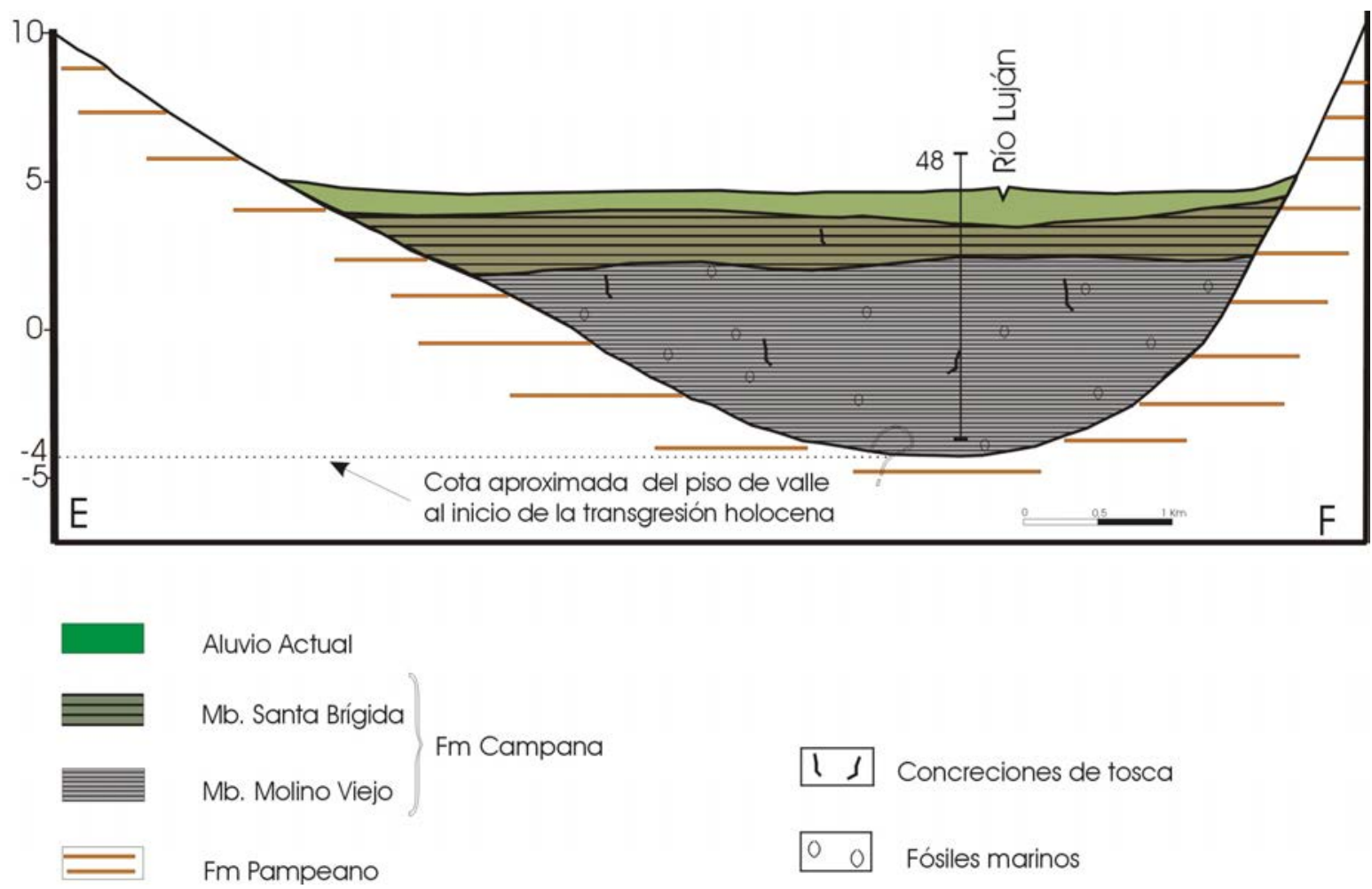

Fig. 4.34 Perfil estratigráfico trasversal al Río Luján en las inmediaciones del ex F.C.G. San Martín. 


\section{OBSERVACIÓN N $N^{\circ} 56$}

Se desarrolla en el sector interno del paleoestuario del Río Luján en un relieve plano cóncavo con cota aproximada de $4 \mathrm{~m}$. (Fig. 4.8)

UNIDAD A: Desde la superficie hasta los 2,50 m se presenta un sedimento arcillo limoso, de color castaño grisáceo a castaño amarillento (2,5Y $5 / 2$ ) resistente y friable. Se observan intercalados láminas de un sedimento arcilloso, de color oscuro y concreciones de tosca equidimensional. (Aluvio actual)

UNIDAD B: Entre los 2,50 a 3,60 m se presenta una arena media a gruesa de color castaño amarillento (10YR 6/4) con intercalaciones laminares de arcilla y fragmentos milimétricos de conchillas. Hacia la base se hace gris oscuro. (Mb Santa Brígida, Fm Campana)

UNIDAD C: A los $3,60 \mathrm{~m}$ se pasa transicionalmente a un sedimento arcilloso de color negro (hoja 2 gley 2,5/10G) fácil de perforar. Se observan conchillas fragmentadas y una alta concentración de tosca de forma alargada de hasta $1,5 \mathrm{~cm}$ de largo y 0,2 cm de diámetro.

Hasta los $6,80 \mathrm{~m}$ se observa una arcilla fluida con restos de conchillas y madera, observándose intercalaciones de arena lo que lo hace perder en sectores la fluidez.

Entre los 6,80 y 7,80 m la arcilla negra (hoja 1 gley 2,5/N) fluida, con restos de valvas de moluscos y pequeños lentes de arcilla consistente de color castaño. (Mb Molino Viejo, Fm Campana) 


\begin{tabular}{|c|c|}
\hline \multicolumn{2}{|c|}{ REFERENCIAS } \\
\hline & Concreciones de tosca \\
\hline & Restos fósiles \\
\hline & Restos vegetales \\
\hline & Suelo actual \\
\hline & Arcillas \\
\hline & Limos \\
\hline & Arenas \\
\hline
\end{tabular}

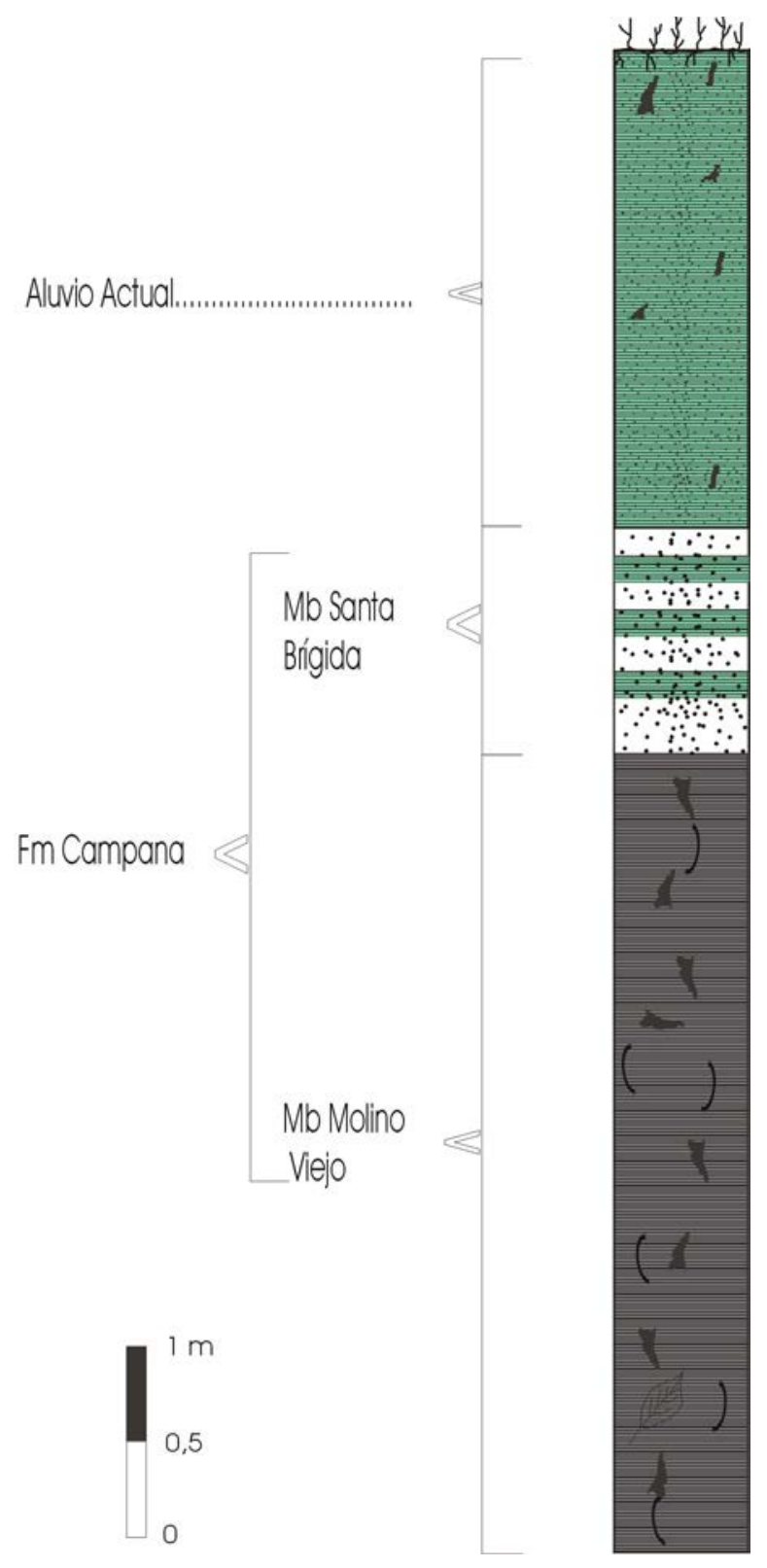

Fig. 4.35 Perfil estratigráfico de la observación n 56 

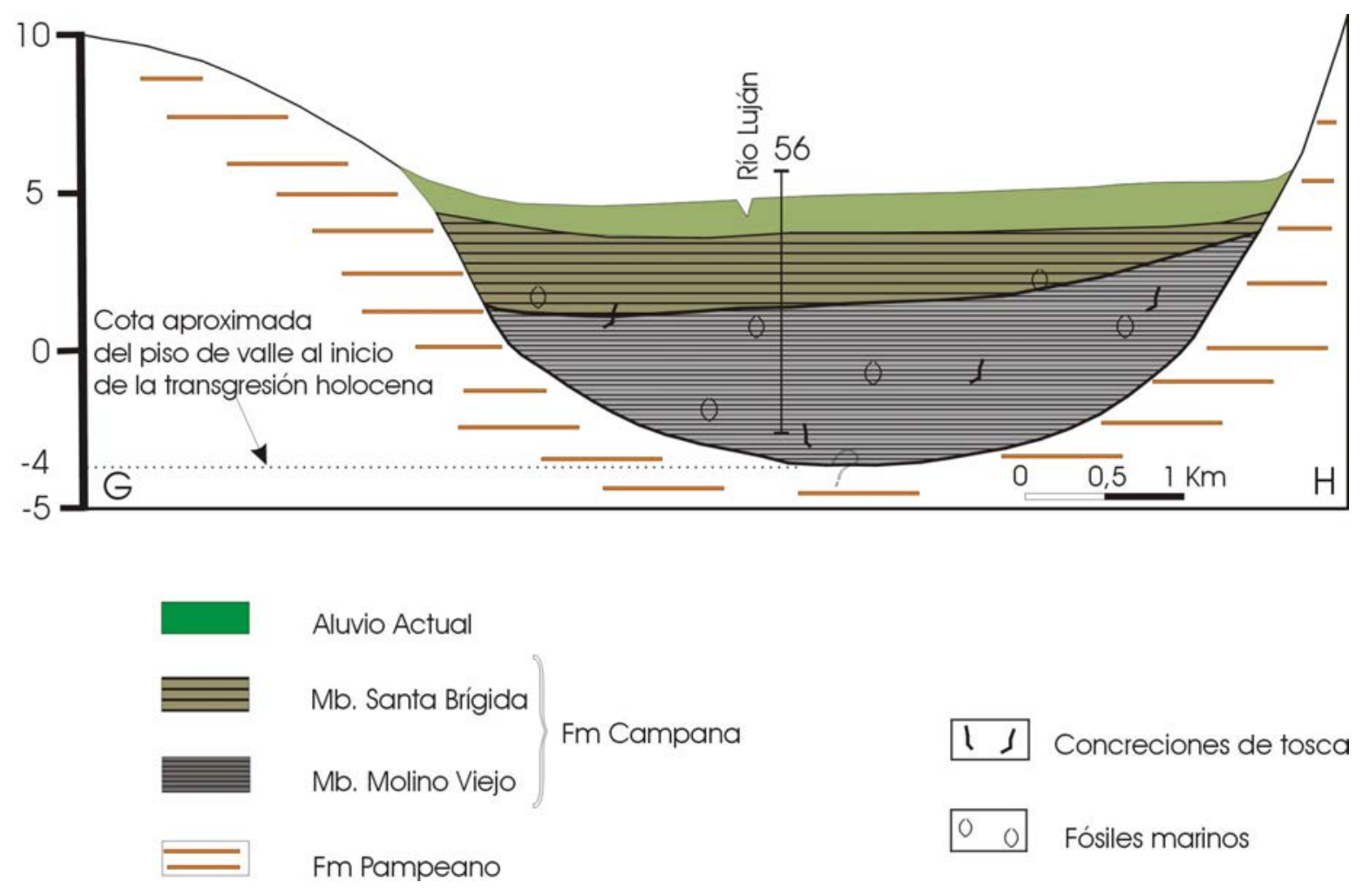

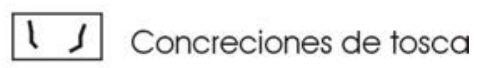

$0 \quad 0$ Fósiles marinos

Fig. 4.36 Perfil estratigráfico transversal al Río Luján en las inmediaciones del ex F. C. G. Belgrano.

\section{OBSERVACION N $N^{\circ} 53$}

La perforación con barreno se desarrolla en la actual planicie de inundación del Río Luján y la ruta 8, a una cota aproximada a los $7 \mathrm{~m}$. La geoforma corresponde al sector mas interno del paleoestuario desarrollado en este curso, presentando una pendiente plano cóncava. (Fig. 4.8)

UNIDAD A: En los primeros $0,30 \mathrm{~m}$ se observa un sedimento castaño verdoso $(2,5 Y$ 5/2) plástico con gran cantidad de raíces.

Desde los 0,30 hasta los $0,55 \mathrm{~m}$ el sedimento se hace hacia la base progresivamente más oscuro (2,5Y 4/2) arcilloso, más plásticos que la parte superior, con abundante cantidad de gasterópodos de agua dulce, 
concentrados fundamentalmente en la base (Planorbis sp.) (Aluvio actual y suelo)

UNIDAD B: Entre los 0,55 y los $1,70 \mathrm{~m}$ se presenta un sedimento limoso a limo arcilloso, de color verde, verde grisáceo (hoja 2 gley 5/10G a 10BG) suelto. Los $0,65 \mathrm{~m}$ superiores se presentan de color verde grisáceo y son más limosos, con una alta concentración de carbonato de calcio diseminado. Se observan manchas de color ocre. En esta secuencia el barreno perfora con gran facilidad. En la base de la barranca del Río Lujan se observa esta unidad con una gran concentración de conchilla enteras y fracturadas de Erodona mactroides. (Mb Santa Brígida, Fm Campana)

UNIDAD C: Entre los 1,70 a los 3,50 m se presenta un sedimento arcilloso negro (hoja 1 gley 2,5/N), con características fluidas. (Mb Molino Viejo, Fm Campana)

UNIDAD D: En forma neta a los $3,50 \mathrm{~m}$ aparece un sedimento consolidado de color castaño claro (10YR 7/3) que pasa a castaño rojizo (7,5YR 5/3), arcillo limoso, con concreciones de tosca de hasta 1,5 cm de diámetro. (Fm Pampeano)

\begin{tabular}{|c|c|}
\hline \multicolumn{2}{|c|}{ REFERENCIAS } \\
\hline I & Concreciones de tosca \\
\hline & Restos fósiles \\
\hline & Suelo actual \\
\hline & Arcillas \\
\hline & Limos \\
\hline
\end{tabular}
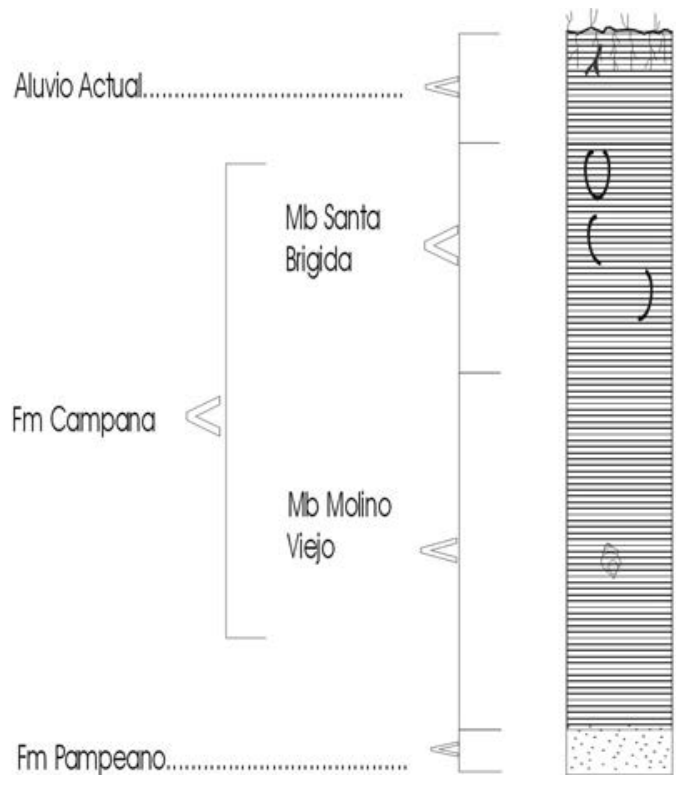

Fig. 4.37 Perfil estratigráfico de la observación n 53 

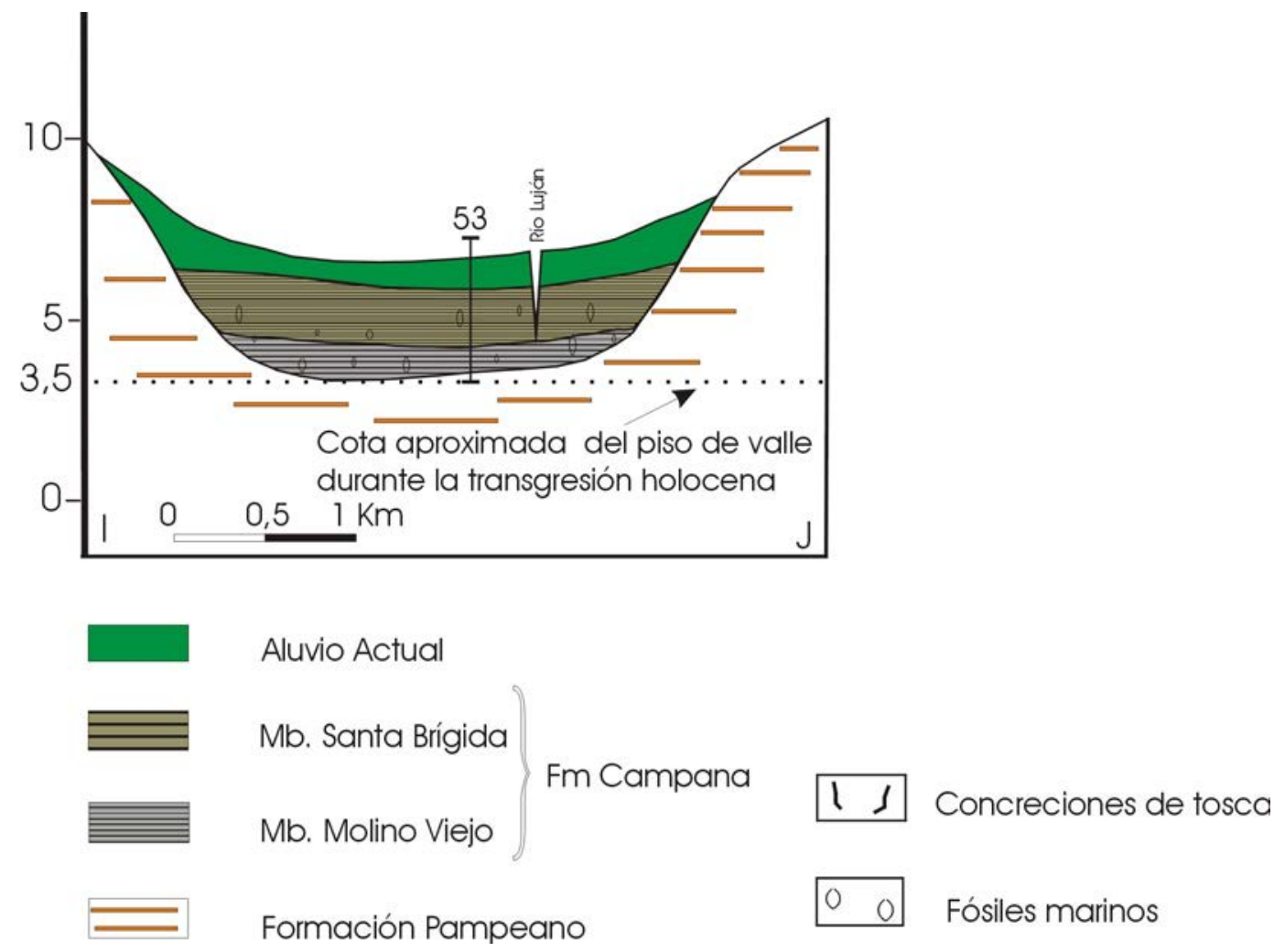

Fig. 4.38 Perfil estratigráfico transversal al Río Luján sobre la ruta 8 


\section{OBSERVACIÓN $N^{\circ} 28$}

La perforación con barreno se realizó a 150 m de la intersección de la margen derecha del Arroyo de la Cruz y la ruta 9, a una cota aproximada a los $3 \mathrm{~m}$. La geoforma corresponde a la barrera generada en la boca del paleoestuario de este curso, donde las pendientes actuales son plano a plano - cóncavas. (Fig. 4.8)

UNIDAD A: Desde la superficie y con 1,10 m de espesor se observa un sedimento arcilloso, negro (2,5Y 3/1), plástico y adhesivo. A lo largo de todo su espesor y sobre la superficie topográfica se observan abundantes gasterópodos de ambientes fluviales (Ampullaria sp. y Biomphallaria sp.)

\section{(Aluvio actual parcialmente edafizado)}

UNIDAD B: A los $1,10 \mathrm{~m}$ se pasa transicionalmente a una arena fina a muy fina, grisácea oscura (10YR 4/1), con manchas ocreáceas. A medida que se avanza en la perforación, el sedimento deja de ser grisáceo pasando a adquirir un color castaño claro (10YR 7/3).

A los $1,50 \mathrm{~m}$ se observan abundantes concreciones limoníticas, ocres, conformadas por arena fina a muy fina, fácilmente deleznable. Se observan fragmentos muy pequeños de conchillas.

A partir de los 2,10 m se observan concreciones blanquecinas alargadas de 1 a $1,5 \mathrm{~cm}$ y la presencia de conchillas enteras y articuladas de Erodona mactroides. (Suelo Enterrado y Mb Escobar, Fm Campana)

UNIDAD C: Entre 2,40 y los $5,00 \mathrm{~m}$ se observa una arcilla fluida, gris oscura a negra (hoja 2 gley 2,5/10G) con conchillas enteras de Erodona mactroides.

Entre 5 y 5,75 m se observan intercalaciones de arcilla, del mismo color y más resistente a la penetración, lentes de arena fina castaña 
amarillenta (1OYR 6/4), con concreciones alargadas de carbonato de calcio de $3 \mathrm{~cm}$ de largo.

A los 5,75 m aparece la arcilla gris negruzca anterior (hoja 2 gley 2,5/10G), con restos de conchillas y de valvas enteras y articuladas de 4 a $5 \mathrm{~mm}$ de Erodona Mactroides y concreciones carbonáticas alargadas. La perforación finaliza a los 6,75 sin encontrar el piso de la unidad. (Mb Molino Viejo, Fm Campana)

\begin{tabular}{|c|c|}
\hline \multicolumn{2}{|c|}{ REFERENCIAS } \\
\hline I & Concreciones de tosca \\
\hline & Restos fósiles \\
\hline & Restos vegetales \\
\hline & Suelo actual \\
\hline & Suelo Enterrado \\
\hline & Yeso en rosetas \\
\hline & Arcillas \\
\hline & Limos \\
\hline$\therefore \because$ & Arenas \\
\hline
\end{tabular}

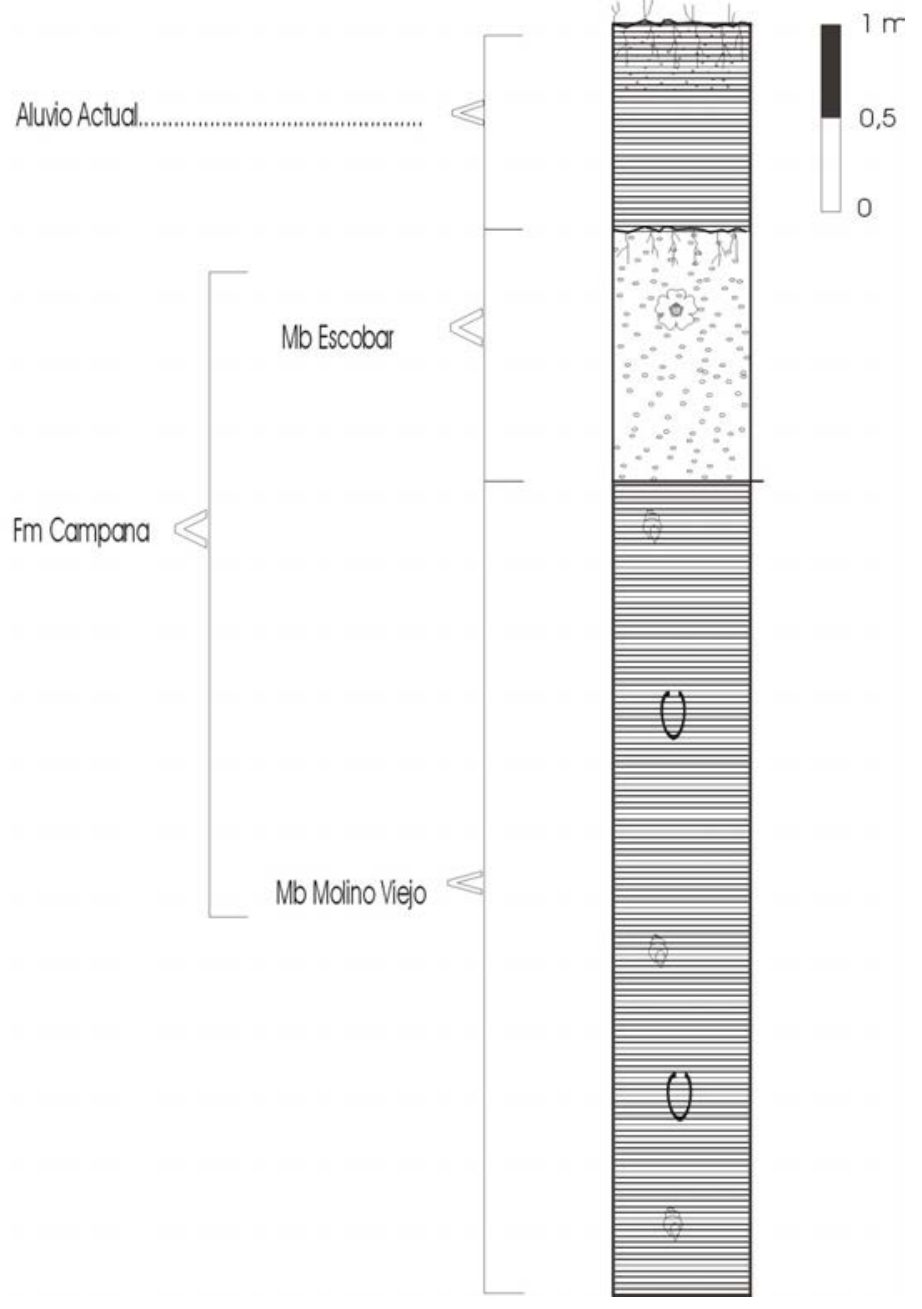

Fig. 4.39. Perfil estratigráfico de la observación n² 28 

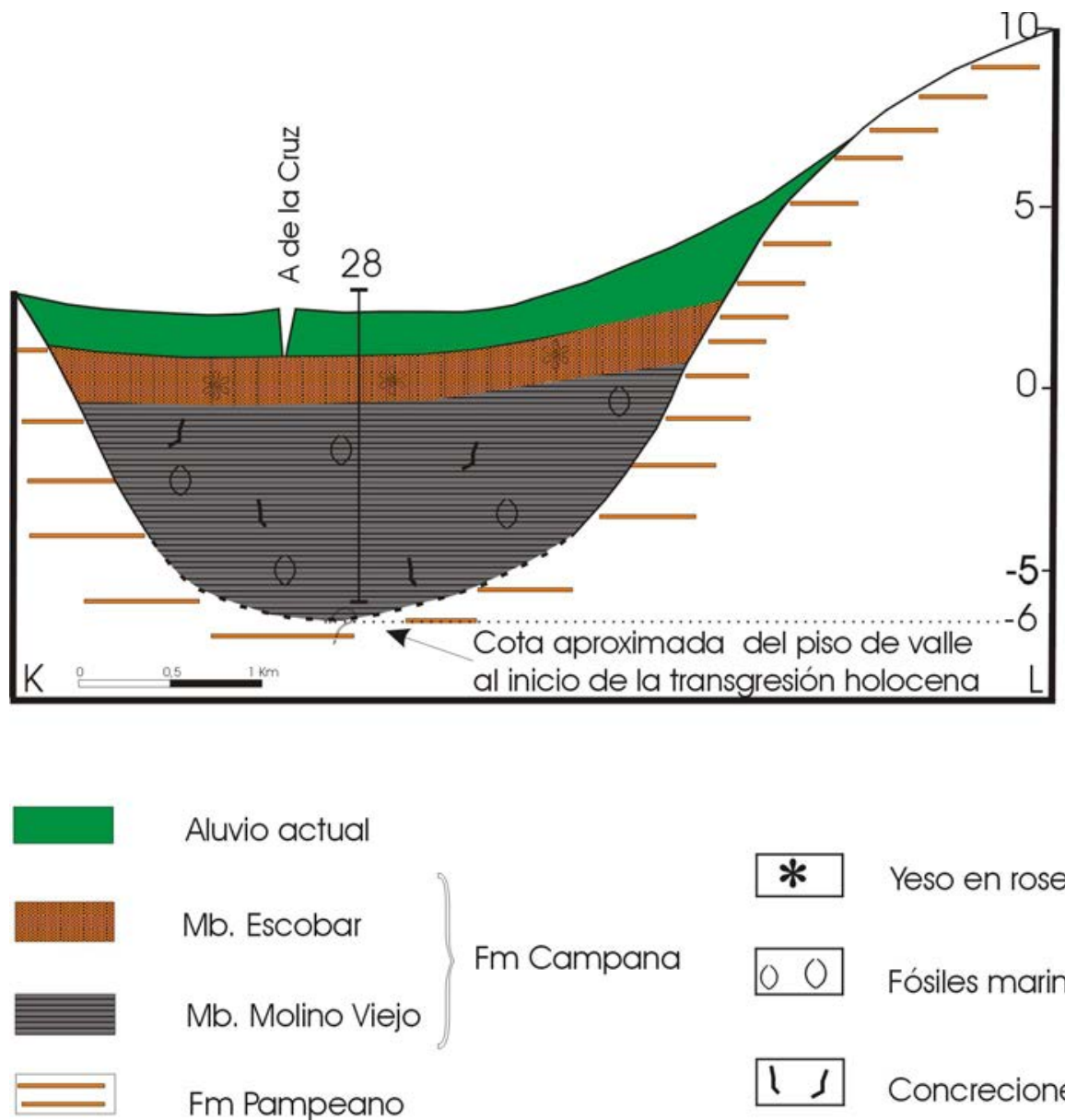

\section{* Yeso en rosetas}

Fm Campana

00 Fósiles marinos

1 Concreciones de tosca

Fig. 4.40 Perfil estratigráfico transversal al arroyo de la Cruz sobre la ruta 9

\section{OBSERVACIÓN N ${ }^{\circ} 62$}

Esta observación se realizó en la barranca de 1,5 m, continuándose a barreno manual sin alcanzarse el piso de la unidad. Se encuentra en la margen derecha del Arroyo de la Cruz a unos $4 \mathrm{Km}$ aguas arriba de la ruta 9 a una cota aproximada a los $3 \mathrm{~m}$. La geoforma corresponde al paleoestuario de este curso, donde las pendientes son plano a plano - cóncavas. (Fig. $4.8)$ 
UNIDAD A: Desde la superficie y con un espesor de 0,90 $\mathrm{m}$ se observa un sedimento limoso a limo arcilloso de color castaño grisáceo (2,5Y 5/2), con una tenue laminación. (Aluvio actual parcialmenente edafizado)

\begin{tabular}{|c|c|}
\hline \multicolumn{2}{|c|}{ REFERENCIAS } \\
\hline 0 & Re stos fó siles \\
\hline 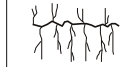 & Sue lo a c tual \\
\hline 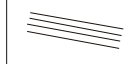 & Estra tific a c ión la $\mathrm{m}$ in a $\mathrm{r}$ \\
\hline & A rc illa s \\
\hline & $\operatorname{Lim}$ os \\
\hline
\end{tabular}

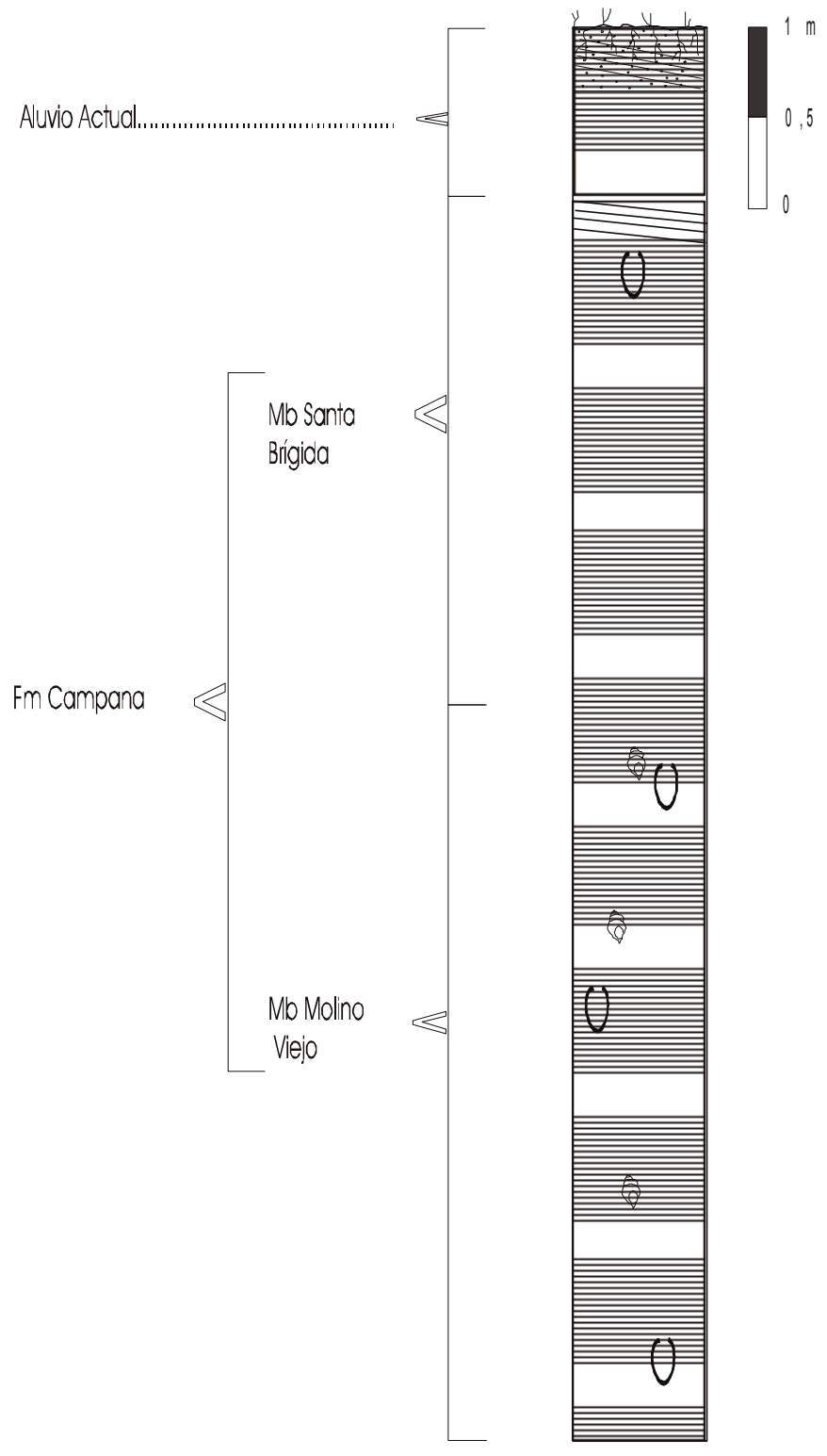

Fig. 4.41 Perfil estratigráfico de la observación nº 62

UNIDAD B: Entre los 0,90 y $1,30 \mathrm{~m}$ se presenta una arcilla castaña muy clara a gris verdosa (10YR 7/3 y hoja 2 gley 5/10G) con gran cantidad de manchas rojizas. El tramo presenta laminación paralela y concentraciones 
importantes de Erodona mactroides. Transicionalmente y hasta los 3,80 m se observa un sedimento arcilloso de color verde grisáceo (hoja 2 gley 5/10G), plástico y fácil de perforar. (Mb Santa Brígida, Fm. Campana)

UNIDAD C: A partir de los $3,80 \mathrm{~m}$ se presenta una arcilla gris verdoso oscuro (hoja 2 gley 4/10G) que se oscurece progresivamente hasta el fin de la perforación a los $7,8 \mathrm{~m}$ sin encontrar el piso de la unidad, donde toma un color negro oscuro (hoja 2 gley 2,5/10G) con escasos restos de Erodona mactroides. (Mb Molino Viejo, Fm. Campana)

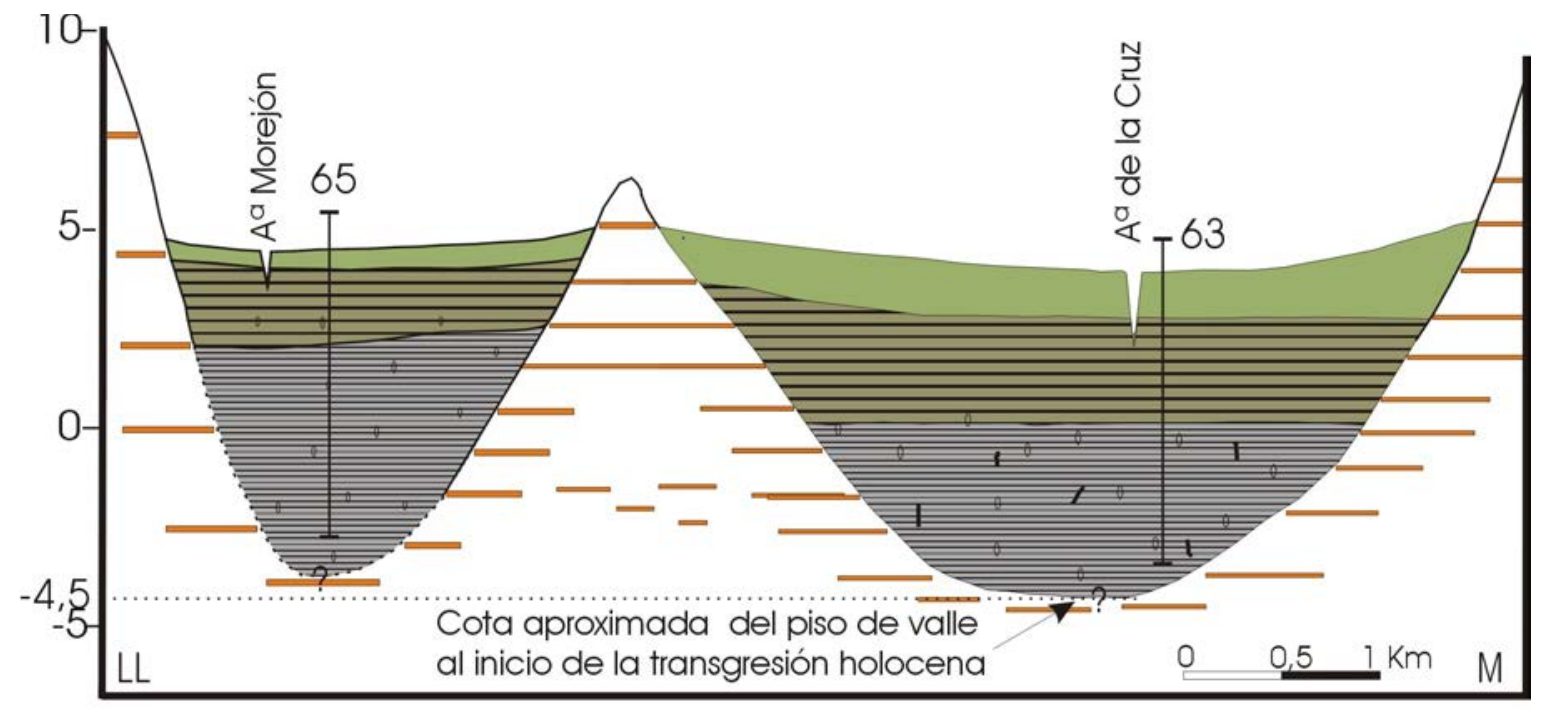

Sedimentos Fluviales Recientes

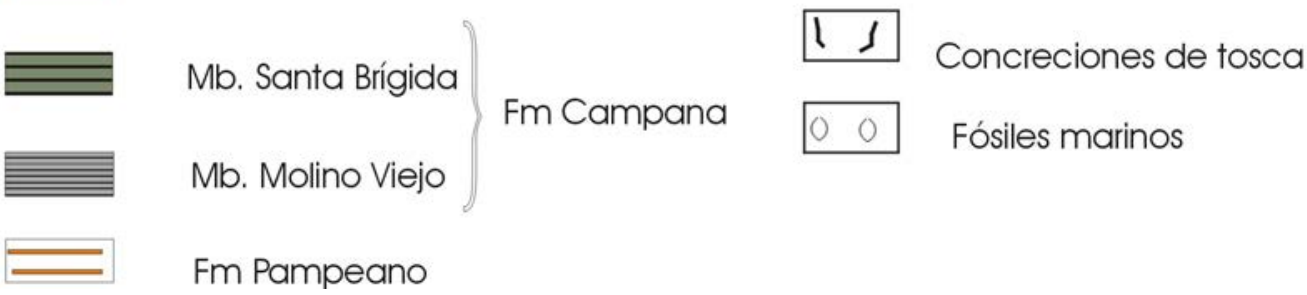

Fig. 4.42 Perfil estratigráfico trasversal al Arroyo de la Cruz frente al barrio Las Acacias. 


\section{OBSERVACION N ${ }^{\circ} 69$}

Esta observación se realizó mediante sondeo manual. Se sitúa en la margen derecha del Arroyo de la Cruz en cota aproximada de $4 \mathrm{~m}$. La geoforma atravesada corresponde al sector interno del paleoestuario de este curso, donde las pendientes son plano a plano - cóncavas. (Fig. 4.8)

UNIDAD A: Se Compone de un sedimento limoso de 0,40 m de espesor, de color castaño grisáceo a castaño amarillento (2,5Y 5/2), resistente y homogéneo. Por debajo, se presenta un sedimento arcilloso, plástico y adhesivo, gris muy oscuro (2,5Y 3/1) con estructura prismática fuerte de $0,75 \mathrm{~m}$ de espesor. (Aluvio parcialmente edafizado $\boldsymbol{y}$ suelo enterrado)

UNIDAD B: A los 1,15 $\mathrm{m}$ se observa en forma neta un sedimento arcilloso, de color verde, verde grisáceo (hoja 2 gley 5/10G a hoja 2 gley 10BG) muy plástico y adhesivo, con escasas concentraciones de tosca de dimensiones milimétricas.

A partir de los $1,40 \mathrm{~m}$ y hasta los $2,50 \mathrm{~m}$ toma un color gris muy oscuro $(2,5 y 3 / 1)$ de textura similar al tramo anterior, con mayor contenido de tosca. En sus $0,50 \mathrm{~m}$ inferiores presenta sectores localizados de tonos rojizos fuertes. (Mb Santa Brígida, Fm Campana)

UNIDAD C: A partir de los $2,50 \mathrm{~m}$ y hasta los $5,80 \mathrm{~m}$ se presenta una arcilla negra oscura (hoja 2 gley 2,5/10G) tixótropica (fluida), con Erodona mactroides, enteras y fragmentadas, y escasos concentraciones de tosca de forma equidimensional. No se halló el piso de la unidad. (Mb. Molino Viejo, Fm. Campana) 

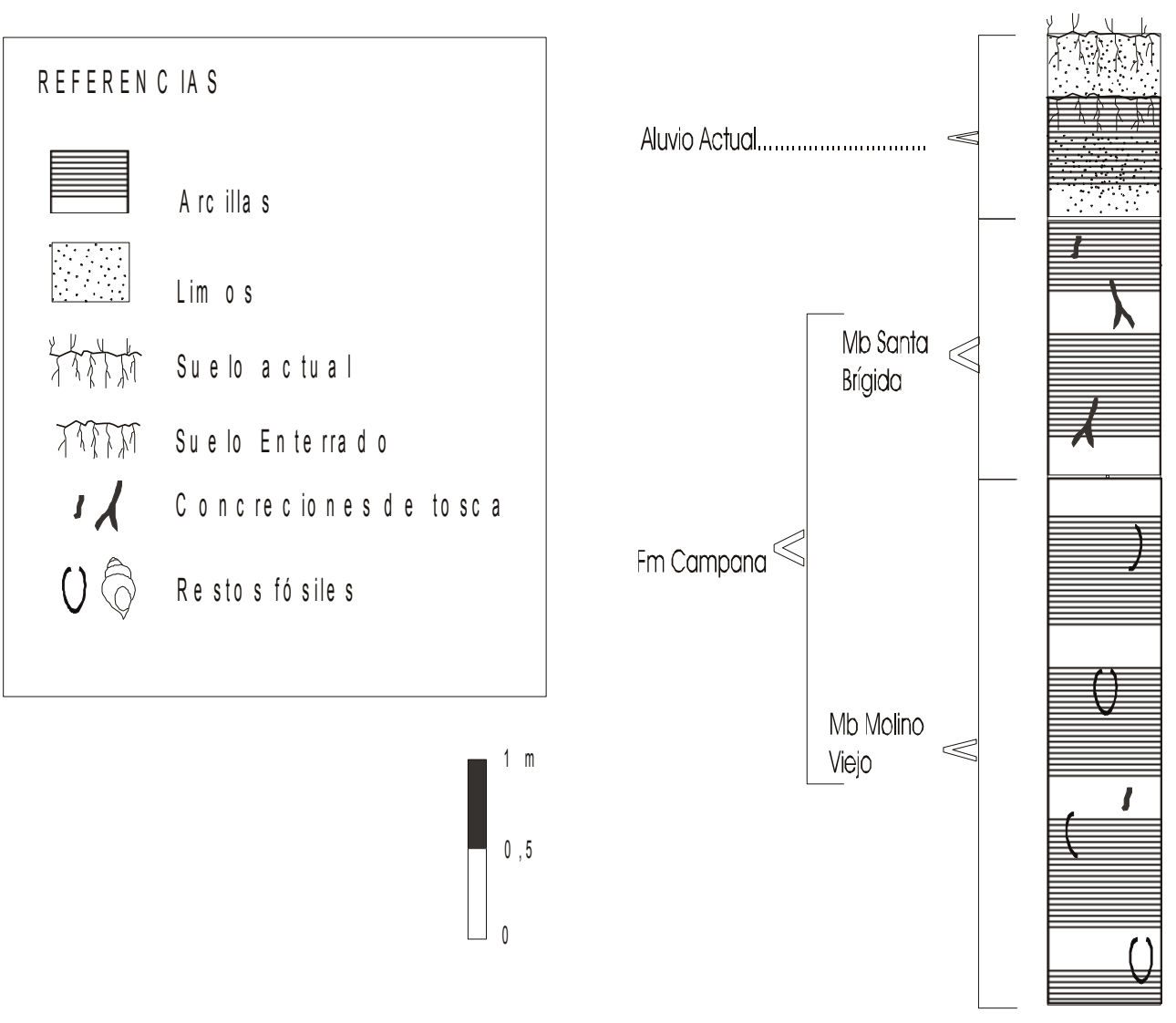

Fig. 4.43 Perfil estratigráfico de la observación nº 69

\section{OBSERVACIÓN No99}

Se desarrolla en el sector más interno del paleoestuario del Arroyo de la Cruz, en su margen derecha a una cota aproximada de $7 \mathrm{~m}$ en un relieve cóncavo (Fig. 4.8). La perforación efectuada mediante barreno presenta, de techo a piso:

UNIDAD A: Se observan $0,80 \mathrm{~m}$ de un sedimento limo arcilloso, castaño grisáceo $(2,5 y$ 5/2) y homogéneo que pasa hacia abajo a un limo de color gris $(2,5 Y$ 6/1). (Aluvio actual)

UNIDAD B: A los $0,80 \mathrm{~m}$ se pasa abruptamente a una arcilla plástica y adhesiva de colores castaños claro (10YR 7/3), gris verdosos (hoja 2 gley 
de 5/10G a 5/5PB) con un espesor de 1 metro, con escasas concreciones de tosca.

A partir de esta profundidad y con un espesor de 0,40 $\mathrm{m}$ se observa un sedimento arcilloso, castaño claro (1OYR 7/3), plástico y adhesivo. (Mb Santa Brígida, Fm Campana)

UNIDAD C: A los 2,20 m de profundidad se observa un sedimento limoso muy resistente a la penetración, de color castaño (7,5YR 5/3) con restos de tosca. (Fm Pampeano)

\begin{tabular}{|c|c|}
\hline \multicolumn{2}{|c|}{ REFEREN C IAS } \\
\hline & A rc illa s \\
\hline$\because \because$ & $\operatorname{Lim}$ os \\
\hline 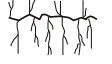 & Sue lo a c tual \\
\hline$s \lambda$ & Concrecionesde tosca \\
\hline
\end{tabular}

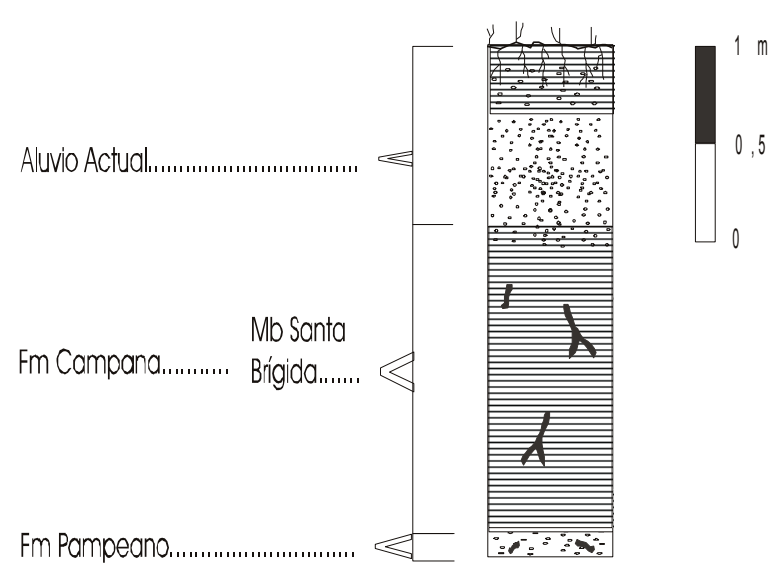

Fig. 4.44 Perfil estratigráfico de la observación nº 99 


\section{CAPITULO V}

\section{GEOMORFOLOGÍA}

Las oscilaciones climáticas que se produjeron durante al Cuaternario han tenido una influencia de indudable importancia en los diversos ambientes de acumulación-erosión en la región pampeana, desarrollándose, en consecuencia, una serie de geoformas que permiten definir un paisaje de génesis poligenético.

Si bien el aspecto general de la llanura pampeana está vinculada a acumulaciones sedimentarias de origen eólico y con diferentes intensidades al retrabajamiento de estos depósitos por acción del viento, el agua y la gravedad, los procesos fluviales han tenido desde el Pleistoceno tardío una participación muy activa en el modelado del paisaje, generando una red de drenaje organizada, dentro del ámbito de la región estudiada, con depositación de secuencias fluvio lacustres.

En áreas litorales, los ascensos y descensos del nivel del mar han permitido la generación de importantes geoformas y depósitos, con la consecuente influencia sobre los ambientes fluviales.

\section{1 CARACTERISTICAS GEOMORFOLOGICAS}

Las características observadas en la zona de estudio han permitido individualizar una serie rasgos geomórficos, cuyas características físicas, componentes litológicos y biológicos, permite realizar una clara diferenciación, entre geoformas vinculadas esencialmente con procesos continentales y otras, asociadas a paleoambientes litorales. Dentro de las primeras se destacan, como rasgos mayores, las cuencas de drenaje y los sectores de interfluvios, desarrollándose en éstos, un conjunto de depresiones cerradas relacionadas con procesos de deflación. (Fig. 4.7 y 5.1). 


\subsubsection{SECTOR CONTINENTAL}

El sector motivo del presente estudio se encuentra comprendido dentro de la Pampa Ondulada (Daus, 1946, Fidalgo, 1983), caracterizada por el desarrollo de cuencas fluviales con cauces bien definidos y moderada a buena integración de la red de drenaje. Estas cuencas que escurren hacia el sector deltaico y el "Río de la Plata" determinan, en general, un paisaje conformado por suaves ondulaciones, las que, fundamentalmente, desde Capital Federal hacia el norte, suelen presentar los contrastes topográficos más acentuados. Esta situación, en gran medida, estará relacionada con la influencia directa de los cambios de nivel de base originados por el Río Paraná, ya que desde la ciudad de Buenos Aires hacia el sur, la cubierta pampeana constituye una suave planicie que inclina suavemente hacia el Río de la Plata, disminuyendo acentuadamente los cambios de nivel de base.

\subsubsection{Cuencas de drenaje}

La mayor parte de la cuenca del Arroyo de la Cruz y el sector inferior de la cuenca Río Luján constituyen prácticamente la totalidad de la red de drenaje del área de estudio. Pequeños sectores son drenados por un conjunto de cursos menores, entre los que sobresale el Arroyo del Pescado y un tramo del Río Paraná de las Palmas.

\subsubsection{1.a Cuenca del Río Luján}

La cuenca presenta forma elongada en el sentido de escurrimiento SSO a NNE y un diseño de drenaje dendrítico. Esta compuesta por un gran número de tributarios, dentro de los que se destacan por su mayor desarrollo, los arroyos Los Leones, del Durazno, de Moyano, Leguizamón, Grande, de Oro y Balta, y en el sector de estudio los arroyos Carabasa, Burgos y de las Flores.

Representa la cuenca de mayor importancia en la zona de estudio con un área total aproximada de $3300 \mathrm{~km}^{2}$. Su cabecera en el Arroyo de los Leones, 
se encuentra fuera del área de estudio a $7 \mathrm{~km}$ al este noreste de la localidad de Castilla a una altitud de 48 metros aproximadamente. Las áreas interfluviales separan hacia el este, la cuenca del río Luján de la del Río Salado, hacia el norte las cuencas del Río Areco y del arroyo de la Cruz, y al sur la del arroyo Escobar y del Río de la Reconquista (Fig. 2.1).

Desde sus nacientes hasta su desembocadura en el "Río de la Plata", presenta una longitud de 243,9 km y una pendiente de 0,019 \%. A lo largo de su recorrido pueden observase tres sectores bien contrastantes. Desde las cabeceras hasta la cota de $25 \mathrm{~m}$ (Sector A, Fig. 5.1) el curso posee amplias áreas aledañas deprimidas, temporalmente anegables y que, ante precipitaciones intensas, son ocupadas por las aguas de escurrimiento. Esta situación se ve propiciada por las exiguas pendientes que se presentan con un gradiente del orden de los 0,036\%

Desde la cota de $25 \mathrm{~m}$ y hasta los $10 \mathrm{~m}$ se presenta una red de drenaje mejor integrada con pendientes de 0,05 \% y el curso principal confinado por barrancas de 5 metros de altura. Puede visualizarse en mapas e imágenes de satélite como el curso se presenta claramente confinado a un talweg estrecho y profundo (Sector B, Fig. 5.1).

Aguas abajo de la cota de 10 m y hasta su desembocadura en el "Río de la Plata", el curso se encuentra limitado entre barrancas que presentan alturas del orden del metro en términos generales, presentando una pendiente que alcanza los 0,012 \%, constituyendo el tramo de menor gradiente (Sector C, Fig. 5.1). Esta situación, sumada a una gran cantidad de caminos y líneas férreas dispuestas transversalmente, producen inundaciones que afectan a todo el ámbito aledaño al curso, geoforma vinculada genéticamente con la ingresión holocena y en su tramo final por el delta paranaense, situadas la mayor parte de estas geoformas en cotas cercanas a los 3 metros.

En relación a su diseño individual, fuera de la zona de estudio posee un diseño groseramente sinuoso a recto y dentro de la zona de estudio en las inmediaciones de Pilar y a partir de la cota de $9 \mathrm{~m}$ comienzan a 
desarrollarse amplios meandros, conformando una franja que varía de 100 a $500 \mathrm{~m}$, pasando en algunos sectores a presentar un diseño individual sinuoso.

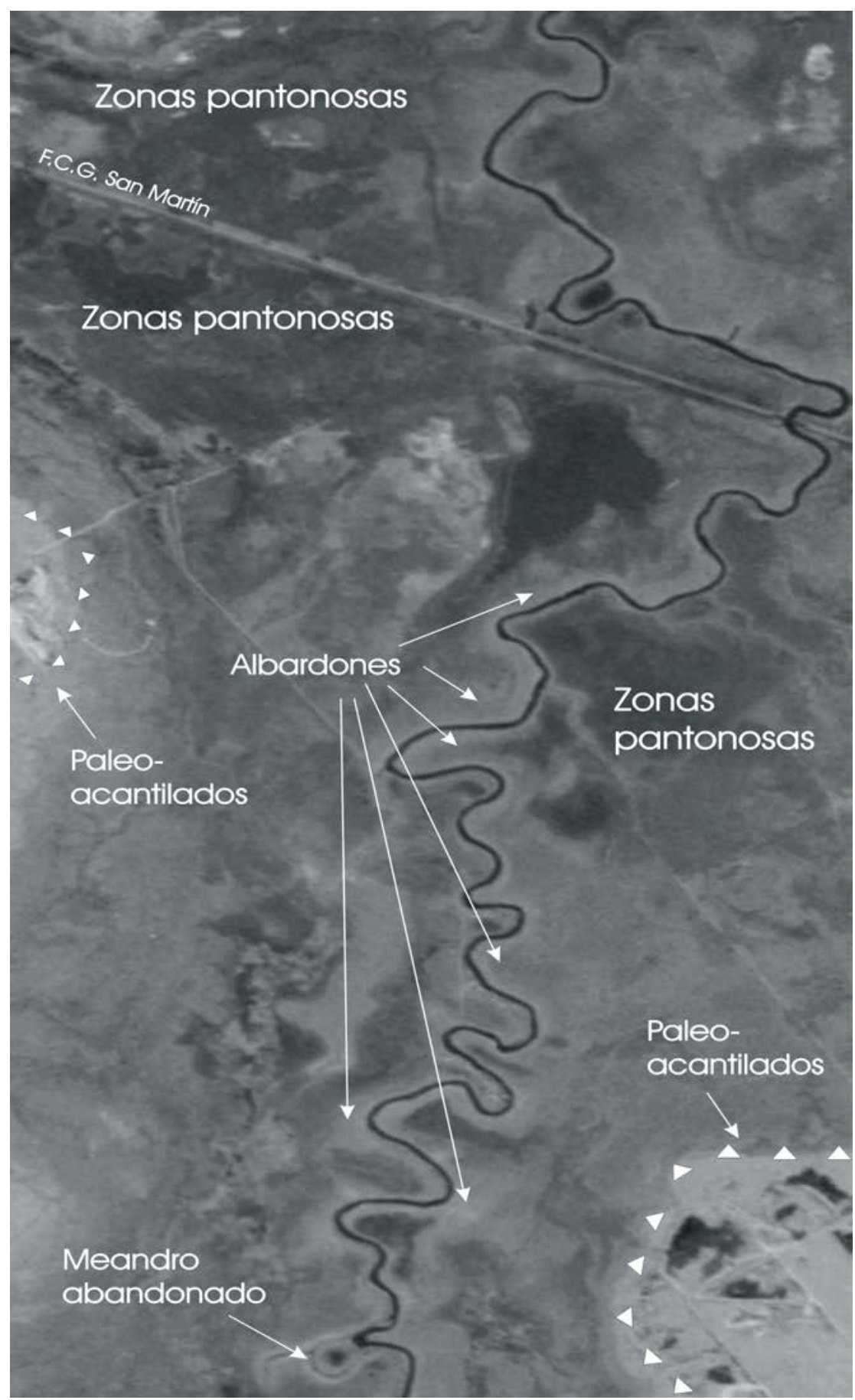

Fig. $\quad 5.2$ Río Luján exponiendo su diseño individual meandroso a sinuoso

Asociado a este curso pueden observarse otras formas de erosión y acumulación fluvial (albardones), zonas inundables y barrancas que 
indican el límite de la ingresión marina, constituyendo acantilados relictos de dimensiones escasas $(2 \circ 3 \mathrm{~m}$ ) pero con pendientes que pueden superar los $30^{\circ}$ (Fig. 5.2).

En su tramo inferior, en cercanías de la ruta 9, en un franja de 400 metros de ancho aproximado, los meandros se acentúan notablemente, observándose con mucha claridad depósitos de barras en espolón (Point Bar) y en sus inmediaciones meandros abandonados, constituyendo estas últimas lagunas semicolmatadas. Este diseño se manifiesta claramente hasta el contacto con el canal aliviador Santa María (Fig. 5.3).

A partir del contacto con el canal santa María, el Río Luján cambia de dirección y de diseño (fig. 5.4) presentando numerosos quiebres a $90^{\circ}$. Esta condición se desarrollaría a partir de este punto por la progradación deltaica, adaptándose el curso a la línea de costa del estuario platense por su margen derecha representado por la llanura costera y sus crestas de playa y por su margen izquierda a los depósitos deltaicos.

El contraste que existe a ambas márgenes de este curso se manifiesta no solo por las rasgos geomorfológicos principales y textura de drenaje, sino por las unidades litoestratigráficas identificadas en perforaciones. Hacia la margen derecha los depósitos sedimentarios corresponden a la fm Campana, Miembros Escobar y Molino Viejo en orden descendente, con un espesor de unos 5 a 6 metros, mientras que hacia la margen izquierda se sitúan los depósitos deltaicos limo arcillosos, oscuros, con abundante cantidad de materia orgánica. En forma infrayacente se desarrollan los depósitos litorales del Mb Molino Viejo (Fucks y De Francesco, 2003; Bonfils, 1962). 


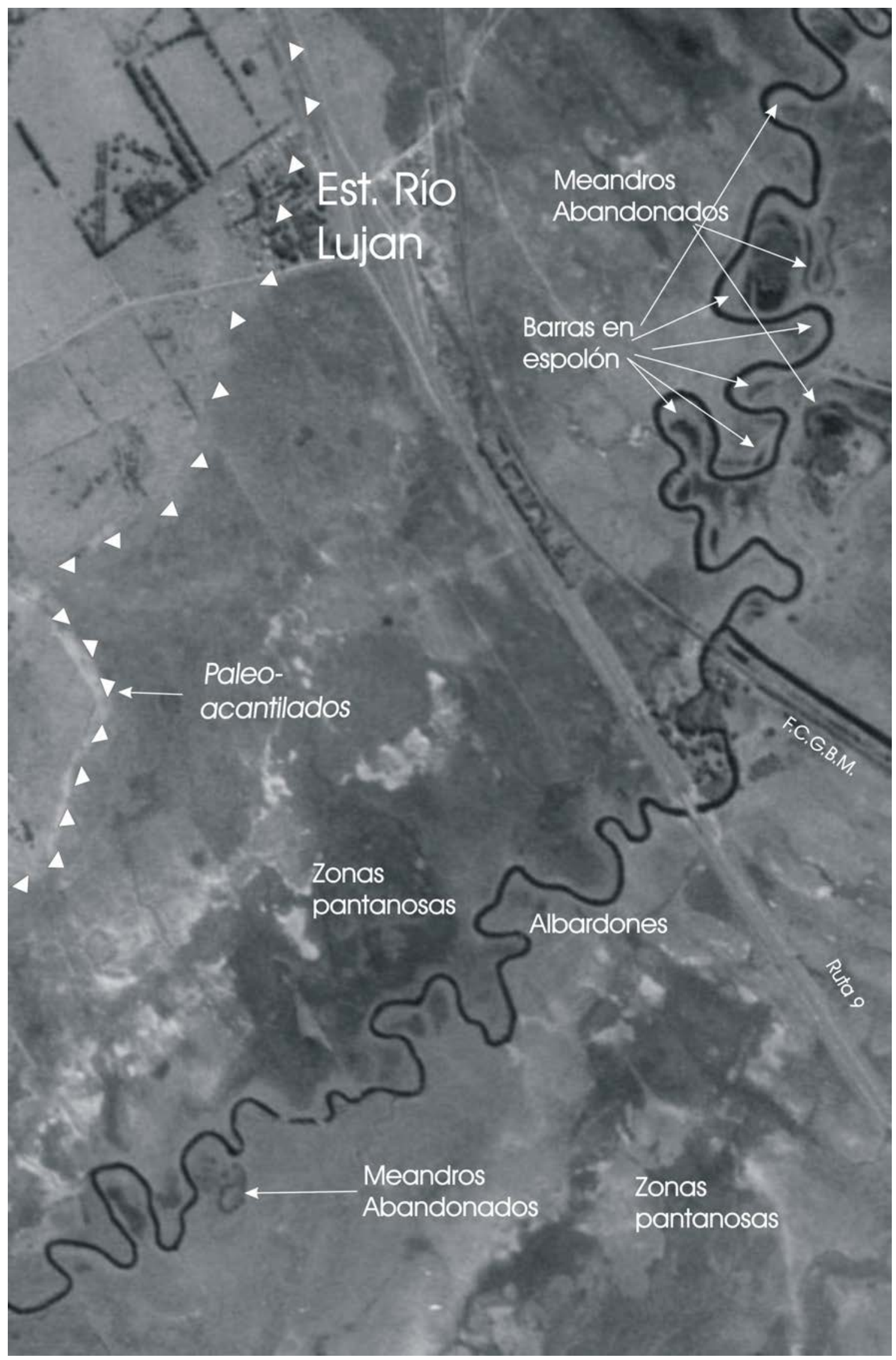


Fig. 5.3 Río Luján con diseño individual meandroso. 


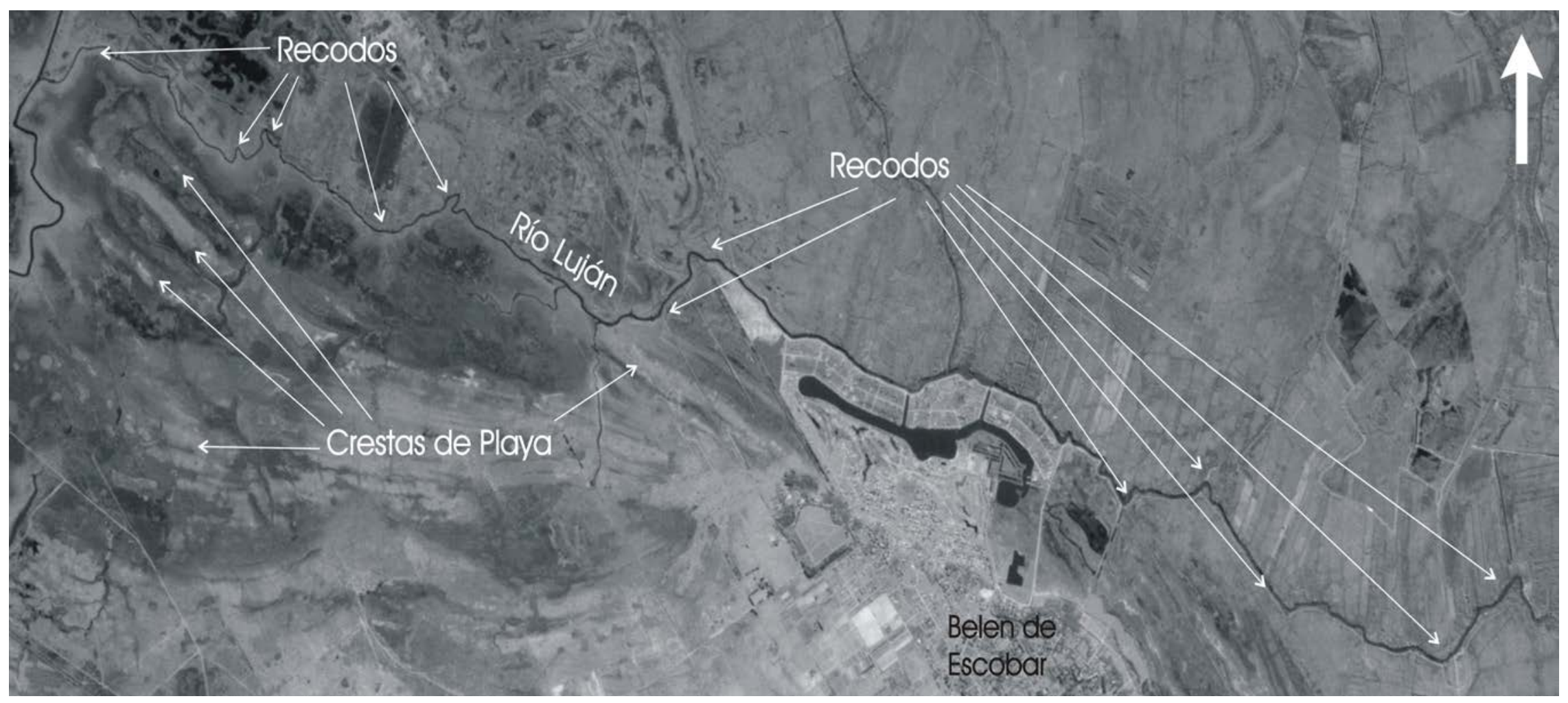

Fig. 5.4 Río Luján donde se observa el tramo final en la zona de estudio con los quiebres en ángulo recto. 
La continua variación de la posición de la desembocadura en el estuario platense constituye un típico ejemplo de alargamiento de cursos de agua. Si bien existen diferentes mapas de la época de la colonia con detalles variables, puede determinarse que el alargamiento particular del Río Luján por la variación continua de la posición de su desembocadura esta en el orden de los $50 \mathrm{~km}$ en los últimos 250 años implicando un promedio de alargamiento de $200 \mathrm{~m}$ por año (Fig. 5.5). Este hecho a determinado que cuencas independientes con drenaje al Río de la Plata sean paulatinamente incorporadas a la cuenca del Río Luján, tal como las cuencas del Arroyo Escobar y del Río de la Reconquista.

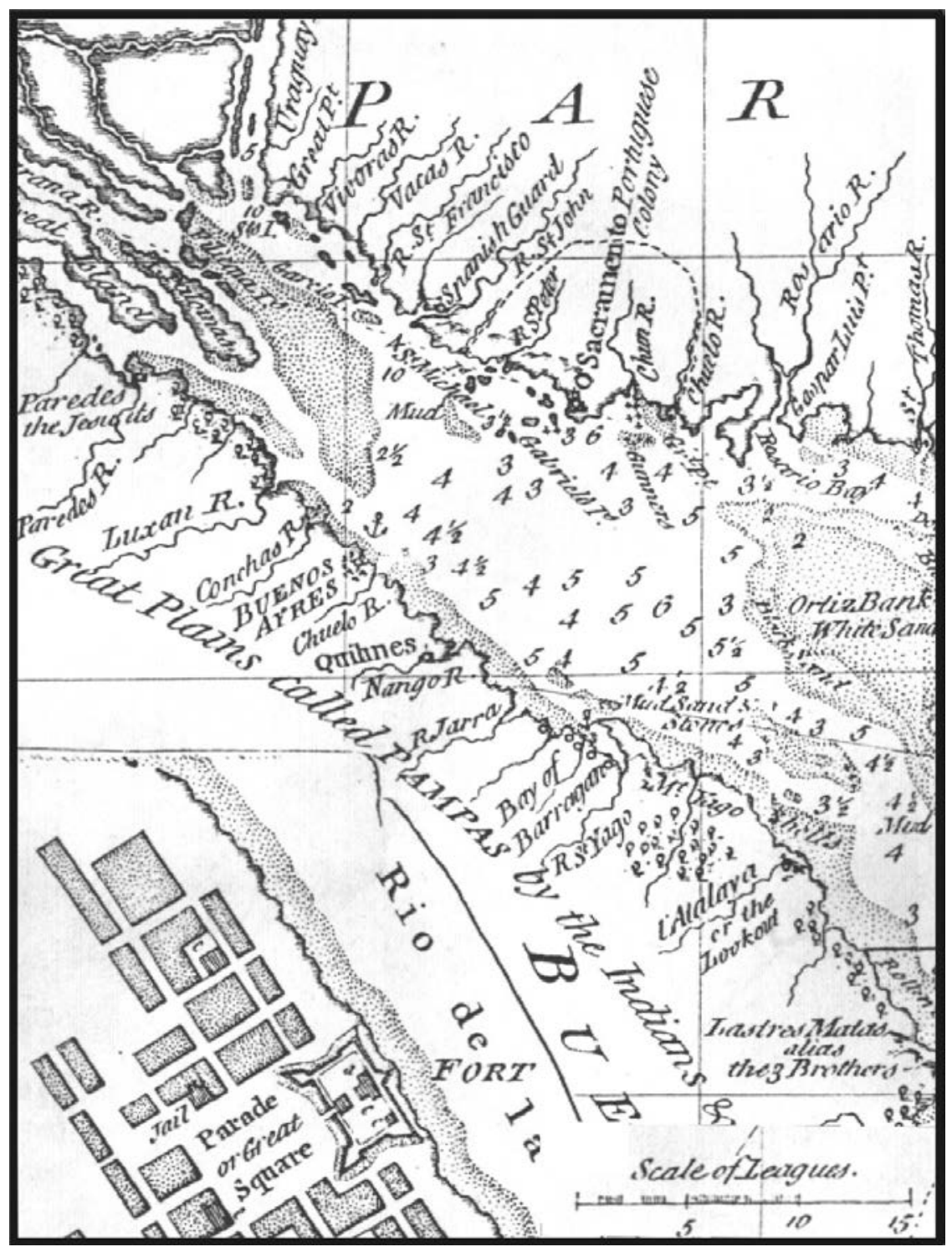

Fig. 5.5 Mapa parcial de 1783 donde se observa la posición del delta con respecto al Río Luján (Cardiff, 1936). 
En el ámbito continental, los procesos fluviales desarrollados, tanto en el Río Luján como en sus afluentes, pueden observarse áreas deprimidas, con abundante vegetación hidrófila, que presentan dimensiones muy variadas, que van de escasos metros en las líneas de escurrimiento de menor magnitud, hasta 700 metros en el curso principal, tal como puede observarse en las adyacencias de la localidad de Manzanares.

Estas geoformas constituyen los ámbitos más proclives a ser afectados por inundaciones y se caracterizan, salvo en el curso principal, por presentar un relieve suave, cóncavo a plano - cóncavo y con canales de escasas dimensiones ( 2 a 3 metros de ancho). Estas características hacen que durante los aumentos de caudal, el agua desborde rápidamente y se mueva en forma mantiforme por toda la depresión.

Es general, estos cursos tienen desarrollado su talweg sobre la Fm Pampeano, observándose en sus márgenes, de acuerdo a su antigüedad, depósitos del Aluvio actual o Fm Luján.

La cuenca de drenaje del Río Luján ha tenido, fundamentalmente durante el Holoceno, la influencia de la ingresión marina, la que le ha impreso una morfología muy particular. Asimismo, dada la presencia a lo largo del ultimo tramo del curso de depósitos de la Fm Pilar (Ruta 9 y Pilar), podría estimarse la existencia de la depresión con anterioridad a los 120.000 A.P. Esta situación es también observada a en otras cuencas vecinas de dimensiones similares a la tratada, quedando asimismo expuesta en el tramo inferior de la cuenca del río salado (Violante y Parker, 1999; López, 2000).

Debido a los procesos litorales sufridos durante el Holoceno, el tramo final del curso se desarrolla en el paleoestuario conformado por esta ingresión, geoforma que será descripta más adelante.

\subsubsection{1.b Cuenca del Arroyo de la Cruz}

Esta cuenca se ubica al norte de la anterior, abarcando una superficie $870 \mathrm{~km}^{2}$. Presenta su cabecera a unos $700 \mathrm{~m}$ al oeste de la localidad de 
Villa Espil a una altitud de 42,5 m y su desembocadura en el Río Paraná de Las Palmas al norte de la ciudad de Campana. Los límites están constituidos por las divisorias que la separan de la cuenca del Río de Areco y Arroyo Pesquería al noroeste y la del Río Luján al este y sureste (Fig. 2.1).

Se desarrolla con una dirección suroeste - noreste, con forma elongada y diseño de drenaje dendrítico. Está constituida por un gran número de afluentes, entre los que sobresalen el Arroyo Romero y el Arroyo Morejón.

El curso principal tiene una longitud total de 65,7 km y un gradiente de 0,065 \%, caracterizado por un diseño individual sinuoso, llegando en un sector de su tramo final a desarrollar un diseño de tipo meandroso. El gradiente a partir de la cota de 5 metros presenta valores del orden de los $0,015 \div$.

A partir de la cota de $5 \mathrm{~m}$ y hasta su desembocadura, en el ámbito de la ingresión marina holocena (postglacial), el curso principal se desarrolla en un relieve plano a plano cóncavo, observándose una gran cantidad de cursos pequeños que en su mayoría no llegan a alcanzarlo, dada la presencia de albardones que determinan la existencia de amplias zonas anegadas (Fig. 5.6.). 


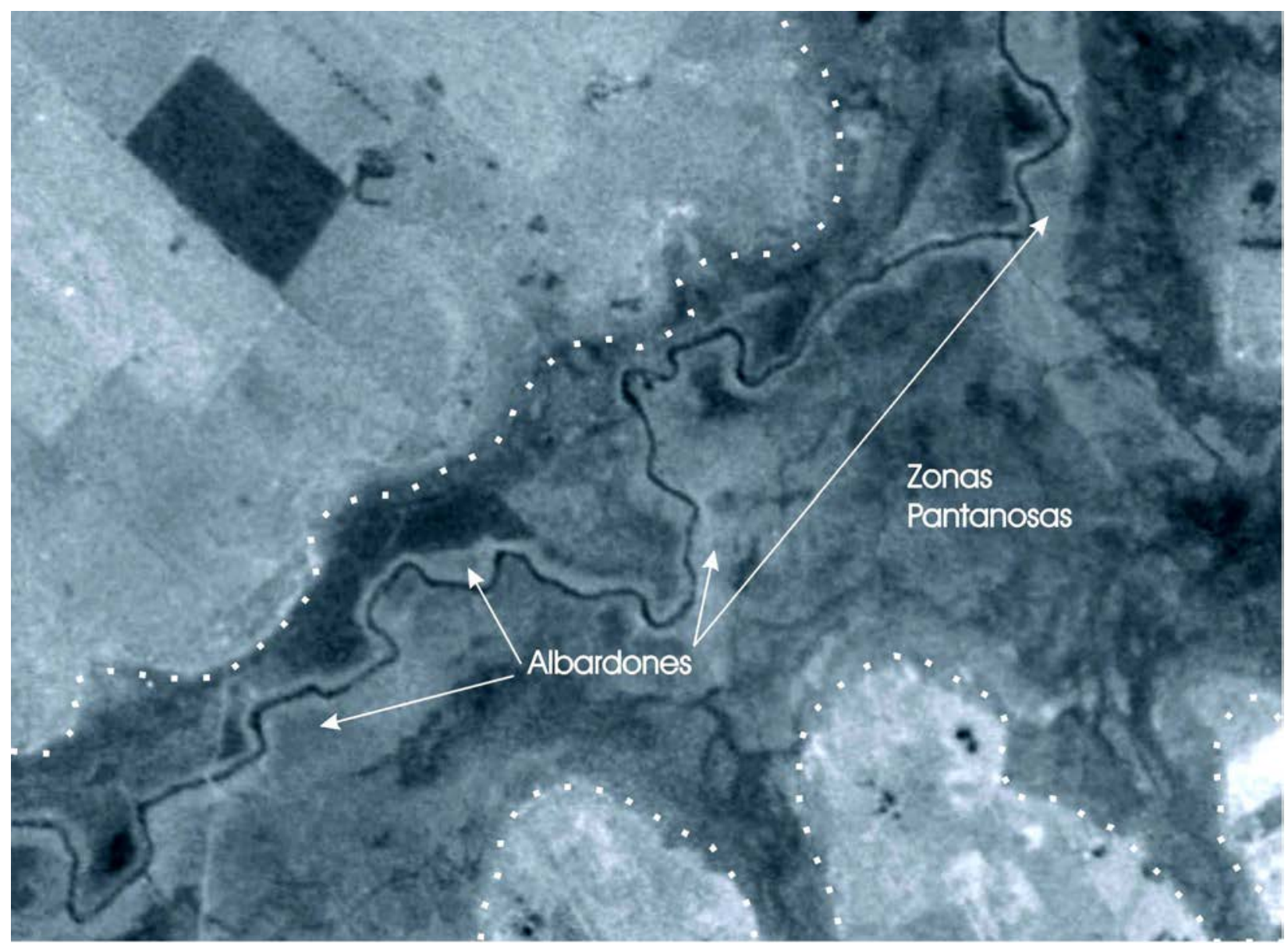

Fig. 5.6 Arroyo de la Cruz escurriendo en el sector más interno del paleoestuario

En las inmediaciones de la ruta 9, en la boca del paleoestuario presenta un diseño meandroso, con escasos meandros abandonados y una gran cantidad de cursos sinuosos de escaso desarrollo. Este diseño se desarrolla localmente ya que a partir de la unión del Arroyo Morejón lo hace en forma sinuosa (Fig. 5.7.). 


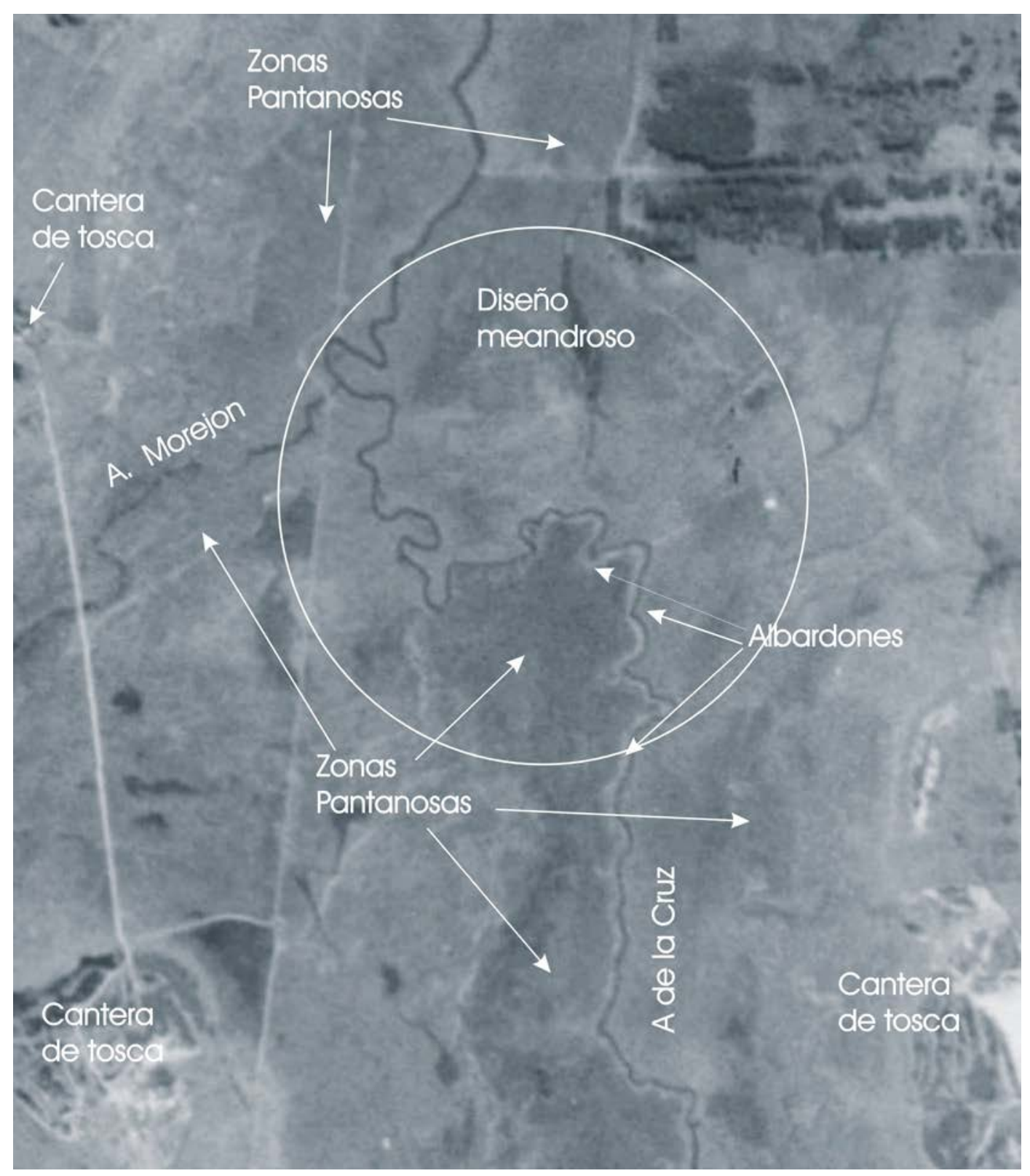

Fig. 5.7 Diseño meandroso del A. de la Cruz cercano a su desembocadura

En el ámbito de su desembocadura en el Río Paraná de las Palmas se presenta con suaves sinuosidades, contrapuesto a lo que sucede con el adyacente arroyo Pequería. Analizando específicamente este sector a través de fotografías aéreas, puede observase la presencia de un paleocauce que unía a los arroyos de la cruz con el Pequería. Esta situación estaría indicando la fluencia del primero al Arroyo Pequería y la salida al Río Paraná de las Palmas sería única para el desagüe de la laguna formada en el interior de estos cursos. Los paulatinos procesos de 
agradación llevaron a la colmatación de esta laguna costera, produciendo también la colmatación y abandono de este curso, conformando un desague independiente (Fig. 5.8).

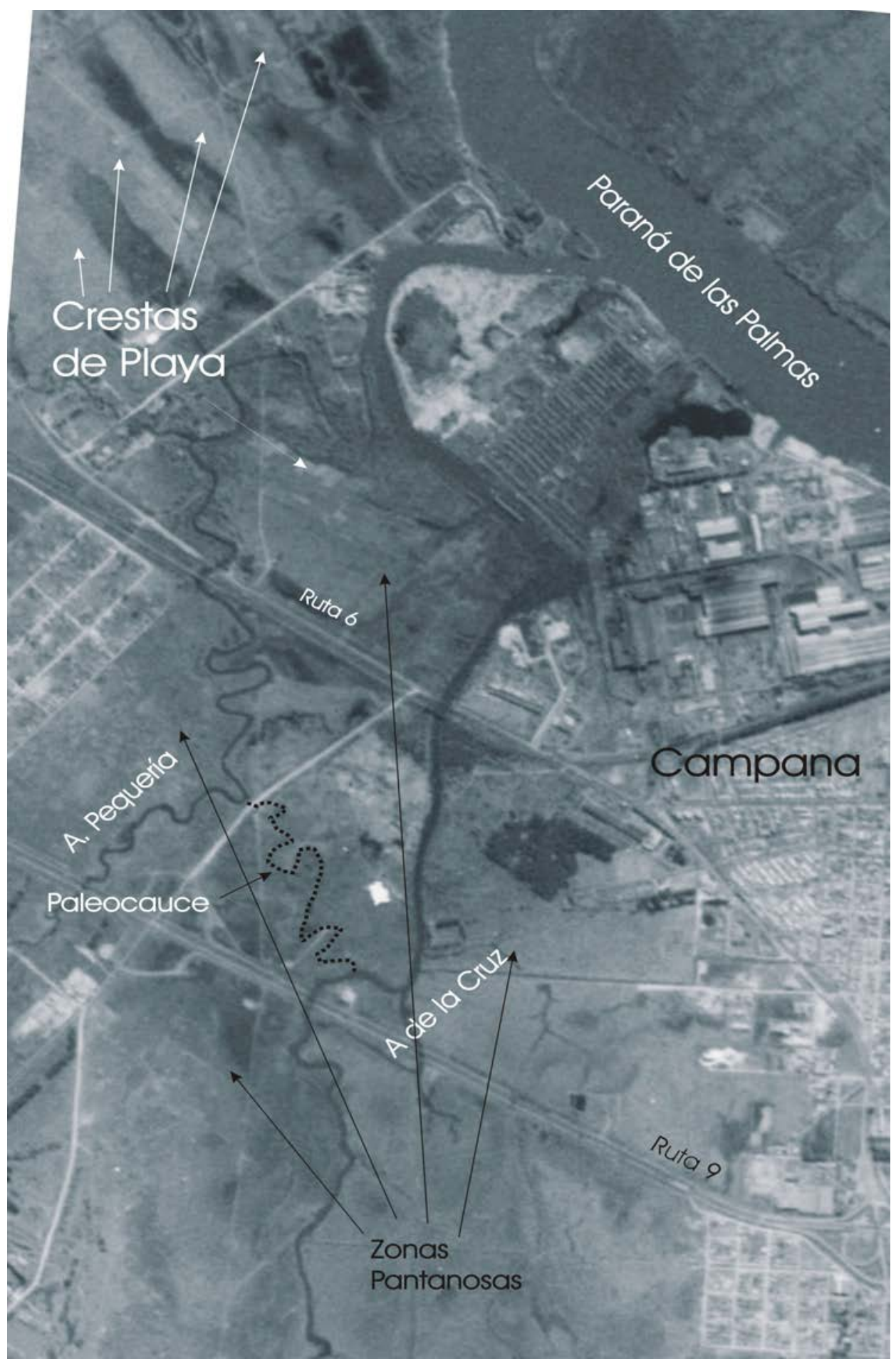

Fig. 5.8 Características del arroyo de la Cruz en el sector de su desembocadura. 
Desde el punto de vista geomorfológico, las diferencias observadas entre las cuencas del Arroyo de la Cruz y del Río Luján, están vinculadas fundamentalmente al menor desarrollo areal de la primera, determinando en consecuencia la menor amplitud del estuario. Si bien se han identificado en esta cuenca depósitos fluviales del Mb La Chumbiada, el escaso espesor y desarrollo que presentan estos sedimentos indicarían una integración de la cuenca muy posterior y vinculada con la integración de cuencas cerradas (Fidalgo et al., 1973 b) .

\subsubsection{1.c Cuenca del Arroyo El Pescado}

Esta cuenca se halla ubicada entre las cuencas mencionadas precedentemente, presentando su cabecera a unos $700 \mathrm{~m}$ al noroeste de la localidad de Cardales en cota de $26 \mathrm{~m}$. Su desembocadura se produce dentro de la llanura litoral en la laguna de igual nombre a una altitud de 2,2 m. La misma presenta forma elongada en el sentido suroeste noreste, con un diseño subparalelo y escasos números de tributarios.

El curso principal se desarrolla a lo largo de 14,2 km, con un diseño sinuoso, presentando una pendiente longitudinal de 0,16 . Si consideramos el tramo a partir de la curva de nivel de 5 metros, se observa una disminución notable de su gradiente, con un valor de 0,05\%. La pendiente comparativamente más importante con respecto a las cuencas anteriores se debe al escaso desarrollo areal de la misma, presentando en su tramo final $(<5 \mathrm{~m})$ valores similares a las demás cuencas.

\subsubsection{1.d Otras Cuencas y Cursos}

La gran mayoría de los cursos menores presentan cauces pequeños pero bien definidos, desarrollándose desde sus nacientes hacia la llanura litoral, donde muchos de éstos desaparecen. Otros se desarrollan directamente en esta geoforma y sobre el "sector deltaico", drenando amplios sectores pantanosos. También se puede observar en estas geoformas, una gran cantidad de lagunas entre las que sobresalen las Laguna Grande y del 
Pescado y una gran cantidad de obras (canales y zanjas) que favorecen la evacuación de las aguas hacia el Río Paraná de la Palmas.

Aparte de las cuencas y cursos anteriormente descriptos, se observan un conjunto de cursos, como el tramo del Río Paraná de las Palmas que constituye el limite Noreste del área de estudio. Posee un sentido de escurrimiento noroeste-sureste y un diseño individual sinuoso, un ancho de $450 \mathrm{~m}$ y una profundidad aproximada entre 15 y 20 m, formándose a la altura Baradero de la bifurcación del Río Paraná Guazú.

Otro curso importante es el Arroyo Las Rosas, que con una longitud de 7 km escurre con un sentido nornoroeste - sursureste y comunica el Río Paraná de las Palmas con el Río Luján. Es de destacar que este arroyo constituye unos de los primeros cursos activos en describir este trayecto, ya que aguas abajo de éste se desarrollan otros que, también originados en el Río Paraná de las Palmas, drenan hacia el río Luján, conformando en su conjunto un diseño distributario en la parte terminal del Río Paraná de las Palmas.

Como complemento de las líneas de escurrimiento naturales se observan un conjunto de canales de drenaje artificiales con secciones diferentes, construidos en la "llanura litoral" y en el "sector deltaico", permitiendo fundamentalmente el desagüe de los excesos hídricos, aunque en ocasiones por ausencia de compuertas, producen el efecto contrario, ya que el mayor nivel del Río Paraná de las Palmas (por sudestadas o inundaciones ordinarias o extraordinaria) produce la inundación más rápida de áreas no afectadas directamente por estos cursos. El canal de mayor importancia, lo constituye el Canal Santa María que se desarrolla desde el Río Luján hacia el Paraná de las Palmas con rumbo SSO-NNE a lo largo de $7,2 \mathrm{~km}$. La construcción de este canal permitió evacuar prácticamente la totalidad de las aguas de este río en épocas normales, impidiendo el escurrimiento normal del tramo del curso que se desarrolla desde este canal hasta el Arroyo Las Rosas. El tramo mencionado precedentemente presenta un caudal muy escaso, que se atrofia, salvo en períodos de inundaciones. 


\subsubsection{Albardones}

Estas geoformas puede observarse fundamentalmente en los cursos principales. Poseen una altura de 0,35 - 0,50 m, la que disminuye hacia la planicie de inundación, hasta confundirse con los depósitos aluviales de las áreas inundables. Las dimensiones de estas formas están directamente asociadas con el desarrollo de los cursos de agua, especialmente con las dimensiones de sus cuencas de drenaje. En general, puede considerarse que estas geoformas como término medio, presentan valores de 15 a $20 \mathrm{~m}$ de ancho. Están integrados por sedimentos limosos a limos arenosos, de color gris claro a castaño grisáceo, en general con estructura masiva, aunque en sectores pueden presentar una laminación muy tenue, disturbada generalmente por procesos edáficos. Se disponen de forma discordante sobre las unidades fluviales más antiguas y/o sobre suelos enterrados o unidades litoestratigráficas litorales.

En determinados sectores, propiciados por disminuciones marcados de las pendientes y actividades antrópicas (caminos y líneas férreas), que en conjunto hacen disminuir la velocidad de escorrentía, se producen acumulaciones excepcionales superiores a los 3 m (Fig. 4.20).

\subsubsection{DIVISORIAS}

Constituyen extensas áreas de pendientes plano a plano convexas, muchas veces dificil de preciar, que limitan las cuencas y subcuencas de drenaje.

Entre las cuencas y cursos mencionadas precedentemente pueden reconocerse divisorias, a partir de las cuales inicialmente en forma mantiforme, el agua escurre pendiente abajo, hasta encauzarse en las líneas de drenaje.

La divisoria principal de la región separa las aguas que escurren hacia el "Río de la Plata" y Río Paraná de aquellas que lo hacen hacia el Río Salado, constituyendo el límite de la Pampa Ondulada. A partir de esta 
geoforma primaria se desprenden las divisorias de menor rango que separan las aguas de las cuencas de los Arroyos Burgueño - Escobar y del Río Luján; la de este último y el Arroyo de la cruz y la de éste con el Arroyo Pequería (Fig.2.1).

La divisoria situada al este sur este de la cuenca del Río Luján, presenta una dirección general nor noreste - sur suroeste, asentándose las localidades de Pilar, Villa Rosa y Belén de Escobar. Su ancho varía de centenares de metros a varios kilómetros y se mantiene a través de una distancia de $26 \mathrm{~km}$, aproximadamente. Presenta su mayor altitud en el borde sur del área de estudio, donde alcanza los $30 \mathrm{msnm}$, para disminuir en dirección nor noreste y finalizar abruptamente a una altitud de $20 \mathrm{~m}$ en la localidad Escobar.

Presenta en sentido longitudinal un relieve ondulado, de escasas pendientes, mientras que en sentido transversal adopta, fundamentalmente, forma convexa con sectores planos y localmente cóncavos.

La divisoria que separa las cuencas del Río Luján y del Arroyo de la Cruz presenta una dirección similar al anterior $y$ una longitud de $47 \mathrm{~km}$ aproximadamente. Sus mayores alturas se sitúan en las inmediaciones de la localidad de Carlos Keen con 38 msnm, que junto con las localidades de Torres, Pavón, Los Cardales y Campana se desarrollan hacia el noreste, para finalizar abruptamente a una cota de $25 \mathrm{~m}$. Presenta características similares al anterior, aunque con una extensión mayor en sentido transversal y predominio de superficies planas sobre las convexas y cóncavas.

Por último, la divisoria que separa al Arroyo de la cruz del Arroyo Pesquería, constituyendo a la vez el límite noroeste del área de trabajo, presenta una dirección sur suroeste - nor noreste, y una longitud de 26 km. Puede observarse que su mayor altitud se ubica en el sector este del área con 38 msnm para descender suavemente en dirección nor noreste, hasta los $5 \mathrm{~m}$. A excepción de las dos anteriores, esta divisoria presenta una dirección predominante rectilínea, como así también la pendiente 
longitudinal se caracteriza por descender suavemente con un valor de 0,12 \% Estas características están asociadas al desarrollo de esta geoforma en un sector interno del continente (paleoestuario de los arroyos de La Cruz y Pequería), en contraposición con los anteriores, que fueron afectados directamente en la parte terminal por la acción erosiva del mar con la consecuente formación de acantilados.

Estas geoformas constituyen los sectores más propicios para el desarrollo de actividades productivas, entre las que podemos mencionar a las explotaciones agropecuarias extensivas e intensivas debido a la importante profundidad que alcanzan los perfiles de suelo, asentamientos urbanos tradicionales y los nuevos tipos de urbanización y, dado el tipo de material de las unidades litológicas que las conforman, el desarrollo de actividades extractivas, entre las prácticas más comunes.

\subsubsection{DEPRESIONES CERRADAS}

A lo largo y ancho de todas las divisorias, especialmente en la ubicada entre los arroyos de la Cruz y Pesquería, se observa el desarrollo de una gran cantidad de depresiones de forma equidimensional y con diámetros que raramente superan los $300 \mathrm{~m}$. Su profundidad es inferior a los 2,5 m, encontrando en su interior cuerpos de agua transitorios (Fig. 5.9).

En general, carecen de líneas de drenaje convergentes hacia ellos, observándose en casos puntuales, la captura de estas geoformas por cuencas de drenaje.

Estas depresiones pueden observarse con gran nitidez en fotografías e imágenes de satélite con tonalidades oscuras, como así también en los mapas de suelos, los que indican la escasa aptitud agropecuaria. 


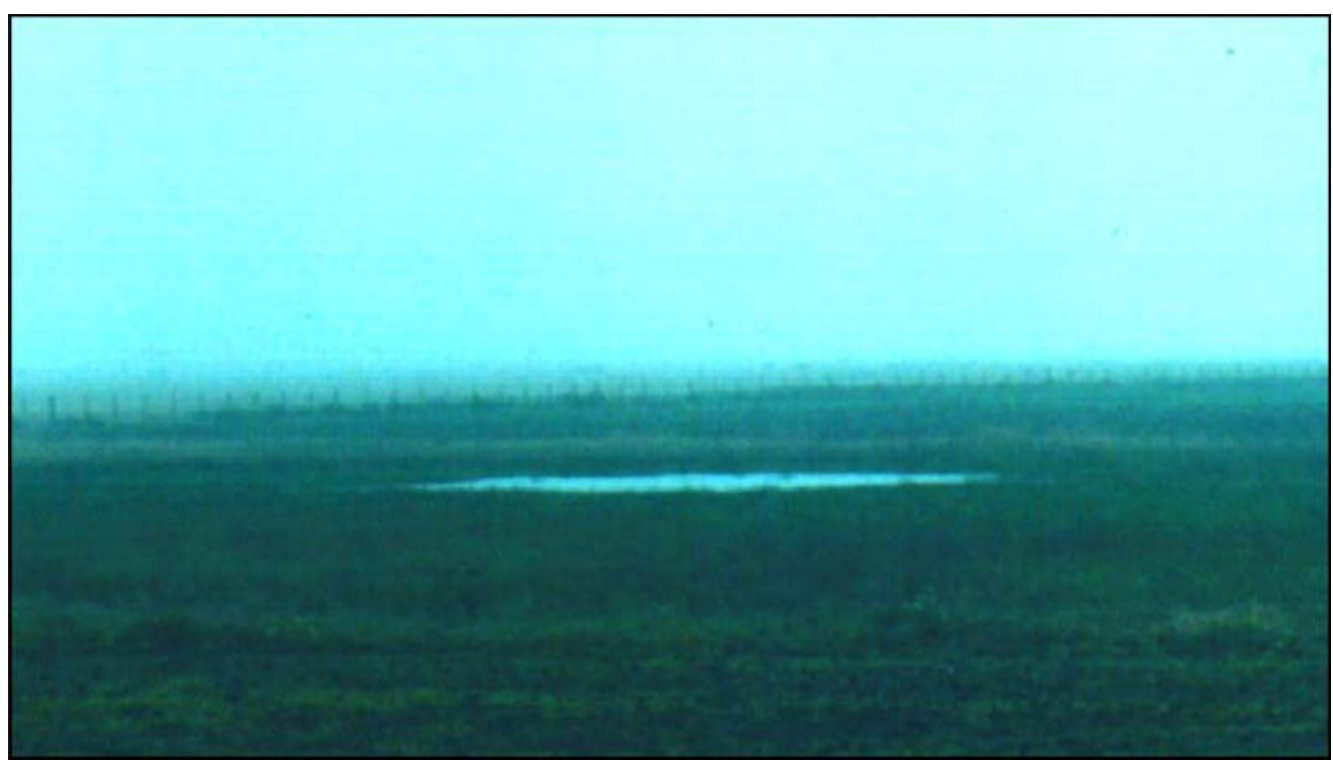

Fig. 5.9 Fotografía de un bajo parcialmente inundado

La génesis de estas formas podría estar vinculada a los ciclos climáticos áridos, y asociados a los depósitos loéssicos de la Fm La Postrera, originados a partir del Pleistoceno tardío (Younger Dryas) Iriondo y Krohling, 1996. Asimismo, la presencia de depósitos fluvio lacustres de escaso desarrollo del Mb La Chumbiada, interpretados como relleno de una cuenca cerrada, permitiría establecer una edad previa para algunas de estas geoformas, que sería anterior o simultánea con la base de la Fm Luján. Esta situación esta asociada a lo establecido por Fidalgo et al., (1973), donde proponen una génesis para la red de drenaje pampeana relacionada a la unión de estas cuencas cerradas.

Tricart (1973) considera que estas cuencas cerradas están asociadas a los depósitos eólicos E1 y E3, excavadas en los Sedimentos Pampéanos.

Un gran numero de estas depresiones desarrolladas en todas las geoformas del Mar de Arena Pampeano con forma elíptica y rumbo SO-NE y E-O y actualmente ocupadas por agua, fueron reconocidas al sur de Santa Fe y atribuidas a un clima seco y frío del Pleistoceno tardío - Holoceno inferior (Iriondo y Krohling, 1996).

Asimismo, en la cuenca del Salado se diferencian una gran cantidad de lagunas correspondientes a cuencas de deflación con secuencias 
sedimentarias atribuidas al Mb La Chumbiada (Dangavs y Blasi, 2003) y con desarrollo de depósitos eólicos de la Fm La Postrera sobre sus márgenes noreste.

\subsection{AMBIENTE LITORAL}

La ingresión marina posglacial ha generado en el ámbito del "Río de la Plata" un conjunto de geoformas con distribución y características distintivas. Se involucra dentro de éstas a las generadas por los procesos de erosión - depositación durante el ciclo transgresivo regresivo en los sectores subaéreos y subácueos del delta del Paraná, las diferentes geoformas reconocidas en el sur entrerriano (Iriondo y Scotta, 1979) y las márgenes del "Río de la Plata" con el desarrollo de extensas llanuras litorales, paleoestuarios y barreras en la costa bonaerense y las representaciones aisladas en la margen uruguaya, en general situadas, todas éstas, por debajo de los $5 \mathrm{~m}$.

Si bien desde el punto de vista regional han sido diferenciadas una gran cantidad de rasgos geomórficos asociados al ultimo evento transgresivo producto de la deglaciación, en la zona de estudio las diferentes unidades reconocidas corresponden a paleoambientes vinculados a un entorno de costas bajas.

\subsubsection{LLANURA LITORAL}

Esta geoforma puede ser observada a partir de la base de los paleoacantilados situada aproximadamente a los 5 metros hasta el contacto con el delta del Paraná. Ha sido observada a lo largo de gran parte del litoral bonaerense recibiendo denominaciones como Terraza Baja (Frenguelli, 1950), Bajíos Ribereños (Bonfils, 1962), Planicie Costera (Fidalgo y Martínez, 1983), Llanuras Costeras (Violante et al., 1992), entre las más conocidas.

El contacto con la zona continental se presenta ondulado de norte a sur y a través de una pendiente que en muchos casos es prácticamente vertical. 
En la zona de estudio y área de influencia se observa nítidamente representada en la boca de los paleoestuarios de los cursos: de la CruzPequería, el Pescado, Luján, Escobar, de la Reconquista y en mayor o menor grado al pie de las divisorias (Fig. 5.10)

El sector más externo del paleoestuario del Río Luján y arroyo El Pescado se presenta constituyendo una franja de 4,5 km de ancho aproximadamente, conformado por lineaciones con forma de arco de circunferencia con centro hacia el noreste hasta el contacto con el delta paranaense. En la boca del estuario relicto de los arroyos de la Cruz-Pequería presenta un ancho de unos 3,5 km, extendiéndose hasta prácticamente el Río Paraná de las Palmas.

En las salientes, frente a las localidades de Escobar, Otamendi y Campana, la llanura litoral se observa de manera muy restringida, observándose como las lineaciones se recuestan sobre los acantilados relictos o se acuñan contra éstos. Frente a Escobar, parcialmente dentro de la zona de estudio, se observan con una clara expresión, representando aproximadamente por 1,5 km de ancho máximo, aumentando gradualmente hacia el noroeste y sureste(Fig. 5.12).

Este conjunto de lineaciones presentan características variables en cuanto a su extensión longitudinal y transversal y relación entre ellas. Se presentan curvas y paralelas entre sí y en general bien definidas, (fig. 5.11) aunque en ocasiones pueden contactarse o bifurcarse. Su altura relativa no sobrepasa los $0,50 \mathrm{~m}$, encontrándose separadas por depresiones de similares dimensiones donde se establecen incipientes líneas de drenaje. Estas geoformas presentan su mejor expresión en los sectores más abiertos, ya sea frente a las salientes o en la parte más amplia de los paleoestuarios (Fig. 5.4).

En estas geoformas la vegetación se desarrolla en correspondencia con las condiciones imperantes en el suelo, de tal forma, que las hace aún más destacables; así se tiene un predominio de gramíneas en los sectores elevados y Ciperáceas (Scirpus Sp) en las zonas deprimidas. 


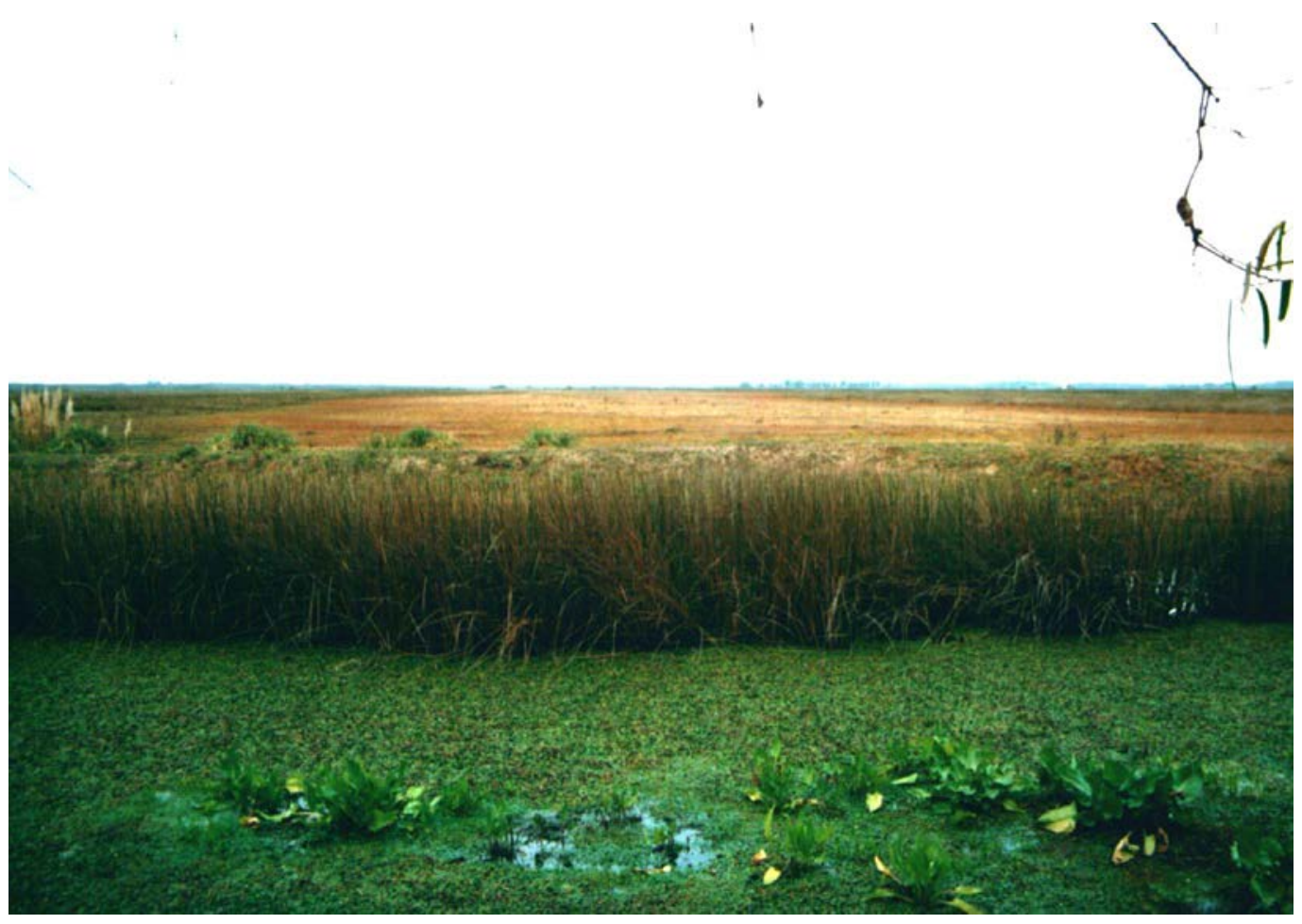

Fig. 5.11 Fotografía individual de una cresta de playa cortada por un canal

Hacia el interior de los paleoestuarios, siempre en la boca de éstos, las geoformas descritas van perdiendo su expresión topográfica, observándose solamente tenues lineaciones y un patrón de vegetación menos definido. El ambiente restringido ha contribuido a que los procesos litorales de acumulación no generaran las crestas de playa con la expresión que lo hacen en los sectores más abiertos (Fig. 5.4).

Los sedimentos que constituyen estas formas son los correspondientes al Mb Escobar, compuestos por arenas finas a limos gruesos con proporciones variables de arcilla. Su color es castaño claro a castaño verdoso, con sectores rojo-amarillentos producto de la oxidación. Suele observarse laminaciones con concentraciones de micas y yeso en rosetas distribuidos en todo el espesor. 


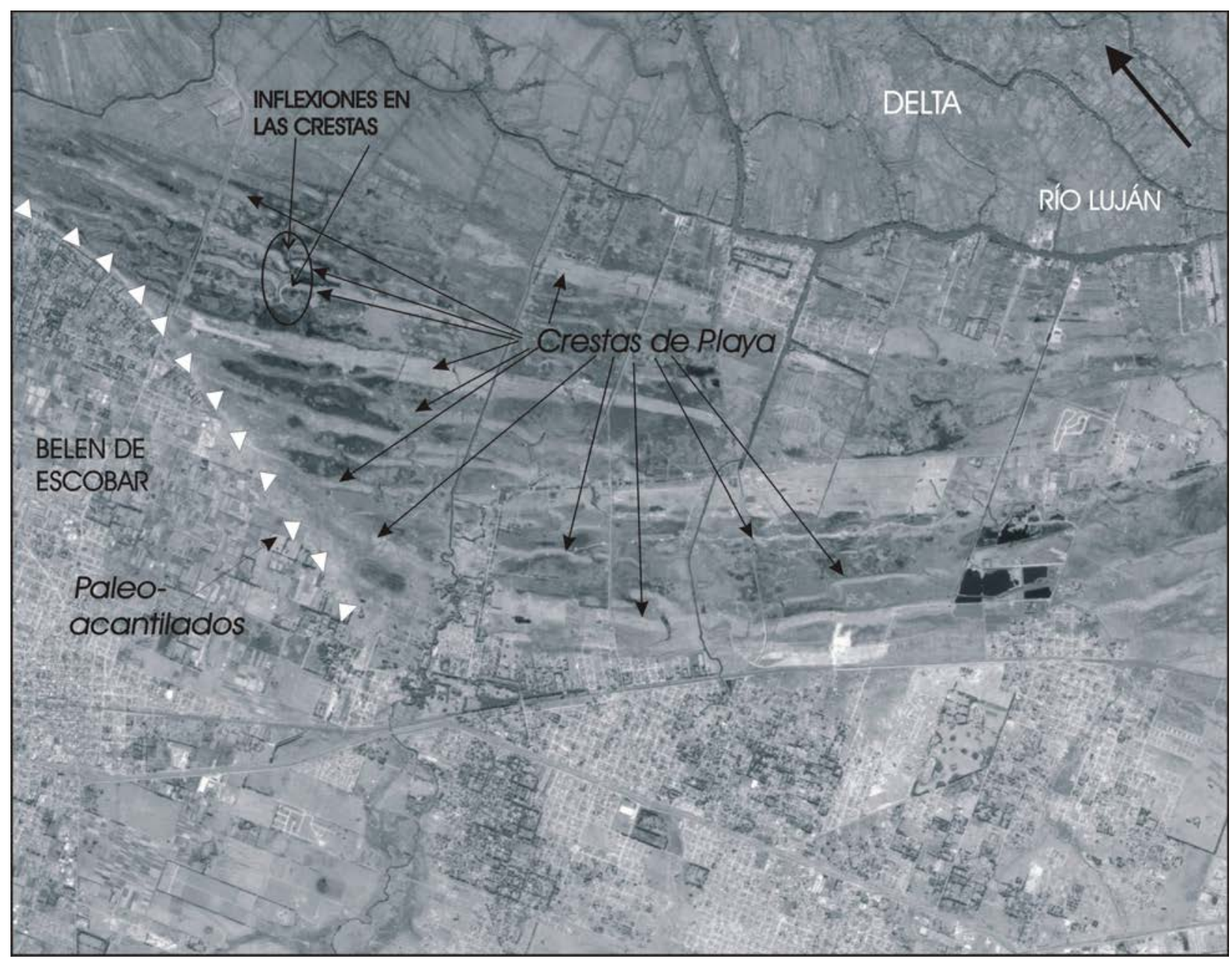

Fig. 5.12 Representación parcial de la llanura litoral frente a Escobar.

Se encuentran cubiertas parcialmente por sedimentos fluviales actuales, arcillosos a arcillo limosos, de 0,30 -0,40 m de espesor, plásticos y adhesivos, de color verde oscuro, mostrando un incipiente grado de pedogénesis. Es común observar en las crestas sectores localizados de escasos metros de diámetros sometidos a deflación, con costras y eflorescencias salinas (fig. 5.13). 


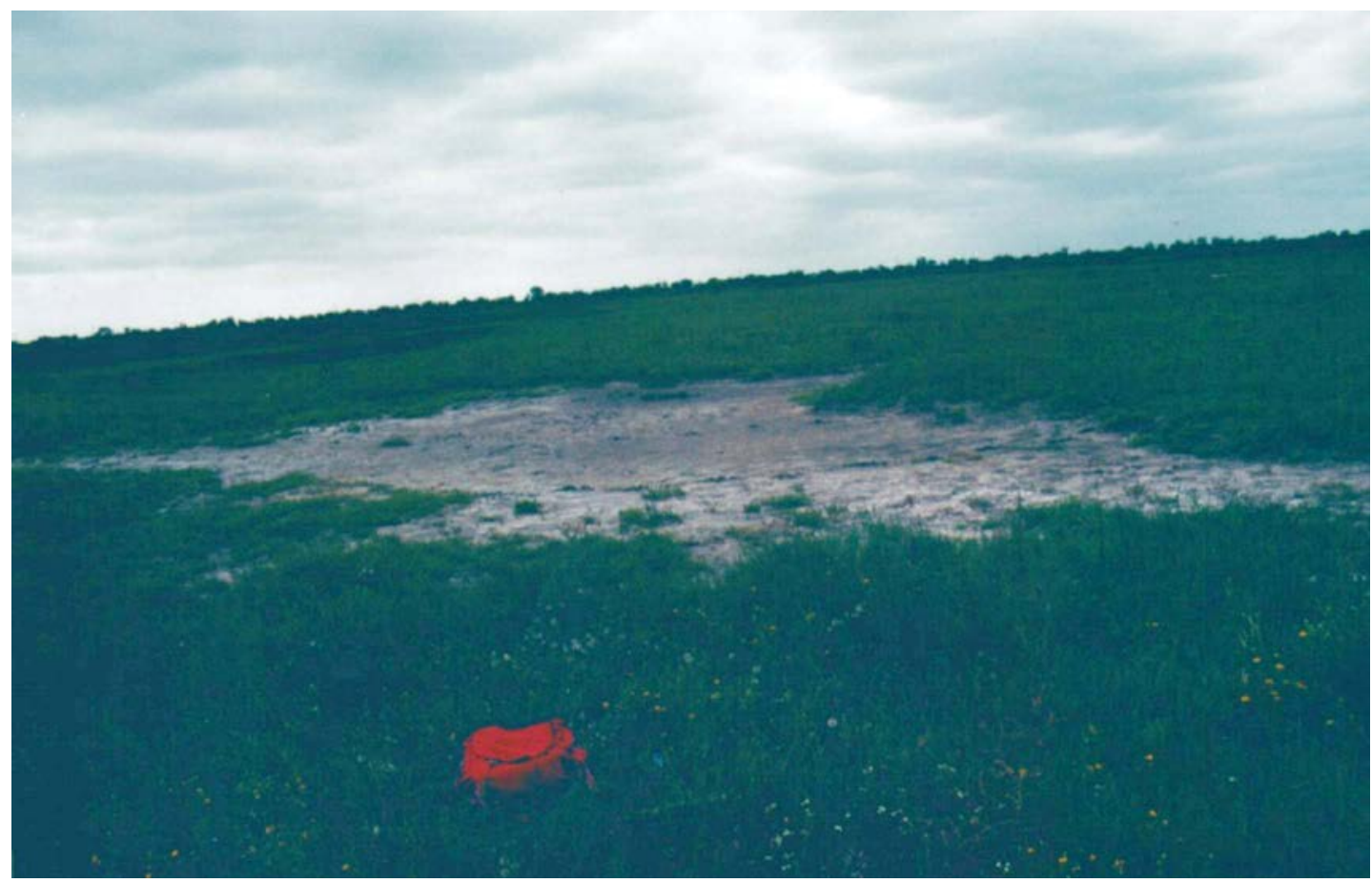

Fig. 5.13 Depresión generada por deflación en una cresta de playa

Estas lineaciones pueden seguirse a lo largo de varios kilómetros, interrumpidas en algunas ocasiones por cursos de agua actuales, y en otros por antiguos canales de marea generados simultáneamente, ya que sus extremos presentan una inflexión hacia el continente, generada probablemente por el oleaje en períodos de mayor energía (inflexiones de las crestas, fig. 5.12) generadas por una muy importante deriva hacia el NO (Herrera, 1993) y merced al fenómeno de difracción y refracción de olas (Codignotto, et al., 1996).

Si bien individualmente representan crestas de playas (beach ridges) que por progradación continental han sido sucesivamente abandonadas durante la regresión, la geoforma mayor en la boca de los paleoestuarios representaría una barrera que dejó inicialmente aislada una laguna costera que fue colmatando por secuencias fluviales. La llanura litoral en las salientes se encuentra adosada directamente a la base de los paleoacantilados, ya sea a través de crestas individuales o por la unión lateral de éstas, que representarían planicies de playa adosadas al continente (Beach strand plain, sensu Reinson, 1984). 


\subsubsection{PALEOESTUARIOS}

Los estuarios constituyen una masa de agua costera parcialmente confinada, que tienen una conexión libre con el mar abierto y en la cual el agua de mar es apreciablemente diluida por el agua dulce del río. La mezcla de aguas con diferentes densidades genera un sistema de circulación que según el modo de difusión de sal y masa de agua salina da lugar a cuatro tipos distintos de estuarios (Pritchard, 1955).

La mayoría de los mas importantes estuarios modernos se formaron por el ahogo de valles de ríos a consecuencia del aumento del nivel del mar postglacial en el Holoceno. Tales estuarios están asociados a zonas de llanuras bajas vinculadas a los márgenes continentales atlántico tipo pasivo (Leeder, 1981).

Fairbridge (1980) define estuario desde el punto de vista geomorfológico, sin considerar las características hidrodinámicas, como la entrada del mar dentro del valle de un río hasta el limite de las mareas. Plantea que los estuarios son modificados por factores vinculados con la historia regional del nivel del mar, factores morfo-tectónicos, factores climáticos y de acuerdo a la provisión de agua dulce y sedimentos.

Los paleoestuarios han sido reconocidos en la región pampeana en un conjunto de cursos que drenan hacia el Río Paraná, Río de la Plata y Mar Argentino (Iriondo, 1980; Herrera, 1993; Cavallotto, 1995; Codignotto, 1996; Isla y Espinosa, 1998).

De acuerdo a la forma que presentan los sectores terminales del Río Luján y el Arroyo de la Cruz y sus componente litológicos y paleontológicos se utilizó el término "paleoestuario o estuarios relicto" para su denominación.

El primero de éstos, asociado al arroyo El Pescado, se presenta con forma de embudo con un ancho máximo de $12 \mathrm{~km}$ entre las localidades de Otamendi y Belen de Escobar, disminuyendo hacia el sudoeste. Así, en la ruta 9 su 
ancho es de 4 km, desde allí se mantiene constante a lo largo de 13 km y posteriormente disminuye progresivamente hasta alcanzar los $800 \mathrm{~m}$ en las inmediaciones de la ruta $\mathrm{N}^{\circ}$ 8, al sudeste del área de estudio. Su longitud total alcanza unos $23 \mathrm{~km}$. Topográficamente se presenta en cota 3,0 m, manteniéndose en general por debajo de los $5 \mathrm{~m}$.

El paleoestuario del Arroyo de la Cruz presenta una forma similar al anterior, integrando el tramo inferior del Arroyo Pequería. Presenta un ancho máximo de unos $3 \mathrm{~km}$ y una longitud de $14 \mathrm{~km}$ aproximadamente, extendiéndose hasta las proximidades de la Ea. Ave María.

Es común observar como los cursos provenientes de las divisorias secundarias pierden su identidad al llegar a esta georforma, transformándose en tenues canales con escurrimiento solamente en épocas de crecidas, ya que comúnmente constituyen minúsculas depresiones con agua estancada.

Estas geoformas constituyen áreas fácilmente anegables. Con abundantes intensidades de precipitaciones, las aguas procedentes de los cursos principales y de sus tributarios, al llegar a esta forma de pendiente plano a plano cóncava, pierden su energía y se expanden lateralmente cubriéndola prácticamente en su totalidad. La mayoría de estos cursos no llegan a los cursos principales, salvo en sectores donde existen cortes en los albardones, o se construyeron canalizaciones.

Litologicamente presentan una sucesión muy regular, que se sitúa en discordancia sobre la Formación Pampeano. Los depósitos estuáricos mas antiguos corresponden al Mb Molino Viejo, desarrollados en un ambiente con nivel del mar en ascenso. Durante el nivel marino mas alto, en la boca de estos paleoestuarios y sobre los depósitos precedentes se acumularon los depósitos areno limosos, oscuros en la base y castaños en el techo conformando una barrera atribuida al Mb Escobar. Hacia el interior de estos estuarios se desarrollaron lagunas costeras con los depósitos fangosos del Mb Santa Brígida, con tonalidades variables (verdes, castañas y grises), fósiles oligohalinos y concreciones de tosca 
con forma radicular. Este conjunto de elementos podrían indicarnos condiciones fluctuantes en el nivel de las aguas, probablemente con épocas secas. En forma suprayacente se desarrollan depósitos aluviales actuales en un ambiente netamente continental.

\subsubsection{ACANTILADOS RELICTOS}

Estos rasgos lineales del paisaje se observan en el contacto entre el ámbito continental y el litoral. Limitan las zonas donde los procesos erosivos vinculados con la elevación del nivel del mar acaecida en el Holoceno actuaron sobre el sector continental compuesto esencialmente por la Fm Pampeano.

En la zona de estudio su mayor expresión desde el punto de vista areal y topográfico se observa en las inmediaciones de las localidades de Campana, Estación Otamendi y Belén de Escobar, aunque su presencia puede seguirse hacia el interior de los paleoestuarios por espacio de muchos kilómetros. En los sectores más externos donde la acción erosiva del oleaje fue más intensa, se originaron acantilados cuyas alturas varían entre 3 y 15 m, con pendientes de alto ángulo, a casi verticales. Al píe de éstos, un cambio abrupto de pendiente con dirección hacia el delta del Paraná se define la plataforma de abrasión que posee una pendiente de 0,7 o frente a la localidad de Escobar, estando cubierta parcialmente por depósitos de los miembros Escobar y Molino Viejo, con claros rasgos de actividad orgánica (Fig. 5.14) 


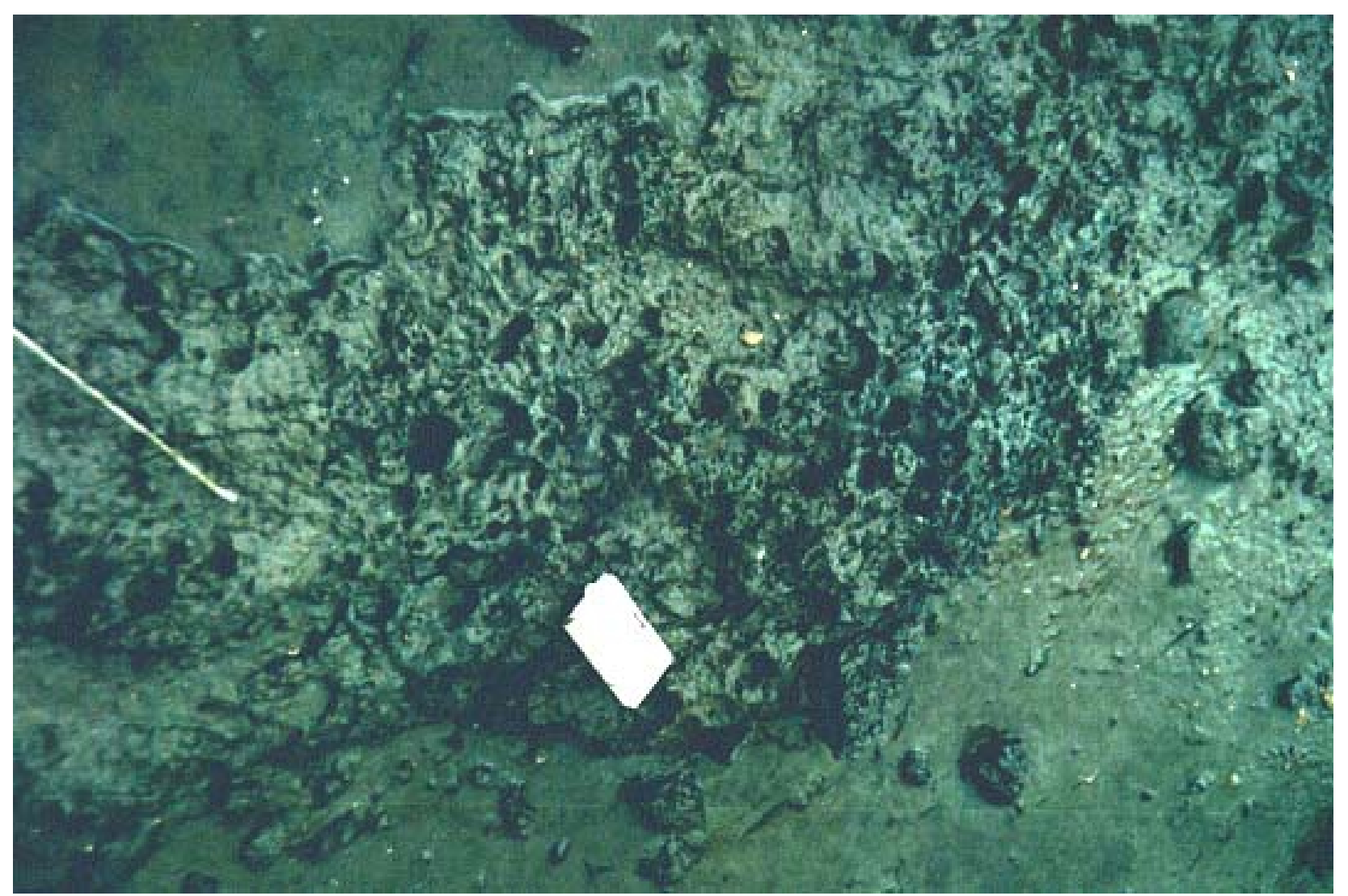

Fig. 5.14 Rasgos de actividad orgánica en la Formación Pampeano.

Actualmente, el límite superior y gran parte de estos a pesar de las fuertes pendientes son ocupados por montes de talas (Celtis spinosa) y sujetos a la acción antrópica y fluvial, donde esta última origina importantes carcavamientos, con el consiguiente retroceso y cambio de fisonomía (fig. 5.15). 


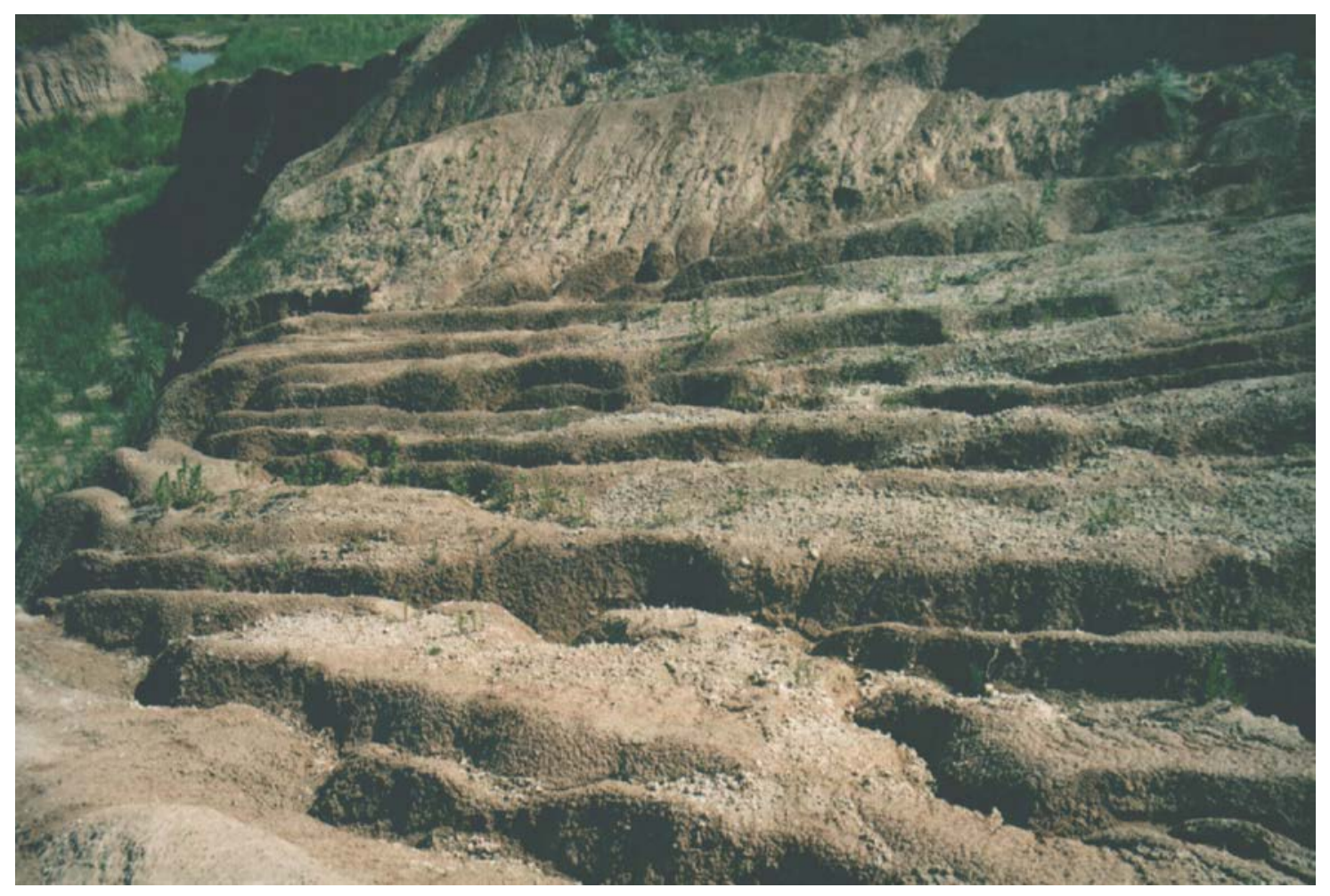

Fig. 5.15 Carcavamientos producidos en los acantilados relictos acentuados por la acción antrópica.

\subsubsection{LLANURA DELTAICA}

Ocupando el noreste del área estudiada se desarrolla parte del delta del Paraná. Un delta esta constituido por tres partes: la llanura deltaica, que es subaérea con un claro dominio del procesos fluviales continentales; el frente deltaico donde se desarrollan procesos de tipo marinos y prodelta, permanentemente sumergido y donde sus materiales de procedencia fluvial se hallan afectados por procesos marinos (Coleman y Gagliano, 1965). La llanura deltaica se extiende desde la ciudad de Diamante (Prov. de Entre Ríos) hasta el "Río de la Plata", con una dirección noroeste a sureste a lo largo de $300 \mathrm{~km}$. Presenta un ancho de 20 km en su ápice, ensanchándose progresivamente hasta alcanzar un ancho máximo de $80 \mathrm{~km}$, cubriendo una superficie aproximada 17.500 km². 
El sistema de drenaje puede considerarse como una asociación de sistemas individuales. Desde su ápice aguas abajo, el sistema individual es de tipo anastomosado, caracterizado por una gran cantidad de cursos de diferentes magnitudes y posiciones relativamente estables. Estos canales se unen y separan alternativamente creando una red compleja, permitiendo de esta manera la división de los aportes de agua y consecuentemente de la carga sedimentaria.

Este gran sistema fluvial del Paraná corresponde a los patrones típicos de los denominados ríos aluviales (Schumm, 1985), caracterizados por la migración de canales, el desarrollo de islas y extensas planicies de inundación de bajos gradientes topográficos.

Asimismo, estos cursos individuales desarrollan diseños meandrosos, con diferentes grados de curvatura, observándose barras en espolón y canales abandonados distribuidos en gran parte de la llanura, asociándose fundamentalmente las primeras a los cursos principales.

Solamente en su parte terminal se observan con claridad diseños distributarios, producidos por el río Paraná Guazú al norte y el río Paraná de las Palmas al sur.

Estas particularidades hidrográficas caracterizan el delta subaéreo. El desarrollo de albardones en las márgenes de los cursos limitan los sectores internos de las islas, sin drenaje y con procesos activos de formación de turba (INTA, 1980). También se observan sectores con antiguos canales de marea como testigos de la acción de éstas durante su evolución.

El delta subácueo o prodelta presenta una suave inclinación hacia el sudeste más allá de la línea Montevideo - Punta Piedras. Está constituido por barras, canales y albardones y conecta la llanura deltaica subaérea con el mar, separando los ambientes sedimentarios fluviales de los marinos (Parker y Marcolini, 1992). En el sector inicial del delta subacueo se observa claramente la corriente suspensiva de tipo continua a 
700 a $800 \mathrm{~m}$ de la costa, con mayor intensidad en el centro del estuario y canales con sentido noroeste sudeste, mientras que en la costa la deriva de material grueso, discontinua y tractiva es con sentido noroeste (Codignotto, 1996).

\subsubsection{Velocidad de avance del delta}

La velocidad de avance del sistema deltaico está asociada fundamentalmente al Río Paraná. Se encuentra confinada en la llanura pampeana por las barrancas y paleoacantilados constituidos por los depósitos "pampeanos" y los litorales generados por la ingresión holocena (postglacial). Su evolución se encuentra estrechamente vinculada al ascenso y descenso del nivel del mar, observándose estos procesos no sólo en la configuración de muchas geoformas sino también en las secuencias estratigráficas constitutivas (Iriondo, 1980; Parker y Marcolini, 1992). Groeber (1961) estima que la ingresión Holocena en su máximo avance habría alcanzado las ciudades de Santa Fe y Paraná.

Soldano (1947) indica un avance anual promedio del delta de $70 \mathrm{~m}$, aumentando ese valor para el sector comprendido entre el río Paraná de

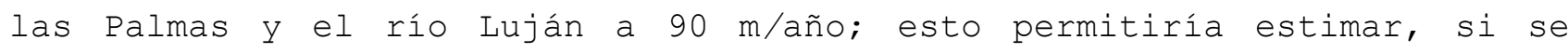
considera el valor medio, que el frente deltaico se encontraba en las cercanías de la Estación Río Luján hace 500 años o, si consideramos la progradación producida por los cursos en la zona de influencia, esta posición habría sido alcanzada a principios de 1600 .

El cambio de rumbo de $90^{\circ}$ hacia el sureste que presenta el Río Luján, constituye superficialmente el límite entre el delta y la "llanura litoral". Este cambio, al igual que lo observado en otros cursos localizados en las inmediaciones de la zona de estudio (Baradero y Arrecifes), permiten considerar que el río Luján evacuaba sus aguas directamente hacia el "Río de la Plata" y debido a la progradación deltaica, fue cambiando progresivamente la ubicación de su desembocadura. 
Si bien los mapas de la época no permiten definir precisamente la posición exacta del frente deltaico, el análisis de un conjunto de mapas elaborados por viajeros y jesuitas a partir de 1635 y a lo largo de toda la época colonial, permite establecer el frente deltaico aproximadamente en las cercanías del cambio de rumbo del río Luján, descripto precedentemente, lo que indicaría un avance del delta de aproximadamente $95 \mathrm{~m} /$ año (fig. 5.5).

Asimismo, cartas del Ministerio de Obras Publicas de la Nación a partir de 1896, conjuntamente con cartas topográficas de la dirección de Geodesia de la provincia de Buenos Aires actualizadas a 1984, indicarían un avance lineal para el sector entre los ríos Luján y Paraná de las Palmas de unos $30 \mathrm{~m}$ anuales (Cavallotto, 1995).

Es importante señalar que el avance del delta no se produce exclusivamente desde el frente de este sinó que la formación de islotes y la acreción de estos en el sentido de flujo y contraflujo y su posterior unión al sistema deltaico produce un avance por pulsos. Como ejemplo puede citarse el aumento de superficie de la Isla Martín García que pasó de tener una superficie de 1,8 km² en 1956 a 3,80 km² en 1996 con una clara tendencia a la unión con el delta paranaense (Codignotto, $1990,1996)$.

Al avance que se produce del complejo deltaico causado por factores naturales, deben sumársele los derivados de la actividad antrópica que, en el pasado reciente y en la actualidad, debido a las canalizaciones, dragados, endicamientos y rectificación de vueltas entre las más importantes soporta este complejo (Ronzoni y Rossello, 1995).

\section{EVOLUCION GEOMORFOLOGICA}

Los diferentes rasgos geomorfológicos caracterizados anteriormente y su asociación con las unidades litoestratigráficas del capitulo anterior, permiten establecer cómo han participado en la conformación del paisaje 
actual un conjunto de procesos con intervenciones variadas, no sólo en la intensidad sino en la extensión temporal y en la superficie afectada.

La mayor parte de la región está conformada por la Formación Pampeano, que debido su espesor, edad y distribución, permiten considerarlos como el sustrato litológico donde se han desarrollado las geoformas y unidades mas recientes.

Estos sedimentos se han depositado en ambientes con climas áridos semiáridos, fríos y secos, acumulados en forma mantiforme o constituyendo grandes acumulaciones medanosas, a las que se asocian, depresiones generadas por deflación. (Iriondo y Krohling, 1996).

Dentro de esta secuencia compuesta por depósitos de loess, loess removilizado, depósitos fluviales y lacustres, pueden observarse a diferentes profundidades y con distintos grados de desarrollo, niveles con pedogénesis, indicativos de estabilización del paisaje debido a condiciones climáticas más benignas e incluso, algunos de éstos, con rasgos hidromórficos (Riggi et al., 1986; Teruggi e Imbellone, 1987; Nabel, et al., 1993 ; Iriondo y Krohling, 1996; Imbellone y Cumba, 2003).

En relación al sistema hidrográfico regional, el sistema fluvial Paranádel Plata durante el Pleistoceno inferior se encontraba independizado de la depresión del salado, en un ambiente con un nivel del mar bajo y depositación en las áreas continentales de las secuencias basales de la Formación Pampeano (Violante y Parker, 1999).

Previamente al ultimo interglacial (Subestadio 5e), incipientes líneas de drenaje afluentes al Río Paraná se presentan con sentido de escurrimiento similar a las actuales, como el Río Luján, Arroyo de la cruz y cuencas vecinas, observándose en el subsuelo de estos cursos depósitos aislados atribuidos a esta transgresión (López, 1999; Fucks y De Francesco, 2000, $2003)$. 


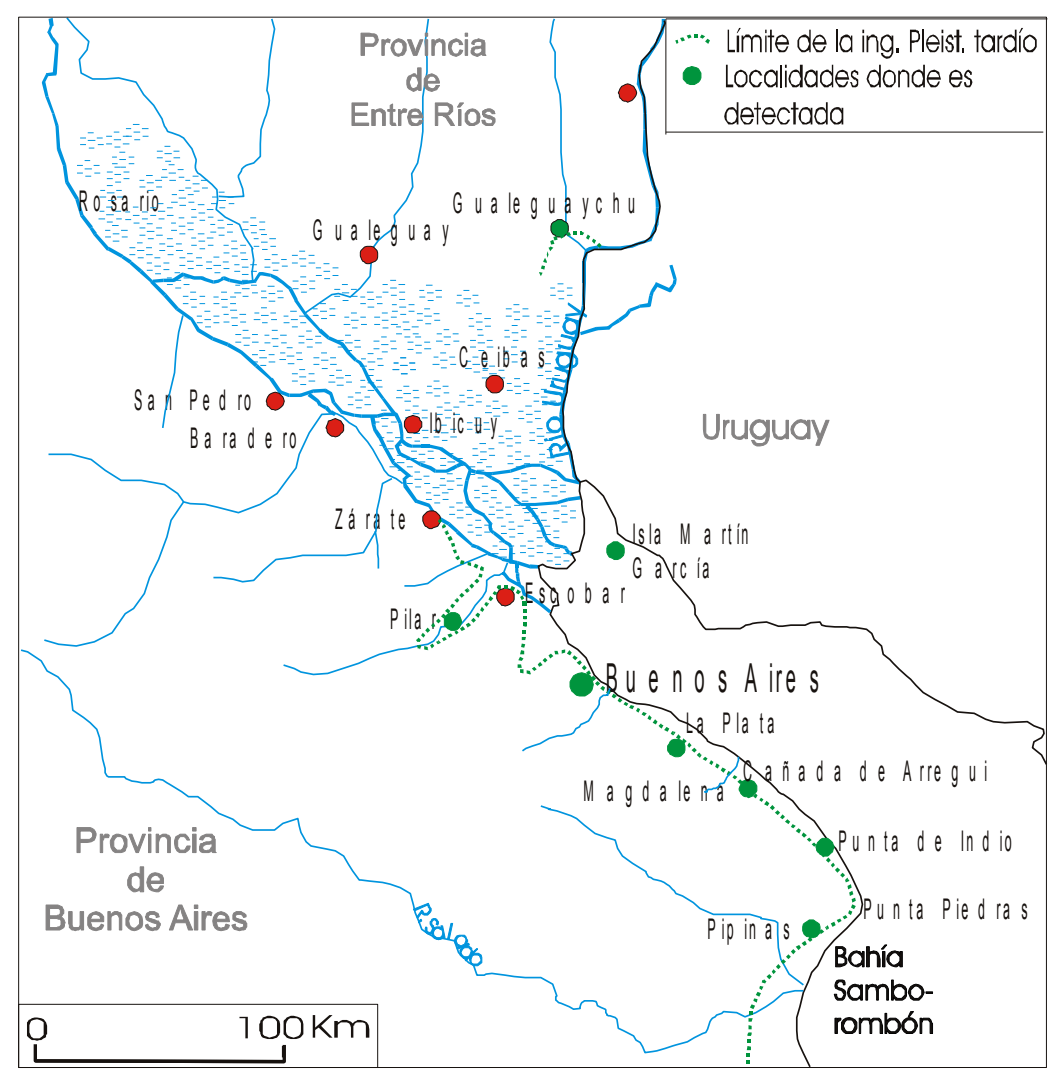

Fig. 5.16. Distribución de la Ingresión del

Pleistoceno tardío.

Posteriormente al descenso del nivel del mar sobrevienen procesos fluviales y eólicos, representados por los depósitos fluviales de canales y los niveles superiores de la Formación Pampeano (Fucks et al., 2002).

Si bien se considera que los depósitos loéssicos son en términos generales mantiformes, algunas geoformas negativas de importancia permanecieron activas parcialmente (depresión de la cuenca del Río Luján, A. de la cruz y Río de la Reconquista), ya que se constituyeron, con posterioridad a la ingresión y a los depósitos loessoides del Pleistoceno tardío, nuevamente en las líneas de drenaje donde comenzarían a desarrollarse las secuencias depositacionales de la Fm Luján (Miembros La Chumbiada y Guerrero) y en divisorias los términos inferiores de la Fm. La Postrera.

Durante el último máximo Glacial (18 $\left.{ }^{14} \mathrm{C} \mathrm{ka}\right)$, los valles fluviales excavaron los depósitos loéssicos controlados por el nivel de base 
general situado muy por debajo de su situación actual (-120 m Guilderson et al., 2000) produciendo incisiones profundas y depósitos prácticamente acotados exclusivamente a los cursos (Fig. 5.17).

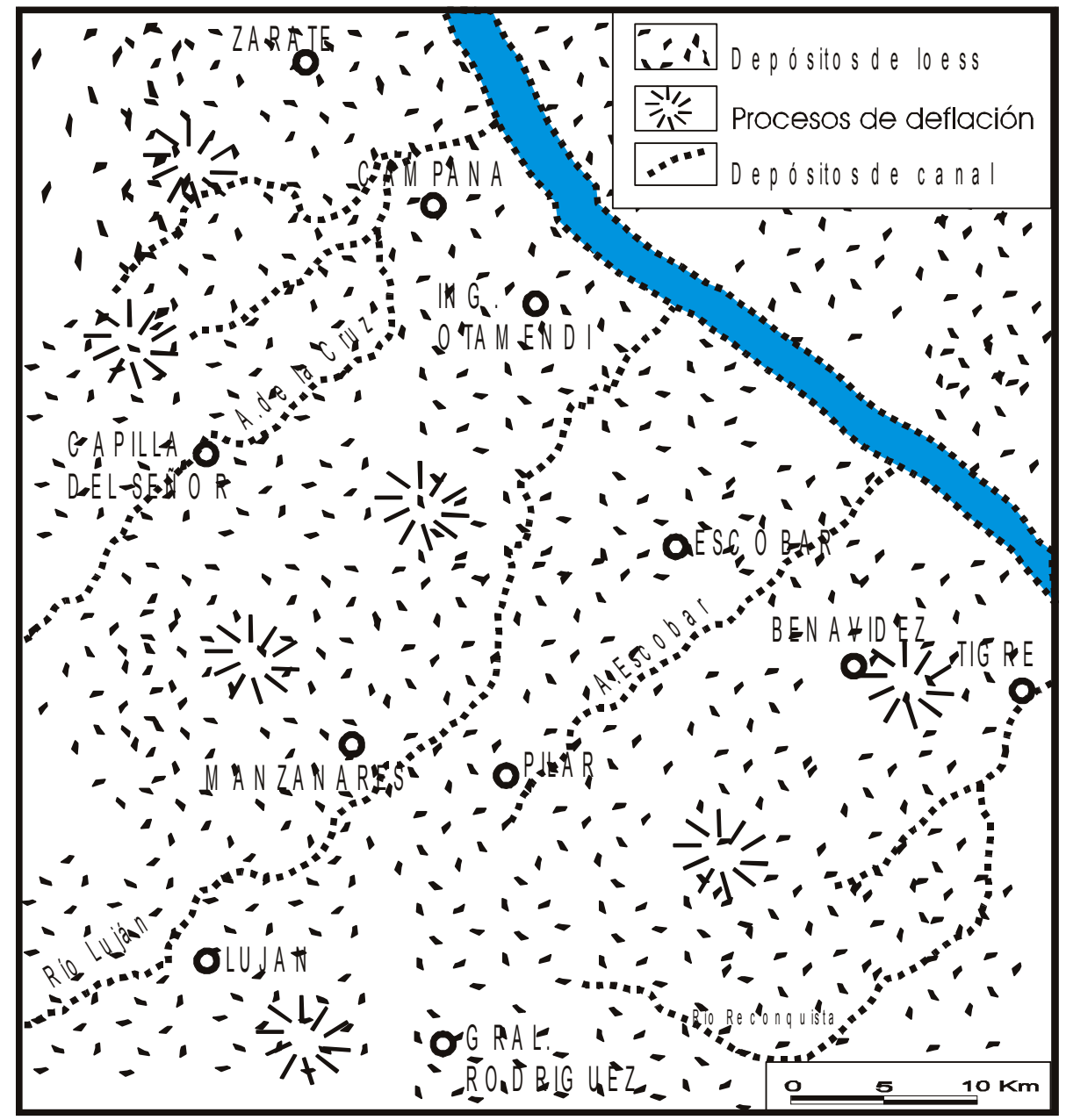

Fig. 5.17 Mapa de la zona exponiendo los procesos desarrollados durante el Pleistoceno tardío

Ple isto c e no ta id io

Durante la deglaciación, con condiciones climáticas más benignas y dentro de un contexto de cierta estabilidad del paisaje se inició el desarrollo de superficies de meteorización en una amplia región, con la formación de paleosuelos, siendo el Geosuelo Puesto Callejón Viejo (Fidalgo et al., 1973 b) el de mayor extensión, con edades que fluctúan entre los 9.000 y 10.000 años ${ }^{14} \mathrm{C}$ A.P aproximadamente (Tonni et al, 1999).

Durante el comienzo de la depositación en el fondo de los valles del Mb Río Salado y en interfluvios de la Fm La Postrera, penetra por el Río Paraná y sus tributarios, la ingresión marina del Pleistoceno tardío 
tardío - Holoceno, observándose su máximo avance en alrededor de los 6.000 años ${ }^{14} \mathrm{C}$ A.P. En la fig. 5.18 puede observarse la variación de la salinidad durante este avance de la línea de costa y su relación con la situación actual.

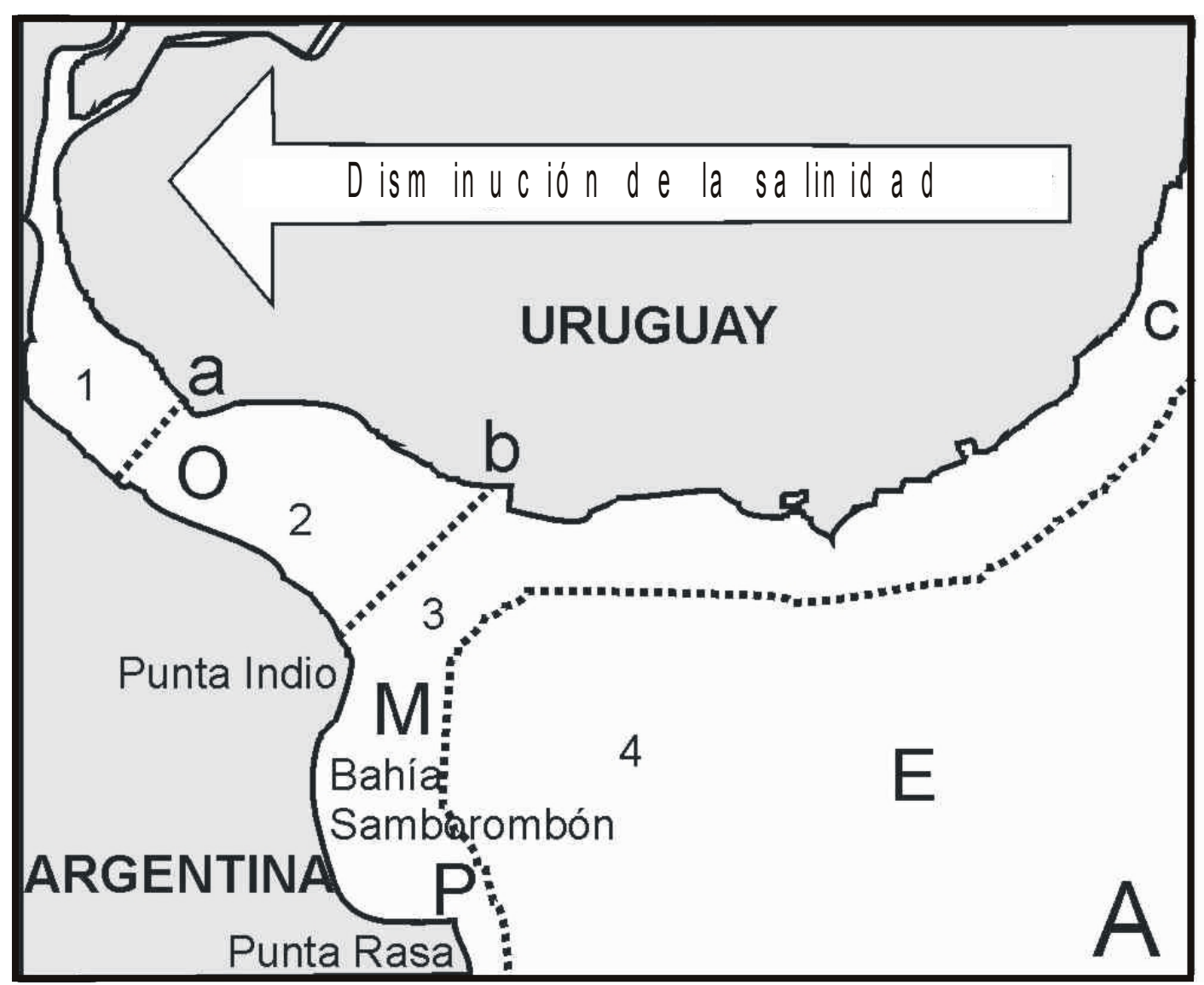




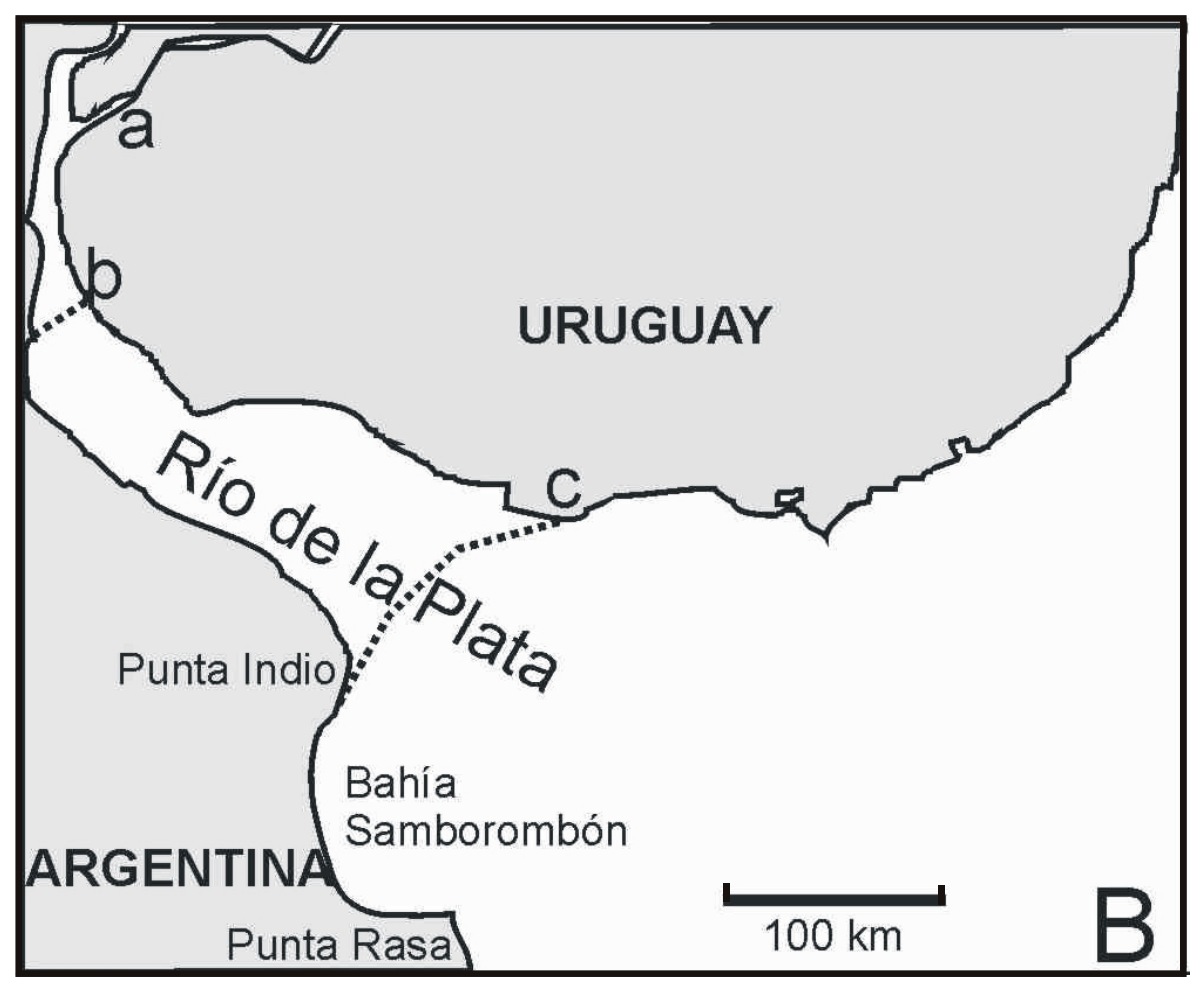

Fig. 5.18. Variación de la salinidad a lo largo del Río de la Plata durante el Cuaternario. A: a, b, c representan los límites desplazados en las zonas estuariales. 1: fluvial interior; 2: fluvial intermedia; 3:fluvio marino; 4: marina. Gradiente de salinidad: 0 : oligohalino (0-5 \%o ); M: mesohalino 0 mixohalino(5-18 \% $)$; $\mathrm{P}$ : polihalino $(18-30 \%)$ : $\mathrm{E}$ : euhalino (> $30 \%$ \% ) A: actualidad y B:máxima transgresión. Parcialmente modificado de Sprechmann (1978); Aguirre (1990); Fucks et al. (2002).

El esquema evolutivo relacionado a la ingresión holocena esta asociado a una situación vinculada a un rápido ascenso del nivel de mar (Kraft, 1978). Esta ingresión marina generó en el ámbito del Río de la Plata, una gran variedad de formas de acumulación - erosión observándose acuñada en su punto de máxima ingresión en los cursos de agua dentro de la Fm Luján (Fig. 5.19). 


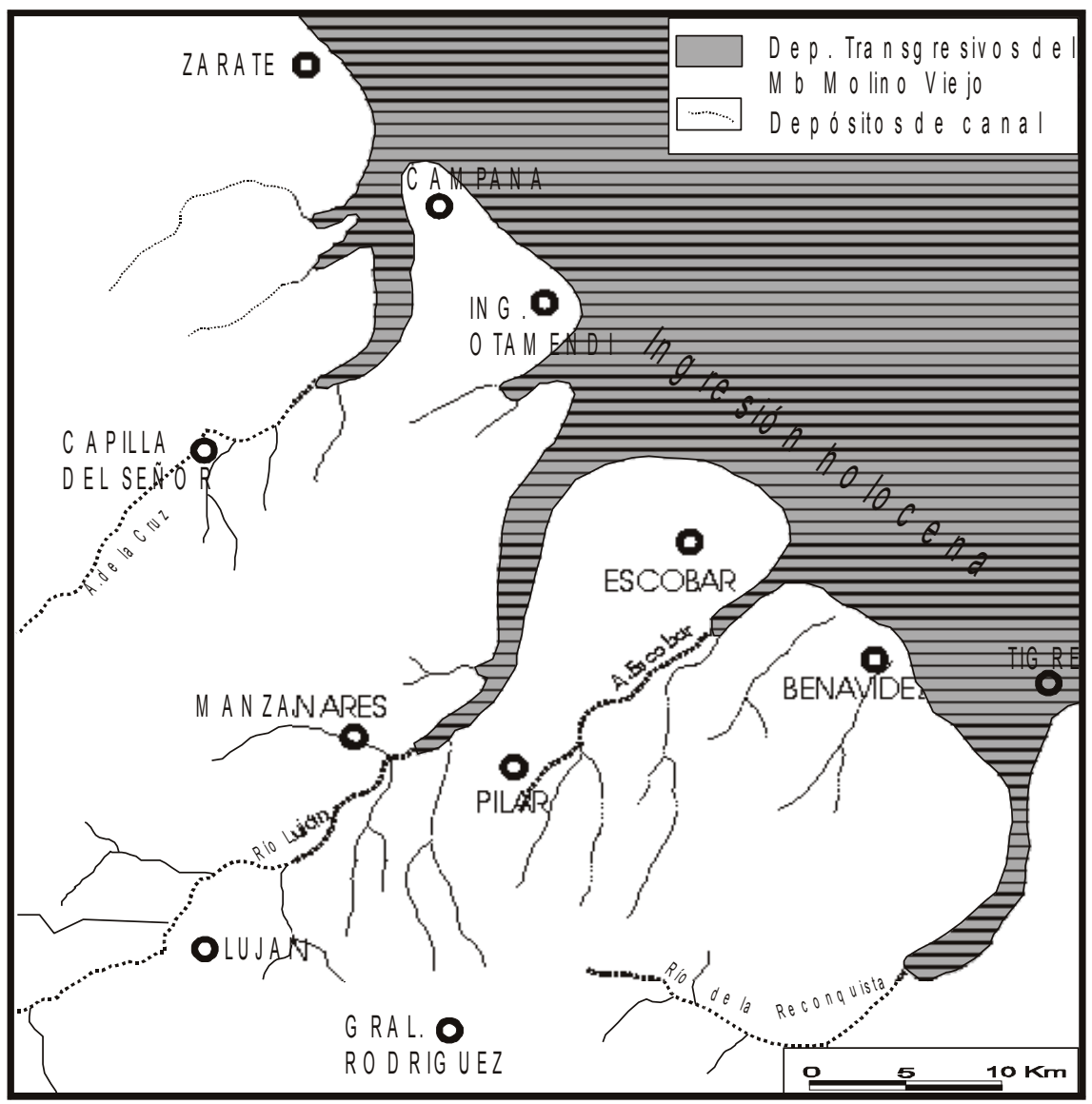

Má xim o tra nsgre sivo

Holocenom ed io $\left(6.000\right.$ a 7.000 años ${ }^{14} \mathrm{C}$ A.P.)
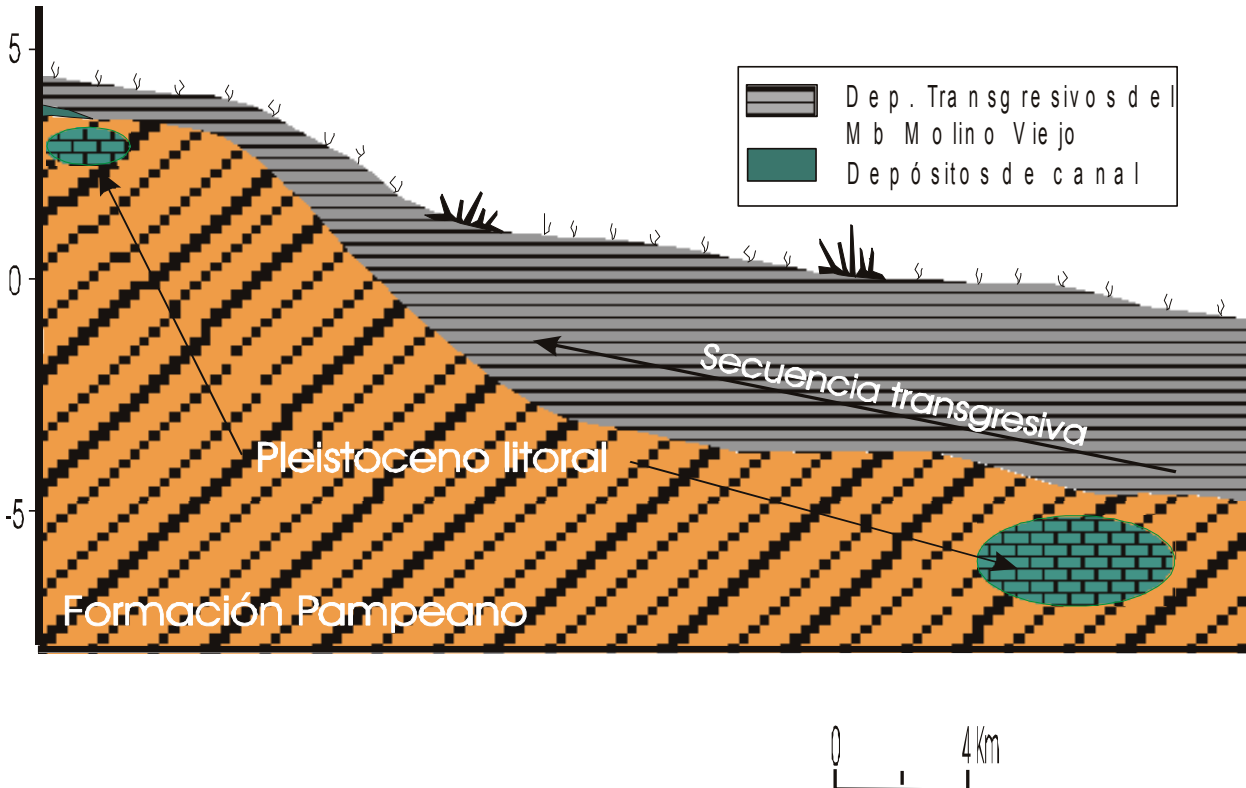

Fig. 5.19.- Situación regional donde se representa el máximo 
En esta etapa transgresiva como respuesta al rápido ascenso del mar se depositaron en el estuario del Paraná y sus tributarios, depósitos fangosos, oscuros, (2,5 N) con fauna mixohalina a oligohalina, propios de ambientes de intermarea a submarea producto de la floculación de arcillas asignables al Mb. Molino Viejo.

Durante los últimos estadios de ascenso del mar y una vez estabilizada la línea de costa comienza a desarrollarse en la boca de los estuarios del Río Luján, Arroyo de la Cruz y otros cursos aledaños, depósitos arenosos finos, de color oscuro que corresponderían a depósitos de barrera subácueos, pasando hacia arriba a sedimentos de texturas similares, pero de tono castaños a castaños amarillentos propios de ambientes de playa correspondientes al Mb Escobar. Superficialmente se forman una serie de crestas de playas y planicies de playa, constituyendo progresivamente una llanura litoral que se desarrolla desde la boca de los paleoestuarios hasta el límite actual con el delta paranaense. Este marco evolutivo constituye otro ejemplo de progradación de barreras como el establecido por Roy et al., (1994); Cooper, (1994).

Simultáneamente, como producto de la situación generada por la acumulación de los sedimentos del Mb Escobar, dentro de los paleoestuarios y limitados por estas barreras, se desarrolla una secuencia arcillosa de colores y tonalidades variables, grises, verdes y castañas, con fauna de ambientes estuáricos, atribuida al Mb Santa Brígida, al que se vincula con ambientes de marismas y lagunas costeras, desarrolladas a partir de los 6.000 años ${ }^{14} \mathrm{C}$ A. P. Las tonalidades propias de ambientes de oxidación y reducción, concreciones de toscas de forma radicular con orificios centrales, estarían indicando condiciones fluctuantes de inundación con superficies periódicamente estabilizadas con el consecuente desarrollo de vegetación (Fig. 5.20). 


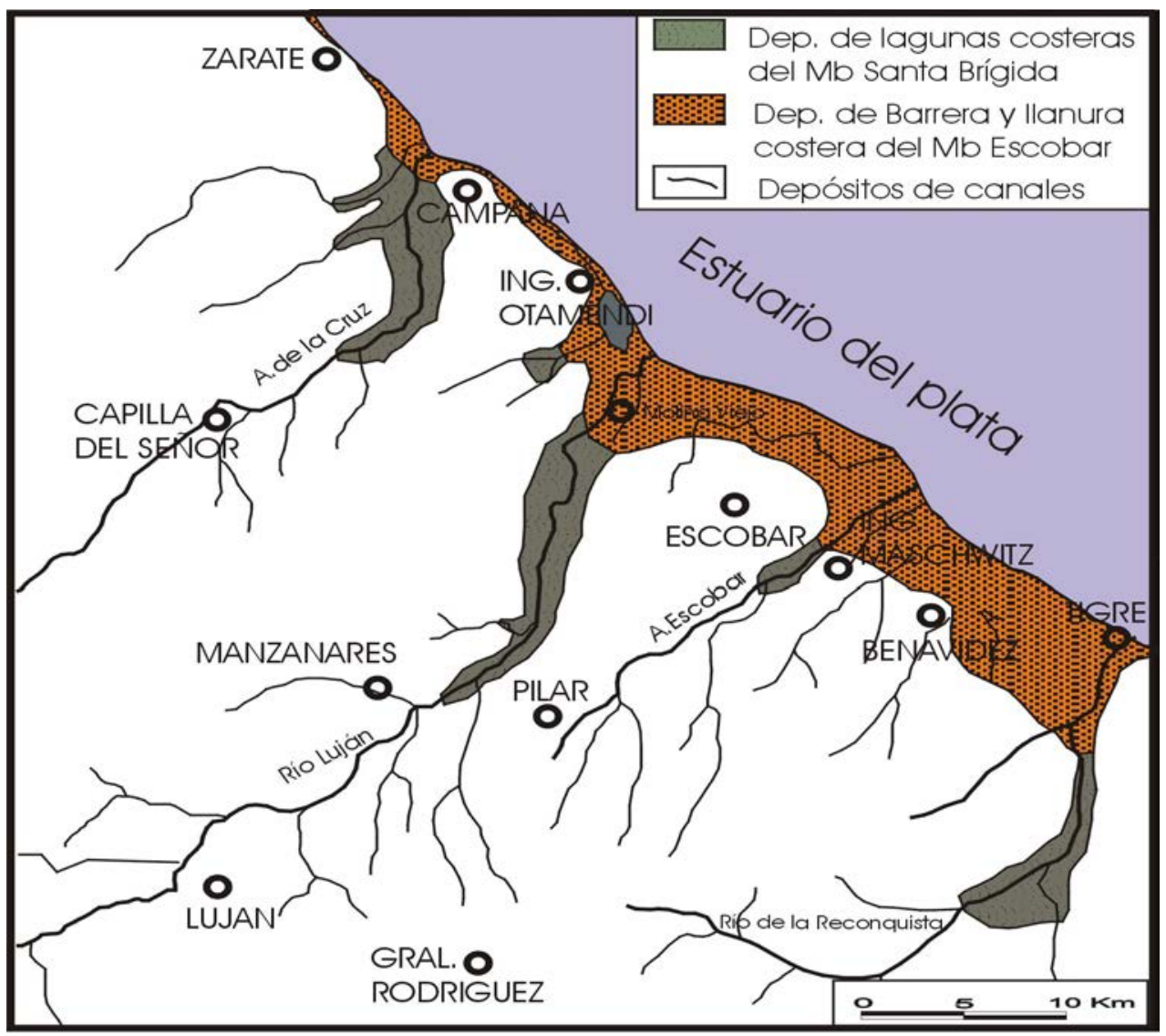

Estabilización y paulatino descenso del nivel del mar (Holoceno medio y superior)

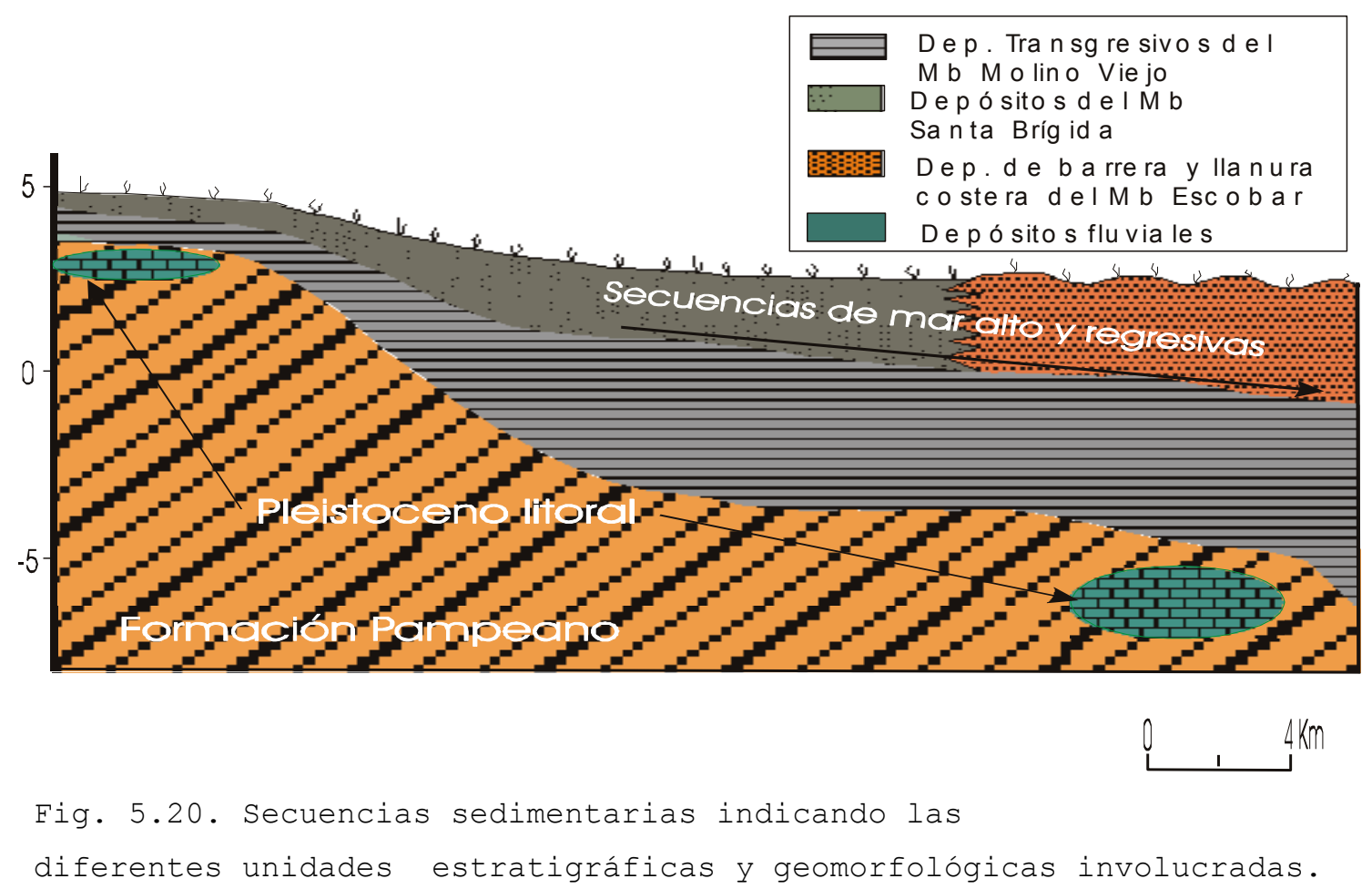


Cuando el nivel del mar se estabiliza y comienza su descenso, se produce la progradación de la llanura litoral hacia el estuario platense, como así también el avance del delta del Paraná con la acumulación de las secuencias deltaicas sobre los depósitos transgresivos del Mb Molino Viejo. En el sector terminal de los paleoestuarios se depositan los sedimentos aluviales del Mb Río Salado de la Fm Luján y prácticamente todas las geoformas negativas de paisaje constituidas por las planicies de inundaciones, estuarios relictos y llanura litoral son cubiertas con distintos espesores por los sedimentos aluviales actuales (Fig. 5.21).

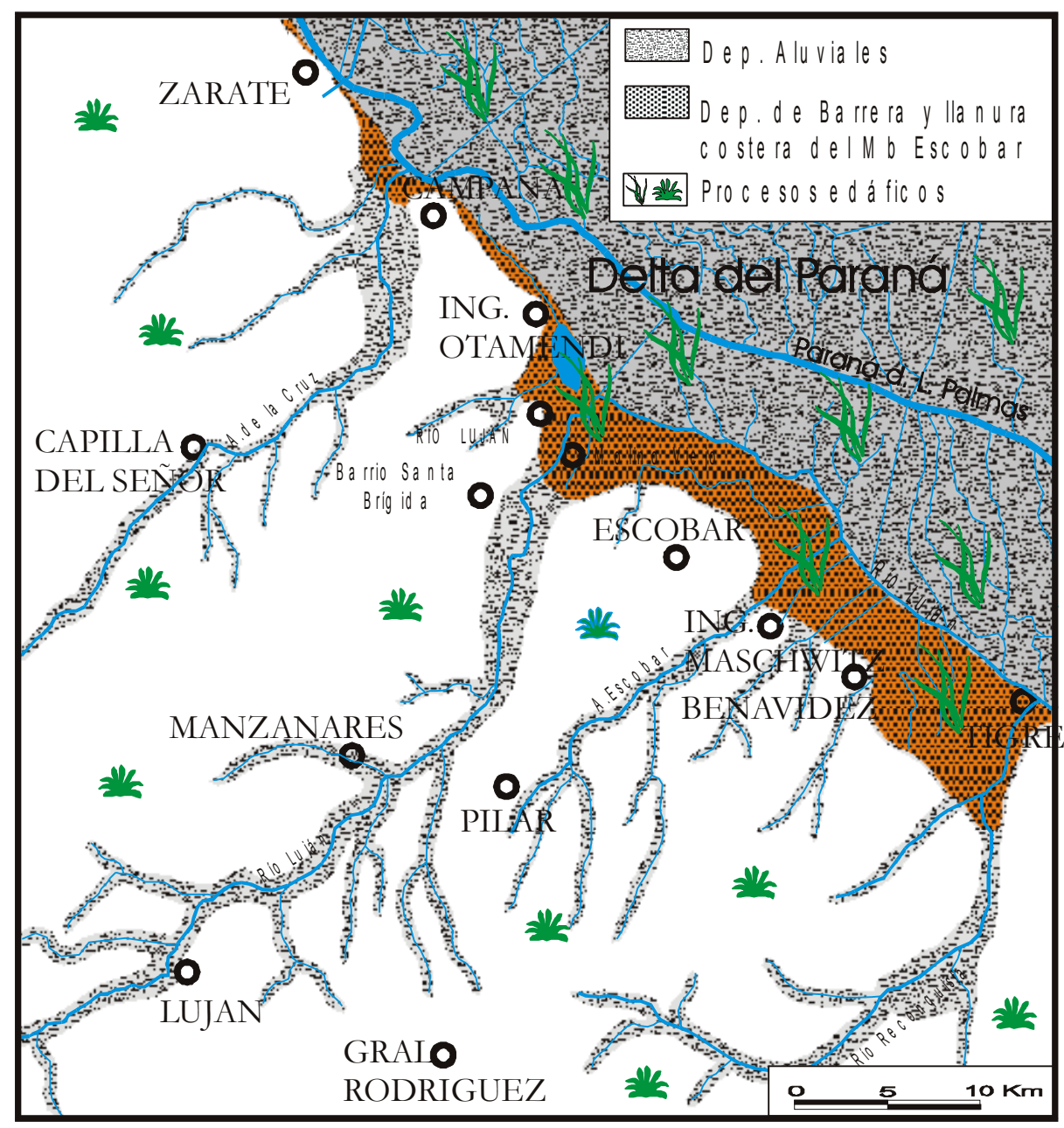

Situ a c ión a c tu al 


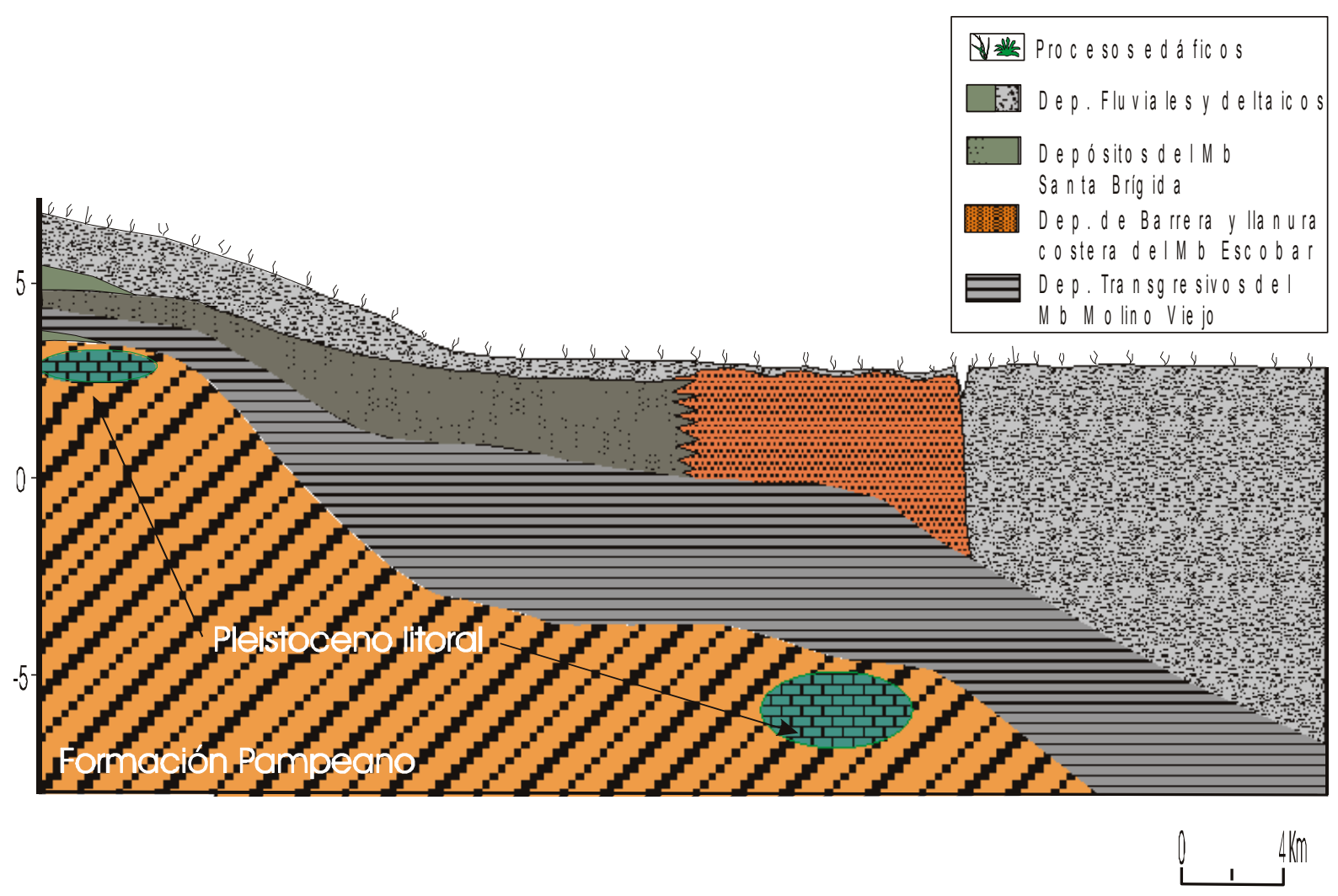

Fig. 5.21. Procesos, unidades y geoformas actuales.

En la actualidad los procesos de acumulación fluvial más importantes se producen en el frente deltaico, produciéndose durante las inundaciones acumulaciones fundamentalmente de desbordes en el conjunto de las geoformas litorales y delta subaéreo. Asimismo, la meteorización constituyen el proceso dominante, no sólo en este sector, sino en prácticamente todo el ámbito pampeano, permitiendo de acuerdo a los condicionantes, la formación de perfiles de suelos con características muy contrastantes.

\section{CAMBIOS PASADOS DEL NIVEL DEL MAR}

Las oscilaciones del nivel del mar del Pleistoceno superior y Holoceno han respondido fundamentalmente a las variaciones en el volumen del agua contenida en los océanos debido a los ciclos glaciales e interglaciales.

Los cambios del nivel del mar a lo largo de las líneas de costa son contrastantes de acuerdo al hemisferio que se analice (Jelgersma y 
Tooley, 1995). Mientras que en el hemisferio norte los últimos 6000 años el nivel del mar ha estado en ascenso, en el sur la tendencia es descendente (Isla, 1989).

Codignotto et al. (1993) consideran que no solo los factores estáticos e hidroisostáticos afectan la costa Argentina durante el Holoceno sino que los movimientos tectónicos locales han participado con ascensos variables a lo largo de ella, acentuados fundamentalmente en la costa patagónica.

Estudios situados latitudinalmente al norte y sur de la zona de estudio con sus respectivas curvas de ascenso y descenso del nivel del mar presentan algunas diferencias, fundamentalmente en lo que respecta al cambio producido en su ascenso a partir de su paso por el actual nivel del mar.

En la plataforma continental Argentina, el nivel del mar se situaba alrededor de los $-110 \mathrm{~m}$ durante el ultimo máximo glacial (18 $\left.{ }^{14} \mathrm{C} \mathrm{ka}\right)$ a partir de donde el ascenso del nivel del mar se produjo en forma rápida, a un ritmo de $11 \mathrm{~m} / 1000$ años. Este ascenso presenta una correspondencia notable con el observado en otras partes del mundo (Guilderson, at al., $2000)$.

A este conjunto de factores de influencia variable, deben sumárseles los ambientes geomorfológicos donde se realizan las determinaciones puntuales de altura y edad. Cavallotto (1995), utilizando dataciones radiocarbónicas de diferentes lugares del ámbito del "Río de la Plata", establece que el mar ascendió desde los $-18 / 20 \mathrm{~m}$ con anterioridad a los $8.600{ }^{14} \mathrm{C}$ A.P. a los $+6,5 \mathrm{~m}$ a los $6.000{ }^{14} \mathrm{C}$ años A.P., con un ascenso promedio de 9,4 mm por año, produciéndose a partir de allí el descenso hasta el nivel actual, a través de dos etapas que abarcan aproximadamente 3000 años cada una, con diferentes estabilizaciones (Fig. 5.21). 


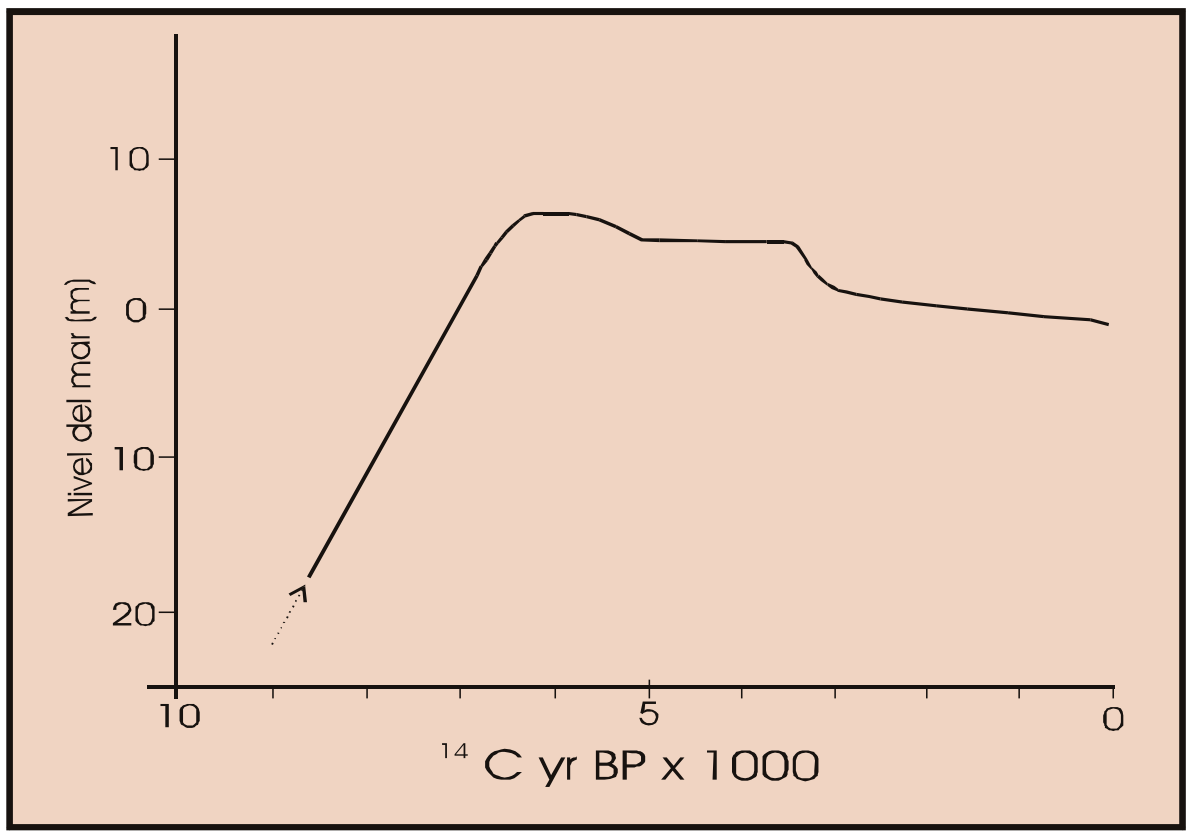

Fig. 5.21 Curva de ascenso del nivel del mar según Cavallotto, 1995.

Para la zona costera atlántica de la provincia de Buenos Aires, Isla (1989) realizó la evolución de la línea de costa para el ascenso postglacial, reflejando la máxima cota entre los 2 y 2,5 m a $10 s 6.500{ }^{14} \mathrm{C}$ años A.P. aproximadamente con un descenso lento y luego más acentuado a partir de los 3.000 años ${ }^{14} \mathrm{C}$ A.P. hasta alcanzar su posición actual (Fig $5.22)$.

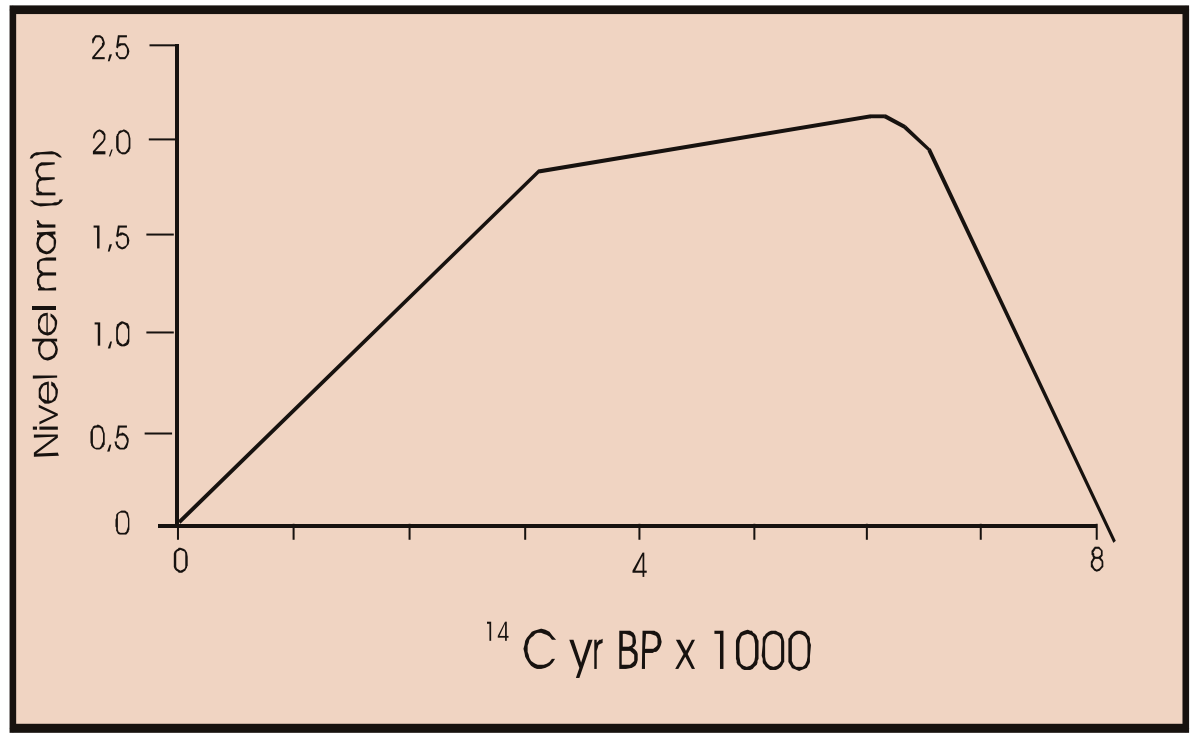

Fig. 5.22. Curva de ascenso del nivel del mar según Isla (1989) . 
En las costas del sudeste de Brasil y considerando un gran número de localidades, se realizaron curvas de variación del nivel del mar para el Holoceno sobre vermitídeos, observándose pequeñas variaciones entre éstas, aunque en líneas generales el máximo de elevación fue de 3,5 m situado aproximadamente a los $5.000{ }^{14} \mathrm{C}$ años A.P. con dos oscilaciones secundarias, posteriores a los 4.000 y $2.800{ }^{14} \mathrm{C}$ años A.P. (Angulo y Lessa, 1997) (Fig. 5.23).

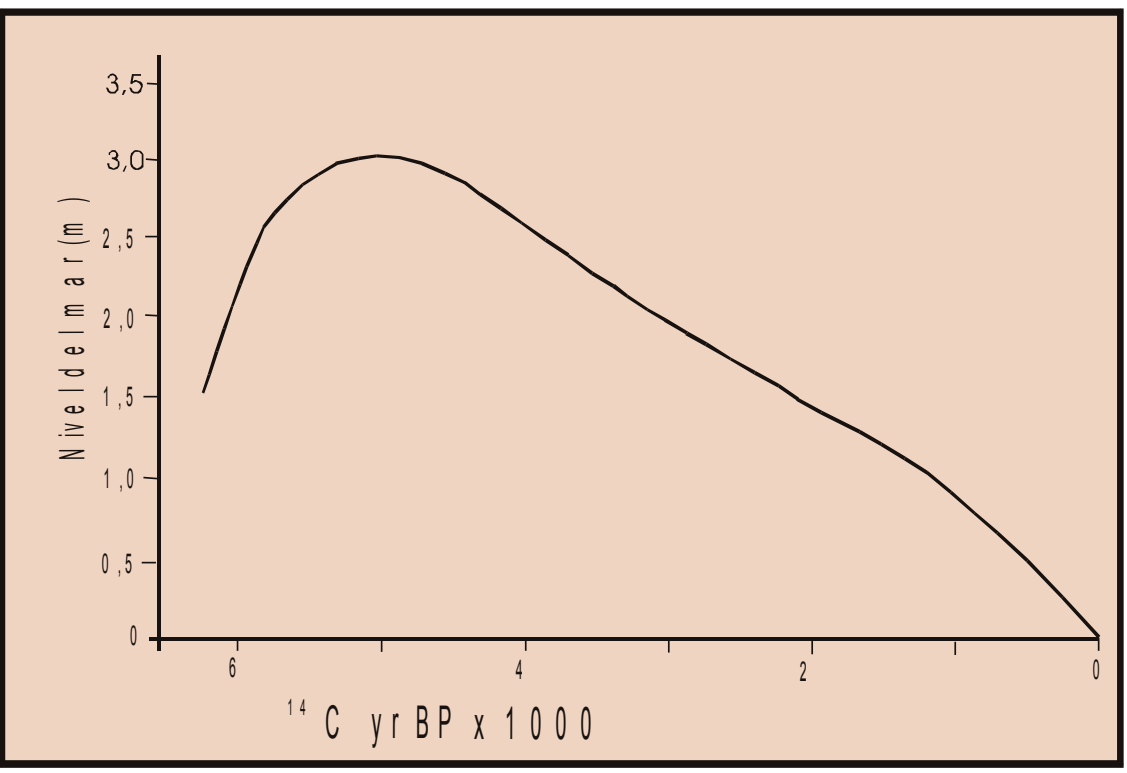

Fig. 5.23 Curva de ascenso del nivel del mar según Angulo y Lessa (1997).

Si bien el número de dataciones realizadas en la zona de estudio y su ámbito de influencia constituyen una base interesante, las exiguas pendientes y la ausencia de mapas topográficos con equidistancias superiores a 1,25 m constituyen un inconveniente para la determinación precisa de su cota y por ende, la determinación de la variación de la línea de costa con el rigor necesario (Vogel y Lerman, 1969; Guida y González, 1984; González y Ravizza, 1987; Figini, 1992; Fucks y De Francesco, 2003).

No obstante, es posible tentativamente determinar la posición de la línea de costa en situaciones particulares. 
De acuerdo a datos de la zona, el mar se situaba a los $-18 / 20$ metros a los 8.600 años ${ }^{14} \mathrm{C}$ A.P. en el subsuelo deltaico (Vogel y Lerman, 1969) y de acuerdo a la datación realizada en el sitio de su máxima penetración en el Río Luján, aledaño a Manzanares se obtiene una edad de $6.370{ }^{14} \mathrm{C}$ A.P (Figini, 1992) a los 4,5 m aproximadamente. Esta variación indica un ascenso promedio del nivel del mar del orden de los 11 mm por año, coincidente con otras curvas de la región (Cavallotto, 1995; Guilderson et al., 2000).

Asimismo, una datación en Erodona mactroides extraída en cercanías de la boca de paleoestuario en cota de 2,5 metros, estaría indicando un descenso hasta los $3.640{ }^{14} \mathrm{C}$ A.P. del orden de los 0,9 mm por año.

Estos datos puntuales coinciden con los de otros ámbitos en cuanto al momento de máxima elevación y velocidad de ascenso. Si bien se difiere en cuanto a la altura máxima alcanzada por la ingresión para otros sectores, existen factores como la acción del viento y de las mareas que pueden generar una elevación superior a los dos metros (Cavalloto, 1995; Kokot at al., 1999). Asimismo, es entendible que existan variaciones entre los diferentes estudios realizados ya que los fósiles utilizadas para las determinaciones provienen de depósitos generados en diferentes ámbitos geomorfológicos e incluso, muchas veces con procesos de retransporte.

\section{CAMBIOS RECIENTES Y FUTUROS DEL NIVEL DEL MAR}

Son muchas las evidencias que manifiestan que el nivel medio del mar ha estado en ascenso en el siglo pasado. La información obtenida de mareógrafos de la costa argentina indican ascensos de 1,6 $00,1 \mathrm{~mm}$ para Buenos Aires desde 1913 a 1984, de 1,4 $\pm 0,5$ mm para la estación Mar del Plata desde 1962 a 1984 (23 años) y de 1,6 $\pm 0,2 \mathrm{~mm}$ para Quequén en 48 años entre 1926 a 1973 (Lanfredi et al., 1998).

El Panel Intergubernamental sobre Cambio Climático (IPCC, 2001) indica que durante el siglo XX la temperatura media en la Tierra ha aumentado 
$0,6{ }^{\circ} \mathrm{C}$ y durante el siglo XXI lo hará entre 1,4 y 5,8 ${ }^{\circ} \mathrm{C}$. Este ascenso térmico producirá un aumento del nivel del mar del orden de 0,09 a 0,88 metros.

Otros autores consideran que es realmente impredecible el comportamiento del nivel del mar con respecto al calentamiento oceánico, ya que no sólo este aumento podría repercutir en un derretimiento de hielos, con el consecuente aumento del nivel del mar, sino también, en un aumento de las precipitaciones en la Antártida con el consecuente descenso del mismo (Oerlemans, 1982; Groger y Plag, 1983 en Isla y Espinosa, 1998).

Sin duda alguna, en un contexto del nivel del mar en ascenso, este aspecto repercutiría de manera muy diferente en el área de estudio de acuerdo a los valores a alcanzarse. Los procesos de inundación temporaria en el sector terminal del delta y llanura litoral constituirían los de mayor relevancia, asociados a una mayor permanencia del agua en sectores hoy parcialmente inundados. Esta situación, y en función del grado de influencia, produciría cambios importantes en las asociaciones florísticas y faunisticas y en determinadas actividades productivas como forestación, ganadería extensiva, apicultura, fruticultura y turismo entre las más representativas.

Un aspecto a considerar, pero muy difícil de predecir, está vinculado a los cambios referentes a las intensidades de los fenómenos climáticos (cambios abruptos de temperatura en cualquier estación; aumentos importantes en la intensidad de las precipitaciones con medias normales, aparición repentina y de gran intensidad de un huracán al sur de Brasil entre los más importantes) ya que podrían representar un aspecto aún más importante que el producido por el aumento del nivel del mar. 


\section{CAPITULO VI}

\section{SUELOS Y VEGETACION}

\subsection{SUELOS}

El suelo es el conjunto de unidades naturales que ocupan las partes de la superficie terrestre que soportan las plantas, y cuyas propiedades se deben a los efectos combinados del clima y de la materia viva sobre la roca madre, en un período de tiempo y en un relieve determinado (Soil Survey Staff, 1960).

Esta concepción del suelo fue expresada por primera vez por Jenny (1941) según la siguiente ecuación: $S=f(c l, o, r, p, t)$, donde el suelo es función (f) del clima "cl", los organismos "o", relieve "r", roca madre "p" y tiempo "t". En la actualidad, debe incluirse al factor antrópico, o sea el desarrollo de las diversas actividades humanas, que en forma directa o indirecta afectan la evolución del suelo.

Esta ecuación es muy importante, pues representa para una determinada combinación de los factores formadores, que sólo puede existir un tipo de suelo (la misma combinación originará siempre el mismo tipo de suelo independientemente del lugar geográfico en que se encuentre). Igualmente importante es la magnitud de cualquiera de las propiedades del suelo, tales como pH, contenido en arcillas, porosidad, etc., determinada por la combinación de estos factores formadores.

Para evaluar la influencia de cada factor formador en las propiedades del suelo, bastaría con mantener constantes todos los demás (hecho que frecuentemente es dificil de encontrar en la práctica). Así, para ver la importancia del tiempo sólo se mantiene variable al mismo y constante al resto de los factores, para este caso, la variación de cualquier propiedad del suelo depende exclusivamente del tiempo. Variando el tiempo irán surgiendo una serie de tipos de suelos, cada vez más evolucionados, cuyas propiedades serán una consecuencia directa de la edad y obtendríamos lo que se llama una CRONOSECUENCIA. 
Si se aísla el factor roca madre (y mantenemos constantes a todos los demás) tendríamos una LITOSECUENCIA. Aislando el factor relieve obtendríamos una TOPOSECUENCIA o CATENA, si es el clima el único factor variable tenemos la CLIMOSECUENCIA y finalmente la acción de los organismos vendría representada en una BIOSECUENCIA.

En el área de estudio se observa un conjunto de suelos con cualidades muy disímiles, dado por la coexistencia de ambientes continentales y litorales, no sólo por las características del relieve, sino también por la naturaleza y edad del material sobre el que éstos se desarrollan.

En los sectores sometidos a inundaciones frecuentes, vinculados a cursos de agua y al delta del Río Paraná, donde el relieve y el régimen hidrológico constituyen los factores más importantes, y donde el material originario de estos suelos es más moderno que los desarrollados en lomadas, el desarrollo de perfiles y estructuras está muy poco acentuado. De acuerdo al ambiente local, también pueden estar sujetos a procesos de acumulación, que trae aparejado "engrosamientos" del perfil.

Los suelos desarrollados sobre limos y loess en lomadas y sectores de pendientes, presentan en general perfiles bien desarrollados, sometidos en los sectores de pendiente a procesos erosivos (Bonfils, 1961).

Los principales Ordenes de suelos de la zona de estudio son Molisoles y Entisoles. Los primeros se caracterizan por ser de colores oscuros en su parte superior, presentar un horizonte superficial bien estructurado, rico en bases y blandos. Los Entisoles son suelos jóvenes, con perfiles indiferenciados y de escaso desarrollo del solum.

En casi toda el área, se presentan uno o más tipos de suelos, que reciben la denominación de Serie (Soil Survey Staff, 1975). Este concepto constituye la unidad taxonómica más pequeña del sistema de clasificación utilizado y se refiere a un grupo homogéneo de suelos desarrollados sobre un mismo material originario y donde la secuencia de horizontes y demás características son suficientemente similares a las de su perfil modal. 
Las principales Series están representadas por Solis, Portela, Capilla de Señor, Cañada Honda, Lima y Complejo Los Cardales, perteneciendo en su gran mayoría al Orden Molisol (INTA, 1996 - 1997).

A su vez, a cada una de las series se le asigna un Índice de Productividad (IP) a fin de establecer comparaciones entre las capacidades de producción entre los distintos tipos de suelos y que varían entre 1 y 100 . A este sistema "Paramétrico Multiplicativo" se le han introducido un conjunto de modificaciones para adaptarlo a las condiciones existentes de esta región, vinculándolo directamente con las metas del Proyecto PNUD ARG 85/019.

También se considera la clasificación por su Capacidad de Uso, que va de la clase I a la VIII. Hasta la clase IV inclusive, los suelos son aptos para la agricultura, y los restantes sonde uso limitado, no sirviendo para labranzas (INTA, 1996 - 1997).

En función de estas características, podemos separar los suelos de la región, según las formas en las cuales se han desarrollado, en siete sectores diferentes (Fig. 6.1) :

\subsubsection{GEOFORMAS Y SUELOS ASOCIADOS}

\subsubsection{Suelos en interfluvios}

Estos suelos constituyen la mayor parte del área de estudio. Se encuentran desarrollados en prácticamente la totalidad de los interfluvios, tanto principales como de ordenes menores. Se presentan en un relieve de suaves lomadas y extensas zonas prácticamente sin pendientes. De acuerdo al lugar donde se encuentren, pueden observarse rasgos de erosión hídrica.

Los suelos observados corresponden a Argiudoles vérticos con perfil típico integrado por los horizontes: Ap, A1, Bt1, Bt2, BC1, 2BCk y 2Ck, con espesores totales cercanos a los 2 metros. 
Se caracterizan por ser bien drenados, de textura franco limosa a arcillosa, permeabilidad lenta debido a los horizontes Bt, sin alcalinidad y salinidad, con una alta a muy alta Capacidad de Intercambio Catiónico (CIC). Presentan una Capacidad de uso de II y un IP de alrededor de 70, destinándoselos generalmente a la actividad agrícola.

6.1.1.2 Suelos en Pendientes: estos suelos se encuentran ubicados entre los anteriormente descriptos y los desarrollados en sectores de Planicies de Inundaciones, Paleoestuarios y Llanura Litoral. Se presentan conformando una delgada franja marginal a las geoformas anteriormente mencionadas, representando en general las paredes de valle.

Las pendientes en estos sectores son del orden de los $4 \%$, motivando que el escurrimiento superficial mantiforme y encauzado, produzca la pérdida parcial del horizonte superior, conformando cárcavas, que en algunos casos alcanzan tamaños importantes. Estos rasgos de erosión fluvial, pueden observarse con mucha regularidad en sectores localizados, coincidentes con los valores de inclinación más altos, no pudiendo ser separados por razones de escala, de otros sectores donde la erosión hídrica no produce los mismos efectos.

En muchos sectores, la erosión y acumulación se ve intensificada por el mal uso de los suelos (monocultivo prolongado), produciendo la reducción del contenido de materia orgánica, y con esto, el deterioro de la estructura y estabilidad. También, la acción de maquinaria pesada, produce compactación, generando lo que se conoce como "piso de arado", produciendo una disminución de la infiltración y una acumulación de agua en el perfil.

Los suelos desarrollados en estos sectores pertenecen a Argiudoles vérticos con perfil tipo Ap, A1, Bt1, Bt2, BCk y Ck, de 1,30 a 1,60 metros de espesor. Se presentan con textura franco arcillosa a arcillosa, moderadamente bien drenados, sin alcalinidad y salinidad, muy alto CIC y con susceptibilidad a la erosión hídrica. Presentan una capacidad de uso III, con problemas de dentro de la zona radicular y de erosión con un índice de productividad cercano a 60. 
6.1.1.3 Suelos en Depresiones Cerradas: se encuentran asociados a depresiones equidimensionales de $300 \mathrm{~m}$ de diámetro como término medio desarrolladas mayormente en las divisorias (Fig. 5.9).

Florísticamente presentan baja densidad poblacional, compuesta por duraznillo (Solanum malacoxylon) y otras especies indicadoras de suelos hidromórficos ácidos. El suelo en su periferia corresponden a un Argiudol vértico con un perfil típico de 1,80 metros de espesor, franco arcillo limoso a arcilloso, compuesto por los horizontes A, E, Bt1, Bt2, BC1, BC2 y C. Estos suelos presentan una permeabilidad escasa y anegamientos transitorios. Presenta una capacidad de uso V, con excesos de agua e índice de productividad del orden de los 35.

6.1.1.4 Suelos en Planicies de Inundaciones, Paleoestuarios y Llanura Litoral (Zonas INUNDABLES): estos suelos se encuentran desarrollados en la planicie fluvial del Río Luján y del Arroyo de la Cruz y en sus afluentes, en los paleoestuarios y llanura litoral.

En líneas generales puede observarse que estos suelos no presentan un gran desarrollo, tanto en profundidad como en la diferenciación de estructura y horizontes, caracterizándose por el elevado contenido de sales solubles (Bonfils, 1969). Esta última característica se observa frecuentemente en aquellos suelos desarrollados sobre sedimentos litorales, ubicados en la boca de los paleoestuarios y llanura litoral.

Se observa que los primeros $30-40 \mathrm{~cm}$ de profundidad presentan una coloración oscura, con tonos verdosos y concreciones de ferromanganíferas en cantidades importantes. Este sector superficial, presenta en sectores una fina laminación, producto de la acumulación fluvial, lo que demuestra el permanente engrosamiento producido por el material proveniente de los cursos principales y por aquellos que los transportan desde las paredes de los valles.

La presencia del nivel freático a escasa profundidad, constituye un elemento de suma importancia, ya que impide el desarrollo del perfil. 
En algunos sectores, debido al elevado contenido de sales y alta alcalinidad, se observan costras y eflorescencias salinas blanquecinas y pulverulentas, prácticamente desprovistas de vegetación (Fig. 5.13).

En aquellos sectores, donde las unidades litológicas están compuestas por sedimentos fluviales, se identifican Natracuoles, Natracualf típicos y argiudoles vérticos, con desarrollos de Horizontes A y Bt que no superan el metro de espesor.

6.1.1.5 Suelos Deltaicos: los suelos desarrollados en el delta presentan características diferentes de acuerdo al sector particular que ocupan. En los albardones se reconoce un perfil pobremente drenado, con un horizonte A cuyo espesor es de aproximadamente $20 \mathrm{~cm}$, abundante materia orgánica (4 \%), y un conjunto de capas sedimentarias infrayacentes. Aquellos ubicados hacia el interior de los albardones, en sectores fácilmente anegables, son suelos mal drenados, sin alcalinidad y salinidad, compuestos por un horizonte superficial A bien provisto de Materia orgánica que va de 5 a 15 \% aproximadamente, cubierto por un Horizonte Oi con vegetación semidescompuesta, reconociéndose hacia abajo una secuencia similar a la anterior. Haplacuoles hísticos, Haplacuent aérico entre otros, caracterizan a este sector (INTA 1989), observándose que las principales limitaciones son el anegamiento por inundaciones y el ascenso del nivel freático.

6.1.1.6 Suelos en Barrancas: se encuentran ubicados en los acantilados relictos desarrollados en los alrededores de las ciudades de Campana, Otamendi y Belén de Escobar. Presentan pendientes que van desde prácticamente verticales a pendientes moderadas (4 \%), observándose en estas últimas el desarrollo de un incipiente horizonte $A$ de escaso espesor. Este desarrollo se debe a la intensa erosión fluvial (encauzada y mantiforme), que deja a los materiales originarios muchas veces aflorantes (Fig. 5.15).

6.1.1.7 Suelos Parcial y Totalmente Urbanizados: si bien estos suelos se encuentran desarrollados en sectores de lomadas y en menor medida en 
sectores de pendientes, la existencia de extensas áreas urbanas y periurbanas, han motivado no solamente el cambio del uso de la tierra, sino también el de sus características superficiales.

Estos sectores han sido ocupados para todo tipo de emprendimientos (urbanizaciones en general y cerradas, emprendimientos industriales, líneas de comunicaciones, entre otras), observándose en forma aislada actividades productivas intensivas.

\subsection{VEGETACIÓN}

Las comunidades vegetales existentes en el sitio de estudio, han sido consideradas utilizando como referencia a Cabrera (1953 y 1976), Cabrera y Willink (1973), Cabrera y Zardini (1978) y Prat y colaboradores (1998), corroborándose con observaciones de campo. El ámbito biogeográfico regional corresponde dentro del Dominio Chaqueño a la provincia Pampeana, Distrito Uruguayense, no obstante sobre las barrancas se desarrollan bosques de tala, una comunidad propia de la provincia del Espinal, Distrito del Tala (Cabrera, 1976). En las márgenes del Río Paraná de las Palmas, sobre los suelos desarrollados en el albardón aparecen bosques higrófilos con especies propias de la Provincia Paranense (Dominio Amazónico), Distrito de las Selvas Mixtas, llamadas también selvas marginales.

En la Pampa Ondulada, por encima del paleoacantilado, se extienden extensas áreas ocupadas principalmente por gramíneas de 0,50 a 1 metro de altura. La comunidad predominante la constituye el "flechillar" (Cabrera y Wilink, 1973) integrado por Bothriocloa laguroides, Stipa neesiana, Stipa tenuissima, Piptochaetuim bicolor, Aristida murina, Briza subaristata, Briza brizoides, Melica brasiliensis, Paspalum dilatatum, Stipa charruana, Setari vaginata, etc. Entre estas gramíneas se encuentran comunidades arbustivas de Baccharis notosergila, Baccharis articulata, Eupatorium buniffolium y Heimia salicifolia, entre otras.

Los suelos desarrollados en interfluvios y en los sectores de pendientes, carecen prácticamente de vegetación autóctona debido a la intensa 
explotación agrícola desarrollada, aquí se observa la introducción de comunidades afines a esta actividad, y comienzan a ser abundantes los pastos duros como Piptochaetum stipoides, Piptochaetum montevidense, Panicum vergii, Melica macra y Aristida murina.

En la llanura litoral, debido a las escasas modificaciones antrópica producidas puede observarse un conjunto de comunidades vegetales autóctonas de acuerdo a los ambientes y subambientes geomorfológicos existentes (fig. 6.1). 


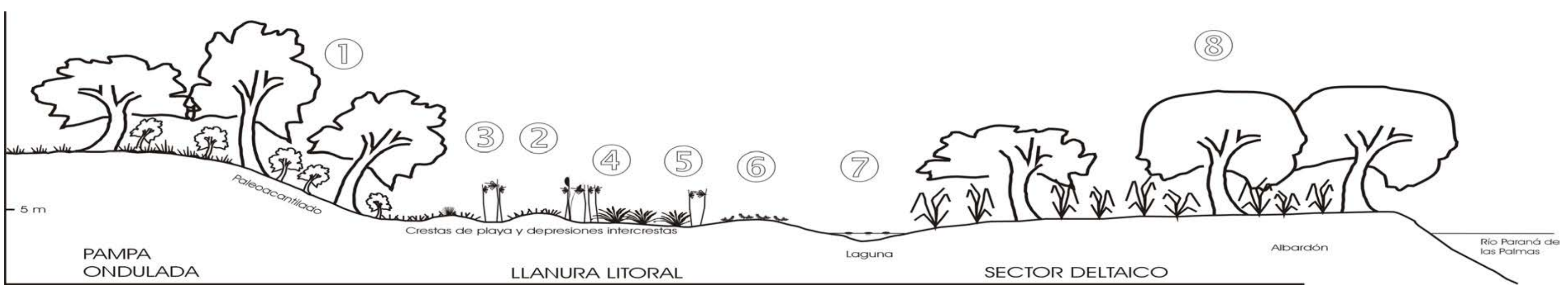

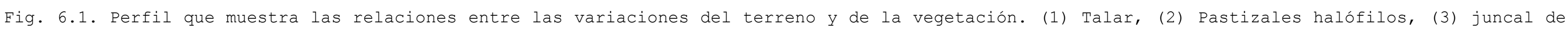

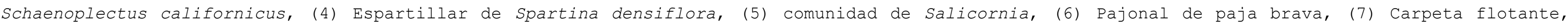
(8) Bosques higrófilos. 
Separando la Llanura Litoral de la Pampa Ondulada se desarrolla el paleoacantilado, observado fundamentalmente en los alrededores de Otamendi, Campana y Belén de Escobar, encontrándose colonizadas por talares de Celtis tala acompañados por Phytolacca dioica (ombúes), Parkinsonia aculeata (cina cina), Sambucus australis (sauco), Prosopis alba y Allophyllus edulis (chal-chal).

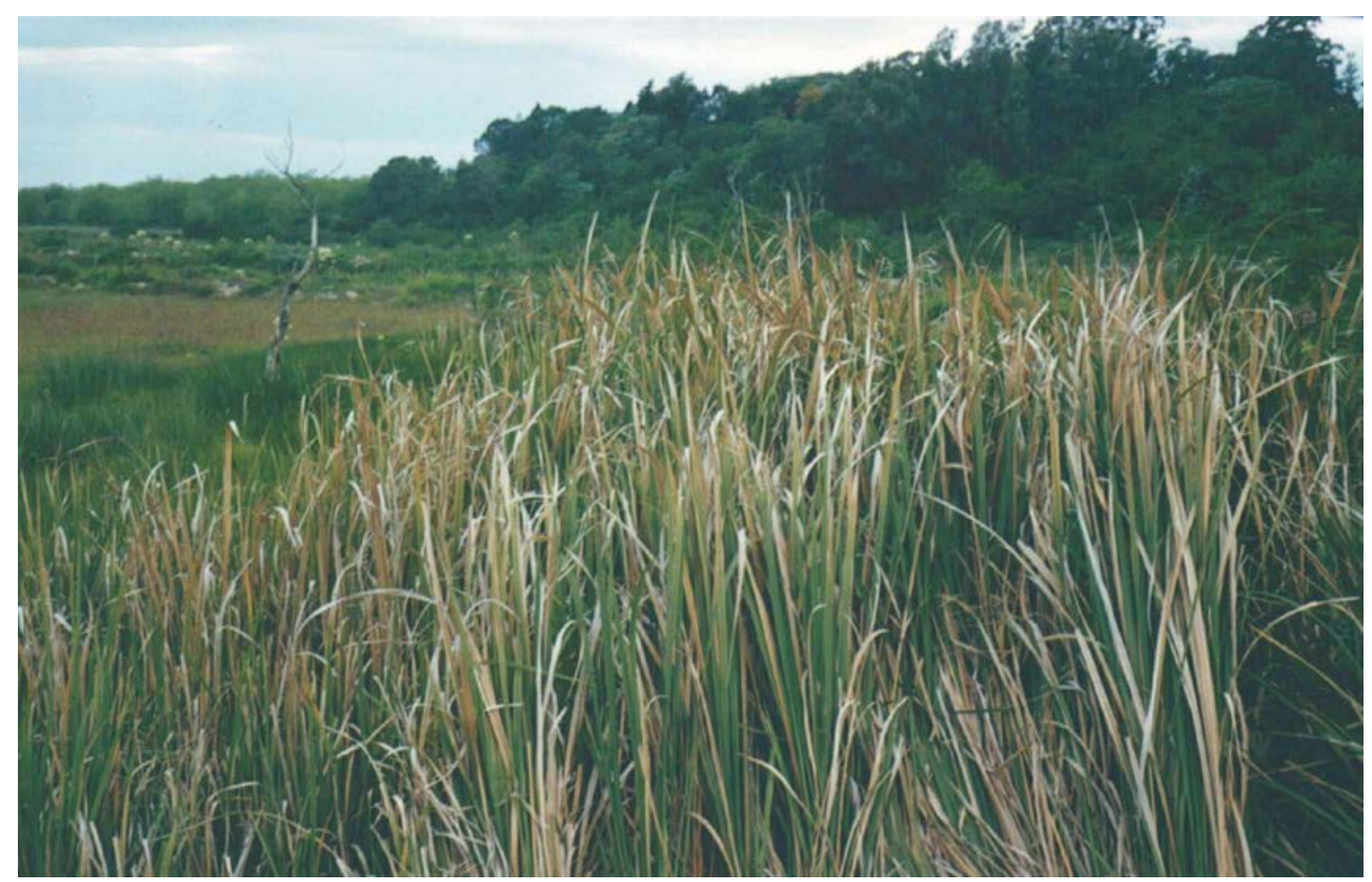

Fig. 6.2 En el sector anterior se observan juncales, disponiéndose en la parte posterior de la fotografía la vegetación natural e introducida resaltando el Paleoacantilado.

En la llanura litoral, las crestas de playa y las depresiones intercrestas, constituyen las geoformas mas características.

En las crestas se desarrollan espartillares de Spartina densiflora junto a Bacopa monieri y Ludwigia peploides (Fig. 6.2). Es común observar concentraciones de sales importantes, donde se presentan pastizales de "pasto salado" de Distichlis spicata (Fig. 6.3), también son abundantes Distichlis scoparia, Juncus acutus, Chaetotropis elongata, Paspalum vaginatum, y extensas comunidades compuestas por Salicornia ambigua, 
Chenopodium macrospermum, Spergularia grandis, Sesuvium portulacastrum, Malvella leprosa y Lythrum maritimun entre otras.

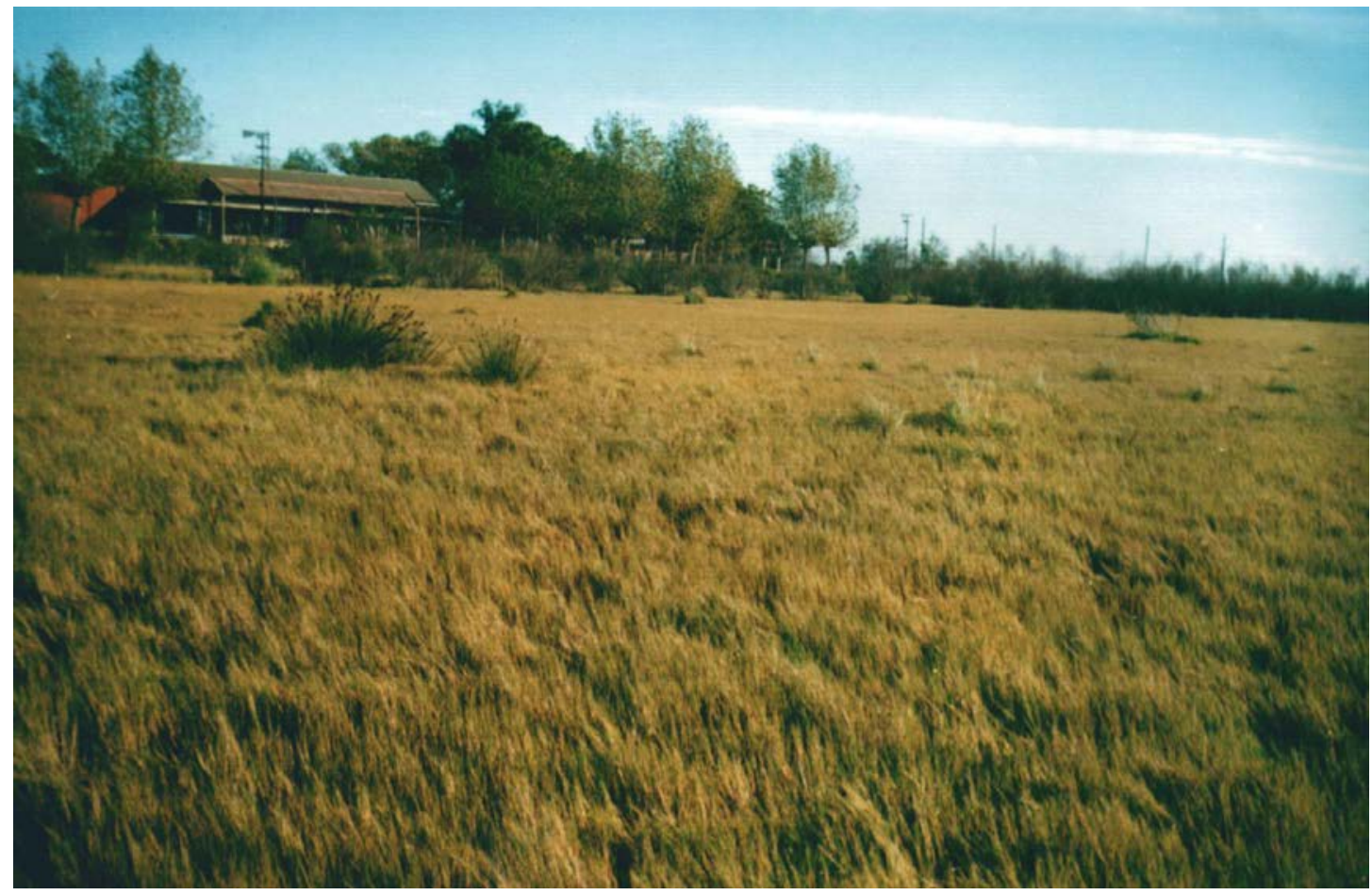

Fig. 6.3 pastizales de "pasto salado" de Distichlis spicata.

En los sectores de intercrestas con agua permanente se desarrollan juncales de Schoenoplectus californicus (Fig. 6.4.) y se forman carpetas flotantes constituidas por Azolla filiculoides, Lemna sp., Spirodella sp., Marsilea concinna, Eleocharis obtusa e Hydrocotile bonariensis (Fig. $6.5)$. 


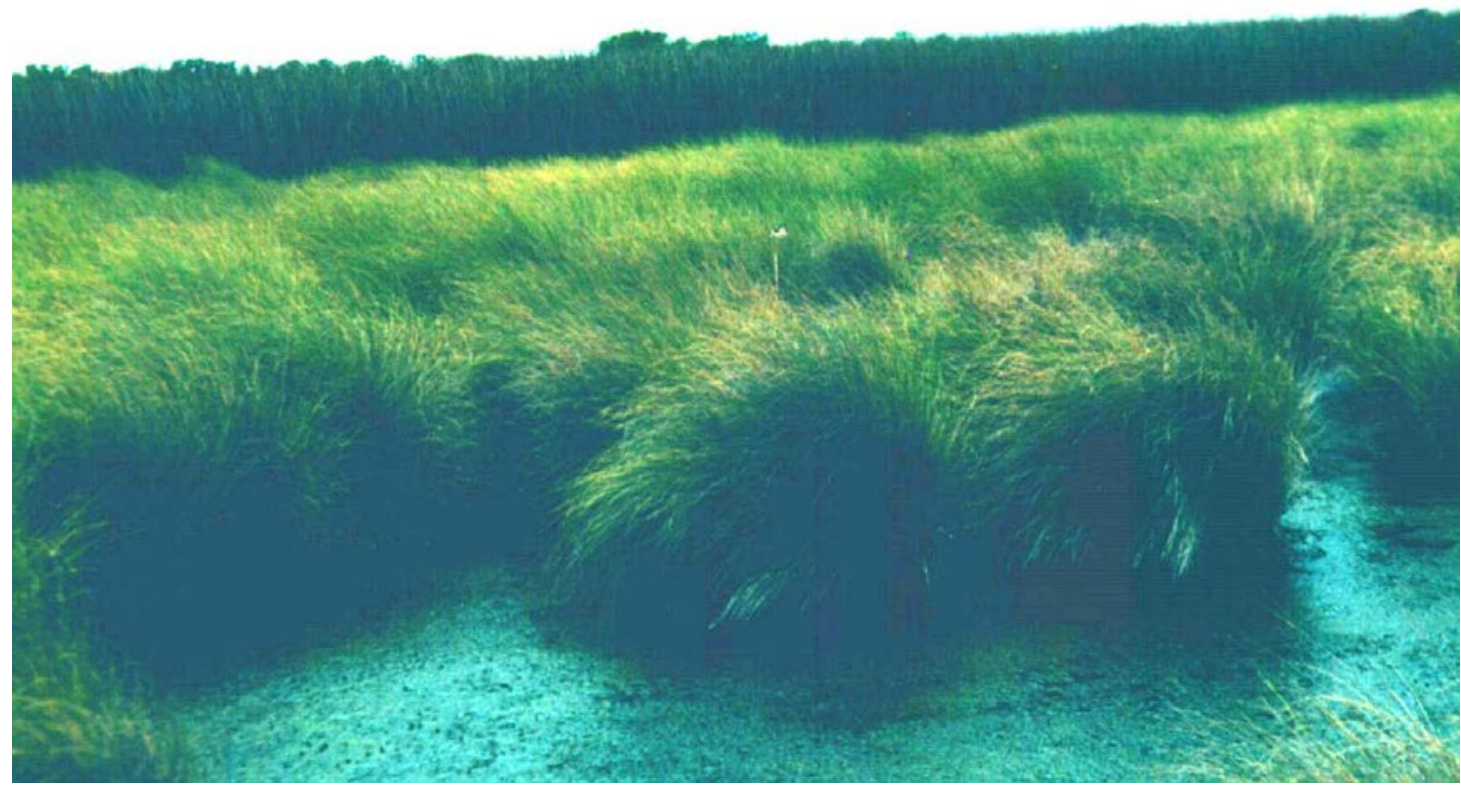

Fig. 6.4 Se observa en la parte anterior de la fotografía una comunidad de Spartina densiflora parcialmente sumergida y en la parte posterior una comunidad de juncales de Schoenoplectus californicus.

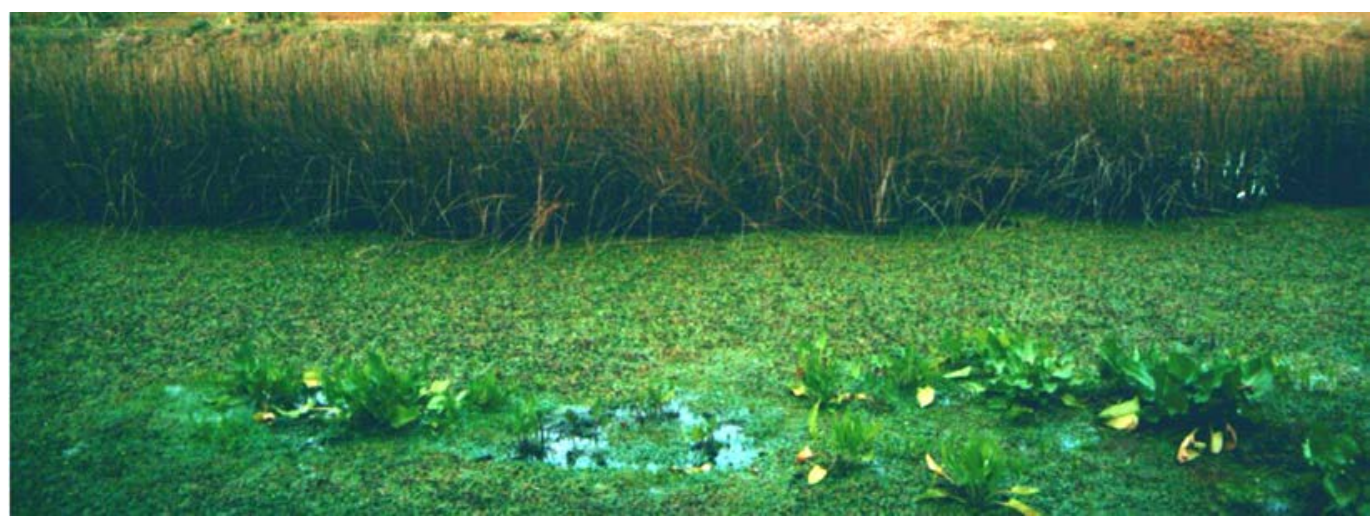

Fig. 6.5 Se observa en la parte anterior de la fotografía una comunidad flotante y en la parte posterior juncales.

La vegetación existente en el Sector Déltico está compuesta por un conjunto de comunidades vegetales que se desarrollan en sectores particulares:

- alejados de los cursos de agua, en sectores parcial o totalmente inundados, se encuentran pajonales de Scirpus giganteus (paja brava), Panicum prionitis (paja de techar), Zizaniopsis 
bonariensis (espadaña), totorales de Typha latifolia y $T$. angustifolia, Panicum grumosum, Schoenoplectus californicus, Scirpus riparius y Canna glauca entre las más importantes (fig. $6.6)$.

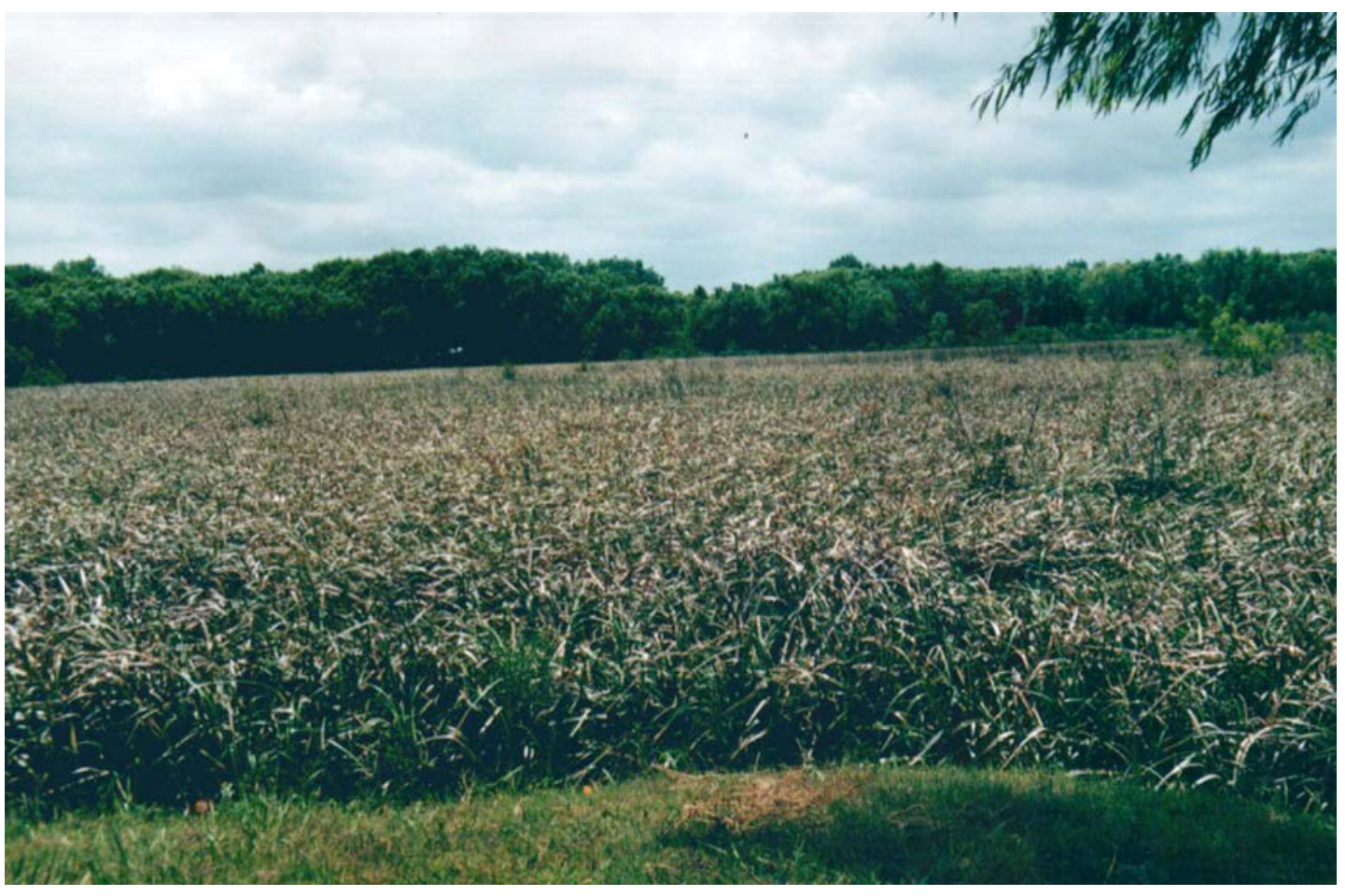

Fig. 6.6 Pajonales de Scirpus giganteus (paja brava) y en la parte posterior Salix humboldtiana (sauce criollo).

- en los albardones de los cursos principales se observa Salix humboldtiana (sauce criollo), Salix alba, Tessaria integrifolia, Erytrina crista-galli (seibo). En sectores naturales encontramos Cathorium polyanthum, Inga sp., Rapanea lorentziana, Nectandra falcifolia y Sapium haematospermum.

Las observaciones de campo han permitido reconocer un conjunto de comunidades en las que se observaron las especies citadas en la Tabla 6.1 .

\begin{tabular}{|l|l|}
\hline Tabla 6.1. Listado de especies por comunidad reconocidas en el campo. \\
\hline COMUNIDAD & ESPECIES \\
\hline Pastizal de "pasto salado": & $\begin{array}{l}\text { Distichlis spicata } \\
\text { Chaetotropis chilensis }\end{array}$ \\
\hline
\end{tabular}




\begin{tabular}{|c|c|}
\hline & $\begin{array}{l}\text { Triglochin striata } \\
\text { Spergularia ramosa } \\
\text { Poa pilcomayensis } \\
\text { Paspalum vaginatum } \\
\text { Rumex ovovatus } \\
\text { Lotus tenuis } \\
\text { Plantago macrostachis } \\
\text { Scirpus cernus } \\
\text { Carex extensa }\end{array}$ \\
\hline Espartillar : & $\begin{array}{l}\text { Spartina densiflora } \\
\text { Bacopa monieri } \\
\text { Ludwigia peploides } \\
\text { Cleome sp. } \\
\text { Samolus valeriandi } \\
\text { Centaurium pulchelum } \\
\text { Heimia salicifolia } \\
\text { Rumex paraguayensis } \\
\text { Lithrum maritimun }\end{array}$ \\
\hline Carpeta flotante: & $\begin{array}{l}\text { Azolla filiculoides } \\
\text { Eleocharis obtusa } \\
\text { Ludwigia peploides } \\
\text { Marcilea consinna } \\
\text { Hydrocotile bonariensis } \\
\text { Distichlis spicata } \\
\text { Solanum malacoxilon }\end{array}$ \\
\hline Pajonales de "paja brava": & $\begin{array}{l}\text { Scirpus giganteus } \\
\text { Lemma minuta } \\
\text { Azolla filliculoides }\end{array}$ \\
\hline Comunidad de Salicornia & $\begin{array}{l}\text { Salicornia ambigua } \\
\text { Lithrum maritimun } \\
\text { Chenopodium sp } \\
\text { Scirpus cernuus } \\
\text { Sida leprosa }\end{array}$ \\
\hline
\end{tabular}




\begin{tabular}{|l|l|}
\hline & Chenopodium album \\
& Limonium brasiliensis \\
& Plantago sp \\
Rumex ps & Centaurium pulchelum \\
\hline Juncal & Schoenoplectus californicus \\
& Ludwigia peploides \\
& Diplotaxis muralis \\
Azolla filiculoides \\
Eleocharis obtusa \\
Lemma minuta \\
Bacopa monieri \\
Lithrum maritimun \\
Sida leprosa
\end{tabular}




\section{CAPITULO VII}

\section{PELIGROSIDAD Y RIESGOS GEOLÓGICOS}

El objetivo de este capítulo es presentar una caracterización de los principales riesgos geológicos del área de estudio que en términos generales están asociados a las inundaciones.

\subsection{INTRODUCCION}

La consideración de los riesgos geológicos es un aspecto esencial dentro de los esquemas de ordenación y protección del entorno ambiental (Cendrero Uceda, 1987).

Debido a que la mayor parte de la superficie afectada por las inundaciones se encuentra libre de asentamientos humanos se realiza conjuntamente con el mapa de riesgo un mapa de peligrosidad.

El concepto de peligrosidad se refiere a la mayor o menor probabilidad de que un determinado fenómeno afecte a una zona con un cierto nivel de intensidad, independientemente que afecte o no a los seres humanos. El concepto de riesgo incluye la posibilidad de daños a personas, instalaciones o actividades, por lo que además de la peligrosidad, habrá de tener en cuenta la existencia de poblaciones, infraestructuras, etc (Cendrero Uceda, 1987). Estos conceptos reflejan que para un área determinada sujeta a inundaciones periódicas represente una zona de alta peligrosidad, pero que por ausencia de asentamientos humanos tenga riesgo nulo.

Una forma de manejar la peligrosidad es conocerla, para lo cual el aporte de las ciencias naturales básicas y aplicadas es imprescindible. Así mismo, algunos autores prefieren utilizar el término "amenaza" en lugar de peligrosidad. 
La vulnerabilidad está definida por las condiciones socioeconómicas previas a la ocurrencia del evento catastrófico. Se entiende el conjunto de todo lo que ha sido realizado por obra del hombre en un cierto territorio y que, directa o indirectamente, es susceptible de un daño material (Panizza, 1993). Los niveles de organización e institucionalización de los planes de mitigación (preparación, prevención, recuperación) son un componente central de la vulnerabilidad. Desde este punto de vista, la vulnerabilidad está directamente asociada al desarrollo. Se refiere al grado de pérdida provocado por la ocurrencia de un fenómeno natural de una magnitud dada, causando en un elemento o conjunto de elementos (Corominas, 1987). Las ciencias sociales son las que aportan un mayor grado de conocimientos sobre esta componente.

\subsection{PROBLEMÁTICAS SOBRE SEQUÍAS E INUNDACIONES EN LA REGIÓN PAMPEANA}

Los ciclos climáticos conocidos como secas e inundaciones constituyen uno de las problemáticas más acuciantes en el ámbito pampeano. Debido al escaso período que abarcan con precisión los registros pluviométricos (1861 en adelante), se hace necesario establecer a través de documentos, crónicas de viajeros, etc., los diferentes escenarios que vivía la población, considerando que la documentación de estas situaciones coincide con los casos más extremos (sequías e inundaciones). De acuerdo a esto, a nivel regional estas problemáticas pueden ser precisadas a partir del establecimiento de los europeos sobre el territorio pampeano a través del estudio de cartas y Actas del Cabildo, donde se hacen referencias sobre las sequías e inundaciones que afectaban a la región. Entre las citas más comunes, están las relacionadas a procesiones por la ciudad de Buenos Aires para pedir lluvia; además del efecto de la mortandad de animales por falta de pasto y agua, la salinidad de cursos de agua, los extensos desborde de cursos y lagunas, etc. (Politis, 1984; Rabassa, 1985; Moncaut, 2003).

La narración más antigua hace referencia a la sequía producida en los años 1575 y comienzos de 1576 donde se manifiesta que en estos años 
"hemos visto llover muy poco, en esta tierra tan estéril de aguas que se siembra y no grana". Como situación inversa se destaca la producida el 11 de agosto de 1857 cuando como consecuencia del desborde de ríos y lagunas de la pampa deprimida, atraca en Chascomús el vapor tipo Mississippi "Río Salado del Sur" permitiendo el intercambio de mercancías a una localidad que se encontraba aislada. Una recopilación importante de estas crónicas es la realizada por Moncaut (2003) exponiéndose en la tabla adjunta una síntesis de esta.

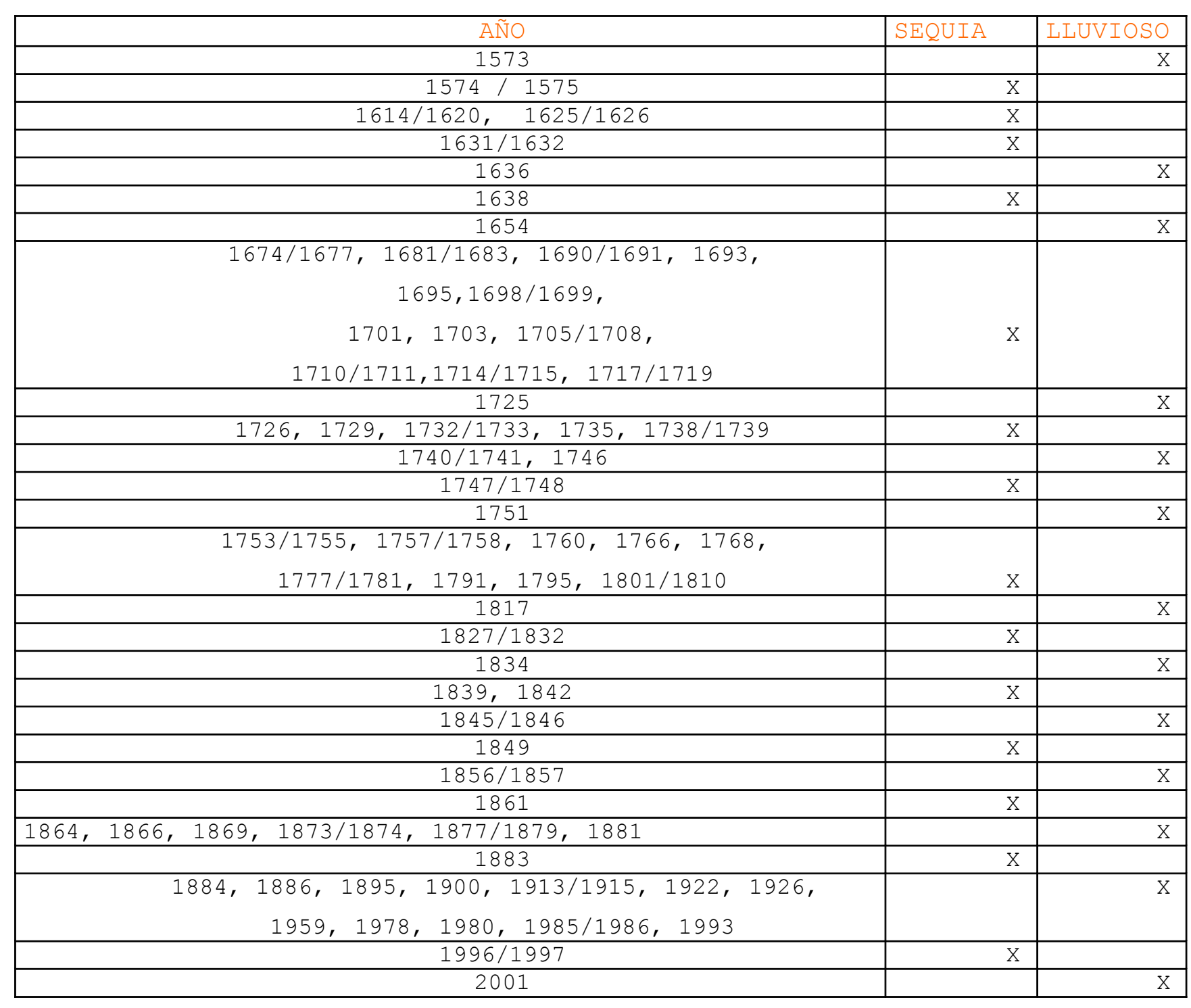

Tabla 7.1 Ubicación temporal de los principales excesos y déficit hídricos (Moncaut, 2003). 
Si bien es probable que muchas de estas citas correspondan a efectos ENSO (ver Fenómeno ENSO), no necesariamente tiene que existir una correspondencia directa, ya que es común que en situaciones de inundación en la cuenca del Paraná exista déficit hídrico en las zonas continentales aledañas.

\subsection{PROBLEMATICAS EN LA ZONA DE ESTUDIO}

Una primer aproximación sobre problemáticas ambientales permite identificar una gran variedad de peligrosidades en la zona de estudio como accidentes tecnológicos: filtraciones de hidrocarburos de estaciones de servicio, explosiones de polos petroquímicos, derrames, explosiones e incendios producidos en el transporte de sustancias peligrosas, inseguridad en el manejo de grandes equipamientos de infraestructura, o de áreas industriales de alta complejidad.

Si bien existe una peligrosidad permanente para la concreción de accidentes tecnológicos y naturales, los desastres "naturales" relacionados con las inundaciones constituyen hasta ahora los de mayor impacto en la zona de estudio. Asimismo, la apertura de canteras crea situaciones conflictivas tanto en el aspecto urbano -paisajístico como el ambiental en sentido amplio.

Específicamente en el área de estudio y de acuerdo a las características topográficas, geomorfológicas y climáticas, se han delimitado los sectores que presentan mayor grado de peligrosidad y riesgo de inundación, considerando a éste último, como la posibilidad de que produzcan daños a las personas o bienes, dependiendo no sólo del proceso en sí, sino también del grado y tipo de la ocupación del suelo por parte de las comunidades humanas (Cendrero, 1987).

Asimismo, también se delimitan los sectores de mayor grado de peligrosidad. El objetivo de esta zonificación es de carácter preventivo, no sólo a fin de evitar la localización de actividades humanas sujetas a 
desastres naturales, sino a proteger sectores que al ser intervenidos conlleven a su degradación parcial y/o total.

Con este criterio se han diferenciado y cartografiado distintas áreas en función de su grado de peligrosidad, indicando los sectores que presentan el mayor o menor riesgo. La superficie que ha sido indicada como peligrosa por inundaciones y que a su vez es de bajo riesgo, se refiere a que las actividades que en la misma se desarrollan son fundamentalmente de ganadería extensiva, forestación, esparcimiento, vivienda y producción, todo con baja densidad poblacional, por lo tanto cuando es necesaria la evacuación por inundaciones, esta es rápida, económica y en general sin mayores pérdidas materiales (Fig.7.1).

Las áreas de alto riesgo de inundación están relacionadas con las áreas urbanas y periurbanas de las localidades de Pilar y Manzanares sobre el Río Luján y Capilla del Señor sobre el arroyo de la Cruz.

Las inundaciones producidas en las localidades de Manzanares y Pilar presentan componentes naturales y artificiales. Dentro de las primeras, puede observarse un cambio marcado de pendiente en el curso de agua (de 0,05 a 0,01 \%, constituyendo el factor más importante que controla el escurrimiento superficial. A este componente debemos sumarle el factor de la intensidad de precipitaciones, aunque la ausencia de mediciones en el ámbito de la cuenca hace muy difícil su tratamiento. Si bien este componente no pudo ser cuantificado, el relato de los damnificados y la observación de las situaciones, permitió corroborarlas en muchas oportunidades. Como ejemplo puede citarse la inundación del 11 de Febrero de 1999. Según los moradores de una vivienda inundada, situada a unos 200 m del Río Luján, entre la ruta 8 y la línea del ex ferrocarril Urquiza, éstos manifestaron que "después de llover durante todo el sábado, el domingo amanecieron inundados". Esta situación pudo ser observada en otras oportunidades (15 noviembre de 2001) donde llevaban una semana inundados, previendo que antes de una semana el nivel de las aguas no descendería (Fig. 7.2). 

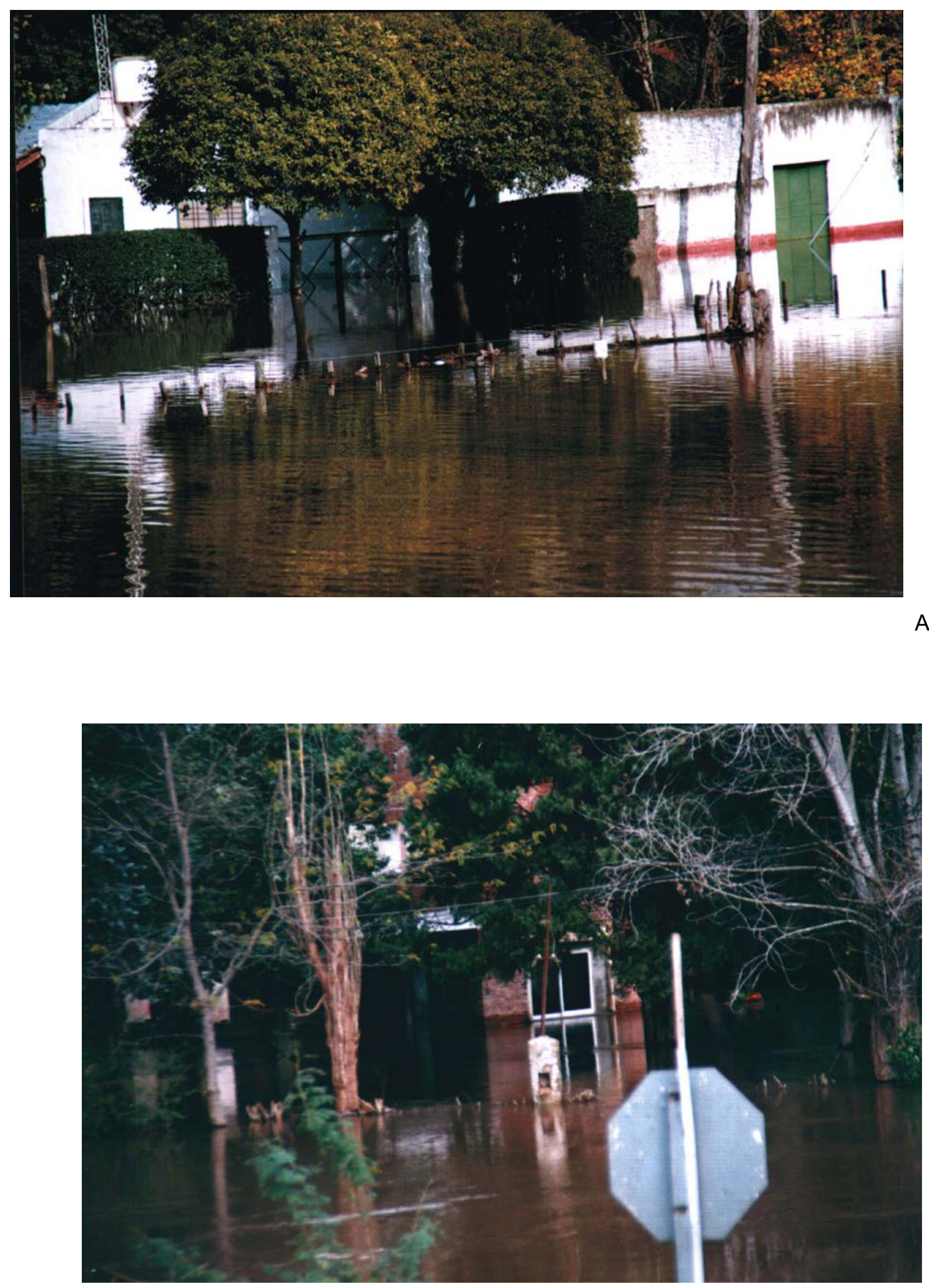
Fig. 7.2 Sector periurbano de Pilar aguas arriba del Río Luján sobre ruta 8 .

A los aspectos naturales expuestos es preciso señalar que en el sector se encuentran construidas tres líneas de comunicación (ex líneas ferroviarias Urquiza y San Martín y la Ruta Nacional $\mathrm{N}^{\circ}$ 8) con el consecuente endicamiento de las aguas. En este sector puede observarse como consecuencia de la disminución de la velocidad del escurrimiento, se producen acumulaciones fluviales actuales del orden de los 3 a 3,5 m de espesor, depósitos que no han podido ser observadas en otras localidades del área (Fig. 5.21)

En la localidad de Capilla del Señor, el Arroyo de la Cruz produce la inundación de los sectores aledaños en un sector restringido a los 300 metros aproximadamente a cada lado de éste. Las precipitaciones importantes en esta cuenca de dimensiones pequeña, producen la elevación rápida del nivel de las aguas, con la consecuente inundación de su planicie, aunque por periodos cortos de tiempo (1-2 días, 15 de mayo del 2000). En este sector es importante señalar que el curso está bien delimitado por barrancas de unos dos metros de alto y sin cambios importantes de pendientes, encontrándose tres líneas de comunicaciones en el sector (ruta y ferrocarriles) transversales al curso. Recientemente se ha canalizado el curso, produciendo el ensanchamiento, profundización y rectificación de curvas, con el objeto de paliar los problemas observados. 


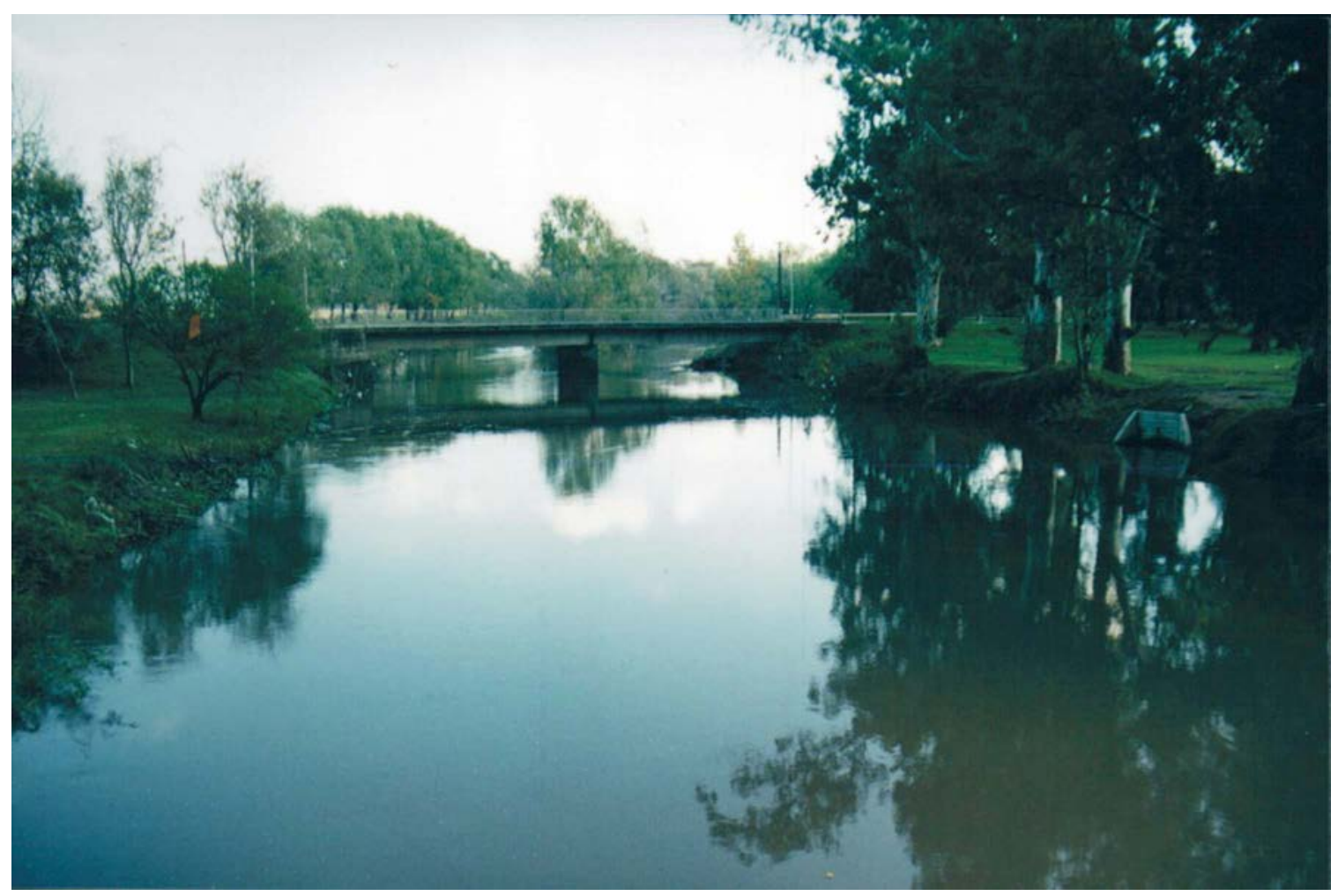

Fig. 7.3 Arroyo de la Cruz en Capilla del Señor en condiciones normales.

El riesgo de inundación producido en sectores de riesgo alto en Capilla del Señor, Manzanares y Pilar y en un conjunto de nuevas urbanizaciones (Clubes de Campo, Barrios Cerrados y Countries) están vinculadas directamente con la planificación y uso del suelo, ya que estas actividades se han desarrollado directamente en las zonas inundables de estos cursos, correspondan o no estrictamente a las planicies de inundación desde el punto de vista geomorfológico.

Relacionado al concepto de peligrosidad, el mayor grado corresponde a los paleoestuarios de los cursos Luján y de la Cruz, a la llanura litoral y al sector deltaico, a las planicies de inundación de los cursos y a las cuencas cerradas.

En los paleoestuarios la inundación de toda la geoforma se produce por las aguas provenientes de los desbordes de los cursos principales y sus afluentes como producto de las precipitaciones. El agua al llegar a estas 
geoformas se moviliza con velocidades muy bajas debido al bajo gradiente que presentan $(0,01 \%)$.
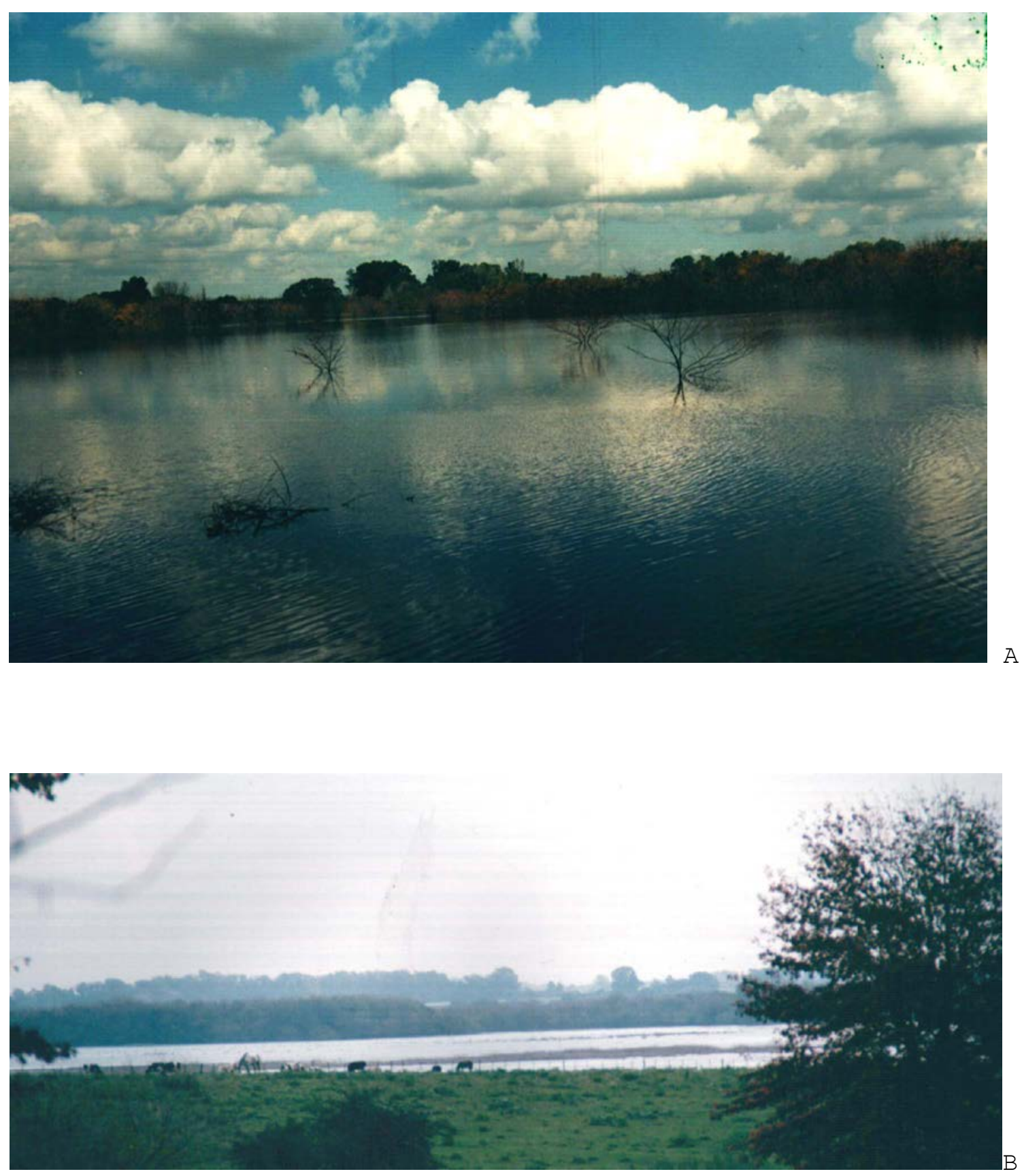

Fig. 7.4 Áreas sin urbanizar del paleoestuario del Río Luján completamente inundadas. B. La vegetación situada en el sector intermedio corresponde al Río Luján. 
En la llanura litoral y delta a los factores anteriores se le suman las aportadas por las sudestadas y por las crecidas del Paraná de las Palmas. El tiempo de permanencia de las aguas es muy variable dependiendo de la intensidad $y$ de los factores intervinientes, observándose periodos superiores a los 15 días (fotos).

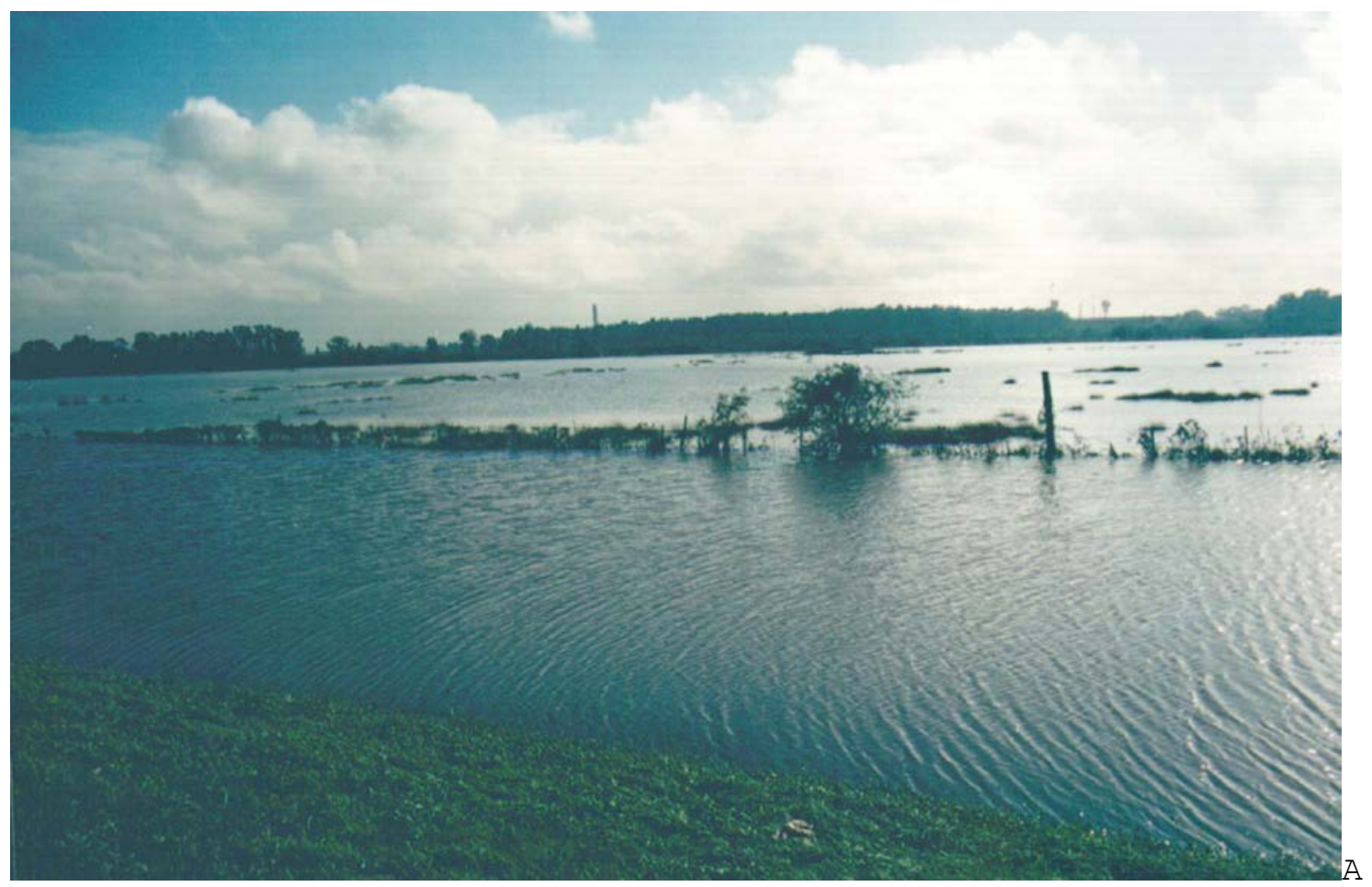



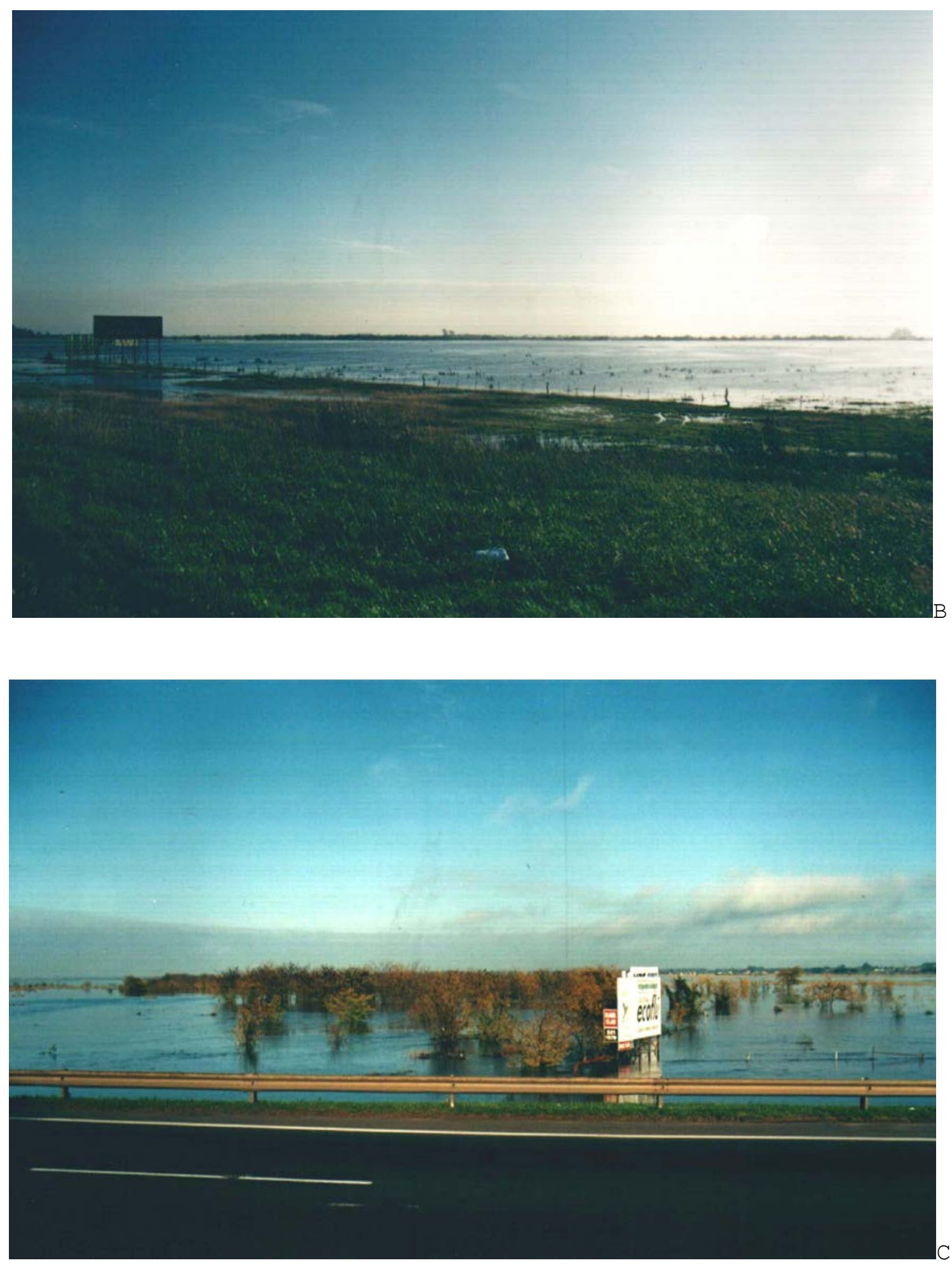

Fig. 7.5 Distintas situaciones en la llanura litoral durante las inundaciones. A: Arroyo de la Cruz y Pequería aguas arriba de la ruta 9. B y C Río Luján aguas abajo y arriba respectivamente de la ruta 9. 
El sector deltaico está directamente influenciado a través del río Paraná de Las Palmas por las crecientes anuales en otoño (marzo - abril) y bajantes a fines de invierno y principio de primavera (agosto - octubre). Sobre este ciclo de crecientes normales, existen otros de crecientes extraordinarias, tales como las producidas en 1940, 1959, 1982-1983, 1992 y anteriores, con sus trágicas consecuencias (ver FENOMENO ENSO).

Los cursos de agua presentan de acuerdo a su grado de desarrollo diferentes superficies que son alternativamente ocupadas por las aguas de desbordes. Estas planicies de inundación tienen desarrollos muy variables y muchas veces aumentadas por obras viales.

El área restante no presenta riesgos y peligrosidad por inundaciones, salvo casos excepcionales, donde sectores del terreno localmente deprimidos pueden ser afectados por precipitaciones torrenciales, presentando un riesgo o peligrosidad real.

La explotación de suelos seleccionado ha llevado a que si bien no se viera afectada la productividad agrícola ganadera de la región, se produjera una importante degradación del ambiente.

Las principales problemáticas asociadas con esta actividad están en relación con la planificación de los usos del suelo y con las tareas de remediación.

Relacionado con la primera, es común que las superficies que han sido explotadas queden a corto o a mediano plazo englobadas dentro de áreas urbanas. Esta situación genera situaciones de peligro para los habitantes ya que no sólo la variación abrupta de las alturas presentan riesgos de accidentes, sino que se constituyen en sectores localizados para el vertido de residuos con la consecuente contaminación atmosférica, del agua y del paisaje.

Desde el punto de vista urbano paisajístico la existencia de una "cantera" o "tosquera" es de muy difícil resolución ya que constituye una 
barrera física a la urbanización y a las líneas de comunicación. Las canteras de la zona son de superficies muy dispares, encontrándose estas en diferente estado de situación, desde pequeñas, menores a una hectárea, hasta las que superan unas 10 veces esta superficie. Las profundidades también son variadas; algunas presentan desniveles de 3 a 4 metros, pero la mayoría posee el piso por debajo de los 10 metros de la superficie topográfica. La profundidad de las canteras está vinculada con la presencia o ausencia de agua. Es de destacar que casi la totalidad de las canteras abandonadas presentan agua con diferentes profundidades en su interior y las que están en explotación, se encuentran en procesos de bombeo, que una vez abandonadas se inundan rápidamente (fig. 7.6). En general no se han observado tareas de remediación en las canteras abandonadas.

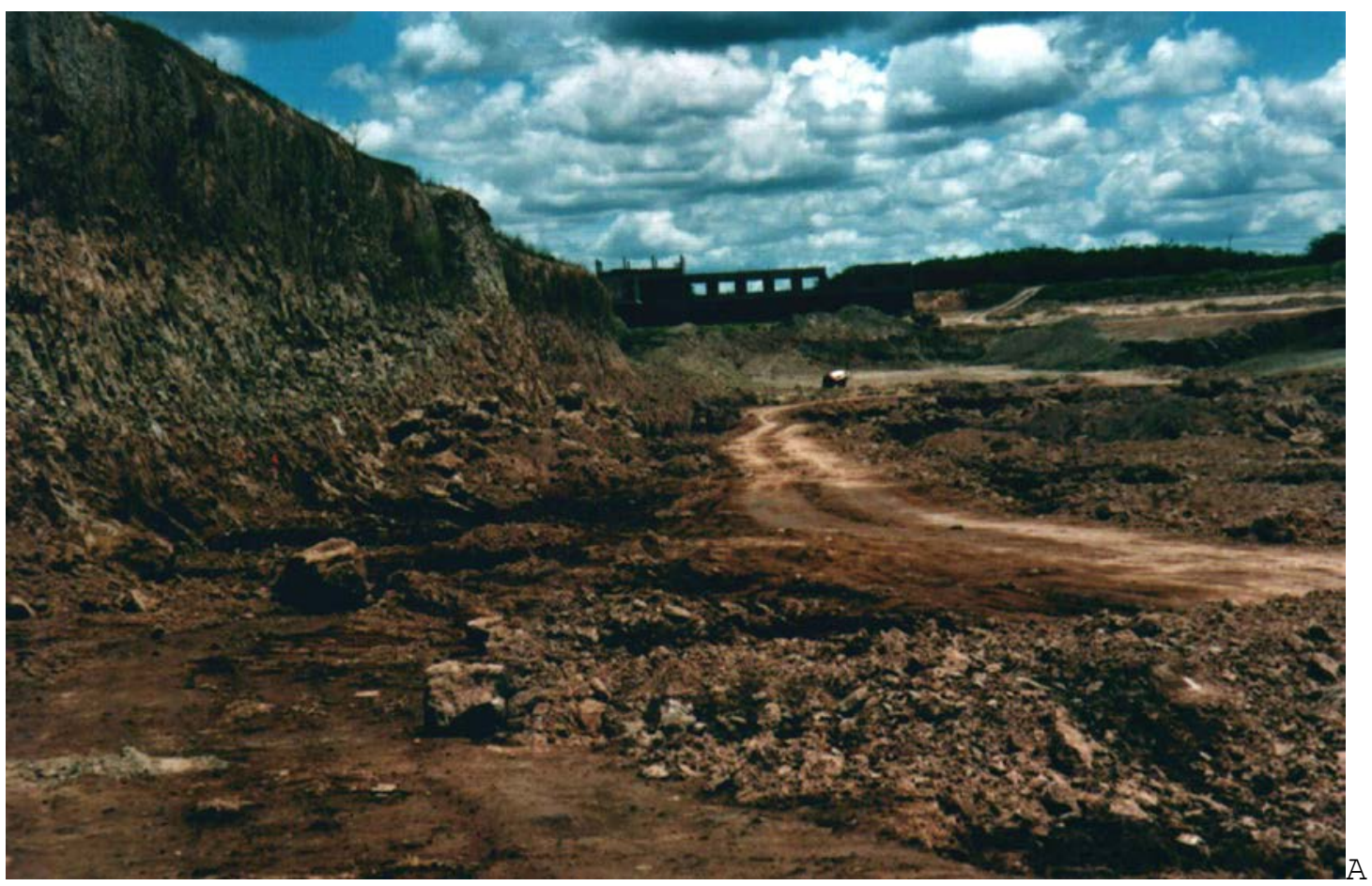




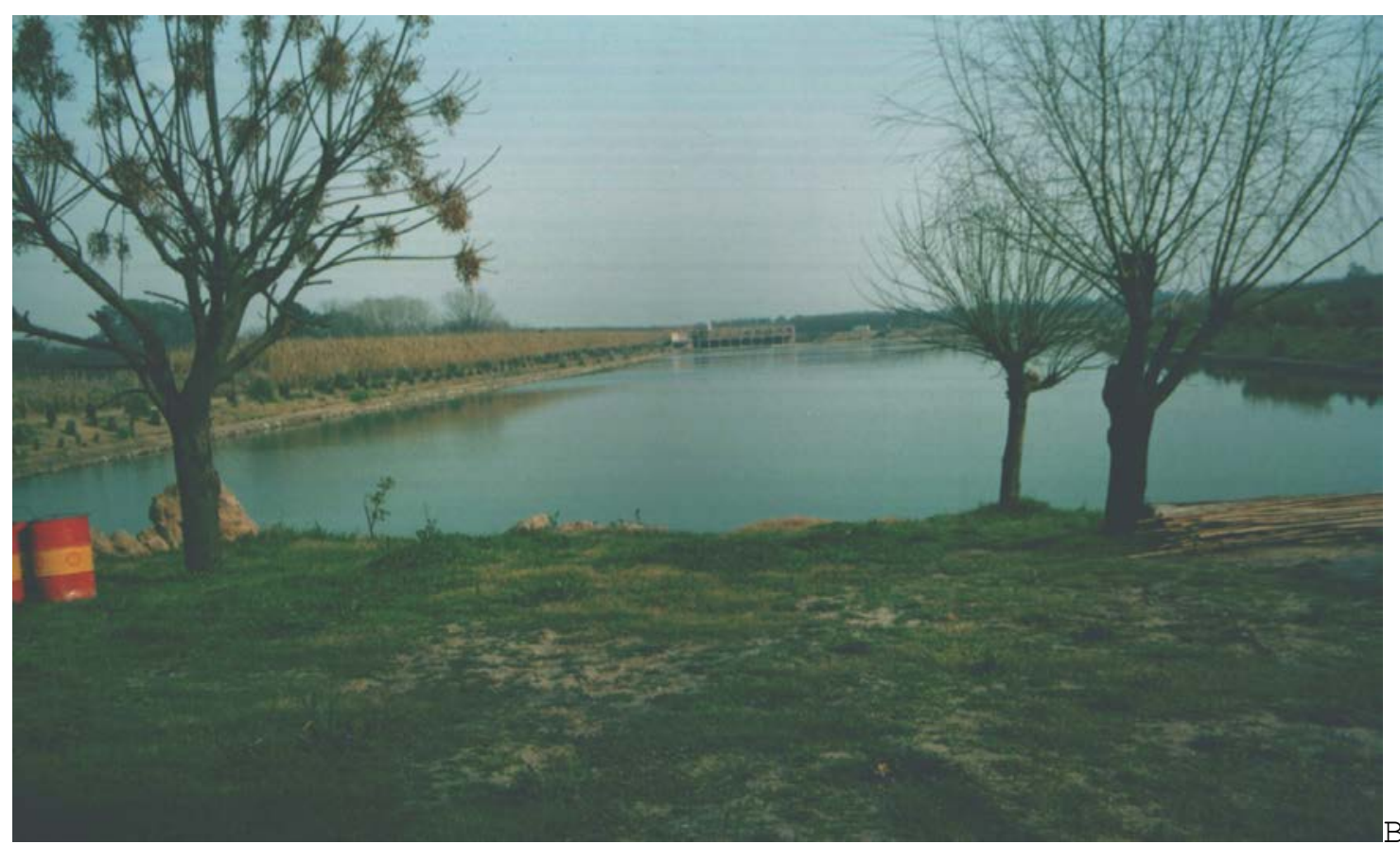

Fig. 7.6 Puede observarse una cantera en etapa de explotación (A) y en abandono (B) con las tareas de remediación realizadas.

Sólo con una planificación integral de los usos del suelo y las tareas de remediación asociadas al entorno inmediato, es posible mitigar una actividad que si bien es necesaria, obliga a una adecuada articulación entre los diferentes organismos intervinientes. 


\section{CAPITULO VIII}

\section{CONCLUSIONES}

- El sector de estudio y área de influencia está representado por una gran variedad de unidades litoestratigráficas y geomorfológicas que indican una evolución poligenética durante el Cuaternario.

- Dos ámbitos de génesis muy contrastantes se observan en la región. El representado por procesos exclusivamente continentales (Fluviales y eólicos) y el litoral.

- En el ámbito continental se destaca la Formación Pampeano (limos loessoides) con distintos niveles con pedogénesis y depósitos fluviales y lacustres, indicativos de climas más benignos que los presentes durante su acumulación.

- Se observa un depósito fluvial de gran desarrollo dentro de la Formación Pampeano, que se lo relaciona con el Río Luján con edades superiores a los 40.000 años ${ }^{14} \mathrm{C}$ A.P.

- En los cursos de agua mas importantes se han observado depósitos fluviales de la Formación Luján y aluvio, observándose a diferentes profundidades dos paleosuelos (Geosuelo Callejón Viejo y Puesto Berrondo) ampliamente registrados en gran parte de la región Pampeana .

- Vinculadas a la secuencias de génesis litoral, fueron determinadas dos unidades con posición estratigráfica y edades diferentes. La de mayor antigüedad (Formación Pilar) del Pleistoceno tardío alcanzó cotas del orden de los 6 a 7 metros y es correlacionada con el estadio e5. La ingresión marina holocena fue generada durante el Holoceno situándose a cotas del orden de los 3 o 4 metros. 
- Los depósitos de la Formación Pilar fueron reconocidos en afloramientos y en el subsuelo, asociados a las líneas de drenaje actuales, interpretándose la existencia de ellas con anterioridad a esta ingresión.

- La Formación Campana presenta variaciones litológicas muy importantes. En la base esta compuesta por sedimentos arcillosos negros atribuidos al Miembro Molino Viejo, de génesis estuárica depositados durante la transgresión. En forma suprayacente y dentro de los paleoestuarios la litología se compone de arcillas verdes, grises y castañas correspondiente al Miembro Santa Brígida y en la boca de los paleoestuarios y llanura litoral por una arena fina castaña atribuida al Miembro Escobar.

- La variación de la línea de costa durante el Pleistoceno tardío tardío - Holoceno esta representada por un ascenso rápido que influye en todo el Río de la Plata y cursos afluentes.

- El máximo avance de la ingresión holocena se sitúa alrededor de los 6.000 años ${ }^{14} \mathrm{C}$ A.P. similar a 10 observado en otros puntos de la región. Su punto de máxima penetración en el continente se sitúo en el Río Luján en cercanías de Pilar, y acunándose en los sedimentos de la Formación Luján.

- Se observa un esquema evolutivo ingresivo - regresivo relacionado con la formación de depósitos estuáricos sobre los que se acumularon sedimentos vinculados con barreras, albuferas y marismas.

- Durante la ingresión marina los sectores terminales de los cursos Luján y de la Cruz constituyeron estuarios, observándose en la actualidad estuarios y acantilados relictuales y llanura litoral, con el desarrollo en esta ultima de crestas de playa con indicios de paleoderiva hacia el noroeste. 
- Se observa una progradación deltaica producida fundamentalmente por los ríos Paraná Guazú al norte y Paraná de las Palmas al sur. Esta progradación ha desviado la desembocadura del Río Luján ubicada originalmente en el estuario platense entre Campana y Escobar hasta su posición actual.

- El estudio de los suelos permitió el análisis y discriminación en siete tipos basados en sus propiedades, ubicación geomorfológica y capacidad de producción, observándose que los de mayor grado de madurez son aquellos desarrollados en el ámbito continental.

- La vegetación asociada a las diferentes unidades geomorfológicas permitió determinar un conjunto de asociaciones florísticas propias para las distintas geoformas integrantes del paisaje.

- El análisis de los riesgos geológicos permitió determinar que la problemática de las inundaciones producidos por desbordes de los cursos fluviales locales y las producidas por el Río Paraná de las Palmas constituyen los de mayor relevancia, fundamentalmente asociados a las geoformas de génesis litoral y delta. La explotación de suelos seleccionados producen una degradación al medio que en la medida que son incorporadas a las áreas urbanas constituyen una problemática de difícil resolución.

- Las condiciones climáticas y paleoclimáticas permitieron reconocer localmente para los últimos 100 años un incremento en las precipitaciones $(250 \mathrm{~mm})$ y temperaturas $\left(1,7{ }^{\circ} \mathrm{C}\right)$. Regionalmente, la generación de diferentes unidades liotoestratigráficas y en éstas, diferentes niveles pedogenéticos, asociados a cambios faunísticos, permiten corroborar los cambios climáticos con condiciones más extremas producidos durante el Pleistoceno - Holoceno. 


\section{CAPITULO IX}

\section{BIBLIOGRAFIA}

Aceñolaza, F., 2000. La Formación Paraná (Mioceno medio): estratigrafía, distribución regional y unidades equivalentes. Correlación geológica 14, 9-27. San Miguel de Tucumán.

Aguirre, E. y Pasini, G., 1985. The Pliocene - Pleistocene boundary. Episodes, $8: 116-120$.

Aguirre, M., 1990. Holocene macrobenthic molluscan associations from norheastern Buenos Aires Province, Argentina. Quaternary of South America and Antartic Peninsula. 7:161-193. Rabassa ed.

Alberdi, M., Bonadonna, F. Y Ortiz Jaureguizar, E., 1997. Chronological correlation, paleoecology and paleobiogeography of the Late Cenozoic South American Rionegran land mammal faunas. A review. Revista Española de Paleontología 12 (2):249-245.

Ameghino, F., 1881. La formación pampeana o estudio de los terrenos de transporte de la cuenca del plata. pp 376. Buenos Aires-Paris.

Ameghino, F., 1884. Excursiones geológicas y paleontológicas en la provincia de Buenos Aires. Boletín Academia Ciencias de Córdoba, 6: 161257.

Ameghino, F., 1889. Contribución al conocimiento de los mamíferos fósiles de la República Argentina. Actas de la Academia Nacional de Ciencias de Córdoba, tomo VI: 1-1027. Buenos Aires.

Andersen, R., Santos, N. y Díaz, H., 1993. An analysis of flooding in the Paraná/Paraguay river basin. LATEN dissemination, note $\mathrm{N}^{\circ} 5$. The Work 
Bank, Latin American Technical Department. Environmental Div. September, $19 \mathrm{pp}$.

Angulo, E., 2001. ¿1544, un año de el Niño? El niño en América Latina. Impactos Biológicos y Sociales. Consejo Nacional de Ciencia y Tecnología, 395-401. Perú.

Angulo R. y Lessa, G., 1997. The Brazilian sea-level curves: a critical review with emphasis on the curves from the Paranaguá and Cananéia regions. Marine Geology 140. 141-166.

Auge, M., 1995. Manejo del agua subterránea en La Plata - Argentina. Facultad de Ciencias Exactas y Naturales. UBA - International Development Research Centre. Tomos I y II. Buenos Aires.

Auge, M. Y Hernández, M., 1983. Características geohidrológicas de un acuífero semiconfinado (Puelches) en la llanura bonaerense. Su implicancia en el ciclo hidrológico de llanuras dilatadas. Coloquio Internacional sobre Hidrología de Grandes Llanuras. Olavarría, UNESCO. Comité Nacional Programa Hidrológico Internacional, Actas:2, 1021-1039. Provincia de Buenos Aires.

Bonfils, C., 1962. Los suelos del Delta del río Paraná. Revista de Investigaciones Agrícolas. XVI (3). INTA.

Borromei, A.,1995. Palinología, estratigrafía y paleoambientes del Pleistoceno tardío - Holoceno en el valle del río Sauce Grande, provincia de Buenos Aires, Argentina. Polen, 7:19-31.

Borus, J. y Goniadzki, D., 2002. Eventos Severos del Niño en el Delta. El Niño: Sus Impactos en el Plata y en la Región Pampeana. CIC-ABC-FCNM.

Bravard, A., 1857. Observaciones geológicas sobre diferentes terrenos de transporte en la hoya del Plata. Biblioteca diario La Prensa, Imprenta y Literatura Bernheim, 113, 80 pp. Buenos Aires. 
Brea, M., Aceñolaza, P. y Zucol, A., 2001. Estudio paleoxilológico en la Formación Paraná, Entre Ríos, Argentina. Asociación Paleontológica Argentina. Pub. Especial 8. XI Simposio Argentino de Paleobotánica y Palinología. 7-17. Buenos Aires

Burgos, J. y Vidal, A., 1951. Los climas de la República Argentina según la nueva clasificación de Thornthwaite. Revista Meteoros, I, (1). SMM. Buenos Aires.

Burmeister, H. 1876. Déscription physique de la République Argentine d 'aprés des observations personelles et étrangéres. T I. Paris.

Cabrera, A. y Willink, A., 1973. Biogeografía de América Latina. OEA. Washington.

Cabrera, A. Y Zardini, E., 1978. Manual de la flora de los alrededores de Buenos Aires. Ed. ACME. Buenos Aires. 755 pp.

Cabrera, A., 1953. Esquema fitogeográfico de la República Argentina. Revista del Museo de La Plata, T VIII. Sección Botánica. 87-168. La Plata.

Cabrera, A., 1976. Regiones Fitogeográficas Argentinas. Enciclopedia Argentina de Agricultura y Jardinería. Acme (Ed), II edición, tomo II, fascículo $1.86 \mathrm{pp}$.

Calmels, A. y Carballo, O., 1993. A Propósito del Cuaternario Europeo. Introducción al Estudio del Cuaternario. 1-26. Santa Rosa, La Pampa.

Carbonari, J., Figini, A., Gomez, G., Tonni, E. Y Fidalgo, F., 1987. Edades isotópicas de cetáceos fósiles de la Formación Las Escobas. NE de la provincia de Buenos Aires, Argentina. Actas X Congreso Geológico Argentino, 3. 179-183. 
Carbonari, J., Huarte, R., Figini, A., 1992. Miembro Guerrero, Formación Luján (Pleistoceno, Prov. de Buenos Aires) Edades ${ }^{14} \mathrm{C}$. La Plata. Actas. Segundas Jornadas Geológicas Bonaerenses. 245-247. Bahía Blanca.

Cardiff, G., 1936. Cartografía Jesuítica del Río de la Plata. Facultad de Filosofía y Letras, $N^{\circ}$ LXXI. Buenos Aires.

Carver, R., 1971. (Ed.). Procedures in Sedimentary petrology. 653 pp. Wiley Interciences. New York.

Cavallotto, J., 1988. Descripción e interpretación morfológica del río de la Plata. Simposio Internacional sobre el Holoceno en América del Sur. 65-68. Paraná.

Cavallotto, J., 1995. Evolución Geomorfológica de la Llanura Costera del Margen Sur del Río de La Plata. Tesis doctoral. Inédito. U.N.L.P.F.C.N.Y M. 237 pp. La Plata.

Cavallotto, J., Colombo, F. Y Violante, R., 2002. Evolución reciente de la llanura costera de Entre Ríos. Actas II, XV Congreso Geológico Argentino. 500-505. El Calafate.

Cendrero Uceda, A., 1987. Riesgos Geológicos, ordenación del territorio y protección del medio ambiente. I Curso de Riesgo Geológico. Instituto Geológico y Minero de España. 226-233. Madrid.

Censo Nacional de Población y Vivienda, 2001. Instituto Nacional de Estadística y Censo de la Republica Argentina. Buenos Aires.

Chebli, G., Tofalo, O. y Turazzini, G., 1989. Mesopotamia, en: Chebli, G y Spalletti, L. (Eds). Cuencas Sedimentarias Argentinas: 79-100. Tucumán.

Codignotto, J., 1990. Avance del Delta del Paraná y la Isla Martín García. XI Congreso Geológico Argentino, Actas I, 272-275. San Juan. 
Codignotto, J., 1996. El Delta del Paraná y el Estuario del río de la Plata. Ramos, V., Codignotto, J., Dalla Salda, L. y Rapalini, A. Excursión Geológica Intracongreso. XII Congreso Geológico Argentino y III Congreso de Exploración de Hidrocarburos, 4-10. Buenos Aires.

Codignotto, J. Y Aguirre, M., 1993. Coastal evolution, change in sea level and molluscan fauna in northeastern Argentina during the Late Quaternary. Marine Geology, 110: 163-175.

Codignotto, J., Kokot, R. y Marcomini, S., 1993. Desplazmaintos verticales y horizontales de la costa Argentina en el Holoceno. Asociación Geológica Argentina, Revista 48 (2) 125-132.

Codignotto, J., Herrera, C. y Aiello, P., 1996. Río de la Plata; Fenómenos Antrópicos, Geodinámicos y Legislación sobre Uso Costero. Actas Asociación Argentina Geólogos Aplicados a la Ingeniería. Vol. X, 82-93, Buenos Aires.

Comité Argentino de Estratigrafía, 1992. Código Argentino de Estratigrafía. Asociación Geológica Argentina, serie "B" $n^{\circ} 20$. Buenos Aires.

Coleman, J. y Gagliano, S., 1965. Sedimentary Structures: Mississippi River deltaic plain. In: MIDDLETON (ed). Primary sedimentary structures and their hidrodinamic interpretation. S.E.P.M. Spec Publ. $n^{\circ}$ 12, 133148 .

Cooper, J., 1994. Lagoons and microtidal coast. Coastal evolution. Late Quaternary shoreline morphodynamics. Carter and Woodroffe, ed. 219-265.

Corominas, J, 1987. Criterios para la confección de mapas de peligrosidad de movimientos de ladera. I Curso de Riesgo Geológico. Instituto Geológico y Minero de España. 193-201. Madrid. 
Crivelli - Montero, E.; Eugenio, E. Y Silveira, M., 1987. El sitio Necochea (provincia de Buenos Aires). El material de superficie. Paleoetnológica 4:7-37. Buenos Aires

d'Orbigny, A, 1842. Voyage dans l’Amerique meridional, III, 3, Geologie, Paris.

Dalla Salda, L., 1981. El basamento de la isla Martín García, Río de la Plata. Asociación Geológica Argentina, Revista 36 (1) 29-43.

Dalla Salda, L., 1999. Basamento Granítico-Metamórfico de Tandilia y Martín García. Capítulo 4. Instituto de Geología y Recursos Minerales. SEGEMAR. Anales 29 (4): 97-100. Buenos Aires.

Dalla Salda, L., Bossi, J. Y Cingolani, C., 1988. The Río de la Plata cratonic region of southwestern Gondwana. Episodes, 11 (4): 263-269.

Dangavs, N. Y Blasi, A., 1992. Formación Lobos, nueva unidad estratigráfica en la cuenca del río Salado, Provincia de Buenos Aires. II Jornada Geológica Bonaerense. Actas, 17-23. La Plata.

Dangavs, N. Y Blasi, A., 1995 a. El Lujanense y Platense (sensu Ameghino) en el Río Luján, Luján, provincia de Buenos Aires. IV Jornadas Geológicas y Geofísicas Bonaerenses. Actas 1, 109-117. Junín

Dangavs, N. Y Blasi, A., 1995 b. El Pampeano Rojo (Ameghino, 1884) del Paso de la Virgen, Río Luján, provincia de Buenos Aires. IV Jornadas Geológicas y Geofísicas Bonaerenses. Actas 1, 127-134. Junín

Dangavs, N. Y Blasi, A., 2003. El Miembro Lobos de la Formación Luján: Cambio de rango de la Fm Lobos, unidad estratigráfica del Pleistoceno superior de la cuenca del río salado de la provincia de Buenos Aires. II Congreso Argentino de Cuaternario y Geomorfología, Actas: 67-74. San Miguel de Tucumán. 
Dangavs, N., Pierrard, L. Y Reynaldi, J., 2003. Paleomniología del Río Salado entre los meridiano 58 y 60, provincia de Buenos Aires. II Congreso Argentino de Cuaternario y Geomorfología, Actas: 75-86. San Miguel de Tucumán.

Darwin, Ch., 1846. Geological observations on South America. 279 pp. London.

Daus, F., 1946. Morfografía General de las Llanuras Argentinas. En: Geografía de la República Argentina, Sociedad Argentina de Estudios Geográficos, GAEA. T III: 115-198. Buenos Aires.

Dawson, A., 1992. Ice Age Earth. Late Quaternary Geology and Climate. Routledge, London \& N.Y., 293 pp.

de Moussy, Martín, 1864. Description géographique et statistique de la Conféderation Argentine. París.

De Salvo, O., Ceci, J. y Dillon, A., 1969. Características geológicas de los depósitos eólicos del Pleistoceno superior de Junín (Provincia de Buenos Aires). Cuartas Jornadas Geológicas Argentinas, Actas I: 269-292. Buenos Aires.

Delachaux, E. 1908. Las regiones físicas de la República Argentina, Revista del Museo de La Plata, Anales XV, Buenos Aires.

Deschamps, C. Y Tonni, E., 1992. Los vertebrados de Pleistoceno tardíoHoloceno del Arroyo Napostá Grande, provincia de Buenos Aires. Aspectos paleoambientales. Ameghiniana 29 (3):201-210. Buenos Aires.

Dillon, C. Y Rabassa, J., 1985. Miembro La Chumbiada, Formación Luján (Pleistoceno, Provincia de Buenos Aires): Una nueva unidad estratigráfica del valle del Río Salado. Primeras Jornadas Geológicas Bonaerenses, Resúmenes, 27 pp. Tandil. 
Doering, A., 1882. Geología; Informe oficial de la Comisión Científica agregada al estado mayor General de la Expedición al Río Negro (Patagonia). Entrega III. Buenos Aires.

Doering, A., 1884. Informe sobre un sedimento lacustre fosilífero del Desaguadero. Anales de la Sociedad Científica Argentina.

Estadísticas Bonaerenses - anuario, 1997. Secretaría General de la Gobernación provincia de Buenos Aires. 487 pp.

Fairbidge, R., 1980. The estuary: its definition and geodynamic cycle. In: Alausson and Cato, eds. Chemistry and Biogeochemistry of Estuaries. $1-33$.

Fidalgo, F., 1979. Upper Pleistocene - Recent Marine Deposits in Northeastern Buneos Aires province (Argentina). Proceeding of the "1978 Internacional Symposium on Coastal Evolution in the Quaternary". 384-404. San Paulo, Brasil.

Fidalgo, F., 1983. Algunas características de los sedimentos superficiales en la cuenca de Río Salado y en la Pampa Ondulada. Coloquio Internacional sobre Hidrología de Grandes Llanuras. Comité Nacional Programa Hidrológico Internacional, 2. Olavarría, Argentina.

Fidalgo, F., 1992. Provincia de Buenos Aires, continental. In: El Holoceno en Argentina. Vol. 1. 23-35. M. Iriondo Ed.

Fidalgo F. y Martínez, 0., 1983. Algunas características geomorfológicas dentro del Partido de La Plata, Provincia de Buenos Aires. Revista de la Asociación Geológica Argentina, 38 (2):263-278.

Fidalgo, F. y Martinez, O., 1995. El perfil de meteorización en unidades estratigráficas superficiales en la Pampa Ondulada. Provincia de Buenos Aires. Cuartas Jornadas Geológicas y Geofísicas Bonaerenses. 187-194. Junín. 
Fidalgo, F., Colado, U. R., De Francesco, F. O., 1973 a. Sobre ingresiones marinas cuaternarias en los partidos de Castelli, Chascomús y Magdalena (Provincia de Buenos Aires). V Congreso Geológico Argentino. Carlos Paz, 4: 225-240

Fidalgo, F.; De Francesco, F. Y Colado, U. R., 1973 b. Geología superficial en las hojas Castelli, J. M. Cobos y Monasterio Provincia de Buenos Aires). V Congreso Geológico Argentino. Carlos Paz, 4: 27-39

Fidalgo, F., De Francesco, F. O. Y Pascual, R., 1975. Geología superficial de la llanura bonaerense (Argentina). Geología de la Provincia de Buenos Aires. VI Congreso Geológico Argentino. Relatorio: 103 -138. Bahía Blanca.

Fidalgo, F., De Francesco, F., Colado, U., Martinez, O., Gentile, O., Nuccetelli, G. Y Fucks, E., 1999. El Cuaternario de la Provincia de Buenos Aires. Capítulo 23. Geología Argentina. Subsecretaría de Minería de la Nación - Servicio Geológico Minero Argentino - SEGEMAR. Anales 29. 700-702.

Figini, A., 1992. Edades C-14 de sedimentos marinos holocénicos de la Prov. de Bs. As. Terceras Jornadas Geológicas Bonaerenses. 147-151. La Plata.

Figini, A. 1993. Geocronología: Métodos de datación en el Cuaternario. Introducción al Estudio del Cuaternario.261-276. Santa Rosa, La Pampa.

Figini, A., Huarte, R.,Y Carbonari, J., 1999. Datación radiocarbónica de carbonatos en las Formaciones Luján y La Postrera. XIV Congreso Geológico Argentino, Actas II, 60-62. salta.

Figini, A., Fidalgo, F., Huarte, R., Carbonari, J., Gentile, R., 1995. Cronología radiocarbónica de los sedimentos de la Fm Luján en el Arroyo 
Tapalqué, Provincia de Buenos Aires. Actas Cuartas Jornadas Geológicas y Geofísicas Bonaerenses. 119-126. Junín.

Figini, A., Rabassa, J., Tonni, E., Huarte, R., Gómez, G., Carbonari, J., Subiaga, A., 1989. Datación radiocarbónica de gasterópodos terrestres en sedimentos del Pleistoceno superior y Holocenos en el valle del río Sauce Grande, Provincia de Buenos Aires. Actas I Jornadas Geológicas Bonaerenses. 809-824. Tandil.

Fray, Ch. y Ewing, M., 1963. Pleistocene sedimentation and fauna of the Argentine Continental shelf. I. Wisconsin sea level as indicated in Argentine Continental shelf Sediments. Proc. Acad. Nat. Sci., Philadelphia 115, 6:113-126.

Frenguelli, J., 1946. Grandes Unidades Físicas del Territorio Argentino. En: Geografía de la República Argentina, Sociedad Argentina de Estudios Geográficos, GAEA. Tomo III.

Frenguelli, J., 1950. Rasgos Generales de la Morfología y la Geología de la Provincia de Buenos Aires. LEMIT. Serie II, $N^{\circ} 33$. La Plata.

Frenguelli, J. 1957. Neozoico. En: Geografía de la República Argentina. Sociedad Argentina de Estudios Geográficos, GAEA, Tomo II, 3 parte.

Fucks, E. y De Francesco, F., 2000. Unidades marinas cuaternarias en el cuenca inferior del Río Luján. Prov. de Buenos Aires. IX Congreso Geológico Chileno. Actas, Vol 1: 467-470. Puerto Varas.

Fucks, E. y De Francesco, F., 2003. Ingresiones marinas al norte de la ciudad de Buenos Aires. Su Ordenamiento Estratigráfico. IIo Congreso Argentino de Cuaternario y Geomorfología. Actas, 101-103. San Miguel de Tucumán.

Fucks, E., M. Aguirre y C. Deschamps, 2002. Late Quaternary Continental And Marine Sediments at Northeastern Bonaerensian Area (Argentina): 
Fossil Content and Paleoenvironmental Interpretation. Journal of South American Earth Sciences. 2002. En prensa.

García, N., 1992. Síntesis Climatográficas de la República Argentina. El Holoceno en la Argentina. 78-102. Iriondo editor.

Gentile, 0., 1995. Nuevos registros de depósitos postconquista (cuenca del arroyo Langueyú, Tandil, Provincia de Buenos Aires. Actas. Cuartas Jornadas Geológicas y Geofísicas Bonaerenses.160-176. Junín.

Gile, L., Peterson, F. and Grossman, R., 1966. Morphological and genetic sequences of carbonate accumulation in desert soils. Soil Science, 101, $347-360$.

Goniadzki, D. y Borus, J., 2002. Impacto hidrológico en los ríos de la cuenca del Plata durante los eventos Niño. El Niño: sus impactos en el Plata y en la Región Pampeana. CIC-ABC-FCNM.

González Bonorino, F., 1965. Mineralogía de las fracciones arcilla y limo del pampeano en el área de la Ciudad de Buenos Aires y su significado estratigráfico y sedimentológico. Revista de la Asociación Geológica Argentina. Tomo XX, (1), 67-148.

González Bonorino, F. y Terruggi, M., 1961. Léxico sedimentológico. Facultad de Ciencias Exactas y Naturales, serie geología II, 164 pp. Buenos Aires.

González Bonorino, F. y Cetrángolo, G., 1962. Minerales de arcilla en el subsuelo de la capital Federal y el origen de la formación terciaria "arcilla Parda". Anales Primeras Jornadas Geológicas Argentinas. T. III. $37-58$.

Gonzalez, M. Y Ravizza, G., 1987. Sedimentos estuáricos del Pleistoceno Tardío y Holoceno en la Isla Martín García, Río de la Plata. Revista Asociación Geológica Argentina, XLII (3-4): 231-243. 
Gradstein, F. y Ogg, J., 1996. A Phanerozoic time scale. Episodes 19, 12.

Groeber, P., 1945. Las aguas surgentes y semisurgentes del norte de la Provincia de Buenos Aires. Revista La Ingeniería. 371-387.

Groeber, P., 1961. Contribuciones al conocimiento geológico del Delta del Paraná y alrededores. Anales Comisión Investigaciones Científicas, V, II. La Plata.

Guida, N. Y González, M., 1984. Evidencias Paleoestuáricas en el Sudeste de Entre Ríos, su Evolución con Niveles Marinos Relativamente Elevados del Pleistoceno Superior y Holoceno. Actas IX Congreso Geológico Argentino, III: 577-594. San Carlos de Bariloche.

Guilderson, T.; Burckle, L., Hemming, S. and Peltier, W., 2000. Late Pleistocene sea level variation from the Argentine shelf. Geochemistry, Geophysics and Geosystems. Volume 1. ISSN:1525-2027.

Herbst, R., 2000. La Formación Ituzaingó (Plioceno). Estratigrafía y distribución. Correlación geológica 14, 181-190. San Miguel de Tucumán.

Herbst, R. y Zabet, L., 1987. Microfauna de la Formación Paraná (Mioceno Superior) de la cuenca Chaco-Paranaense (Argentina). Facena 7: 165-206.

Hernández, M., González, N., Ruiz de Galarreta, A., y Minghinelli, L., 1995. Geohidrología aplicada en un sector del Partido de Zárate (provincia de Buenos Aires). Cuartas Jornadas Geológicas y Geofísicas Bonaerenses. Actas 2. Junín.

Herrera, C., 1993. Evolución Holocena en sectores de la costa bonaerense del estuario del Río de la Plata. Trabajo final de Licenciatura. UBA. 100 pp. Buenos Aires. 
Imbelloni, P. Y Cumba, A., 2003. Una sucesión de paleosuelos superpuestos del Pleistoceno medio-tardío, Holoceno. Zona sur de la Plata, Provincia de Buenos Aires. Revista Asociación Argentina de Sedimentología. Vol. $10 \mathrm{n}^{\circ}$ $1: 3-21$.

INTA, 1980. Suelos y Erosión de la provincia de Entre Ríos. Tomo 1, serie relatorio de Recursos Naturales $\mathrm{N}^{\circ}$ 1: 71-95.

INTA, 1989. Mapa de Suelos de la Provincia de Buenos Aires. Escala $1: 500.000$.

INTA, 1996-1997. Cartas de suelos de las hojas Campana Sur, Pilar, Open Door y Capilla del Señor a escala 1:50.000.

IPCC, 2001. Vulnerabilidad, impactos y adaptación al cambio climático. Resumen, grupo de trabajo II, Ginebra, Suiza. 12 pag.

Iriondo, M., 1973. Análisis ambiental de la Formación Paraná en su área tipo. Boletín de la Asociación Geológica (Córdoba) 2:19-24.

Iriondo, M., 1980. Esquema evolutivo del delta del Paraná durante el Holoceno. Simposio sobre problemas geológicos del Litoral Atlántico Bonaerense. Comisión de Investigaciones Científicas. Mar del Plata. Resúmenes: 73-88

Iriondo, M., 1987. Geomorfología y Cuaternario de la provincia de Santa Fé. D’Orbignyana 4:1-54. Corrientes.

Iriondo, M., 1999. El Cuaternario en el Chaco y Litoral. Cuaternario. Capítulo 23. Instituto de Geología y Recursos Minerales. SEGEMAR. Anales 29 (4).696-699. Buenos Aires.

Iriondo y García, 1993. Climatic variations in the Argentine plains during the last 18.000 years. Paleogeography, Paleoclimatology, Paleoecology, 101: 209-220. Elsevier Sc. Publ., Ámsterdam. 
Iriondo y Krohling, 1999. Los sedimentos eólicos del noreste de la llanura pampeana (Cuaternario Superior). XIII Congreso Geologico Argentino y III Congreso de Exploracion de Hidrocarburos. Actas IV:27-48. salta.

Iriondo, M. y Scotta, E., 1979. The evolution of the Paraná River Delta. International symposium on coastal evolution in the Quaternary, Sao Paulo, Brasil. 405-418.

Isla, F., 1989. The Southern Hemisphere sea level fluctuation. Quaternary Science Reviews 8, 161-179.

Isla y Espinosa, 1998. Modelo sedimentario de colmatación de pequeños estuarios dominados por limo, Provincia de Buenos Aires. VII Reunión Argentina de Sedimentología. 24-36. Salta.

Isla, F., Rutter, N., Schnack, E. Y Zarate, M, 2000. La trasgresión Belgranense en Buenos Aires. Una revisión a cien años de su definición. Cuaternario y Ciencias Ambientales. Vol 1:3-14.

Jelgersma, S. and Tooley, M, 1995. Sea-Level Change During the Recent Geological Past. Journal of Coastal Research Special Issue $N^{\circ}$ 17: Holocene Cycles: Climate, Sea Level, and Sedimentation. Chapter 19. 123139.

Janis, C., 1993. Tertiary mammal evolution in the context of changing climates, vegetation, and tectonic events. Annual Review of Ecology and systematic 24: 467-500.

Jenny, H., 1941. Factors of soil formation. McGraw Hill. New York.

Kokot, R., Codignotto, J., Richter, P. Y Herrera, C., 1999. Evaluación del comportamiento del proyecto de la rivera de Vicente López. Revista de 
Geología Aplicada a la Ingeniería y al Ambiente. N 13, 73-86. Buenos Aires.

Köppen, W., 1923. Die Klimate der Erde, Grundriss der Klimakunde. Walter de Gruyter Co., Berlín. (En A. Strahler, Geografía Física)

Kraft, J., 1978. Coastal stratigrafic sequences. In Coastal sedimentary environmnents, Davis (ed). 361-383, New York.

Kuhn, F., 1922. Fundamentos de Fisiografía Argentina, Vol XLIX, L Biblioteca oficial, Buenos Aires.

Lanfredi, N.; Pousa, J. y D'onofrio, E., 1998. Sea -level rise and related potential hazards on the Argentine coast. Journal or Coastal Research, 14 (1):47-60.

Leeder, M., 1981. Sedimentology. Process and Product. George allen \& Unwin. London.

López, A., 2000. Curvas de nivel del techo del Pampeano antiguo en la zona de Tigre. XV Congreso Argentino de mecánica de suelos e Ingeniería Geotécnica. V. 1. 515-523. Buenos Aires.

Malumnián, N. y Náñez, C., 1996. Microfósiles y nanofósiles calcáreos de la plataforma continental. En: Ramos, V. y Turic, M., (Eds): Geología y Recursos Naturales de la Plataforma Continental Argentina. 13 Congreso de Exploración de hidrocarburos. Relatorio 5:73-93.

Moncaut, C., 2003. Inundaciones y sequías tienen raíces en la pampa bonaerense (1576-2001). Capítulo I, Inundaciones en la región pampeana. UNLP. 27-47. La Plata.

Nabel, P., 1999. Transición Pleistoceno temprano-medio en la Región Pampeana. Primer Congreso Argentino de Cuaternario y Geomorfología. Actas. 43-46. La Pampa. 
Nabel, P, Camilion, M., Machado, G., Spiegelman, A y Mormeneo, L., 1995. Magneto y litoestratigrafía de los sedimentos pampeanos en los alrededores de la ciudad de Baradero, provincia de Buenos Aires. Revista de la Asociación Geológica Argentina, T 48 (3-4). 193-206.

Nuñez, M., 2002. El Niño y la Oscilación Austral. El Niño: sus impactos en el plata y en la Región Pampeana. CIC-ABC-FCNM.

Oerlemans, J.,1982. Response of the Antartic ice sheet to a climatic warning. Jornadas Climatology, 2, 1-12.

Panizza, M., 1993. La cartografía del riesgo geológico como instrumento de planificación territorial. Simposio Internacional sobre riesgos naturales e inducidos en los grandes centros urbanos de américa latina. Serie Scienza, México. 223-226.

Pascual, R., Ortega, E., Gondar, D. Y Tonni, E., 1965. Las edades del cenozoico mamalífero en Argentina. Anales Comisión Investigaciones Científicas de la Provincia de Buenos Aires, La Plata, 6. 165-193.

Pascual R. y Bondesio, P., 1985. Mamíferos terrestres del Mioceno mediotardío de las cuencas de los Ríos Colorados y Negro (Argentina): Evolución Ambiental. Ameghiniana, 22 (1-2): 133-145. Buenos Aires.

Pardiñas, U., Tonni, E. Y Gelfo, J., 1995. Asociación faunística del Lujanense inferior (Pleistoceno Superior) Nordeste de la Provincia de Buenos Aires (Argentina).4 Jornadas Geológicas y Geofísicas Bonaerenses, 1:55-61. Junín.

Parker, G., 1990. Estratigrafía del Río de la Plata. Revista Asociación Geológica Argentina, XLV. (3-4): 193-204. 
Parker, G. Y Marcolini, S., 1992. Geomorfología del Delta del Paraná y su extensión hacia el Río de la Plata. Revista Asociación Geológica Argentina, 47 (2): 243-249.

Politis, G., 1984. Climatic Variations During Historical Time in Eastern Buenos Aires Pampas, Argentina. Quaternary of South America and Antartic Peninsula, Vol 2, Art. 9:133-162.

Politis, G.; Prado, J. Y Beukens, R., 1995. The Impact In PleistoceneHolocene Extinctions In South America-The Pampean Case. Ancient Peoples and Landscapes. Eileen Johnson, ed. Museum of Texas University, Lubbock. 187-205. Texas.

Prat, M., Salomón, J., Gentile, E. y Natnzon, C., 1998. El delta del Paraná, aspectos naturales y antrópicos. Travaux du Laboratoire de Geographie Physique Aplliquee. Numère Special.

Prieto, A.; Blasi, A.; De Francesco, C. Y Fernández, C., 1998. Paleoambientes y cronología desde el límite Lujanense-Platense en el Río Luján (Provincia de Buenos Aires). Quintas Jornadas Geológicas y Geofísicas Bonaerenses. V 2. Mar del Plata.

Prieto, A. R., Blasi, A. M., De Francesco, C. G., Fernández, C., 2000. Historia ambiental del $\mathrm{NE}$ de la estepa pampeana durante los últimos 11.000 años: evidencias a partir de registros-proxy de secuencias aluviales del Río Luján, 34º. Ameghiniana 37 (4) Supl.: 78.

Pritchard, D., 1955. Estuarine circulation patterns. Proceedings, Amarican Society Civil Engeneers, 81.

Quattrocchio, M. y Borromei, A., 1998. Paleovegetational and paleoclimatic change during the late Quaternary in southwestern Buenos Aires province and southern Tierra del Fuego (Argentina). Palinology 22, 67-82. 
Rabassa, 1985. Geología de los depósitos del Pleistoceno superior y Holoceno en las cabeceras del río Sauce Grande. Primeras Jornadas Geológicas Bonaerenses. 9 pp. Tandil.

Rabassa, J., 1999. Cuaternario de la cordillera patagónica y Tierra del Fuego. Capitulo 23. Instituto de Geología y Recursos Minerales. SEGEMAR. Anales 29 (4).710-714. Buenos Aires.

Rabassa, J., Brandani, A., Salemme, M. Y Politis, G., 1989. La "pequeña edad de hielo" (siglos XVI a XIX) y su posible influencia en la aridización de áreas marginales de la pampa húmeda (Provincia de Buenos Aires). Primeras Jornadas Geológicas Bonaerenses. Actas, 559- 577. Tandil.

Ramage,C., 1986. El Niño. Investigación y Ciencia. 119:40-48.

Ramos, V., 1999. Los depósitos sinorogénicos terciarios de la región andina. Capítulo 22. Instituto de Geología y Recursos Minerales. SEGEMAR. Anales 29 (4): 651-682. Buenos Aires.

Reinson, G., 1984. Barrier island and Associated Strand-plain Systems. Facies Model. Geoscience Canada, reprint Series 1. Ed: R. Walker

Re, G. Y Orgeira, M., 1991. Estudio paleomagnético de una secuencia de sedimentos del "Ensenadense-Bonaerense" del subsuelo de la ciudad de Buenos Aires. Revista Asociación Geológica Argentina. Tomo XLVI, N ${ }^{\circ} 3-4$. $159-166$.

Ricciardi, H., 1995. Cambio Global. Causas, Ciencia, Tecnología e implicancias Humanas. Academia Nacional de Geografía, Publicación Especial 10: $462 \mathrm{pp}$. 
Riggi, J., Fidalgo. F., Martínez, O. y Porro, N., 1986. Geología de los "Sedimentos Pampeanos" en el Partido de La Plata. Revista Asociación Geológica Argentina, XLI (3-4): 316-333.

Rolleri, E., 1975. Provincias geológicas bonaerenses. VI Congreso Geológico Argentino. Relatorio: 29-53. Bahía Blanca.

Ronzoni, E. y Rossello, E., 1995. Evolución del sector austral del frente del Delta del Paraná. Posible influencia de la actividad antrópica. Cuartas Jornadas Geológicas y Geofísicas Bonaerenses. 75-83. Junín.

Roy, P., Cowell, P., Ferland, M and Thom, B., 1994. Wave-dominated coasts. Coastal evolution. Late Quaternary shoreline morphodynamics. Carter and Woodroffe, ed. 121-186.

Ruddiman, w., 1977. Late Quaternary deposition of ice-rafted sand in the sub-polar North Atlantic (Lat. 40-65 N) Geol. Soc. Am. Bull. 88, 18131827.

Rusconi, C., 1933. Apuntes preliminares sobre las arenas Puelchenses y su fauna. Am. Soc. Cient. Arg., T. 116.

Sala, M.,1969. El agua subterránea en el nordeste de la provincia de Buenos Aires. Reunión sobre geología del agua subterránea de la Provincia de Buenos Aires. Relatorio. La Plata.

Santa Cruz, J., 1972. Estudio sedimentológico de la Formación Puelches en la Provincia de Buenos Aires. Revista Asociación Geológica Argentina, Tomo XXVII, $\mathrm{N}^{\circ} 1.5-62$

Santa Cruz, J., 1994 . Aspectos hidrogeológicos e interpretación de una nueva característica formacional de subyacencia del acuífero Puelches. Temas actuales de Hidrología subterránea. Univ. Nac. de Mar del Plata CFI. Bocanegra, E. y Rapaccini, A. Eds. 
Schnack, E., Colado, U., De Francesco, F., García Lozano, L. Y Schnack , J., 2001. El Niño y las inundaciones en el noreste argentino. El Niño en América Latina. Impactos Biológicos y Sociales. Consejo Nacional de Ciencia y Tecnología. 179-185. Perú.

Schumm, S., 1985. Patterns of alluvial rivers, Ann. Rev. Earth Planet, 13: $5-27$.

Servicio Meteorológico Nacional. Estadísticas Climatológicas 1901/2003. Buenos Aires.

Servicio Meteorológico Nacional, 1989. Inundaciones, Sudestadas y Crecientes Repentinas. Fuerza Aérea Argentina. Bol. Inf. $\mathrm{N}^{\circ}$ 2. Buenos Aires.

Shacketon, N. Y Opdyke, J., 1973. Oxygen isotope and Paleomagnetic stratigraphy of equatorial Pacific core V28-238: Oxygen isotope temperatures and ice volumes on a $10^{5}$ year and $10^{6}$ year scale. Quat. Res. $3: 39-55$.

Shacketon, N., Berger, A. Y Peltier, w. 1990. An alternative astronomical calibration of the lower Pleiostocene timescale based ODP site 677 . Transacion of the Royal Society of Edinburgh: Earth Sciewces 81, 251-261.

Soil Survey Staff, 1975. Soil Taxonomy. A Basic System of Soil Classification for Making and Interpreting soil surveys. USDA. Agric. Handbook, $436 \mathrm{pp}$.

Soldano, F., 1947. Régimen y aprovechamiento de la red fluvial argentina. Parte I: El río Paraná y sus tributarios. Editorial Cimera, Buenos Aires.

Spalletti, L., 1980. Paleoambientes Sedimentarios en Secuencias Silicoclásticas. Asociación Geológica Argentina. Serie "B" n 8 . Buenos Aires. 
Sprechmann, P., 1978. The Paleoecology and Paleogeography of the Uruguayan coastal Area During the Neogene and Quaternary. Zitteliana 4: 3-72, Munchen.

Stevaux, J., 1997. Climatic Events during the late Pleistocene and Holocene in the Parana River and their correlation with northeastern Argentina and central and southern Brazil. VI Congresso da Associaçao Brasileira de Estudos do Cuaternario e Reuniao sobre o Quaternario da America do Sul. 496-496. Curitiba, Brasil.

Tapia, A., 1937. Datos Geológicos de aguas Minerales de la República Argentina. II Provincia de Buenos Aires. Min. del Interior, Comisión Nacional Climat. y Aguas Minerales (Buenos Aires).

Teruggi, M. Y Imbellone, P., 1987. Paleosuelos loéssicos superpuestos en el Pleistoceno superior - Holoceno de la región de la Plata. Provincia de Buenos Aires. Argentina. Ciencia del Suelo 5: 175-188.

Thornthwaite, C. Y Mather, 1957. Introduction and tables for computing the potential evapotranspiration an the water balance. Climate Drexel Inst. of Tech., 10, 3, 185-311.

Tonni, E., 1985. Mamíferos del Holoceno del Partido de Lobería, provincia de Buenos Aires. Aspectos paleoambientales y bioestratigráficos del holoceno del sector oriental de Tandilia y área interserrana. Ameghiniana. $22(3-4): 283-288$.

Tonni, E., 1990. mamíferos del Holoceno en la provincia de Buenos Aires. Paula Coutiana, Revista de la Fundación Zoobotánica. Río Grande do sul, Brasil 4:3-21.

Tonni, E., 1992. Mamíferos y clima del Holoceno en la Provincia de Buenos Aires. In: El Holoceno en Argentina. Vol. 1. M. Iriondo Ed. 64-78. 
Tonni, E. Y Fidalgo, F., 1978. Consideraciones sobre los cambios climáticos durante el Pleistoceno tardío - reciente de la provincia de Buenos Aires. Aspectos ecológicos y zoogeográficos relacionados. Ameghiniana 15:235-253.

Tonni, E., Cione, A. Y Figini, A., 1999. Predominance of arid climates indicated by mammals in the pampas of Argentina during the Late Pleistocene and Holocene. Paleogeography, Paleoclimatology, paleoecology 147: 257-281.

Tricart, J., 1973. Geomorfología de la Pampa Deprimida. INTA, Col. Cient., 12: 202 pp. Buenos Aires.

Violante, R. y Parker, G., 1999. Historia evolutiva del Río de La Plata durante el Cenozoico superior. Actas XIV Congreso Geológico Argentino. 504-507. Salta.

Violante, R., Parker, G., Cavallotto, J. Y Marcolini., 1992. La secuencia depositacional del Holoceno en el Río de la Plata y plataforma del noroeste Argentino. IV Reunión Argentina de Sedimentología: 275-282. La Plata.

Vogel, J. y Lerman, J., 1969. Groeningen Radiocarbon Dates VIII. Radiocarbon 11, 2: 351-390.

Yrigoyen, M., 1975. Subsuelo y Plataforma Continental. Relatorio VI Congreso Geológico Argentino:139-168. Bahía Blanca.

Yrigoyen, 1992. Geografía y geología de Buenos Aires y sus alrededores. Revista Buenos Aires nos Cuenta, 21. Buenos Aires.

Yrigoyen, M., 1999 a. Situación de la Argentina en el marco geológico de América del sur. Capítulo 2. Instituto de Geología y Recursos Minerales. SEGEMAR. Anales 29 (4): 35-40. Buenos Aires. 
Yrigoyen, M., 1999 b. Los depósitos Cretácicos y Terciarios de las cuencas del Salado y Colorado. Capítulo 21. Instituto de Geología y Recursos Minerales. SEgEMAR. Anales 29 (4). 245-249. Buenos Aires.

Zárate, M., Espinosa, M. Y Ferrero, L., 1995. La Horqueta II, río Quequén Grande: Ambientes sedimentarios de la transición Pleistoceno-Holoceno. Actas Cuartas Jornadas Geológicas y Geofísicas Bonaerenses. 2: 95-204. Junín.

Zarauza, Y., Sanuy, J., De La Torre, L., Torres, J. y Vilas Minondo, L., 1977. Estratigrafía. Ed. Rueda, Madrid.

Zavala, C. Y Quattrocchio, M., 2001. Estratigrafía y evolución geológica del río Sauce Grande (Cuaternario), provincia de Buenos Aires, Argentina. Revista de la Asociación Geológica Argentina, 56 (1):25-37. 


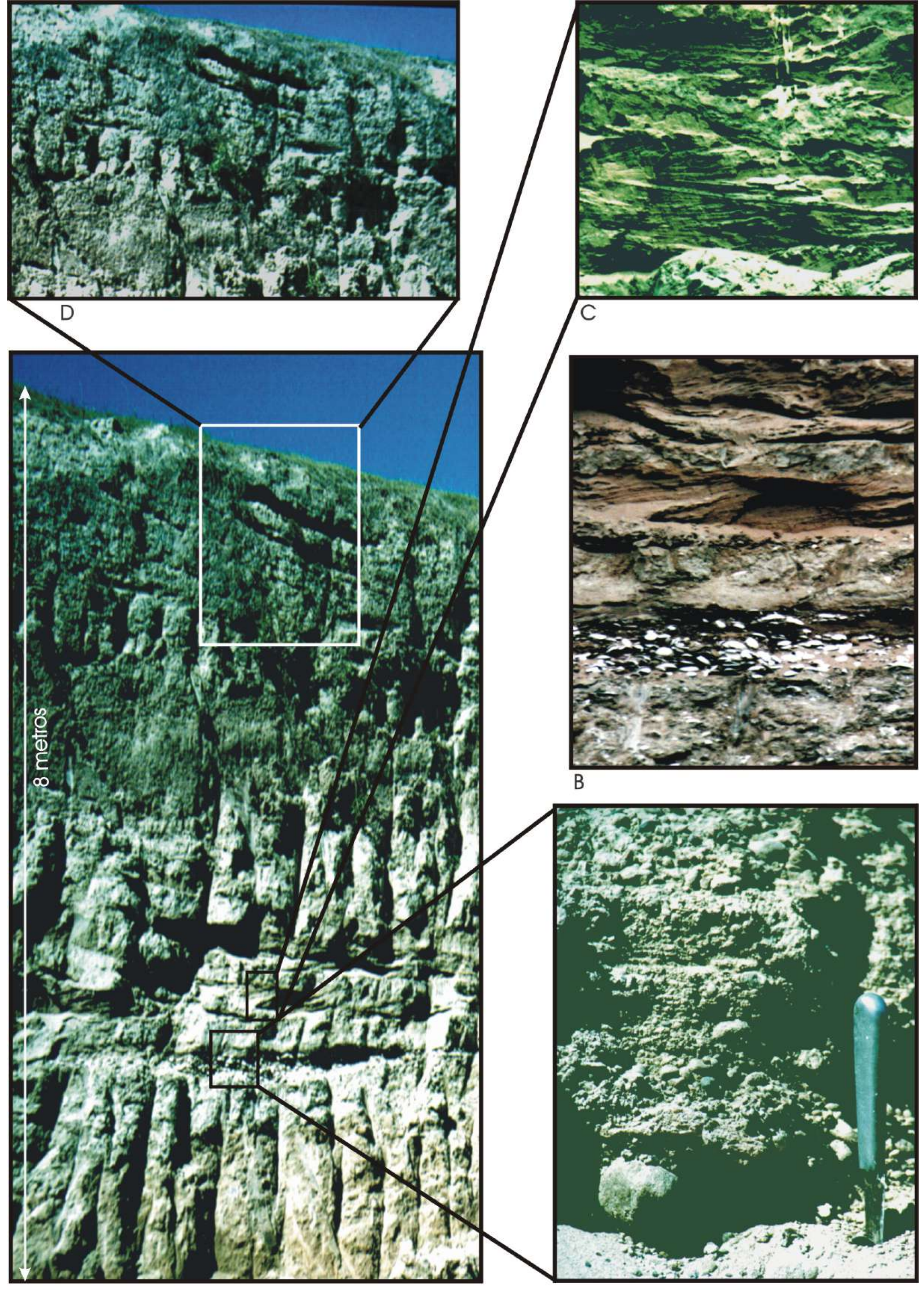



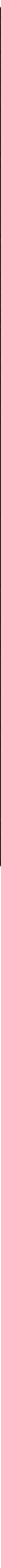

Descripción

A: Secuencia marina, integrada

por arcillas verdes (B),

limos amarillo claro $(\mathrm{Cl})$ y arenas

amarillo grisácea $(\mathrm{C} 2)$, infrayaciendo

y suprayaciendo materiales disturbados (A y D).

Corresponde a facies submareales a intermareales, culminando

con sedimentos eólicos.

B Grieta producida en la unidad (B) y

rellenada por sedimentos de la unidad $(\mathrm{C})$,

C: Tagelus plebeins en posición de vida dentro

de la unidad (B).

Edad $>40.000$ AP. 


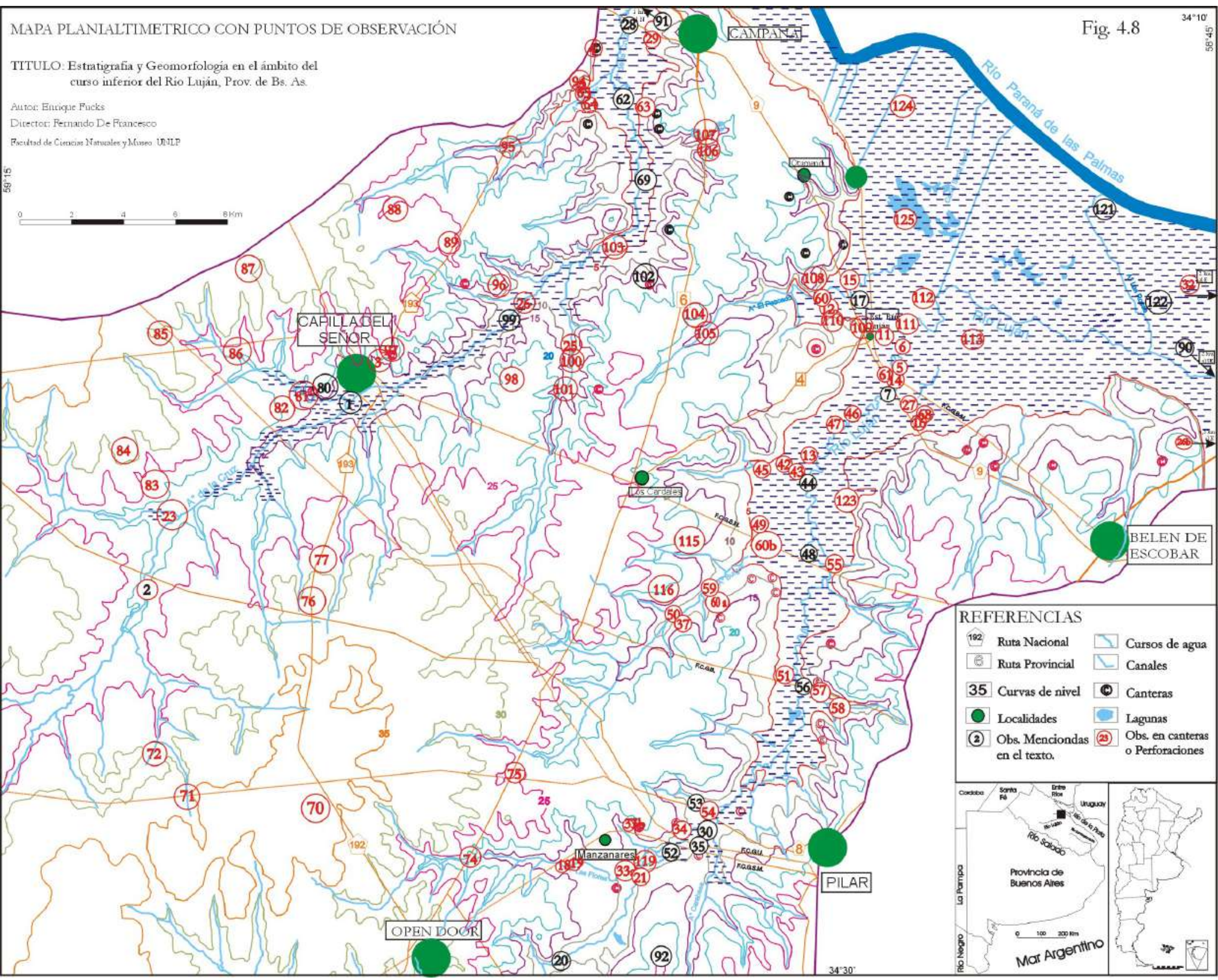




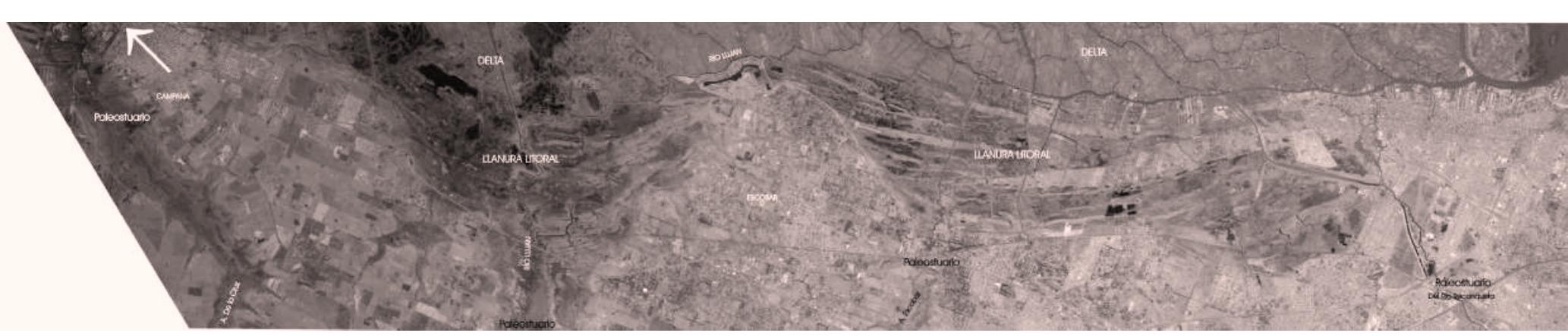




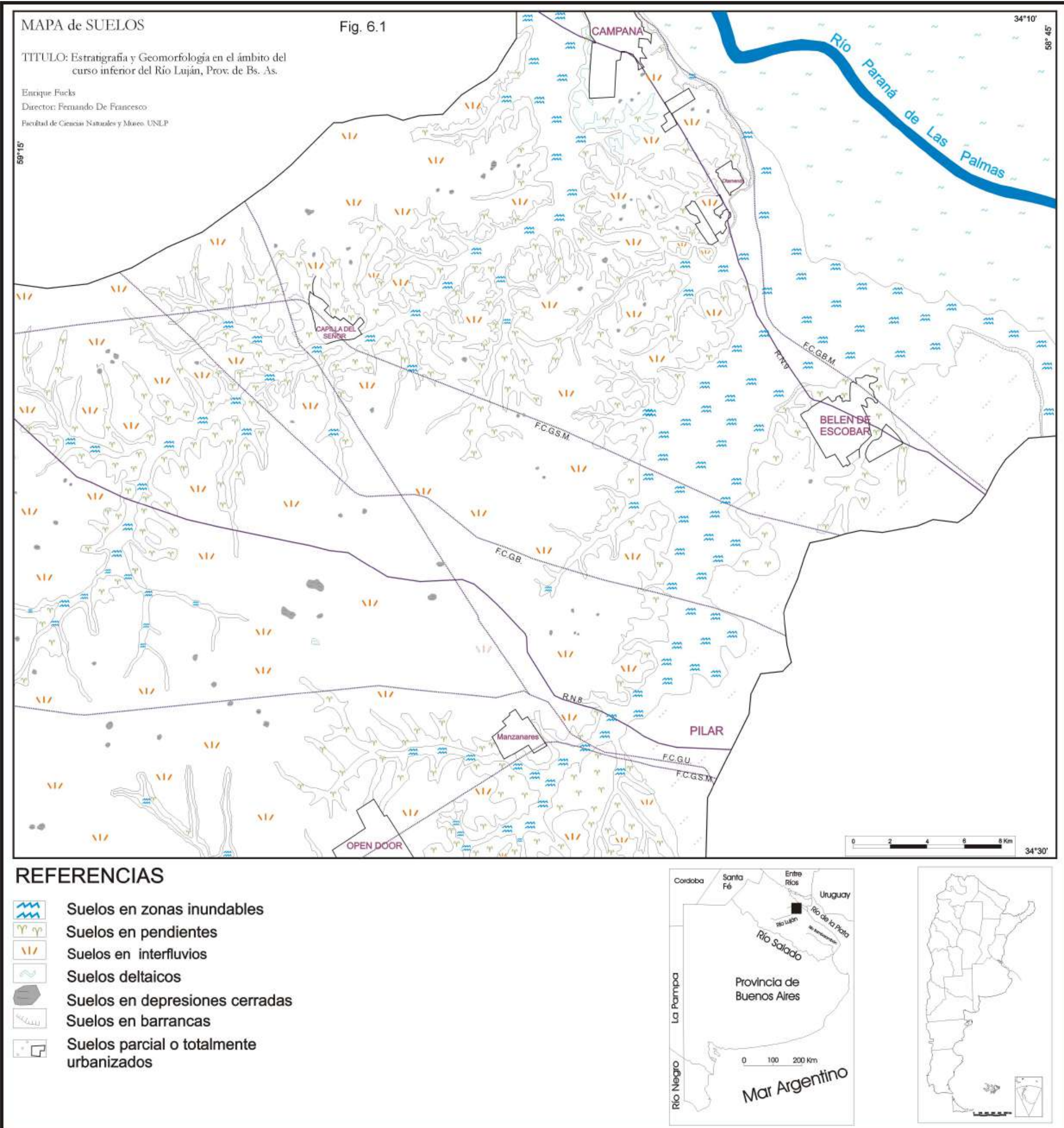


